\title{
Cochrane
}

Library

Cochrane Database of Systematic Reviews

\section{Interventions to improve adherence to inhaled steroids for asthma} (Review)

Normansell R, Kew KM, Stovold E

Normansell R, Kew KM, Stovold E.

Interventions to improve adherence to inhaled steroids for asthma.

Cochrane Database of Systematic Reviews 2017, Issue 4. Art. No.: CD012226.

DOI: 10.1002/14651858.CD012226.pub2.

www.cochranelibrary.com 
TABLE OF CONTENTS

HEADER

ABSTRACT

PLAIN LANGUAGE SUMMARY

SUMMARY OF FINDINGS

BACKGROUND

OBJECTIVES

METHODS

RESULTS

Figure 1.

Figure 2.

Figure 3.

DISCUSSION

AUTHORS' CONCLUSIONS

ACKNOWLEDGEMENTS

REFERENCES

CHARACTERISTICS OF STUDIES

DATA AND ANALYSES

Analysis 1.1. Comparison 1 Adherence education versus controls, Outcome $1 \%$ Adherence (objective measures).

Analysis 1.2. Comparison 1 Adherence education versus controls, Outcome $2 \%$ Adherence (all measures).

Analysis 1.3. Comparison 1 Adherence education versus controls, Outcome $3>85 \%$ adherence.

Analysis 1.4. Comparison 1 Adherence education versus controls, Outcome 4 Exacerbations requiring OCS (people with 1 or more).

Analysis 1.5. Comparison 1 Adherence education versus controls, Outcome 5 Asthma control.

Analysis 1.6. Comparison 1 Adherence education versus controls, Outcome 6 Unsheduled visits to a healthcare provider (people with 1 or more).

Analysis 1.7. Comparison 1 Adherence education versus controls, Outcome 7 Quality of life (AQLQ).

Analysis 2.1. Comparison 2 Electronic trackers or reminders ( \pm feedback) versus controls, Outcome $1 \%$ Adherence (objective measures).

Analysis 2.2. Comparison 2 Electronic trackers or reminders ( \pm feedback) versus controls, Outcome $2 \%$ Adherence (all measures).

Analysis 2.3. Comparison 2 Electronic trackers or reminders ( \pm feedback) versus controls, Outcome 3 Exacerbations requiring OCS (people with at least 1 ).

Analysis 2.4. Comparison 2 Electronic trackers or reminders ( \pm feedback) versus controls, Outcome 4 Asthma control. ........... Analysis 2.5. Comparison 2 Electronic trackers or reminders ( \pm feedback) versus controls, Outcome 5 Unscheduled visits to a healthcare provider.

Analysis 2.6. Comparison 2 Electronic trackers or reminders ( \pm feedback) versus controls, Outcome 6 Unscheduled visits to a healthcare provider.

Analysis 2.7. Comparison 2 Electronic trackers or reminders ( \pm feedback) versus controls, Outcome 7 Absenteeism. ............... Analysis 2.8. Comparison 2 Electronic trackers or reminders ( \pm feedback) versus controls, Outcome 8 Absenteeism. ............... Analysis 2.9. Comparison 2 Electronic trackers or reminders ( \pm feedback) versus controls, Outcome 9 Quality of life (AQLQ). ... Analysis 3.1. Comparison 3 Simplified versus usual regimens, Outcome $1 \%$ Adherence.

Analysis 3.2. Comparison 3 Simplified versus usual regimens, Outcome 2 Exacerbations requiring OCS.

Analysis 3.3. Comparison 3 Simplified versus usual regimens, Outcome 3 Asthma control (ACQ)

Analysis 3.4. Comparison 3 Simplified versus usual regimens, Outcome 4 Unscheduled visits.

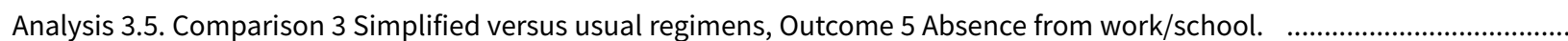
Analysis 3.6. Comparison 3 Simplified versus usual regimens, Outcome 6 Quality of life (ITG-ASF \% change from baseline). .... Analysis 3.7. Comparison 3 Simplified versus usual regimens, Outcome 7 All adverse events.

Analysis 4.1. Comparison 4 School-based ICS therapy versus controls, Outcome 1 Unscheduled visits (1 or more hospitalisations for any cause).

Analysis 4.2. Comparison 4 School-based ICS therapy versus controls, Outcome 2 Quality of life (PAQLQ). ............................. 
Analysis 5.3. Comparison 5 Subgroup analyses for $\%$ adherence, Outcome 3 Comparison 2. Children vs adults. 
[Intervention Review]

\section{Interventions to improve adherence to inhaled steroids for asthma}

Rebecca Normansell ${ }^{1}$, Kayleigh M Kew² ${ }^{2}$ Elizabeth Stovold 3

${ }^{1}$ Cochrane Airways, Population Health Research Institute, St George's, University of London, London, UK. 2British Medical Journal Technology Assessment Group (BMJ-TAG), BMJ Knowledge Centre, London, UK. 3Population Health Research Institute, St George's, University of London, London, UK

Contact address: Rebecca Normansell, Cochrane Airways, Population Health Research Institute, St George's, University of London, London, SW17 ORE, UK. rnormans@sgul.ac.uk.

Editorial group: Cochrane Airways Group.

Publication status and date: New, published in Issue 4, 2017.

Citation: Normansell R, Kew KM, Stovold E. Interventions to improve adherence to inhaled steroids for asthma. Cochrane Database of Systematic Reviews 2017, Issue 4. Art. No.: CD012226. DOI: 10.1002/14651858.CD012226.pub2.

Copyright @ 2017 The Cochrane Collaboration. Published by John Wiley \& Sons, Ltd.

\section{A B S T R A C T}

\section{Background}

Despite its proven efficacy in improving symptoms and reducing exacerbations, many patients with asthma are not fully adherent to their steroid inhaler. Suboptimal adherence leads to poorer clinical outcomes and increased health service utilisation, and has been identified as a contributing factor to a third of asthma deaths in the UK. Reasons for non-adherence vary, and a variety of interventions have been proposed to help people improve treatment adherence.

\section{Objectives}

To assess the efficacy and safety of interventions intended to improve adherence to inhaled corticosteroids among people with asthma.

\section{Search methods}

We identified trials from the Cochrane Airways Trials Register, which contains studies identified through multiple electronic searches and handsearches of other sources. We also searched trial registries and reference lists of primary studies. We conducted the most recent searches on 18 November 2016.

\section{Selection criteria}

We included parallel and cluster randomised controlled trials of any duration conducted in any setting. We included studies reported as fulltext articles, those published as abstracts only and unpublished data. We included trials of adults and children with asthma and a current prescription for an inhaled corticosteroid (ICS) (as monotherapy or in combination with a long-acting beta 2 -agonist (LABA)). Eligible trials compared an intervention primarily aimed at improving adherence to ICS versus usual care or an alternative intervention.

\section{Data collection and analysis}

Two review authors screened the searches, extracted study characteristics and outcome data from included studies and assessed risk of bias. Primary outcomes were adherence to ICS, exacerbations requiring at least oral corticosteroids and asthma control. We graded results and presented evidence in 'Summary of findings' tables for each comparison.

We analysed dichotomous data as odds ratios, and continuous data as mean differences or standardised mean differences, all using a random-effects model. We described skewed data narratively. We made no a priori assumptions about how trials would be categorised but conducted meta-analyses only if treatments, participants and the underlying clinical question were similar enough for pooling to make sense. 


\section{Main results}

We included 39 parallel randomised controlled trials (RCTs) involving adults and children with asthma, 28 of which ( $n=16,303)$ contributed data to at least one meta-analysis. Follow-up ranged from two months to two years (median six months), and trials were conducted mainly in high-income countries. Most studies reported some measure of adherence to ICS and a variety of other outcomes such as quality of life and asthma control. Studies generally were at low or unclear risk of selection bias and at high risk of biases associated with blinding. We considered around half the studies to be at high risk for attrition bias and selective outcome reporting.

We classified studies into four comparisons: adherence education versus control (20 studies); electronic trackers or reminders versus control (11 studies); simplified drug regimens versus usual drug regimens (four studies); and school-based directly observed therapy (three studies). Two studies are described separately.

All pooled results for adherence education, electronic trackers or reminders and simplified regimens showed better adherence than controls. Analyses limited to studies using objective measures revealed that adherence education showed a benefit of 20 percentage points over control ( $95 \%$ confidence interval (CI) 7.52 to 32.74; five studies; low-quality evidence); electronic trackers or reminders led to better adherence of 19 percentage points ( $95 \% \mathrm{Cl} 14.47$ to 25.26 ; six studies; moderate-quality evidence); and simplified regimens led to better adherence of 4 percentage points ( $95 \% \mathrm{Cl} 1.88$ to 6.16; three studies; moderate-quality evidence). Our confidence in the evidence was reduced by risk of bias and inconsistency.

Improvements in adherence were not consistently translated into observable benefit for clinical outcomes in our pooled analyses. None of the intervention types showed clear benefit for our primary clinical outcomes - exacerbations requiring an oral corticosteroid (OCS) (evidence of very low to low quality) and asthma control (evidence of low to moderate quality); nor for our secondary outcomes unscheduled visits (evidence of very low to moderate quality) and quality of life (evidence of low to moderate quality). However, some individual studies reported observed benefits for OCS and use of healthcare services. Most school or work absence data were skewed and were difficult to interpret (evidence of low quality, when graded), and most studies did not specifically measure or report adverse events.

Studies investigating the possible benefit of administering ICS at school did not measure adherence, exacerbations requiring OCS, asthma control or adverse events. One study showed fewer unscheduled visits, and another found no differences; data could not be combined.

\section{Authors' conclusions}

Pooled results suggest that a variety of interventions can improve adherence. The clinical relevance of this improvement, highlighted by uncertain and inconsistent impact on clinical outcomes such as quality of life and asthma control, is less clear. We have low to moderate confidence in these findings owing to concerns about risk of bias and inconsistency. Future studies would benefit from predefining an evidence-based 'cut-off' for acceptable adherence and using objective adherence measures and validated tools and questionnaires. When possible, covert monitoring and some form of blinding or active control may help disentangle effects of the intervention from effects of inclusion in an adherence trial.

\section{PLAIN LANGUAGE SUMMARY}

\section{Strategies to help people with asthma take their steroid inhaler as prescribed}

\section{Background to the question}

Inhalers containing steroids improve asthma-related symptoms and reduce asthma attacks when taken regularly. But many people with asthma do not take them as prescribed. This leads to more symptoms and flare-ups, which have been linked to a third of asthma deaths in the UK.

Missing doses is sometimes called 'non-adherence'. Reasons for missing doses vary from person to person. For example, people often forget to take their inhaler or have a busy and unpredictable lifestyle that makes it difficult to fit this in. Some people do not appreciate the need for taking inhalers as prescribed. Some people choose to reduce or discontinue taking steroids. This can happen for many reasons, including side effects, fear of side effects or a perception that benefits do not outweigh disadvantages.

The aim of this review was to find out whether strategies to help people with asthma take their steroid inhaler really work, and whether improved adherence leads to other benefits.

\section{Study characteristics}

We found 39 studies including more than 16,000 adults and children with asthma who were taking a steroid inhaler. Most studies collected data at six months, so we can really apply the messages in this review only over six months - we cannot say whether these methods are effective in a few years time, for example. We searched multiple sources for relevant studies. This review is current as of November 2016.

Different studies tried different ways to help people take their inhaler more regularly. We grouped studies according to four ways of helping people take their inhaler: providing education about adherence ( 20 studies); using electronic monitoring or reminders to take the inhaler 
(11 studies); making the drug easier to take (e.g. once instead of twice a day, one inhaler instead of two) (four studies); and giving the inhaler during school hours (three studies).

We mainly looked for whether strategies helped people to take their inhaler as prescribed, and whether people had fewer asthma attacks and better asthma control.

\section{Key results}

People who were given education were better at taking their inhaler than controls; $20 \%$ more people took their treatment (likely to be somewhere between $8 \%$ and $33 \%$ more). Those given trackers or electronic reminders were $19 \%$ better at using their inhaler than controls $(14 \%$ and $25 \%)$. People who were given an easier way of taking their inhaler (e.g. fewer times a day) were only $4 \%$ better than those who carried on as usual ( $2 \%$ and $6 \%)$.

Unfortunately, these efforts to help people take their inhaler as prescribed generally did not lead to obvious benefit for things like asthma control and number of attacks, but in most cases, we could not tell either way. We also did not see a difference for quality of life or time people needed off school or work, but the evidence was often uncertain.

Studies investigating the possible benefit of giving children their inhaler during school hours did not actually measure how often they missed doses.

\section{Quality of the evidence}

It's difficult to tell whether these different strategies are worth using because studies were quite different from one other. This variation means that we cannot be sure what the real benefit is, beyond improving adherence. Sometimes we did not find enough studies to detect a difference between groups. The fact that most people knew which group they were in also reduced our confidence in the findings because this can affect things like how positively people respond to questionnaires. We had concerns about how many people dropped out of about half the studies, and we are uncertain whether studies reported everything they measured.

\section{Key message}

The studies we found suggest that various strategies can help people with asthma take their inhaler better, compared with "control" (e.g. usual asthma care). However, many of these studies were quite different from one another, and we are not certain about whether people will find that their asthma is improved as a result of this approach. 


\begin{tabular}{|c|c|c|c|c|c|c|c|}
\hline \multicolumn{8}{|c|}{\begin{tabular}{|l} 
S U M M A R Y O F F I N D I N G S \\
Summary of findings for the main comparison. Adherence education compared with controls for asthma
\end{tabular}} \\
\hline \multicolumn{8}{|c|}{ Adherence education compared with controls for asthma } \\
\hline \multicolumn{8}{|c|}{$\begin{array}{l}\text { Patient or population: asthma } \\
\text { Setting: community } \\
\text { Intervention: adherence education } \\
\text { Comparison: control group (no education) }\end{array}$} \\
\hline \multirow{2}{*}{\multicolumn{2}{|c|}{ Outcomes }} & \multicolumn{2}{|c|}{ Anticipated absolute effects* $(95 \% \mathrm{Cl})$} & \multirow{2}{*}{$\begin{array}{l}\text { Relative ef- } \\
\text { fect } \\
(95 \% \mathrm{CI})\end{array}$} & \multirow{2}{*}{$\begin{array}{l}\text { Number of } \\
\text { participants } \\
\text { (studies) }\end{array}$} & \multirow{2}{*}{$\begin{array}{l}\text { Quality of the } \\
\text { evidence } \\
\text { (GRADE) }\end{array}$} & \multirow[t]{2}{*}{ Comments } \\
\hline & & $\begin{array}{l}\text { Risk with con- } \\
\text { trols }\end{array}$ & Risk with adherence education & & & & \\
\hline \multirow[t]{2}{*}{$\begin{array}{l}\% \text { Adherence } \\
\text { WMD of fol- } \\
\text { low-up } 71.7 \\
\text { weeks (all stud- } \\
\text { ies) }\end{array}$} & $\begin{array}{l}\text { Objective } \\
\text { measures }\end{array}$ & $\begin{array}{l}\text { Mean adher- } \\
\text { ence in the con- } \\
\text { trol group was } \\
\mathbf{4 6 . 7 \%}\end{array}$ & $\begin{array}{l}\text { Mean adherence with adherence educa- } \\
\text { tion was } \mathbf{2 0 . 1 3} \% \text { higher ( } 7.52 \text { higher to } \\
32.74 \text { higher) }\end{array}$ & - & $\begin{array}{l}280 \\
\text { (5 RCTs) }\end{array}$ & $\begin{array}{l}\oplus \oplus \Theta \odot \\
\text { LOW a,b,c }\end{array}$ & $\begin{array}{l}\text { Only studies in } \\
\text { which adherence } \\
\text { was measured with } \\
\text { an electronic mon- } \\
\text { itor }\end{array}$ \\
\hline & All measures & $\begin{array}{l}\text { Mean adher- } \\
\text { ence in the con- } \\
\text { trol group was } \\
\mathbf{5 7 . 1 \%}\end{array}$ & $\begin{array}{l}\text { Mean adherence with adherence educa- } \\
\text { tion was } 11.59 \% \text { higher ( } 3.72 \text { higher to } \\
19.46 \text { higher) }\end{array}$ & - & $\begin{array}{l}1693 \\
(10 \mathrm{RCTs})\end{array}$ & $\begin{array}{l}\oplus \oplus \Theta \ominus \\
\text { LOW a,b,c }\end{array}$ & \\
\hline \multicolumn{2}{|c|}{$\begin{array}{l}\text { Exacerbations requiring OCS } \\
\text { (people with } 1 \text { or more) }\end{array}$} & 149 per 1000 & $\begin{array}{l}242 \text { per } 1000 \\
(148 \text { to } 370)\end{array}$ & $\begin{array}{l}\text { OR } 1.82 \\
\text { (0.99 to } 3.36)\end{array}$ & $\begin{array}{l}349 \\
\text { (3 RCTs) }\end{array}$ & $\begin{array}{l}\oplus \oplus \Theta \ominus \\
\text { LOW a,d }\end{array}$ & \\
\hline \multicolumn{8}{|c|}{ WMD of follow-up 30.8 weeks } \\
\hline \multicolumn{2}{|c|}{$\begin{array}{l}\text { Asthma control (ACQ) } \\
\text { WMD of follow-up } 28.5 \text { weeks }\end{array}$} & $\begin{array}{l}\text { Mean ACQ score } \\
\text { was } \mathbf{1 . 5 2}\end{array}$ & $\begin{array}{l}\text { Mean score with adherence education } \\
\text { was } 0.03 \text { better ( } 0.49 \text { better to } 0.43 \\
\text { worse) }\end{array}$ & - & $\begin{array}{l}455 \\
\text { (4 RCTs) }\end{array}$ & $\begin{array}{l}\oplus \oplus \oplus \ominus \\
\text { MODERATE } \\
\text { a,e }\end{array}$ & $\begin{array}{l}\text { Lower score indi- } \\
\text { cates better con- } \\
\text { trol. Scale } 0 \text { to } 6 \text {. } \\
\text { MCID } 0.5\end{array}$ \\
\hline \multicolumn{2}{|c|}{$\begin{array}{l}\text { Asthma control (ACT) } \\
\text { WMD of follow-up } 29.5 \text { weeks }\end{array}$} & $\begin{array}{l}\text { Mean ACT score } \\
\text { was } \mathbf{1 8 . 8 8}\end{array}$ & $\begin{array}{l}\text { Mean score with adherence education } \\
\text { was } 0.30 \text { better } \\
\text { ( } 1.43 \text { better to } 0.82 \text { worse) }\end{array}$ & - & $\begin{array}{l}333 \\
\text { (3 RCTs) }\end{array}$ & $\begin{array}{l}\oplus \oplus \oplus \ominus \\
\text { MODERATE } \\
\text { a,e }\end{array}$ & $\begin{array}{l}\text { Higher score indi- } \\
\text { cates better con- } \\
\text { trol. Scale } 5 \text { to } 25 \text {. } \\
\text { MCID } 3\end{array}$ \\
\hline
\end{tabular}




\begin{tabular}{|c|c|c|c|c|c|c|}
\hline $\begin{array}{l}\text { Unsheduled visits to a health- } \\
\text { care provider } \\
\text { (people with } 1 \text { or more) } \\
\text { WMD of follow-up } 67.2 \text { weeks }\end{array}$ & 159 per 1000 & $\begin{array}{l}\mathbf{8 3} \text { per } \mathbf{1 0 0 0} \\
\text { (35 to } 184)\end{array}$ & $\begin{array}{l}\text { OR } 0.48 \\
\text { (0.19 to } 1.19)\end{array}$ & $\begin{array}{l}688 \\
\text { (4 RCTs) }\end{array}$ & $\begin{array}{l}\oplus \ominus \ominus \ominus \\
\text { VERY LOW } \\
\text { a,b,d,f }\end{array}$ & $\begin{array}{l}\text { Includes visits to } \\
\text { ED, GP, hospital for } \\
\text { any cause }\end{array}$ \\
\hline $\begin{array}{l}\text { Absenteeism } \\
\text { WMD of follow-up } 63.3 \text { weeks }\end{array}$ & \multicolumn{2}{|c|}{$\begin{array}{l}\text { We did not perform an analysis of absences because the da- } \\
\text { ta were heavily skewed }\end{array}$} & - & $\begin{array}{l}109 \\
(2 \text { RCTs })\end{array}$ & Not graded & \\
\hline $\begin{array}{l}\text { Quality of life (AQLQ) } \\
\text { WMD of follow-up } 27.4 \text { weeks }\end{array}$ & $\begin{array}{l}\text { Mean AQLQ } \\
\text { score was } 5\end{array}$ & $\begin{array}{l}\text { Mean score with adherence education } \\
\text { was } 0.01 \text { better }(0.20 \text { worse to } 0.23 \text { bet- } \\
\text { ter) }\end{array}$ & - & $\begin{array}{l}734 \\
\text { (6 RCTs) }\end{array}$ & $\begin{array}{l}\oplus \oplus \oplus \ominus \\
\text { MODERATE } \\
a, e\end{array}$ & $\begin{array}{l}\text { Higher score indi- } \\
\text { cates better QOL. } \\
\text { Scale } 1 \text { to } 7 . \mathrm{MCID} \\
0.5\end{array}$ \\
\hline
\end{tabular}

${ }^{\star}$ The risk in the intervention group (and its $95 \%$ confidence interval) is based on assumed risk in the comparison group and the relative effect of the intervention (and its $95 \% \mathrm{Cl})$

ACQ: Asthma Control Questionnaire; ACT: Asthma Control Test; AQLQ: Asthma Quality of Life Questionnaire; Cl: confidence interval; ED: emergency department; GP: general practitioner; MCID: minimal clinically important difference; OCS: oral corticosteroid; OR: odds ratio; QOL: quality of life; RCT: randomised controlled trial; WMD: weighted mean duration

\section{GRADE Working Group grades of evidence}

High quality: We are very confident that the true effect lies close to the estimate of effect

Moderate quality: We are moderately confident in the effect estimate: The true effect is likely to be close to the estimate of effect but may be substantially different

Low quality: Our confidence in the effect estimate is limited: The true effect may be substantially different from the estimate of effect

Very low quality: We have very little confidence in the effect estimate: The true effect is likely to be substantially different from the estimate of effect

aDowngraded once primarily owing to risk of bias from open-label trials and some concerns regarding attrition bias, selective reporting and selection bias (-1 risk of bias)

bowngraded once owing to inconsistency between study results (-1 inconsistency)

cFunnel plot examined; no clear evidence of publication bias (no downgrade for publication bias)

${ }^{d}$ Confidence intervals include no difference and/or potential important harm or benefit of the intervention (-1 imprecision)

e Confidence intervals fall within the established MCID for this scale (no downgrade for imprecision)

fStudies contributing to this analysis reported different types of unscheduled visits and some recorded visits for any cause rather than asthma alone (-1 indirectness)

gunclear how absenteeism was defined or reported, and different participants may have different thresholds for missing work or school. One study was conducted in children and the other in adults. Combined, this makes the outcome hard to interpret

Summary of findings 2. Electronic trackers or reminders ( \pm feedback) compared with controls for asthma

\section{Electronic trackers or reminders ( \pm feedback) compared with controls for asthma}

Patient or population: asthma 


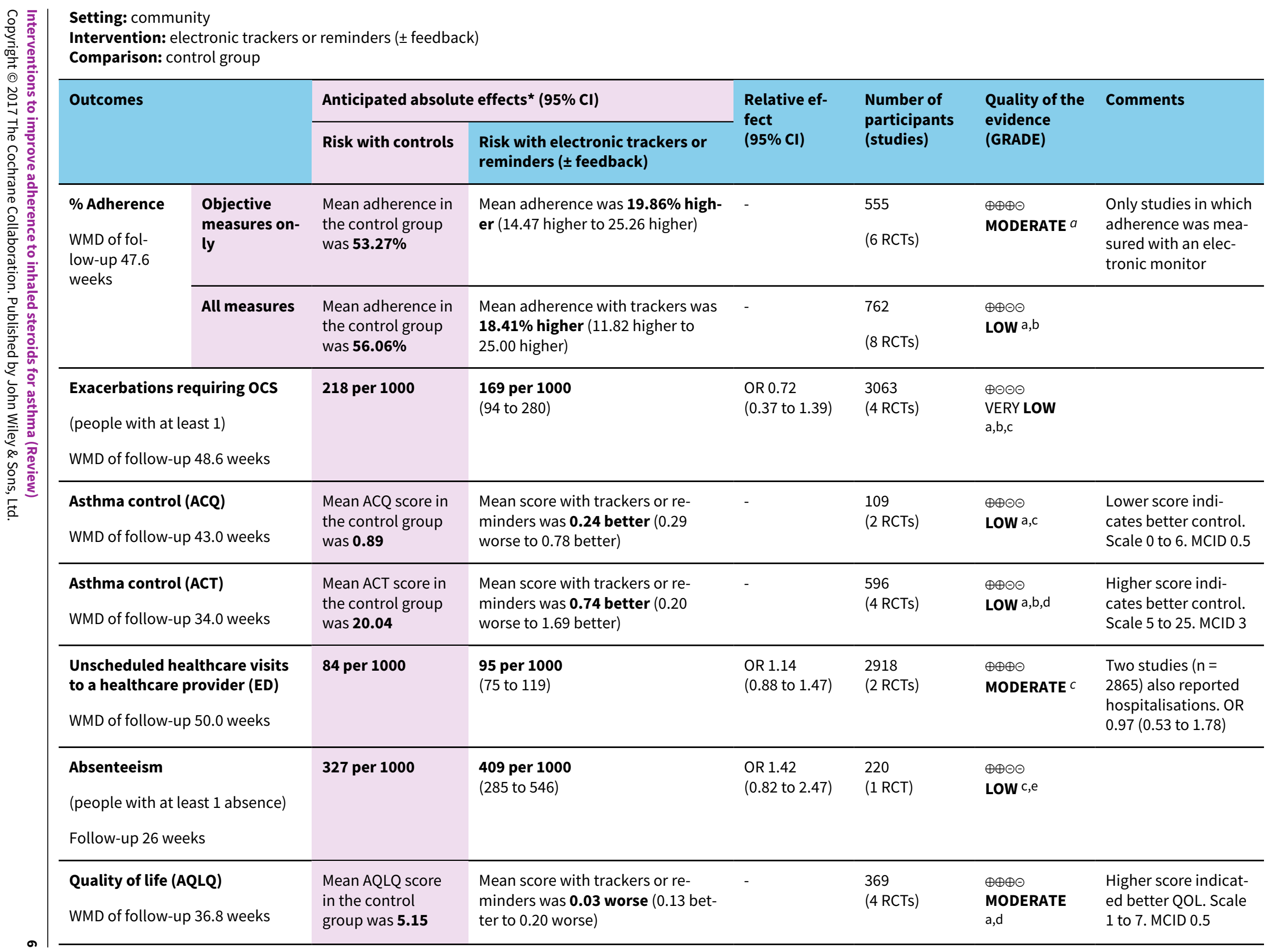


${ }^{\star}$ The risk in the intervention group (and its $95 \%$ confidence interval) is based on assumed risk in the comparison group and the relative effect of the intervention (and its $95 \% \mathrm{Cl})$.

ACQ: Asthma Control Questionnaire; ACT: Asthma Control Test; AQLQ: Asthma Quality of Life Questionnaire; CI: confidence interval; ED: emergency department; MCID: minimal clinically important difference; OCS: oral corticosteroid; OR: odds ratio; QOL: quality of life; RCT: randomised controlled trial; WMD: weighted mean duration

\section{GRADE Working Group grades of evidence}

High quality: We are very confident that the true effect lies close to the estimate of effect

Moderate quality: We are moderately confident in the effect estimate: The true effect is likely to be close to the estimate of effect but may be substantially different

Low quality: Our confidence in the effect estimate is limited: The true effect may be substantially different from the estimate of effect

Very low quality: We have very little confidence in the effect estimate: The true effect is likely to be substantially different from the estimate of effect

a Downgraded once primarily owing to risk of bias from open-label trials and some concerns regarding attrition bias, selective reporting and selection bias (-1 risk of bias)

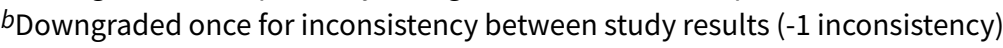

cConfidence intervals include no difference and potential important harm and benefit of the intervention (-1 imprecision)

${ }^{d}$ Confidence intervals fall within the MCID for this scale (no downgrade for imprecision)

eDowngraded once owing to risk of performance and detection bias (-1 risk of bias)

Summary of findings 3. Simplified compared with usual regimens for asthma

\section{Simplified compared with usual regimens for asthma}

\section{Patient or population: asthma}

Setting: community

Intervention: simplified regimens

Comparison: usual regimens

\begin{tabular}{|c|c|c|c|c|c|c|}
\hline \multirow[t]{2}{*}{ Outcomes } & \multicolumn{2}{|c|}{ Anticipated absolute effects* $(95 \% \mathrm{Cl})$} & \multirow{2}{*}{$\begin{array}{l}\text { Relative effect } \\
(95 \% \mathrm{Cl})\end{array}$} & \multirow{2}{*}{$\begin{array}{l}\text { Number of par- } \\
\text { ticipants } \\
\text { (studies) }\end{array}$} & \multirow{2}{*}{$\begin{array}{l}\text { Quality of the } \\
\text { evidence } \\
\text { (GRADE) }\end{array}$} & \multirow[t]{2}{*}{ Comments } \\
\hline & $\begin{array}{l}\text { Risk with usual } \\
\text { regimens }\end{array}$ & Risk with simplified regimens & & & & \\
\hline $\begin{array}{l}\text { \% Adherence (objective } \\
\text { measures) } \\
\text { WMD of follow-up } 12.9 \\
\text { weeks }\end{array}$ & $\begin{array}{l}\text { Mean adherence in } \\
\text { the control group } \\
\text { was } \mathbf{8 6 . 7 3 \%}\end{array}$ & $\begin{array}{l}\text { Mean adherence with simplified regi- } \\
\text { mens was } \mathbf{4 . 0 2} \% \text { higher } \\
\text { (1.88 higher to } 6.16 \text { higher) }\end{array}$ & - & $\begin{array}{l}1310 \\
\text { (3 RCTs) }\end{array}$ & $\begin{array}{l}\oplus \oplus \oplus \ominus \\
\text { MODERATE } a\end{array}$ & $\begin{array}{l}\text { Only studies in } \\
\text { which adherence } \\
\text { was measured } \\
\text { with an electron- } \\
\text { ic monitor }\end{array}$ \\
\hline $\begin{array}{l}\text { Exacerbations requiring } \\
\text { OCS }\end{array}$ & 125 per 1000 & $\begin{array}{l}\mathbf{2 5 0} \text { per } 1000 \\
\text { (24 to } 823 \text { ) }\end{array}$ & $\begin{array}{l}\text { OR } 2.33 \\
\text { (0.17 to } 32.58)\end{array}$ & $\begin{array}{l}16 \\
(1 \mathrm{RCT})\end{array}$ & $\begin{array}{l}\oplus \oplus \ominus \ominus \\
\text { LOW } b\end{array}$ & \\
\hline
\end{tabular}

People with 1 or more 


\begin{tabular}{|c|c|c|c|c|c|c|c|}
\hline \multicolumn{8}{|c|}{ 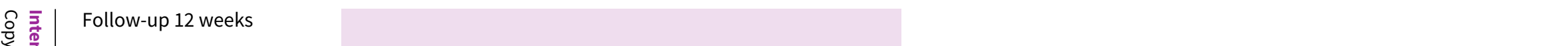 } \\
\hline \multirow{2}{*}{\multicolumn{2}{|c|}{ 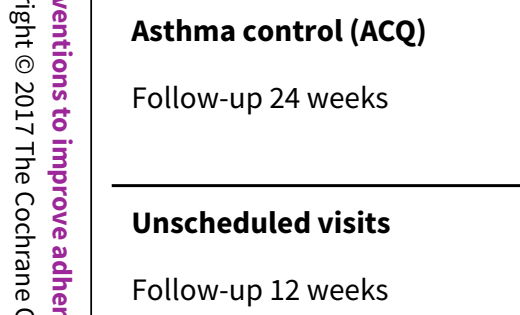 }} & $\begin{array}{l}\text { Mean ACQ score in } \\
\text { the control group } \\
\text { was } \mathbf{0 . 8 9}\end{array}$ & $\begin{array}{l}\text { Mean score with simplified regimens } \\
\text { was } 0.03 \text { better }(0.34 \text { better to } 0.28 \\
\text { worse) }\end{array}$ & - & $\begin{array}{l}103 \\
(1 \mathrm{RCT})\end{array}$ & $\begin{array}{l}\oplus \oplus \oplus \ominus \\
\text { MODERATE } c\end{array}$ & $\begin{array}{l}\text { Lower score indi- } \\
\text { cates better con- } \\
\text { trol. Scale } 0 \text { to } 6 . \\
\text { MCID } 0.5\end{array}$ \\
\hline & & 63 per 1000 & $\begin{array}{l}72 \text { per } 1000 \\
(46 \text { to } 113 \text { ) }\end{array}$ & $\begin{array}{l}\text { OR } 1.17 \\
(0.72 \text { to } 1.90)\end{array}$ & $\begin{array}{l}1037 \\
(1 \mathrm{RCT})\end{array}$ & \multicolumn{2}{|l|}{$\begin{array}{l}\oplus \oplus \ominus \ominus \\
\text { LOW a,d }\end{array}$} \\
\hline 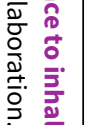 & $\begin{array}{l}\text { Absence from work/school } \\
\text { Follow-up } 12 \text { weeks }\end{array}$ & 19 per 1000 & $\begin{array}{l}18 \text { per } 1000 \\
(7 \text { to } 43)\end{array}$ & $\begin{array}{l}\text { OR } 0.93 \\
\text { (0.37 to } 2.30)\end{array}$ & $\begin{array}{l}1037 \\
(1 \mathrm{RCT})\end{array}$ & \multicolumn{2}{|l|}{$\begin{array}{l}\oplus \oplus \odot \odot \\
\text { LOW a,d }\end{array}$} \\
\hline 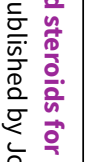 & $\begin{array}{l}\text { Change in quality of life } \\
\text { (ITG-ASF) } \\
\text { Follow-up } 12 \text { weeks }\end{array}$ & $\begin{array}{l}\text { Mean change in } \\
\text { quality of life in the } \\
\text { control group was } \\
\mathbf{1 4}\end{array}$ & $\begin{array}{l}\text { Mean change with simplified regimens } \\
\text { was } 6 \text { points better } \\
\text { ( } 0.76 \text { worse to } 12.76 \text { better) }\end{array}$ & - & $\begin{array}{l}1037 \\
(1 \mathrm{RCT})\end{array}$ & $\begin{array}{l}\oplus \oplus \ominus \ominus \\
\text { LOW a,e }\end{array}$ & $\begin{array}{l}\text { Higher score indi- } \\
\text { cates better QOL. } \\
\text { Range } 0 \text { to } 100 . \\
\text { MCID not known }\end{array}$ \\
\hline 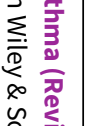 & $\begin{array}{l}\text { All adverse events } \\
\text { Follow-up } 12 \text { weeks }\end{array}$ & 175 per 1000 & $\begin{array}{l}\mathbf{1 3 9} \text { per } \mathbf{1 0 0 0} \\
(106 \text { to } 181)\end{array}$ & $\begin{array}{l}\text { OR } 0.76 \\
\text { (0.56 to } 1.04)\end{array}$ & $\begin{array}{l}1233 \\
(1 \mathrm{RCT})\end{array}$ & $\begin{array}{l}\oplus \oplus \odot \odot \\
\text { LOW a,f }\end{array}$ & \\
\hline$=$ & \multicolumn{7}{|c|}{$\begin{array}{l}\text { *The risk in the intervention group (and its } 95 \% \text { confidence interval) is based on assumed risk in the comparison group and the relative effect of the intervention (and its } \\
95 \% \mathrm{CI} \text { ) } \\
\text { ACQ: Asthma Control Questionnaire; CI: confidence interval; ITG-ASF: Integrated Therapeutics Group - Asthma Short Form; MCID: minimal clinically important difference; } \\
\text { OCS: oral corticosteroid; OR: odds ratio; QOL: quality of life; RCT: randomised controlled trial; WMD: weighted mean duration }\end{array}$} \\
\hline & \multicolumn{7}{|c|}{$\begin{array}{l}\text { GRADE Working Group grades of evidence } \\
\text { High quality: We are very confident that the true effect lies close to the estimate of effect } \\
\text { Moderate quality: We are moderately confident in the effect estimate: The true effect is likely to be close to the estimate of effect but may be substantially different } \\
\text { Low quality: Our confidence in the effect estimate is limited: The true effect may be substantially different from the estimate of effect } \\
\text { Very low quality: We have very little confidence in the effect estimate: The true effect is likely to be substantially different from the estimate of effect }\end{array}$} \\
\hline
\end{tabular}

aDowngraded once primarily owing to lack of blinding and some concerns regarding attrition bias, selective reporting and selection bias (-1 risk of bias)

bone very small trial resulting in very wide confidence intervals (-2 imprecision)

cAlthough confidence intervals fall within the MCID, only one study contributed to this outcome (-1 imprecision)

${ }^{d}$ Confidence intervals include both important potential harm and benefit of the intervention (-1 imprecision)

eConfidence intervals do not exclude no difference (-1 imprecision)

fConfidence intervals range from no difference to an important benefit of simplified regimens (-1 imprecision) 
Summary of findings 4. School-based ICS therapy compared with home therapy for asthma

School-based ICS therapy compared with home therapy for asthma

Patient or population: children with asthma

Settings: school

Intervention: ICS given at school

Comparison: ICS given at home

\begin{tabular}{|c|c|c|c|c|c|c|}
\hline \multirow[t]{3}{*}{ Outcomes } & \multicolumn{2}{|c|}{ Illustrative comparative risks* $(95 \% \mathrm{Cl})$} & \multirow{3}{*}{$\begin{array}{l}\text { Relative effect } \\
(95 \% \mathrm{CI})\end{array}$} & \multirow{3}{*}{$\begin{array}{l}\text { Number of par- } \\
\text { ticipants } \\
\text { (studies) }\end{array}$} & \multirow{3}{*}{$\begin{array}{l}\text { Quality of the } \\
\text { evidence } \\
\text { (GRADE) }\end{array}$} & \multirow[t]{3}{*}{ Comments } \\
\hline & Assumed risk & Corresponding risk & & & & \\
\hline & Control & School-based ICS therapy & & & & \\
\hline $\begin{array}{l}\text { Unscheduled visits } \\
1 \text { or more hospitalisations for any } \\
\text { cause }\end{array}$ & 49 per 1000 & $\begin{array}{l}29 \text { per } 1000 \\
(8 \text { to } 96)\end{array}$ & $\begin{array}{l}\text { OR } 0.58 \text { ( } 0.16 \text { to } \\
2.05)\end{array}$ & $\begin{array}{l}279 \\
\text { (2 RCTs) }\end{array}$ & $\begin{array}{l}\oplus \oplus \Theta \Theta \\
\mathbf{L O W} a, b\end{array}$ & \\
\hline WMD of follow-up 35.8 weeks & & & & & & \\
\hline $\begin{array}{l}\text { Quality of life (PACQLQ) } \\
1 \text { to } 7 \text {; higher is better } \\
\text { WMD of follow-up } 35.8 \text { weeks }\end{array}$ & $\begin{array}{l}\text { Mean PAQLQ score } \\
\text { in the control } \\
\text { group was } 6.31\end{array}$ & $\begin{array}{l}\text { Mean score in the interven- } \\
\text { tion groups was } \\
\mathbf{0 . 2 5} \text { higher }(0.01 \text { to } 0.49 \\
\text { higher) }\end{array}$ & - & $\begin{array}{l}279 \\
\text { (2 RCTs) }\end{array}$ & $\begin{array}{l}\oplus \oplus \oplus \ominus \\
\text { MODERATE } a\end{array}$ & \\
\hline $\begin{array}{l}\text { Adverse events } \\
\text { Follow-up } 30 \text { weeks }\end{array}$ & \multicolumn{2}{|c|}{ No events observed in either arm } & - & $\begin{array}{l}99 \\
(1 \mathrm{RCT})\end{array}$ & Not graded & \\
\hline
\end{tabular}

${ }^{*}$ The basis for the assumed risk (e.g. median control group risk across studies) is provided in footnotes. The corresponding risk (and its $95 \%$ confidence interval) is based on assumed risk in the comparison group and the relative effect of the intervention (and its $95 \% \mathrm{CI}$ )

CI: confidence interval; ICS: inhaled corticosteroid; OR: odds ratio; PAQLQ: Paediatric Asthma Quality of Life Questionnaire; RCT: randomised controlled trial; WMD: weighted mean difference

GRADE Working Group grades of evidence

High quality: Further research is very unlikely to change our confidence in the estimate of effect

Moderate quality: Further research is likely to have an important impact on our confidence in the estimate of effect and may change the estimate

Low quality: Further research is very likely to have an important impact on our confidence in the estimate of effect and is likely to change the estimate

Very low quality: We are very uncertain about the estimate 
o data could be meta-analysed for adherence, exacerbations requiring OCS, asthma control or absenteeism. Some data are presented narratively in the review ${ }^{a}$ Both contributing studies considered at high risk for performance and detection bias

Confidence intervals include both potential harm and benefit of the intervention 


\section{B A C K G R O U N D}

\section{Description of the condition}

Asthma is a chronic breathing condition that affects more than 300 million adults and children worldwide (Global Asthma Report 2014). Asthma can cause shortness of breath, chest tightness and cough and typically presents with wheezing. Many people with asthma experience intermittent worsening of their asthma symptoms, known as 'exacerbations', 'flare-ups' or 'attacks' (GINA 2016). Approximately $20 \%$ of people with asthma have at some point been admitted to hospital or attended an emergency department for asthma treatment (Rodrigo 2004). Attacks can be triggered by common irritants and allergens such as pollution, tobacco smoke, pollen and house dust mites (CDC 2016). Asthma is under-diagnosed and under-treated worldwide. Most asthmarelated deaths occur in middle-income and low-income countries. Poorly controlled asthma places a huge burden on individuals, their families and society (WHO 2013).

The mainstay of asthma treatment for all but the mildest cases consists of inhaled corticosteroids (ICSs) (Barnes 1993), which are also known as 'preventer' or 'controller' medications (i.e. the intention is that they are used once or twice daily (depending on the preparation), even when well, to maintain control over symptoms). Inhaled corticosteroids, which are delivered directly to a patient's airways via an inhaler or a nebuliser, work by suppressing the multiple inflammatory cascades that are activated in the airways of a person with asthma. Inflammation leads to increased mucus production and airway constriction, which in turn contribute to symptoms of asthma. Reduction in underlying inflammation through sustained use of an ICS can result in symptom improvement and reduced asthma-related morbidity and mortality (Barnes 2003; Bårnes 2015).

Inhaled corticosteroids commonly used today include budesonide, beclomethasone, fluticasone (propionate and furoate), mometasone and ciclesonide. They can be given alone or in combination with other preventer medications such as longacting beta ${ }_{2}$-agonists (LABAs) or leukotriene receptor antagonists (LTRAs) (BNF).

\section{Description of the intervention}

Despite its proven efficacy, many patients are not fully adherent to their prescribed ICS (Bårnes 2015). Adherence is described by the World Health Organization (WHO) as "the degree to which use of medication by the patient corresponds with the prescribed regimen"; WHO emphasises the "diversity and complexity of adherence behaviour". In addition, patients with asthma may be fully adherent to preventer medication when symptomatic but poorly adherent when well (WHO Report 2003). This may reflect the fact that, unlike rescue medication, which gives immediate relief of symptoms (i.e. a 'reliever' or 'rescue' inhaler containing a shortacting beta ${ }_{2}$-agonist (SABA) such as salbutamol), an ICS given for airway inflammation may take several weeks to provide maximal benefit.

Reasons for non-adherence to asthma therapies, including ICSs, vary among individuals. Commonly cited reasons include complexity of the treatment regimen; cost; administration route; and patient beliefs about therapy, including safety, necessity and risk of dependence. Lower socioeconomic status, inclusion in a minority ethnic group and fewer years of education have also been associated with reduced adherence (Bårnes 2015; Bender 2005; Clark 1999; Cochrane 1999).

Understanding the underlying reasons for non-adherence is essential for tackling the problem. The WHO Report 2003 has subcategorised these reasons as follows.

- 'Erratic non-adherence' - perhaps most common and largely the result of forgetfulness or a busy, unpredictable lifestyle.

- 'Unwitting non-adherence' - usually the result of failure to appreciate the specifics of regimens or the need for adherence.

- 'Intelligent non-adherence' - the result of a purposeful choice to reduce or discontinue ICS use for many reasons, including side effects, fear of side effects or a perception that the benefits do not outweigh the disadvantages.

Similarly, Horne 2002, which reported a cross-sectional survey of people with asthma who completed validated questionnaires, identified that adherence was primarily associated with doubts about the necessity for the medication and concerns about the side effects of treatment. This study reported that a more negative perception of the consequences of illness is associated with poorer adherence to preventer medication. A possible explanation for this unexpected finding is that those who are already poorly adherent may be more likely to experience poorer asthma control and thus may rate the consequences of illness more negatively.

Interventions to improve adherence to ICS may take many forms, including audiovisual reminders (Charles 2007), electronic monitoring of dosing with clinician feedback (Onyirimba 2003), interactive voice response system via mobile phone (Mulvaney 2013), text message reminders (Johnson 2015) and more comprehensive patient or parent education (Bender 2002).

\section{How the intervention might work}

How the intervention works will be directly related to the type of non-adherence targeted and the type of intervention offered. The simplest interventions proposed to tackle 'erratic non-adherence' might work by providing a very basic prompt to patients to remember to use their inhaler. Multi-faceted interventions that involve tackling 'unwitting' or 'intelligent' non-adherence might comprise patient education and partnership building between healthcare professionals and patients and are likely to work through more complex psychological and behavioural pathways.

A recently updated Cochrane Review assessing the evidence for interventions to improve adherence across the whole spectrum of health care identified 109 randomised controlled trials (RCTs) for inclusion. Review authors concluded that a small number of trials, which implemented complex interventions, demonstrated improvement in adherence and clinical outcomes, suggesting that the more rudimentary interventions generally have little impact. This may reflect the likelihood that any individual under treatment for asthma will likely have a combination of reasons for nonadherence, possibly both intentional and unintentional (Horne 2002). However, the highly complex nature of the interventions implemented in these 'successful' trials casts doubts on their feasibility in a real-life setting (Nieuwlaat 2014).

Medication adherence is recognised to deteriorate often during adolescence (Dinwiddie 2002). Patients in this age group might 
be particularly receptive to newer technologies for assisting with adherence, for example, Internet-based care and text message reminders. However, the authors of Nieuwlaat 2014 concluded that evidence is currently insufficient to show with certainty whether these newer methods of improving adherence are effective.

Lower levels of adherence in minority communities and among those from lower socioeconomic groups suggest that even when access to health care and prescription coverage is equal (Krishnan 2001), cultural tailoring of interventions may be required for successful treatment.

\section{Why it is important to do this review}

Suboptimal adherence leads to poorer clinical outcomes and increased health service utilisation. Although difficult to quantify, studies report that up to, and possibly in excess of, $50 \%$ of participants are non-adherent to their prescribed ICS (Bårnes 2015; Bender 2004; Mahkinova 2015; Murphy 2012; Rand 1994; Williams 2003). Failure to take appropriate medication was found to be a potentially avoidable factor contributing to approximately one-third of asthma deaths in the UK over the course of a year (NRAD 2014). Mahkinova 2015 demonstrated that patients who are adherent to their preventer medication make fewer claims for oral corticosteroid prescriptions, reflecting a lower rate of exacerbation. Williams 2003 identified an association between hospitalisations and emergency department visits and non-adherence to ICS. Murphy 2012 found that non-adherence was an independent predictor of the need for ventilation therapy in acute severe asthma, as well as lower forced expiratory volume in one second $\left(\mathrm{FEV}_{1}\right)$ and higher sputum eosinophils, both of which are markers of poorly controlled asthma. A 2015 review of ICS adherence in asthma found that $24 \%$ of exacerbations and $60 \%$ of asthmarelated hospitalisations could be attributed to poor adherence (Bårnes 2015). In addition, it is well recognised that uncontrolled asthma places a greater financial burden on an economy than is incurred by controlled asthma (Barnes 1996; Global Asthma Report 2014).

Evidence shows that many people with asthma benefit greatly from regular use of an ICS. However, ways that healthcare professionals can best assist patients in maintaining adherence remain unclear. We are conducting this review to explore this topic.

\section{O B JE C T IVES}

To assess the efficacy and safety of interventions intended to improve adherence to inhaled corticosteroids among people with asthma.

\section{METHODS}

\section{Criteria for considering studies for this review Types of studies}

We included parallel and cluster RCTs of any duration conducted in any setting. If we identified cross-over trials, we included only data from the first part of the study because of the potential for carryover effects of the intervention.

We included studies reported as full-text articles, those published as abstracts only and unpublished data.

\section{Types of participants}

We included adults and children of any age with a diagnosis of asthma, according to international or national guidelines or as diagnosed by a healthcare professional, and currently prescribed an ICS alone or in combination with a LABA. We excluded participants with other respiratory comorbidities such as chronic obstructive pulmonary disease (COPD) or bronchiectasis. If we identified trials in which only a subset of participants had received a diagnosis of asthma, we included these participants if we could obtain disaggregated data. If we identified trials targeting improved adherence to asthma therapies generally, and at least $80 \%$ of participants were using an ICS at baseline, we included these trials in the review. We also included trials in which the intervention was targeted at a healthcare professional (the trial "participant"), who in turn would deliver the adherence intervention to patients with asthma.

\section{Types of interventions}

We included trials that compared an intervention primarily aimed at improving adherence to ICS ( \pm LABA) versus:

- usual care/no additional intervention;

- an alternative intervention that does not primarily aim to increase adherence; or

- an alternative intervention of a different type or intensity, also aimed at improving adherence.

Interventions may range from simple automated reminders to more complex behavioural, psychological and motivational interventions. Interventions may be delivered to the participant or to the parent/career by any healthcare professional or trained peer. Interventions may also be delivered to a healthcare professional. We allowed other co-interventions in the management of asthma provided they were provided in the same way for intervention and comparison groups, for example, a personalised asthma action plan (PAAP) + adherence prompt versus PAAP alone.

\section{Types of outcome measures}

\section{Primary outcomes}

- Adherence to ICS (as reported by trialists; e.g. self-report via diary or questionnaire, electronic monitoring, prescription monitoring/pharmacy claims data).

- Exacerbations requiring at least oral corticosteroids.

- Asthma control (ideally measured on a validated scale such as the Asthma Control Test (ACT)).

\section{Secondary outcomes}

- Unscheduled visits to a healthcare provider.

- Absenteeism from work/school.

- Quality of life (ideally measured on a validated scale such as the Asthma Quality of Life Questionnaire (AQLQ)).

- All adverse events*.

We chose adherence as a primary outcome, as studies will be aiming to improve this outcome. However, we believe it is important to assess whether improvement in adherence translates into improved clinical outcomes; thus, we have included exacerbations and asthma control as primary outcomes in the belief that these are important to patients. Outcomes of adverse 
events, absenteeism and quality of life are also important to patients. Unscheduled visits to a healthcare provider are important to patients as well and serve as a marker of usage of healthcare services.

If outcomes were reported at multiple time points, we extracted and included the latest reported time point. If studies reported post-intervention follow-up, we extracted this information and presented it narratively.

Reporting one or more of the outcomes listed here was not a criterion for inclusion of trials in this review.

*If we identified serious adverse events reported as 'asthma', we described these narratively, as they are likely to represent a severe exacerbation requiring at least hospitalisation.

\section{Search methods for identification of studies}

\section{Electronic searches}

We identified trials from the Cochrane Airways Trials Register, which is maintained by the Information Specialist for the Group. The Cochrane Airways Trials Register contains studies identified from several sources.

- Monthly searches of the Cochrane Central Register of Controlled Trials (CENTRAL), through the Cochrane Register of Studies Online (crso.cochrane.org/).

- Weekly searches of MEDLINE Ovid SP 1946 to date.

- Weekly searches of Embase Ovid SP 1974 to date.

- Monthly searches of PsycINFO Ovid SP.

- Monthly searches of the Cumulative Index to Nursing and Allied Health Literature (CINAHL) EBSCO.

- Monthly searches of the Allied and Complementary Medicine Database (AMED) EBSCO.

- Handsearches of the proceedings of major respiratory conferences.

Studies contained in the Trials Register are identified through search strategies based on the scope of Cochrane Airways. Details of these strategies, as well as a list of handsearched conference proceedings, are provided in Appendix 1 . See Appendix 2 for search terms used to identify studies for this review. We conducted the primary search on 20 May 2016, and updated the search on 18 November 2016.

We conducted additional searches of the Cochrane Central Register of Controlled Trials (CENTRAL) (all years to 18 November 2016) and MEDLINE Ovid (1946 to 18 November 2016) to identify adherence trials targeting mixed populations including people with asthma (Appendix 2).

We searched the following trials registries on 20 May 2016 and 18 November 2016.

1. US National Institutes of Health Ongoing Trials Register ClinicalTrials.gov (www.clinicaltrials.gov).

2. World Health Organization International Clinical Trials Registry Platform (apps.who.int/trialsearch/).

We did not apply any restrictions on the language of publication.

\section{Searching other resources}

We checked the reference lists of all primary studies and review articles for additional references. We searched relevant manufacturer websites for trial information.

We searched on 23 November 2016 for errata or retractions from included studies published in full text on PubMed (www.ncbi.nlm.nih.gov/pubmed).

\section{Data collection and analysis}

\section{Selection of studies}

We used the Rayyan Web app (Elmagarmid 2014) to independently screen titles and abstracts of all studies identified by the search for possible inclusion, and we coded each study as 'include' (eligible or potentially eligible/unclear) or 'exclude'. KK screened all titles and abstracts, and RN and ES each screened one-half. We retrieved full-text study reports/publications, and two review authors (RN and KK) independently screened them to identify studies for inclusion, and to identify and record reasons for exclusion of ineligible studies. We resolved disagreements through discussion, or, if required, we consulted the third review author (ES). We identified and excluded duplicates and collated multiple reports of the same study, so that each study rather than each report was the unit of interest in the review. We recorded the selection process in sufficient detail to complete a PRISMA (Preferred Reporting Items for Systematic Reviews and Meta-Analyses) flow diagram and Characteristics of excluded studies table (Moher 2009).

\section{Data extraction and management}

We planned to use Covidence 2015 to extract study characteristics and outcome data, but we found it too time consuming and instead used an Excel data extraction form that we each piloted on at least one study. We planned that one review author (RN) would extract the following study characteristics from included studies, but instead we shared the studies equally between all three review authors (RN, ES and KK).

- Methods: study design, total duration of study, details of any 'run-in' period, number of study centres and locations, study setting, withdrawals and date of study.

- Participants: N, mean age, age range, gender, severity of condition, diagnostic criteria, baseline lung function, smoking history, inclusion criteria and exclusion criteria.

- Interventions: intervention, comparison, concomitant medications and excluded medications.

- Outcomes: primary and secondary outcomes specified and collected and time points reported.

- Notes: funding for trial and notable conflicts of interest of trial authors.

Each review author extracted outcome data independently from two-thirds of the studies so that data from each study were extracted twice. We noted in the Characteristics of included studies table if outcome data were not reported in a useable way. We resolved disagreements by reaching consensus or by involving a third review author (RN, KK or ES). One review author (RN) transferred data to the Review Manager (RevMan 2014) file. We double-checked that data had been entered correctly by comparing data presented in the systematic review against study reports. A 
second review author (KK or ES) spot-checked study characteristics for accuracy against the trial report.

\section{Assessment of risk of bias in included studies}

As for numerical data extraction, each review author independently assessed risk of bias for two-thirds of the included studies, so that each study was assessed twice. We used the criteria outlined in the Cochrane Handbook for Systematic Reviews of Interventions (Higgins 2011). We resolved disagreements by discussion or by consultation with the third review author who had not already assessed the study (RN, KK or ES). We assessed risk of bias according to the following domains.

- Random sequence generation.

- Allocation concealment.

- Blinding of participants and personnel.

- Blinding of outcome assessment.

- Incomplete outcome data.

- Selective outcome reporting.

- Other bias.

We graded each potential source of bias as high, low or unclear and provided a quote from the study report together with a justification for our judgement in the 'Risk of bias' table. We summarised risk of bias judgements across different studies for each of the domains listed. We considered blinding separately for different key outcomes when necessary (e.g. for an unblinded outcome assessment, risk of bias for all-cause mortality may be very different than for a patient-reported pain scale). When information on risk of bias relates to unpublished data or correspondence with a trialist, we noted this in the 'Risk of bias' table.

When considering a treatment effect, we took into account the risk of bias for studies that contributed to that outcome.

\section{Assesment of bias in conducting the systematic review}

We conducted the review according to this published protocol and reported deviations from it in the Differences between protocol and review section of the systematic review.

\section{Measures of treatment effect}

We analysed dichotomous data using Mantel-Haenzsel odds ratios (ORs) with a random-effects model and $95 \%$ confidence intervals (Cls). When rare events were reported, we used Peto ORs. When data were reported as rates or times-to-events (e.g. exacerbations), we analysed them as time-to-event or rate ratios. We transformed reported rate ratios into log-rate ratios and analysed them using a random-effects model and generic inverse variance (GIV) in Review Manager 5 (RevMan 2014). We entered data presented as a scale with a consistent direction of effect.

We analysed continuous outcomes (e.g. ACT, AQLQ) as mean differences (MDs) or as standardised mean differences (SMDs) using a random-effects model and $95 \% \mathrm{Cls}$. We used change from baseline scores when available.

We undertook meta-analyses only when this was meaningful (i.e. if treatments, participants and the underlying clinical question were similar enough for pooling to make sense).
We narratively described skewed data reported as medians and interquartile ranges.

When multiple trial arms were reported in a single trial, we included only the relevant arms. If two comparisons (e.g. intervention A vs usual care, intervention B vs usual care) were combined in the same meta-analysis, we halved the control group to avoid doublecounting.

If both change from baseline and endpoint scores were available for continuous data, we used change from baseline unless most studies reported endpoint scores. Similarly, we preferred adjusted data examined by analysis of variance (ANOVA) to account for baseline differences when available.

When both per-protocol/completer and intention-to-treat (ITT) analyses were provided in a single report, we used the latter.

\section{Unit of analysis issues}

We analysed dichotomous data using participants (rather than events) as the unit of analysis. However, if exacerbations were reported as rate ratios, we analysed them on this basis. We metaanalysed data from cluster RCTs only if available data had been, or could be, adjusted to account for clustering. We adjusted data from Foster 2014 for meta-analysis using an intracluster correlation coefficient (ICC) of 0.037 (based on the ACT score, kindly supplied by the study author team). However, this adjustment had very little impact on the meta-analyses, and so we have used the raw unadjusted data.

\section{Dealing with missing data}

We contacted investigators or study sponsors to verify key study characteristics and to request missing numerical outcome data when possible (e.g. when a study is identified as abstract only). When this was not possible, and missing data were thought to introduce serious bias, we considered this in the GRADE rating for the affected outcome.

\section{Assessment of heterogeneity}

We used the $I^{2}$ statistic to measure heterogeneity among the trials in each analysis. If we identified substantial heterogeneity, we reported this and explored possible causes through prespecified subgroup analyses.

\section{Assessment of reporting biases}

When we were able to pool more than 10 studies, we created and examined a funnel plot to explore possible small study and publication biases.

\section{Data synthesis}

We used a random-effects model and performed a sensitivity analysis using a fixed-effect model.

\section{'Summary of findings' table}

We created four 'Summary of findings' tables, one for each of the comparisons, using the following outcomes: adherence to ICS; exacerbations requiring at least an oral corticosteroid (OCS); asthma control; quality of life; unscheduled visits to a healthcare provider; absenteeism from work/school; and adverse events. We used the five GRADE (Grades of Recommendation, Assessment, 
Development and Evaluation Working Group) considerations (study limitations, consistency of effect, imprecision, indirectness and publication bias) to assess the quality of a body of evidence as it relates to studies that contributed data to the prespecified outcomes. We used methods and recommendations described in Section 8.5 and Chapter 12 of the Cochrane Handbook for Systematic Reviews of Interventions (Higgins 2011) and GRADEpro software (GRADEpro GDT). We justified all decisions to downgrade or upgrade the quality of studies by using footnotes, and we made comments to aid readers' understanding of the review when necessary.

\section{Subgroup analysis and investigation of heterogeneity}

We planned the following subgroup analyses.

- Type of intervention: interventions meeting the definition of a complex intervention* versus simpler interventions.

- Age of participants: adults versus adolescents versus children.

- To whom the intervention is delivered: participant/parent/ career versus healthcare professional.

We constructed an additional table to present other potential factors across studies that may alter the treatment effect (e.g. type, delivery, dose and schedule of ICS; whether treatment was given in a combination inhaler with a LABA; baseline severity of asthma).

We used the following outcomes in subgroup analyses.

- Adherence to ICS.

- Exacerbations requiring at least an OCS.

- Asthma control.

We used the formal test for subgroup interactions provided in RevMan 2014.

${ }^{*}$ Complex interventions are conventionally described as those including 'several interacting components' (Campbell 2000). From a public health point of view, complex interventions, which are likely to involve a substantial educational element, and population- based interventions, which may include cluster RCTs, are thought to have greater overall impact on patient behaviour. Simpler interventions, such as cue reminders, will not address the more complex issues of adherence, and effects may be less likely to persist beyond removal of the intervention. Thus, we considered this an important subgroup analysis for inclusion.

\section{Sensitivity analysis}

We planned the following sensitivity analyses.

- Excluding unpublished data.

- Excluding trials considered at high risk of selection bias.

- Excluding trials in which not all participants were prescribed ICS at baseline.

- Excluding trials in which adherence was measured via nonobjective methods (e.g. diary, self-report). In a post hoc change to our analysis plan, we have presented studies using objective measures (i.e. electronic inhaler monitors) as the primary analysis for $\%$ adherence, as we deemed this to be a more useful analysis. An analysis including studies using all measures then follows.

\section{RES U L T S}

\section{Description of studies}

\section{Results of the search}

Through database searches, we retrieved 2707 references. Our searches of other resources, including trials registries, revealed 127 additional records. Once duplicates had been removed, we had a total of 1725 records left to screen. We excluded 1575 records on the basis of titles and abstracts. We obtained the full text of the remaining 150 records. We excluded 45 studies (51 references), added five studies to Studies awaiting classification and listed 13 studies as ongoing ( 15 records). We included 39 studies (79 references). For further details of our screening process, see the study flow diagram (Figure 1). 
Figure 1. Study flow diagram.

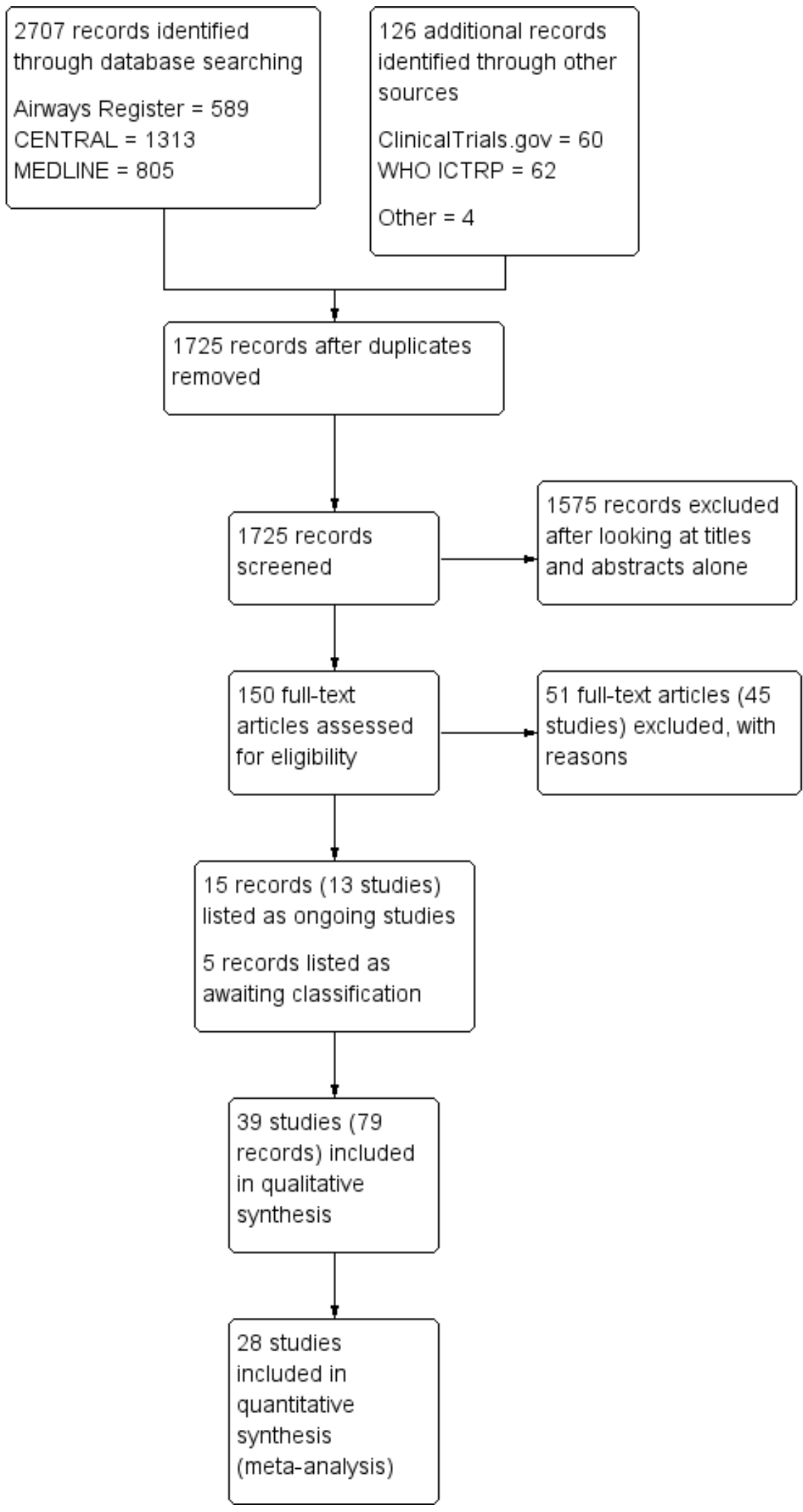




\section{Included studies}

Thirty-nine studies met our inclusion criteria, and 28 of these contributed data to at least one meta-analysis. These studies included a total of 16,303 participants who were randomly assigned to comparisons of interest in this review. The largest study was a pragmatic trial that included 9603 pre-existing users of ICS, and the smallest included 12. The median total number of participants was 102. Investigators reported three trials as conference abstracts only (Black 2008; Hart 2002; NCT02451709), one on the clinicaltrials.gov website (NCT02413528) and one as a pharmaceutical company report (ADERE PEDIATRIC 1). The remainder were full-text peer-reviewed journal articles. We present a summary of the characteristics of included studies in Table 1.

\section{Methods}

As per our protocol, all included trials were RCTs with parallel design that compared an intervention to improve adherence to inhaled corticosteroids versus usual care or an alternative intervention not specifically designed to improve adherence, or of a lower intensity. Two studies used a cluster randomised design (Foster 2014; NCT00459368); the remainder were randomised at an individual participant level. One study included four relevant arms (personalised adherence discussion (PAD); inhaler reminders and feedback (IRF); PAD + IRF; and usual care; Foster 2014). Two studies included three relevant arms: NCT00233181 randomised participants to adherence monitoring and education, education or usual care; and NCT00166582 randomised participants to a team work intervention, an asthma education intervention (not deemed relevant to this review) or usual care. The remainder were two-arm parallel-group trials.

Intevention length varied, and follow-up continued from two months to two years. The median duration of follow-up was 24 weeks. Several studies reported a previous run-in period during which participants were stabilised on an asthma treatment regimen. Outcome data were extracted at the last time point reported to assess enduring effects of the intervention. Trials were conducted in a variety of mainly high-income countries worldwide. Most were carried out in the USA (Bender 2010; Gerald 2009; Halterman 2004; Kamps 2008; Mann 1992; NCT00115323; NCT00149487; NCT00166582; NCT00233181; NCT00414817; NCT00459368; NCT00958932; NCT01169883; NCT01175434; NCT01714141; NCT02413528; Onyirimba 2003), the UK (Bosley 1994; Hart 2002; Koufopoulos 2016; NCT01064869; NCT02451709; Price 2010), New Zealand (ACTRN12606000508572; Black 2008; Chan 2015; Charles 2007) and Australia (ACTRN12607000489493; Burgess 2007; Foster 2014). The remainder were carried out in Brazil (ADERE PEDIATRIC 1; Chatkin 2006), Norway (Gallefoss 1999), Sweden (NCT00516633), The Netherlands (Vasbinder 2015 E-MATIC), Canada (NCT01132430), Belgium (Mehuys 2008), Denmark (Strandbygaard 2010) and Denmark and Switzerland (Ulrik 2009).

\section{Participants}

We included studies involving both children and adults. Eighteen studies included only children, 20 studies included adults and/or adolescents only and one study recruited both adults and children. Most studies did not specify the ethnicity of participants.

All studies included participants with a diagnosis of asthma. Almost all studies required participants to be using ICS at baseline, although in two studies (Strandbygaard 2010; Ulrik 2009), some participants were commenced on ICS during the run-in period. Asthma severity at baseline was inconsistently reported, so it is not possible to characterise the population in this review as a whole. When available, we extracted information about baseline severity and reported this in the Characteristics of included studies tables.

\section{Interventions}

Studies included a variety of comparisons, which we classified into four broad groups. Some studies appear in more than one comparison, as they included three or more arms. Most studies did not specify which additional medications were allowed or disallowed, so we assume that most participants continued their usual asthma medication regimen. We have outlined below the four broad comparisons.

\section{Adherence education versus control (Table 1)}

We included the following studies in this group: Bender 2010; Chatkin 2006; Foster 2014; NCT00115323; NCT00149487; NCT00166582; NCT00958932 (PAD and PAD + IRF groups vs IRF and control groups); ADERE PEDIATRIC 1; Gallefoss 1999; Hart 2002; Kamps 2008; Mehuys 2008; NCT00233181 (adherence monitoring and education vs control and education alone vs control); NCT00516633; NCT01064869; NCT01132430; NCT01169883; Onyirimba 2003 (adherence education and usual care arms); and Ulrik 2009; and NCT00414817. As per our protocol, we further classified these studies into those delivering a complex intervention versus those not delivering a complex intervention. We performed subgroup analysis when possible according to this classification.

Included studies tested a wide range of educational interventions, including one-to-one and group face-to-face adherence education sessions; motivational interviewing; family-based problemsolving interventions; team work interventions; nurse-led psychoeducation; telephone interventions; and interactive voice recognition systems. Full details can be found under Characteristics of included studies and are summarised in Table 1.

We classified most of the education interventions as complex (i.e. they involved multiple interacting components and were tailored to the individual). However, we classified as noncomplex three studies using voice recognition software to deliver adherence education and reminders (Bender 2010; NCT00414817; NCT00958932). Participants in Chatkin 2006 received a maximum 10-minute phone call from a trained nursing student to promote adherence; we judged this intervention to be non-complex, although we lacked detail about the contents of the call. Another study, which deviated from protocol and for which we do not have results, stated that participants received telephone 'medical guidance'; we classified this intervention as non-complex (ADERE PEDIATRIC 1).

\section{Electronic trackers or reminders versus control (Table 2)}

Studies that used electronic adherence trackers plus feedback to participants included ACTRN12607000489493; Foster 2014 (IRF and IRF + PAD groups VS PAD and control groups); NCT00233181 (adherence education and monitoring vs education alone); NCT01714141; NCT02451709; and NCT00459368. 
Studies that used electronic reminders alone, without an adherence feedback discussion, included Black 2008; Chan 2015; Charles 2007; Strandbygaard 2010; and Vasbinder 2015 E-MATIC.

We classified studies in this group as non-complex if they tested automated reminders such as text messages or an inhaler device with an audible or visual alarm system. However, if participants received tailored feedback from a healthcare professional based on adherence data acquired through electronic monitoring, we classified this intervention as complex (ACTRN12607000489493; Foster 2014; NCT00233181; NCT00459368; NCT02451709). Full details can be found under Characteristics of included studies and are summarised in Table 2.

\section{Simplified drug regimen versus usual drug regimen (Table 3)}

Studies that aimed to improve adherence by randomising participants to a simplified therapeutic regimen included ACTRN12606000508572; Bosley 1994; Mann 1992; and Price 2010. We classified all four studies as providing a non-complex intervention.Full details can be found under Characteristics of included studies and are summarised in Table 3.

\section{School-based directly observed therapy (Table 4)}

Gerald 2009, Halterman 2004 and NCT01175434 randomised children to receive their ICS at school or usual care. Gerald 2009 and Halterman 2004 were classified as non-complex, as the intervention was largely limited to providing school-based ICS therapy. NCT01175434 was classified as complex, as participants also underwent web-based screening to assess children's asthma which generated a report that was sent to their primary care provider and was used to adjust the medication regimen. Full details can be found under Characteristics of included studies and are summarised in Table 4.

Finally, we were unable to classify several studies according to the above categories. Burgess 2007 used an "incentive" inhaler device (the "Funhaler") to encourage children to adhere to their inhaled medication. Koufopoulos 2016 trialled use on an online community of people with asthma ("AsthmaVillage") to improve adherence.

We have provided additional details of these studies under Characteristics of included studies.

\section{Outcomes}

Outcomes reported were not consistent across reviews, and investigators did not always use validated scales. Almost all included studies reported some measure of adherence, usually as a percentage, with $100 \%$ showing complete adherence, but the way in which this was captured and calculated varied between studies. When possible, we extracted and presented this information in Characteristics of included studies and Table 1. The three studies in which the intervention consisted of supervised ICS therapy at school did not report adherence as an outcome (Gerald 2009; Halterman 2004; NCT01175434).

Many included studies used an objective measure of adherence; this was often an electronic inhaler monitoring device. Named devices used included the "SmartInhaler" (ACTRN12606000508572; Burgess 2007; Charles 2007; NCT02451709); the "SmartTrack" device (Chan 2015; Foster 2014); the "MDILog or MDILog-II (Bender 2010; Kamps 2008; NCT00149487; NCT00166582); the "Doser Clinical Trials" (Doser-CT) device (Bender 2010; NCT01169883); the "E-haler/Adhaler" (Vasbinder 2015 E-MATIC); the "Tubuhaler Inhalation Computer (TIC)" (Bosley 1994); the "Diskus Adherence Monitor" (Bender 2010); the "MDI Chorololog" (Onyirimba 2003); and the "Nebuliser Chronolog" (Mann 1992). Hart 2002 and NCT00115323 report using dose-counting devices but do not name the specific product used. ADERE PEDIATRIC 1, Chatkin 2006, Price 2010, Strandbygaard 2010 and Ulrik 2009 report counting the doses actuated/remaining on the returned inhaler but do not describe use of a monitoring device.

With the exception of the MDILog-II, these devices record the time and date of inhaler actuation, and most disregard multiple actuations in a short space of time ("dose-dumping"). The MDI-LogII also includes a measure of whether the drug was inhaled via a "temperature sensitive thermistor". Data can be uploaded onto a computer (for review and discussion in some studies) but in most cases were not visible to the participant day-to-day. In Vasbinder 2015 E-MATIC, the device sent data back to the study database via the mobile phone network, which allowed real-time tailoring of adherence reminder text messages for participants. Some of the devices described above (e.g. the SmartInhaler) are capable of producing audiovisual inhaler reminders; studies investigating this as an intervention disabled this function in control groups (see comparison 2).

Remaining studies used canister weight (Bender 2010; NCT00516633) or a combination of pharmacy data and self-report (Gallefoss 1999; Mehuys 2008; NCT00233181; NCT00414817; NCT00459368; NCT00958932; NCT01064869; NCT01132430). Two studies relied on self-report (Koufopoulos 2016; NCT01714141).

The three studies that investigated school-based therapy (Gerald 2009; Halterman 2004; NCT01175434) did not measure or report adherence.

Included studies reported the following outcomes: lung function (e.g. $\mathrm{FEV}_{1}$, peak expiratory flow rate $\left.(\mathrm{PEFR})\right)(\mathrm{n}=15)$; quality of life (e.g. AQLQ) $(n=13)$; rescue medication use $(n=11)$; asthma control (e.g. ACT, Asthma Control Questionnaire (ACQ)) $(n=10)$; hospitalisations $(n=9)$; exacerbations $(n=8)$; asthma symptoms $(n=8)$; absences from school/work $(n=7)$; emergency department (ED) visits $(n=7)$; OCS use $(n=4)$; participant satisfaction $(n=4)$; use of healthcare services $(n=5)$; beliefs about medication $(n=3)$; costs $(n=3)$; primary care/general practitioner (GP) visits $(n=3)$; adverse events $(n=3)$; unscheduled visits to a healthcare provider $(n=3)$; self-efficacy $(n=2)$; anxiety and depression (e.g. Hospital Anxiety and Depression Scale (HADS)) $(n=2)$; asthma knowledge $(n=2)$; fractional exhaled nitrous oxide $(n=2)$; asthma morbidity $(n=1)$; parent and adolescent conflict $(n=1)$; functional severity index $(n=$ $1)$; episodes of poor asthma control $(n=1)$; inhaler technique $(n=1)$; feasibility $(n=1)$; activity limitation $(n=1)$; parent sleep interruption $(n=1)$; and change in family plans due to the child's asthma $(n=1)$.

We extracted and reported only our prespecified outcomes of interest.

\section{Excluded studies}

After full-text review, we excluded 52 records, which were related to 45 unique studies. The most common reason for exclusion (n $=20$ ) was that adherence to ICS was not the primary focus of the intervention, for example, the study involved multi-faceted asthma education or shared decision making. The second most common 
reason $(n=12)$ was that the study was a trial of different ICS types, regimens or inhaler devices, in which adherence was observed and reported but improved adherence was not the main intention of the intervention. Nine studies were not of appropriate design for inclusion, one study recruited a mixed disease population, one recruited participants among whom less than 50\% were using ICS and one study aimed to improve treatment adherence generally in asthma, rather than ICS specifically, and did not report the proportion using ICS. A final study aimed to investigate if Symbicort Maintenance and Reliever Therapy (SMART) could improve adherence, but our outcomes of interested would have been confounded by the different drugs and doses used in each arm; therefore, we excluded this study.

\section{Risk of bias in included studies}

As planned, we assessed each trial according to the Cochrane 'Risk of bias' tool (Figure 2). In some cases, we assessed blinding, or lack or blinding, as associated with a different level of risk, depending on the outcome in question. We have noted in the Characteristics of included studies tables when this was the case, and we factored this into our GRADE decisions for these outcomes (e.g. a study at high risk of detection bias for patient-reported outcomes, such as quality of life, might be at lower risk for other, more objective outcomes, such as electronically monitored adherence). 
Figure 2. Risk of bias summary: review authors' judgements about each risk of bias item for each included study.

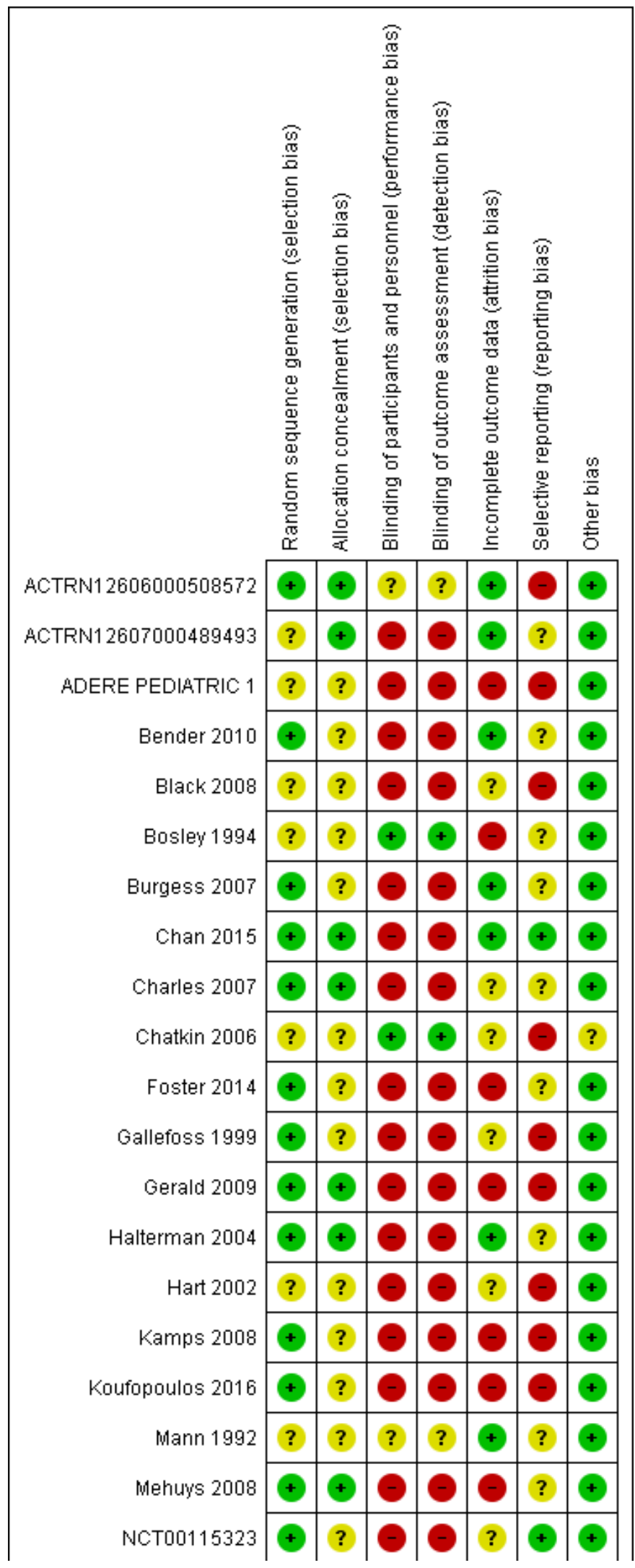


Figure 2. (Continued)

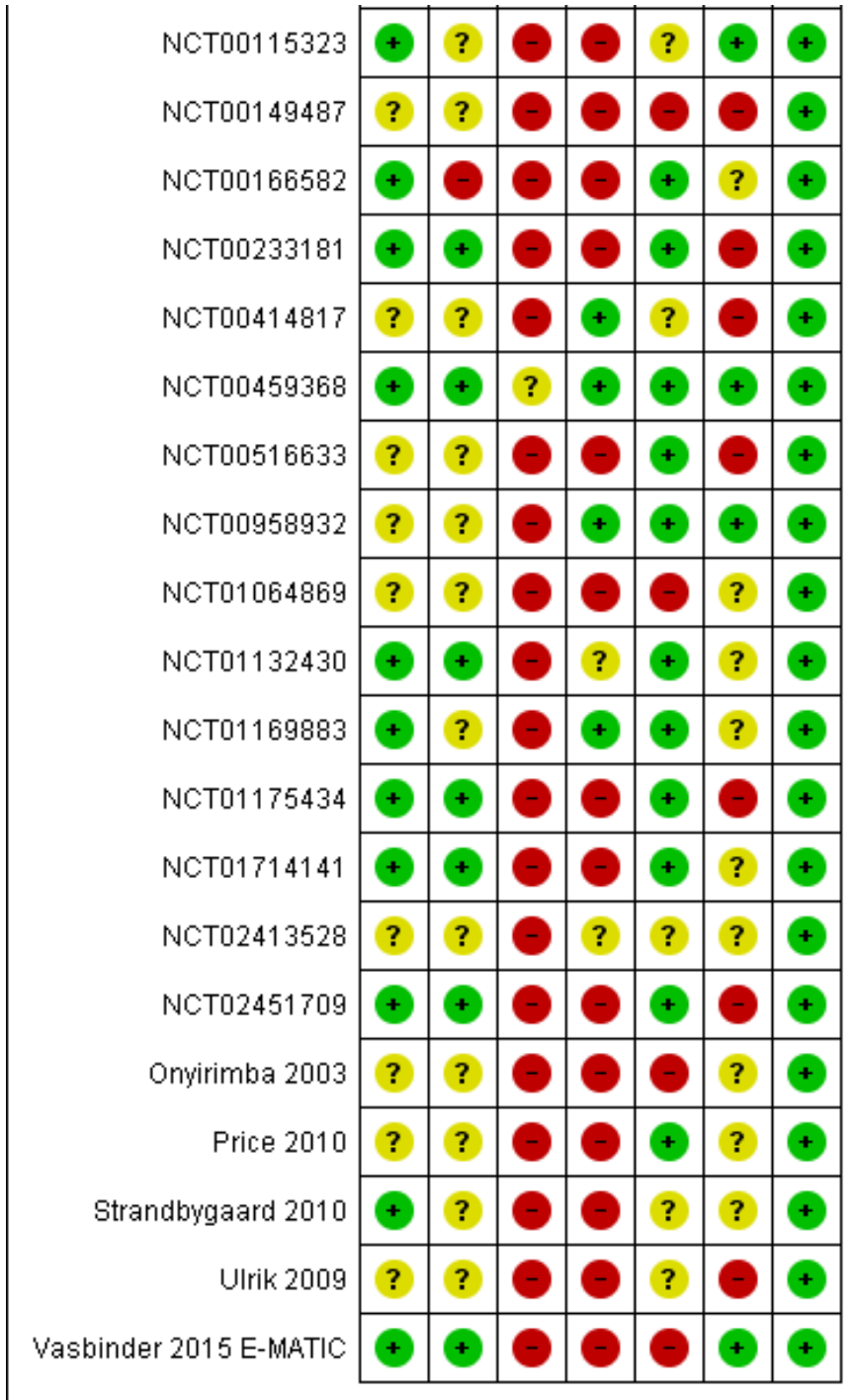

\section{Allocation}

We considered all included studies to be at low $(n=23)$ or unclear $(n=16)$ risk of bias for the random sequence generation domain. We considered the following studies to be at low risk because study authors described an accepted method of generating a random sequence (e.g. using a computergenerated random sequence): ACTRN12606000508572; Bender 2010; Burgess 2007; Chan 2015; Foster 2014; Gallefoss 1999; Gerald 2009; Halterman 2004; Kamps 2008; Koufopoulos 2016; Mehuys 2008; NCT00115323; NCT00166582; NCT00233181; NCT00459368; NCT01132430; NCT01169883; NCT01175434; NCT01714141; NCT02451709; Strandbygaard 2010; Vasbinder 2015 E-MATIC. We were unable to make a judgement on the following studies considered at unclear risk because investigators described them as 'randomised' but provided no other details: ACTRN12607000489493; ADERE PEDIATRIC 1; Black 2008; Bosley 1994; Chatkin 2006; Hart 2002; Mann 1992; NCT00149487; NCT00414817; NCT00516633; NCT00958932; NCT01064869; NCT02413528; Onyirimba 2003; Price 2010; Ulrik 2009.
Only 14 included studies (ACTRN12606000508572; ACTRN12607000489493; Chan 2015; Charles 2007; Gerald 2009; Halterman 2004; Mehuys 2008; NCT00233181; NCT00459368; NCT01132430; NCT01175434; NCT01714141; NCT02451709; Vasbinder 2015 E-MATIC) described the method of allocation concealment adequately to be considered at low risk of bias in this domain. Accepted methods included use of sequentially numbered, sealed, opaque envelopes. We considered one study (NCT00166582) to be at high risk because the sequence was available to the research assistant who recruited participants. We judged the remaining 24 studies to be at unclear risk, as investigators did not describe methods used to conceal allocation (ADERE PEDIATRIC 1; Bender 2010; Black 2008; Bosley 1994; Burgess 2007; Chatkin 2006; Foster 2014; Gallefoss 1999; Hart 2002; Kamps 2008; Koufopoulos 2016; Mann 1992; NCT00115323; NCT00149487; NCT00414817; NCT00516633; NCT00958932; NCT01064869; NCT01169883; NCT02413528; Onyirimba 2003; Price 2010; Strandbygaard 2010; Ulrik 2009). 


\section{Blinding}

Owing to the nature of the intervention, blinding of participants and personnel was not possible in most trials, and we judged 34 of the 39 included studies to be to be at overall high risk of performance bias. We judged two studies (Bosley 1994; Chatkin 2006) to be at low risk of performance bias. Bosley 1994 measured only outcomes of lung function and electronically monitored adherence, which are more objective outcomes and therefore are less likely to be susceptible to performance bias. In addition, participants were unaware that they were being monitored. Similarly, Chatkin 2006 did not describe blinding but reported only the outcome of electronically monitored adherence. We assessed three studies (ACTRN12606000508572; Mann 1992; NCT00459368) to be at unclear risk of performance bias. Mann 1992 did not describe procedures used to mask participants or personnel, and although some outcomes were more objective and were less prone to bias, others, including asthma symptoms, were more at risk. Therefore, we judged this study to be at unclear risk overall. Similarly, for ACTRN12606000508572, participants were unaware that the main outcome of interest was adherence and they were monitored covertly, but other outcomes, such as ACQ, were at greater risk of bias. Finally, NCT00459368 randomised healthcare practitioners rather than individuals. Practitioners were aware of their group allocation, and it is unclear how this knowledge may have influenced adherence of their patients in ways unintended by the intervention itself.

Many of the outcomes of interest in this review are patient reported (e.g. asthma control, quality of life), and the unblinded participant is often the outcome assessor. We therefore judged 29 of the included studies to be at high risk of bias in the outcome assessment domain. We judged six studies to be at low risk (Bosley 1994; Chatkin 2006; NCT00414817; NCT00459368; NCT00958932; NCT01169883). We made this judgement because the outcomes measured were objective and were unlikely to be influenced by outcome assessors' knowledge of group allocation (e.g. usage of healthcare services from medical records, data from electronic monitoring devices), and for some specific measures, studies described masking outcome assessors to group allocation. We judged the remaining four studies (ACTRN12606000508572; Mann 1992; NCT01132430; NCT02413528) to be at unclear risk of bias. NCT01132430 included a mixture of outcomes objectively assessed by a blinded outcome assessor and patient-reported outcomes, so overall we judged this study to be at unclear risk. Similarly, Mann 1992 and ACTRN12606000508572 included a mix of objective outcomes and patient-reported outcomes. NCT02413528 reported very minimal details, so we could not make a judgement.

\section{Incomplete outcome data}

We judged 18 studies to be at low risk of attrition bias; dropout was low and balanced, and withdrawn participants were adequately described (ACTRN12606000508572; ACTRN12607000489493; Bender 2010; Burgess 2007; Chan 2015; Halterman 2004; Mann 1992; NCT00166582; NCT00233181; NCT00459368; NCT00516633; NCT00958932; NCT01132430; NCT01169883; NCT01175434; NCT01714141; NCT02451709; Price 2010). We judged 11 studies to be at high risk, usually owing to high and/or unbalanced drop-out from study arms (ADERE PEDIATRIC 1; Bosley 1994; Foster 2014; Gerald 2009; Kamps 2008; Koufopoulos 2016; Mehuys 2008; NCT00149487; NCT01064869; Onyirimba 2003; Vasbinder 2015 E-MATIC). We judged another 10 studies to be at unclear risk, usually because drop-outs were not adequately described to allow a judgement (Black 2008; Charles 2007; Chatkin 2006; Gallefoss 1999; Hart 2002; NCT00115323; NCT00414817; NCT02413528; Strandbygaard 2010; Ulrik 2009).

\section{Selective reporting}

We judged five trials to be at low risk of reporting bias. We were able to identify a prepublished protocol or prospective trial registration and found that all stated outcomes of interest were appropriately reported (Chan 2015; NCT00115323; NCT00459368; NCT00958932; Vasbinder 2015 E-MATIC). We judged 15 studies to be at high risk of selective reporting. Reasons included that the study was identified only as a conference abstract with minimal details, that key outcomes were reported only narratively or in a way that prevented meta-analysis or that we noted an important deviation between protocol/registration and published results (ACTRN12606000508572; ADERE PEDIATRIC 1; Black 2008; Chatkin 2006; Gallefoss 1999; Gerald 2009; Hart 2002; Kamps 2008; Koufopoulos 2016; NCT00149487; NCT00233181; NCT00414817; NCT00516633; NCT02451709; Ulrik 2009). We judged the remaining 18 studies to be at unclear risk, primarily because we were unable to identify a prepublished protocol or prospective trial registration.

\section{Other potential sources of bias}

We did not note any additional potential sources of bias in any included studies.

\section{Effects of interventions}

See: Summary of findings for the main comparison Adherence education compared with controls for asthma; Summary of findings 2 Electronic trackers or reminders ( \pm feedback) compared with controls for asthma; Summary of findings 3 Simplified compared with usual regimens for asthma; Summary of findings 4 School-based ICS therapy compared with home therapy for asthma

\section{Comparison 1. Adherence education versus controls}

\section{Adherence}

Our primary analysis of adherence included only studies that used an objective electronic monitor to measure adherence. Mean adherence for those receiving adherence education was $20 \%$ better than for those in the control group (Analysis 1.1; mean difference (MD) 20.13, 95\% confidence interval (CI) 7.52 to 32.74 ; 280 participants; five studies; low-quality evidence). A benefit favouring adherence education is seen when studies using both objective and subjective measures are included, but the effect is attenuated (Analysis 1.2; MD 11.59, 95\% Cl 3.72 to 19.46; 1693 participants; 10 studies; low-quality evidence).

We noted great variation between individual study results in both analyses ( $12=81 \%$ and $88 \%$, respectively), and concerns about effects of performance bias and selection bias reduced our confidence in the results. We created a funnel plot to look for evidence of publication bias (Figure 3 ) and found none. 
Figure 3. Funnel plot of comparison: 1 Adherence education vs controls, outcome: $1.2 \%$ Adherence (all measures).

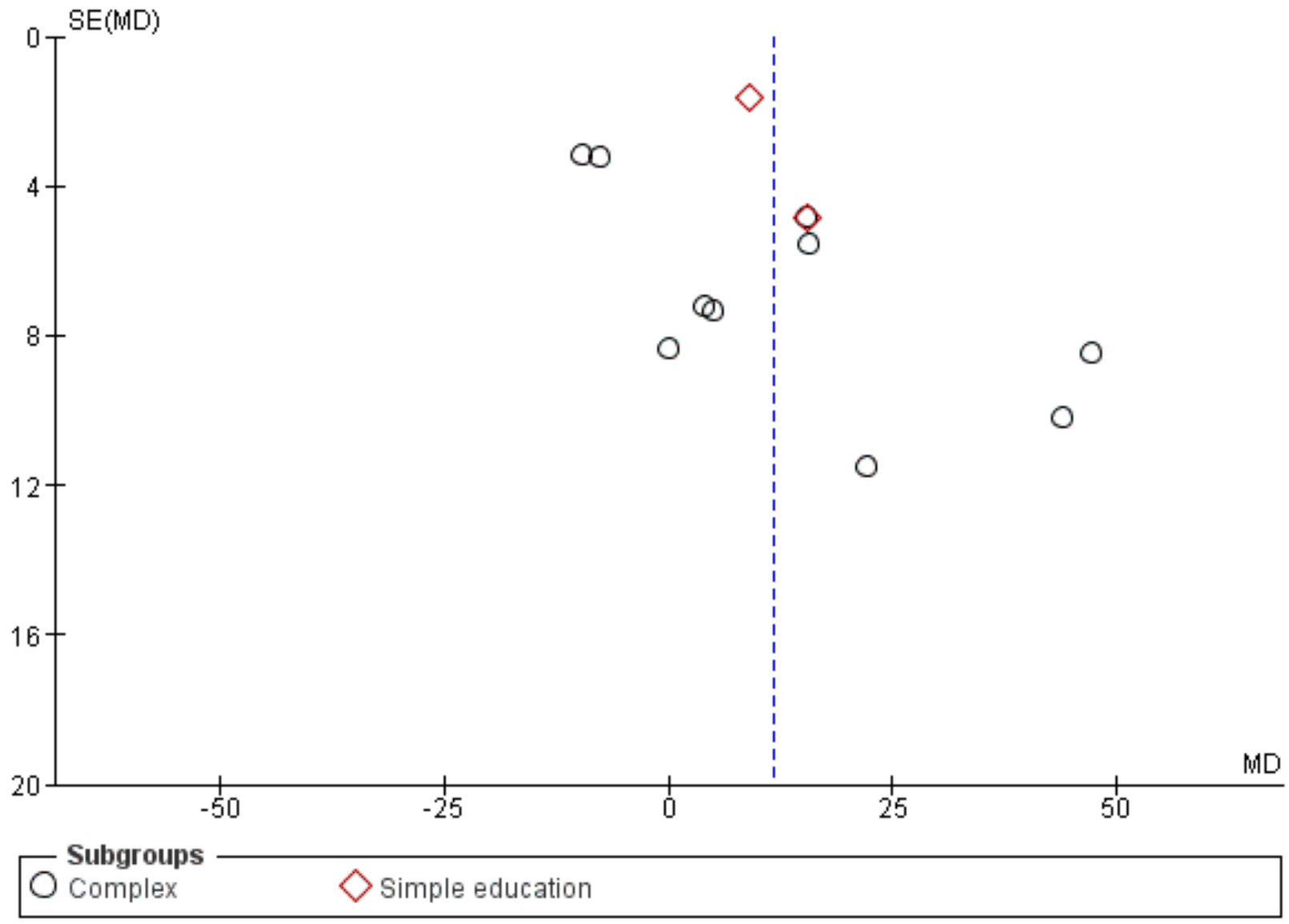

One larger study (Chatkin 2006) dichotomised participants into those who achieved greater than $85 \%$ adherence and those who did not; results showed benefit of the educational intervention (Analysis 1.3; odds ratio (OR) 2.68, 95\% Cl 1.61 to $4.46 ; 271$ participants; one study).

A test for subgroup differences between interventions judged to be 'complex' (i.e. multi-faceted) and interventions offering simpler forms of education detected no differences between the two types of interventions $\left(1^{2}=0 \%\right)$, but it should be noted that we classified as 'simple' only one study using objective measures. Testing suggested no important differences between studies of adults, studies of adults and adolescents and studies of children (Analysis 5.1) when all measures of adherence were considered. If the same subgroup analysis is performed only on studies using objective measures, only one study in the child subgroup remains; although this analysis suggests that the intervention is more effective in children, we interpret this finding with extreme caution. We planned a subgroup analysis based on the recipient of the intervention, but this was not necessary, as all interventions were delivered to adults or children with asthma or their parents.

\section{Exacerbations requiring OCS}

It was not possible to discern with certainly whether education had an effect on the odds that a patient would need oral steroids for an exacerbation (OR 1.82, 95\% Cl 0.99 to 3.36; 349 participants; three studies; $1^{2}=10 \%$; low-quality evidence). The point estimate lay in favour of control, but confidence intervals around the pooled estimate showed no differences between groups (Analysis 1.4). We downgraded the evidence for risk of bias and for imprecision. We did not perform subgroup analyses on this primary outcome because we identified too few studies and we did not observe significant heterogeneity in the analysis.

Three other studies (NCT00233181; NCT00958932; NCT01064869) reported the mean number of exacerbations per person over six or 12 months, but the data were skewed so we did not pool the results. NCT00233181 reported a significant reduction in OCS use (incident rate ratio $0.83 ; 95 \% \mathrm{Cl} 0.73$ to $0.95 ; \mathrm{P}=0.008$ ) when both intervention groups were compared with the control group. Conversely, NCT00958932 reported increased oral steroid use in the intervention group over the 24 months of the study (mean (standard error (SE)) oral steroid bursts per person per year 0.21 $(0.18)$ in the control group and 0.27 (0.23) in the intervention group; $P=0.05)$. NCT01064869 reported a small reduction in courses of oral steroids at 12-month follow-up in the intervention group compared with the control group, but this finding was not significant (mean (standard deviation (SD)) 1.7 (1.1) in the intervention group and 2.0 (1.4) in the control group; $P=0.41$ ).

\section{Asthma control}

Studies used the Asthma Control Questionnaire (Bender 2010; NCT00115323; NCT01064869; NCT01132430) and the Asthma Control Test (Foster 2014; Mehuys 2008; NCT01132430) as validated 
measures of asthma control (Analysis 1.5) and reported no differences between adherence education and control on the ACQ (MD $-0.03,95 \% \mathrm{Cl}-0.49$ to $0.43 ; 455$ participants; four studies; $\mathrm{I}^{2}=$ $38 \%$; moderate-quality evidence) nor on the ACT (MD 0.30, 95\% Cl -0.82 to 1.43 ; 333 participants; three studies; $1^{2}=40 \%$; moderatequality evidence). We noted some variation in study results, but our confidence in these results was mainly reduced by risk of performance and detection bias. Upper and lower confidence limits for both estimates fell within the minimal clinically important differences (MCIDs) for the scales ( 0.5 point for the ACQ and 3 points for the ACT), so we did not consider the evidence imprecise. It was not possible to perform subgroup analyses on this primary outcome because we identified too few studies and we did not observe substantial heterogeneity in the analysis.

\section{Unscheduled visits}

Studies reported unscheduled visits inconsistently as hospital visits, ED visits or GP visits, and this made the estimate difficult to interpret (Analysis 1.6). The pooled estimate lay predominantly in favour of adherence education, but the effect was imprecise and the upper confidence limit crossed the line of no difference (OR $0.48,95 \% \mathrm{Cl} 0.19$ to $1.19 ; 688$ participants; four studies; I $^{2}$ $=59 \%)$. We considered evidence for this outcome to be of very low quality owing to risk of bias, inconsistency between study results, imprecision and variation in the way unscheduled visits were defined. Also, effects presented separately suggest possible benefit of adherence education for ED and GP visits, but we did not set out to assess these outcomes separately, so this must be interpreted with caution.

Three other studies (Gallefoss 1999; NCT00233181; NCT00958932) reported the mean number of unscheduled visits per person, but the data were skewed so we have not presented a mean difference. Gallefoss 1999 reported a reduction in the mean (SD) number of GP consultations in the intervention group compared with the control group: 0.7 (2.0) versus 2.6 (3.6); P<0.001. NCT00233181 also reported a significant reduction in the number of ED visits in the intervention group (incident rate ratio $0.88 ; 95 \% \mathrm{Cl} 0.78$ to $0.99 ; \mathrm{P}=$ 0.03), NCT00958932 reported ED and after-hours visits but did not detect a significant between-group difference for either outcome ( $P$ $=0.23$ and $\mathrm{P}=0.12$, respectively)

\section{Absence from work/school}

Two studies reported rates of absenteeism per person over 12 months (Gallefoss 1999) or 18 months (NCT00516633). The mean number of absence days per person in Gallefoss 1999 was eight in the adherence education group $(n=25)$ and 26 in the control group $(n=24)$, but standard deviations were 32 and 70 days, respectively, suggesting that the data were heavily skewed. Consequently, we did not consider it appropriate or useful to analyse the data for a mean difference. The other study reporting this outcome (NCT00516633) observed a mean of 2.1 days in the adherence education group $(n=32)$ and 3.9 days in the control group $(n=28)$; the $P$ value for this difference as reported in the paper was 0.08 .

\section{Quality of life}

Results showed no difference between adherence education and control on the Asthma Quality of Life Questionnaire (Analysis 1.7; MD $0.01,95 \% \mathrm{Cl}-0.20$ to $0.23 ; 734$ participants; six studies; $1^{2}=34 \%$; moderate-quality). Upper and lower confidence limits fell within the 0.5 MCID for the scale, so we did not downgrade for imprecision. We had concerns regarding performance and detection bias because the scale is self-rated.

\section{All adverse events}

No studies measured or reported adverse events other than the need for oral steroids or unscheduled visits, which have already been considered.

\section{Comparison 1 sensitivity analyses}

No unpublished data were included in the analyses, so we found that this sensitivity analysis was not necessary.

Only one study in the objective \% adherence outcome was rated at high risk for either of the selection bias domains, and results without this study showed a slightly smaller pooled effect than was evident in the main analysis (MD 16.23, 95\% Cl 3.86 to 28.60). No studies in the 'Exacerbation requiring OCS' or 'Asthma control' analyses were at high risk in either of the selection bias domains.

Mehuys 2008 and Gallefoss 1999 were the only Comparison 1 studies in which not all participants were taking an ICS at baseline (although proportions were between 89.5\% and $97 \%$ in each group). Mehuys 2008 did not contribute to the objective \% adherence outcome, as researchers did not measure adherence using an electronic monitor. Both studies contributed to 'Exacerbations requiring OCS' and their exclusion left just the two Foster 2014 comparisons (PAD vs control and IRF + PAD vs IRF) in the analysis. The point estimate favours control over education (OR $3.44,95 \% \mathrm{Cl} 1.35$ to $8.81 ; 131$ participants; one study), but results were reported by a single small study and should be interpreted with caution. Mehuys 2008 contributed to the ACT analysis, but our conclusions did not change when we excluded this study (MD 0.72 , $95 \% \mathrm{Cl}-0.58$ to 2.02 ).

As described previously, instead of excluding studies that did not measure adherence objectively in a sensitivity analysis, we have presented this as our main analysis (Analysis 1.1).

\section{Comparison 2. Electronic trackers or reminders versus controls}

\section{Adherence}

As for Comparison 1, our primary analysis of adherence included only studies that used an objective electronic monitor to measure adherence. Mean adherence of those using electronic trackers or reminders was $20 \%$ better than mean adherence of those in the control group (Analysis 2.1; MD 19.86, 95\% Cl 14.47 to 25.26; 555 participants; six studies; $\mathrm{I}^{2}=34 \%$; moderate-quality evidence). As with Comparison 1, our confidence in the estimate was reduced by possible performance and selection bias. Pooling studies using any measure of adherence had little impact on the estimate, but greater inconsistency was evident (MD 18.41, 95\% Cl 11.82 to 25.00; 762 participants; eight studies; $\left.\right|^{2}=66 \%$; low-quality evidence).

Subgroup analyses for the objectively measured adherence outcome provides weak evidence that inhaler reminders combined with individual feedback may be more effective than inhaler reminders alone (test for subgroup difference: $\mathrm{P}=65.2 \%$; $\mathrm{P}=$ 0.09; Analysis 2.1). The test for subgroup differences between interventions judged to be 'complex' (i.e. multi-faceted) and simpler interventions also provides weak evidence that complex interventions may be more effective, but this effect was seen only 
when the analysis was limited to studies using objective measures of adherence $\left(I^{2}=65.2 \% ; P=0.09\right.$; Analysis 5.2$)$. Testing also suggested no important differences between studies of adults (or adults and adolescents) and children ( $12=0 \%$; Analysis 5.3). As with Comparison 1, the subgroup analysis based on the recipient of the intervention was not necessary, as all interventions were delivered to adults or children with asthma or their parents.

Three other studies reported data about adherence that could not be pooled with data from studies reporting \% adherence. Data from Chan 2015 were skewed and were reported as medians; this study showed large benefit of an audiovisual inhaler reminder, with an intervention median adherence of $84 \%$ (10th to 90th percentile 54 to $96 ; N=110$ ) compared with a control median adherence of $30 \%$ (10th to 90th percentile 8 to $68 ; \mathrm{N}=110$ ). NCT00459368, a large cluster study, reported adherence as a refill rate and showed similar results between groups (21.3 in the feedback group (SE 2.5), 23.2 in the control group (SE 2,2)). NCT01714141 collected adherence data in several ways from a self-report questionnaire, none of which were comparable with those of other studies; scores generally favoured the treatment group.

\section{Exacerbations requiring OCS}

It was not possible to say with certainty whether electronic trackers or reminders improved the odds of needing oral steroids for an exacerbation (OR $0.72,95 \% \mathrm{Cl} 0.37$ to $1.39 ; 3063$ participants; four studies; $1^{2}=60 \%$; very low-quality evidence). Confidence limits included important benefit in one direction and important harm in the other (Analysis 2.3). We downgraded the evidence further for risk of bias and inconsistency.

Again, as with the first comparison, we did not perform subgroup analyses on this primary outcome because we identified too few studies. Similarly, some studies (NCT00233181; NCT00459368; NCT02451709; Vasbinder 2015 E-MATIC) reported the mean number of exacerbations per person over a period of time and the data were skewed, so we did not consider a mean difference to be a valid measure for comparison. NCT00233181 reported no difference between the adherence monitoring with feedback group and the asthma education group for oral steroid use $(P=0.32)$. Similarly, NCT00459368 reported oral steroid use and found no clear benefit of adherence feedback over usual care $(P=0.277)$. Vasbinder 2015 E-MATIC reported exacerbations as requiring OCS, an ED visit or hospitalisation and reported no advantage of the text messaging intervention over control ( $\mathrm{P}=0.432$ ). Finally, NCT02451709 adjusted the analysis to account for the skew and found that children receiving adherence feedback had fewer exacerbations per 100 days compared with controls (rate ratio $0.23,95 \% \mathrm{Cl} 0.08$ to 0.64 ).

\section{Asthma control}

Studies used the Asthma Control Questionnaire (NCT02451709; Strandbygaard 2010) or the Asthma Control Test (Chan 2015; Foster 2014; NCT01714141; Vasbinder 2015 E-MATIC) as validated measures of asthma control (Analysis 2.4). Results did not show an important difference between reminders/trackers and controls on the ACQ (MD $0.24,95 \% \mathrm{Cl}-0.29$ to $0.78 ; 109$ participants; two studies; $1^{2}=0 \%$; low-quality evidence) nor on the ACT (MD 0.74 , $95 \% \mathrm{Cl}-0.20$ to 1.69 ; 596 participants; four studies; ${ }^{2}=47 \%$; lowquality evidence). The upper limit for the ACQ estimate includes the MCID for the scale (0.5), so trackers and reminders could have an important effect on this measure of asthma control; we downgraded the evidence for imprecision for this reason. We noted some variation between ACT results, but confidence limits fell below the 3 point MCID for the scale, so we did not consider the estimate imprecise.

It was not possible to perform subgroup analyses on this primary outcome because we identified too few studies and we did not observe significant heterogeneity in the analysis.

\section{Unscheduled visits}

Some studies reported unscheduled visits as ED visits and some as hospital visits (Analysis 2.5); we did not pool the two because NCT00459368 reported both. It was not possible to say with certainly whether electronic trackers or reminders reduced the odds of unscheduled visits to the ED (OR $1.14,95 \% \mathrm{Cl} 0.88$ to 1.47 ; 2918 participants; two studies; $\mathrm{I}^{2}=0 \%$; moderate-quality evidence) or to the hospital (OR $0.97,95 \% \mathrm{Cl} 0.53$ to $1.78 ; 2865$ participants; two studies; $I^{2}=0 \%$; not graded), as the estimates were imprecise.

NCT02451709 reported data that could be analysed as rate ratios (Analysis 2.6) and showed a reduction in hospital visits (rate ratio $4.38,95 \% \mathrm{Cl} 1.46$ to 13.14 ) but not in GP or ED visits (rate ratio 1.15, $95 \% \mathrm{Cl} 0.83$ to 1.59$)$.

\section{Absence from work/school}

Chan 2015 reported that the number of parents taking at least one absence favoured controls but results were imprecise (Analysis 2.7; OR $1.42,95 \% \mathrm{Cl} 0.82$ to 2.47 ; low-quality evidence). We considered evidence for the outcome to be of low quality owing to imprecision and risk of bias. NCT02451709 reported absences per 100 child days that favoured reminders, but results were imprecise (Analysis 2.8; rate ratio $1.16,95 \% \mathrm{Cl} 0.97$ to 1.39 ; evidence quality not graded).

\section{Quality of life}

Studies reported no difference between electronic trackers or reminders and controls on the Asthma Quality of Life Questionnaire (MD $-0.03,95 \% \mathrm{Cl}-0.20$ to $0.13 ; 369$ participants; four studies; $\mathrm{I}^{2}$ $=0 \%$; moderate-quality evidence). Upper and lower confidence limits lay well within the 0.5 point MCID for the scale, so we did not consider the effect imprecise, although we had the usual concerns related to risk of bias.

\section{All adverse events}

Only Vasbinder 2015 E-MATIC measured and reported adverse events; this study reported serious adverse events of any cause and observed none in either group.

\section{Comparison 2 sensitivity analyses}

No unpublished data contributed to any of the three primary outcomes, so this sensitivity analysis was not necessary. Similarly, we rated no contributing studies at high risk of selection bias, so this was also not necessary.

Before the study commenced, not all participants in Strandbygaard 2010 were taking an ICS (59\%), but all were taking an ICS at the start of the study. Excluding this study made little difference in the objective \% adherence analysis (MD 20.62, 95\% Cl 14.30 to 26.95) but greatly decreased the precision of the ACQ analysis (MD 0.19 , $95 \% \mathrm{Cl}-1.37$ to 1.75 ). This study did not contribute to exacerbations requiring oral steroids. 
As for Comparison 1, instead of excluding studies that did not measure adherence objectively in a sensitivity analysis, we have presented this as our main analysis (Analysis 2.1).

\section{Comparison 3. Simplified versus usual drug regimens}

\section{Adherence}

All three studies contributing to this outcome assessed adherence using an objective measure. Adherence was $4 \%$ better with simplified drug regimens than with usual drug regimens (Analysis 1.1; MD 4.02, $95 \% \mathrm{Cl} 1.88$ to $6.16 ; 1310$ participants; three studies; $12=0 \%)$. We downgraded the evidence only for risk of bias and rated it as moderate quality. The effect is difficult to interpret as two studies compared combined versus separate inhalers (Bosley 1994; ACTRN12606000508572), and one study compared once-daily versus twice-daily dosing (Price 2010).

Adherence data in Mann 1992 could not be combined with those from other studies. Twice-daily and four-times-daily groups in Mann 1992 took a similar mean number of correct daily inhalations. Data from the same study showing the percentage of days with missed inhalations favoured twice daily but were skewed (twice daily $36.8 \%$, SD 48.3; four times daily $57.1 \%$, SD 49.6).

\section{Exacerbations requiring OCS}

It was not possible to tell whether simplifying drug regimens had an effect on exacerbations, as only one study of 16 people reported this outcome (Analysis 3.2; OR 2.33, 95\% Cl 0.17 to 32.58 ; low-quality evidence). This study compared twice-daily treatment versus treatment given four times daily (Mann 1992).

\section{Asthma control}

One study (ACTRN12606000508572) comparing combined inhalers (simplified regimen) versus separate inhalers showed no difference between regimens on the ACQ (MD $-0.03,95 \% \mathrm{Cl}-0.34$ to $0.28 ; 103$ participants; one study). Both confidence limits fell within the 0.5 MCID for the ACQ, so we did not downgrade for imprecision. We had the usual concerns regarding risk of bias through lack of blinding, so we rated the evidence as moderate quality.

\section{Unscheduled visits}

Price 2010 did not show benefit of once-daily dosing (simplified regimen) versus twice-daily dosing for unscheduled visits (Analysis 3.4; OR $1.17,95 \% \mathrm{Cl} 0.72$ to 1.90 ; 1037 participants; one study; low-quality evidence). The effect lay close to no difference, and confidence limits showed important benefit in one direction and important harm in the other; we downgraded the evidence for this imprecision and for risk of bias.

\section{Absence from work/school}

On the basis of data from one study (Price 2010), it was, again, not possible to tell whether once-daily dosing (simplified regimen) showed benefit for this outcome compared with twice-daily dosing; only one study reported this, and confidence intervals included important benefit and harm (Analysis 3.5; OR $0.93,95 \% \mathrm{Cl} 0.37$ to 2.30; low-quality evidence).

\section{Quality of life}

One study comparing once-daily dosing (simplified) versus twicedaily dosing (Price 2010) reported quality of life on the Therapeutics
Group Asthma Short Form (Analysis 3.6); the lower confidence limit crossed the line of no effect, so we were not confident in the estimate (MD $6.00,95 \% \mathrm{Cl}-0.76$ to $12.76 ; 1037$ participants; lowquality evidence). The scale ranges from 1 to 100 , and we could find no information on an agreed MCID.

\section{All adverse events}

Price 2010 reported adverse events and observed fewer in the simplified regimens group (once-daily dose) than in the control group (twice-daily dose), but confidence intervals included no difference (OR $0.76,95 \% \mathrm{Cl} 0.56$ to 1.04 ; low-quality evidence). We downgraded the evidence for imprecision and for risk of performance bias.

\section{Comparison 3 subgroup and sensitivity analyses}

We did not perform any subgroup analyses for this comparison as we included no more than three studies in any single analysis. None of the sensitivity analyses were necessary because we located no unpublished data, no contributing studies were at high risk of selection bias and all used objective measures of adherence.

\section{Comparison 4. School-based ICS therapy versus control}

The three studies performing this comparison provided no data for adherence, exacerbations requiring OCS, asthma control or adverse events. Gerald 2009 reported a composite measure of episodes of poor asthma control (EPAC), which we could not combine with any other measures. We identified too few studies to consider any of the planned subgroup or sensitivity analyses, but we have presented below data that could be analysed.

\section{Unscheduled visits}

Two studies reported unscheduled visits, but the data could not be combined. Halterman 2004 reported that 18 of 89 children in the intervention group and 26 of 91 in the control group had three or more visits over 10 months. NCT01175434 reported that 9 of 48 children in the intervention group and 1151 in the control group had one or more unscheduled visits over six to eight months.

Both studies reported the number of people who had one or more hospitalisations for any cause during the study; confidence intervals showed an important benefit in either direction, so it was not possible to say whether school-based ICS has a beneficial effect (OR 0.58, 95\% Cl 0.16 to 2.05; 279 participants; two studies; $12=0 \%$; low-quality evidence).

\section{Absence from work/school}

Halterman 2004 reported mean absences per child over the 10month study: 6.8 absences (SD 9.5) for the intervention group and 8.8 days (SD 8.8) for the control group. NCT01175434 reported a mean of 0.37 absences (SD 0.7) in the intervention group over two weeks and 0.85 (SD 1.3) in the control group. Both sets of data were skewed and were not suitable for combination in a mean difference analysis.

\section{Quality of life}

The same two studies reported results of the Paediatric Asthma Quality of Life Questionnaire (PAQLQ). A statistically significant effect favoured giving ICS at school, but the upper end of the confidence limit lay under the $0.5 \mathrm{MCID}$ for the scale, so the difference is unlikely to be clinically important (MD 0.25, 95\% Cl 0.01 
to $0.49 ; 279$ participants; two studies; $1^{2}=0 \%$; moderate-quality evidence).

\section{Adverse events}

NCT01175434 reported that no one in the intervention group ( $\mathrm{n}=$ $48)$ and no one in the control group $(n=51)$ had any adverse events.

\section{Unclassified studies}

We were unable to classify Koufopoulos 2016 and Burgess 2007, as both tested interventions that did not fit into any of our four main categories.

Burgess 2007 reported that a novel spacer device, the 'Funhaler', did not improve adherence to ICS in children over the 12-week study period. End of follow-up median adherence (range) was $46 \%$ (2\% to $100 \%$ ) in the intervention group and $53 \%$ (0 to $100 \%$ ) in the control (Aerochamber) group. Investigators measured adherence with a SmartInhaler. Study authors reported the number of children experiencing an exacerbation requiring an OCS: 11 of 24 in the intervention group and 6 of 20 in the control group.

Koufopoulos 2016 investigated whether an online asthma community ("AsthmaVillage") can improve self-reported adherence, measured on the Simplified Medication Adherence Questionnaire (SMAQ). Results show that the control group reported better adherence to ICS during the study period and control group participants were more likely to use the online diary than those in the AsthmaVillage group.

\section{DISCUSSION}

\section{Summary of main results}

This review found 39 eligible parallel randomised controlled trials (RCTs), 28 of which ( $n=16,303$ ) contributed data to at least one meta-analysis. Eighteen studies included only children, 20 included adults and/or adolescents and one recruited individuals of all ages; all participants had asthma and a vast majority were using an inhaled corticosteroid (ICS) at baseline. Followup of analysed studies ranged from two months to two years (median six months). Trials were conducted mainly in high-income countries. Outcomes reported were not consistent across reviews, and investigators did not always use validated scales. Almost all included studies reported some measure of adherence, usually as a percentage, but the way in which this information was captured and calculated varied between studies. Studies were generally at low or unclear risk of selection bias and at high risk of bias associated with blinding (although this varied by outcome). Review authors considered around half of these studies to be at high risk for attrition bias and selective outcome reporting.

Studies were classified into four comparisons by consensus: adherence education versus control (20 studies); electronic trackers or reminders versus control (11 studies); simplified drug regimens versus usual drug regimens (four studies); and school-based directly observed therapy (three studies). Two multi-arm studies appeared in two comparisons (Foster 2014; NCT00233181), and two studies were described separately (Burgess 2007; Koufopoulos 2016).

All pooled results for adherence education, electronic trackers or reminders and simplified regimens led to better adherence than for controls, both when adherence was measured objectively and when all measures were considered. However, our confidence in the evidence was reduced by risk of bias and inconsistency. When measured objectively (e.g. using a dose counter), adherence education showed $20 \%$ benefit over controls (95\% confidence interval $(\mathrm{Cl}) 7.52$ to 32.74 ; five studies; low-quality evidence), and the effect was attenuated to $12 \%$ when all measures were considered. Electronic trackers or reminders led to $20 \%$ (18\% if all measures were included) better adherence than for controls ( $95 \% \mathrm{Cl} 14.47$ to 25.26 ; six studies; low-quality evidence). Simplified regimens led to $4 \%$ better adherence than usual care $(95 \% \mathrm{Cl}$ 1.88 to 6.16 ; three studies; moderate-quality evidence), but the effect is difficult to interpret, as two studies compared combined versus separate inhalers (ACTRN12606000508572; Bosley 1994) and one study compared once-daily versus twice-daily dosing (Price 2010). When we were able to conduct subgroup analyses, we found that 'complex' or multi-faceted educational interventions were not statistically better than simpler interventions, but weak evidence suggested that complex interventions involving adherence reminders and feedback may be more effective than simpler interventions within this comparison. Similarly, weak evidence from subgroup analysis suggested that combining reminders with feedback is more effective than using reminders alone. Overall, results for adults and children were similar.

Improvements in adherence were inconsistently translated into observable benefit for clinical outcomes, with some studies reporting a reduction in usage of healthcare services or courses of oral steroids favouring the intervention, and other studies reporting the opposite, or no difference. None of the pooled analyses showed clear benefit for exacerbations requiring an oral corticosteroid (OCS) (evidence of low quality), unscheduled visits (evidence of very low to moderate quality), asthma control or quality of life (evidence for both of low to moderate quality). School or work absence data were mostly skewed and were difficult to interpret (evidence of low quality, when graded), and most studies did not report adverse events.

Studies investigating the possible benefit of administering an ICS at school did not measure adherence, exacerbations requiring OCS, asthma control or adverse events. One study showed fewer unscheduled visits, and another found no difference; data could not be combined.

\section{Overall completeness and applicability of evidence}

The findings of this review appear to support the premise that interventions specifically intended to improve adherence to ICS are effective in improving percent adherence in both adults and children. However, a wide range of interventions have been used in the included studies, and even within the four comparisons, interventions are variable. We cannot be sure to what extent improvement in adherence was a result of the intervention itself, rather than a result of participation in a trial in which the stated aim was to improve adherence (the "Hawthorne effect" (McCambridge 2014)). Indeed, in many trials all participants showed improvement in several outcomes, irrespective of the group to which they were assigned. In some included trials, participants' adherence was covertly monitored to minimise the impact of performance bias, but participants would likely have been aware of the overall aims of the trial nonetheless. In addition, many of the interventions, especially in Comparison 1, would require considerable investment of resources and in a budget-constrained healthcare system would 
be unlikely to be widely adopted. All three considerations limit the applicability of review findings to a real-world setting.

Although all three of the comparisons that measured percentage adherence demonstrated improvement (albeit with low to moderate confidence), it is not always clear whether this was a clinically meaningful improvement, with no established minimal clinically important difference for this outcome. Studies have suggested that median ICS adherence to maintain asthma control is in excess of $80 \%$ (Lasmar 2009). It may have been helpful for interpretation if more trialists had prespecified what they considered to be 'acceptable' adherence, for example, greater than $80 \%$, and had dichotomised participants into those achieving this level of adherence and those not achieving it. The clinical applicability and usefulness of observed improvements in percent adherence could be further disputed by observation of an inconsistent impact on clinical outcomes such as asthma control, quality of life or exacerbations. Most participants, despite improvements in percent adherence, may not have reached the 'threshold' necessary for discernible clinical improvement (Comparisons 1 and 2), or baseline/control group adherence was already at a high level (Comparison 3), thus allowing little room for discernible improvement (Summary of findings for the main comparison; Summary of findings 2; Summary of findings 3). It must be noted that very few studies specifically measured or reported adverse events beyond asthma-related events such as exacerbations. Therefore, we cannot comment on the safety of the interventions studied.

Objectvely measured adherence would generally be considered more reliable than patient-reported measures or pharmacy data. In a post hoc decision, we presented objectively measured adherence as our main adherence analysis. It came as a surprise that in Comparison 1, limiting the analysis to objectively measured adherence resulted in a greater effect size. One possible explanation for this is that when participants were asked to selfreport and had received an educational intervention, they were able to make a more realistic assessment of their adherence than were participants in the control group, who may have consciously or unconsciously inflated their adherences rates. This could have resulted in an underestimation of the effect of the intervention.

Our protocol clearly stated that we would include only studies for which adherence to ICS was the main aim of the trial. This resulted in the exclusion of many studies for which adherence education was just one component of a broader asthma education or self-management education intervention. This may have led to the exclusion of potentially informative studies; however, their inclusion would have further hampered interpretation, as it would be almost impossible to be sure which element of the intervention had led to observed clinical benefit. Mann 1992 included a comparison (four-times-daily dosing) that is not relevant in current practice, but we did not state that we would exclude 'historical' comparisons, and this study was not combined with any other study in a meta-analysis.

Some included studies specifically targeted people with poorly controlled asthma, those known to have suboptimal adherence levels or those in especially high-risk groups, such as adolescents. We did not plan to analyse such trials separately from those that recruited a more general asthma population. It may have been illuminating to do so, as it is conceivable that these groups would benefit most from a potentially resource-consuming intervention and could be therefore be targeted in a real-world setting.

We were not able to carry out all of our planned subgroup analyses, and our subgrouping by complexity may have imposed some limitations. This was inevitably a subjective judgement, although we involved all three review authors in the assessment and revised three of our classifications after peer review. Some of the included studies provided only a brief description of the intervention, which also hampered our confidence in our classification. Although subgroup analysis did not provide strong evidence that more complex interventions are more effective than less complex interventions, a different classification process may have led to different conclusions.

\section{Quality of the evidence}

Studies were generally at low or unclear risk of selection bias, but we downgraded many of the analyses for inherent risk of bias associated with studies of behavioural interventions that cannot be blinded. To some extent, performance and detection biases varied by outcome, and by the nature of interventions within a given comparison, but we agreed that performance biases can be present even for more objective outcomes (such as unscheduled visits or exacerbations) because people who know they are receiving the intervention, or know they are not, might be more or less likely to visit their doctor or report a negative outcome. Lack of blinding was a problem especially for self-rated outcomes such as asthma control and quality of life and may have affected how participants, study investigators and healthcare professionals behaved in each group, producing a more indirect effect on other, more objective outcomes, including adherence itself. Thus, our confidence in many of the outcomes was reduced by risk of bias, especially when we had additional concerns about attrition or uncertainties about the selection process.

Inconsistency between study results tended to be more of an issue for adherence, and this may be explained at least in part by methodological differences such as measurements used and length of the study, or by differences in the underlying populations. Subgroup analyses generally did not help to explain observed heterogeneity. Most studies showed better adherence in the intervention group, but some outliers showed an effect close to no difference or in the opposite direction, which reduced our confidence in the findings.

Dichotomous analyses of fairly rare events such as exacerbations and unscheduled visits tended to be limited by imprecision. For these outcomes, confidence intervals stretched from an important benefit of the intervention to a possible benefit of controls, which prevented firm conclusions.

Indirectness of evidence was less of an issue in this evidence base, as we applied eligibility criteria stringently. In only a couple of instances, indirectness in the measurement of an outcome reduced our confidence in the effect (absences and unscheduled visits in Comparison 1). Similarly, we did not detect or strongly suspect publication bias for any outcomes.

\section{Potential biases in the review process}

As much as possible, we carried out this review as presented in the published protocol (Kew 2016) and recorded deviations from it under Differences between protocol and review. We could 
not perform planned subgroup or sensitivity analyses on some outcomes because studies were too few or fell into a single subgroup.

We did not attempt to contact study authors for additional outcome data or risk of bias clarification owing to the number of studies identified. Therefore, we may have overstated the uncertainty in risk of bias, particularly as related to allocation concealment. Published reports may not have provided unpublished data that were not included in the meta-analyses. However, it is unlikely that eligible studies were missed by the searches conducted because they covered multiple sources and were sifted in duplicate.

We could not anticipate all the ways in which intervention groups and control groups would differ across studies; as a result, our post hoc classification of studies into four comparisons could have introduced bias. It is conceivable that a different classification system may have yielded different results.

\section{Agreements and disagreements with other studies or reviews}

Several recent reviews have investigated adherence interventions in people with chronic diseases, such as asthma. Both Ershad 2016 and Yasmin 2016 examined the effectiveness of text messaging interventions for people with chronic disease. Ershad 2016 presented a narrative review that included six asthma studies. In keeping with our review, these review authors found that text messaging was effective in promoting adherence among different patient populations, although three of the asthma studies showed no differences between groups in adherence to treatment. Yasmin 2016 included two asthma studies of text message and voice call interactions. These review authors concluded that people with chronic disease showed improvement in adherence, but review authors did not see a significant impact on clinical outcomes, which is consistent with our findings. In addition, these review authors found variation in types of interventions provided and outcome measurements assessed, which made it difficult to draw firm conclusions, and cost-effectiveness remains questionable. Anglada-Martinez 2014 reviewed m-health interventions proposed to increase medication adherence and concluded that studies provided mixed evidence of the benefits of these interventions, probably because of variation in study methods. We also encountered problems with between-study heterogeneity.

Hall 2014 considered effects of medical device dose memory functions on medication adherence and included one study on asthma medication adherence. These review authors found evidence of benefit for these device functions in terms of medication adherence and patient confidence in managing their condition. We did not attempt to extract outcomes related to participant confidence or self-efficacy. Wu 2014 reviewed adherence interventions delivered by healthcare providers and included 23 studies of people with asthma, most of whom were children. Review authors found that interventions delivered by a healthcare provider improved adherence and recommended that future reviews should focus on particular patient populations and adherence behaviours. They planned to perform subgroup analyses based on the identified recipient of the intervention but were unable to do so, as all interventions were delivered directly to study participants.
Recent reviews of adherence interventions among asthma populations show a similar picture. Dibello 2014 brought together trials of text messaging services aimed at adults 18 to 45 years of age. Review authors found that adherence improved and noted some impact on control and lung function. However, they were not able to perform a meta-analysis because of heterogeneity. Tran 2014 reviewed studies of patient reminder systems. These review authors were not able to pool the data but concluded, "All studies in our analysis suggest that reminder systems increase patient medication adherence, but none documented improved clinical outcomes".

Bårnes 2015 provides a wide-ranging review of adherence in asthma and includes studies on adherence levels and effects of poor adherence, as well as studies of interventions aimed at improving adherence. In the intervention studies, review authors found mixed results, with most studies showing improved adherence, although this did not always translate to improvement in other outcomes.

The results of our review of interventions to improve adherence in asthma are consistent with the findings of other reviews examining asthma populations and the broader category of chronic disease, as described. We found that adherence rates increased, but that the impact on clinical outcomes was unclear, and our conclusions must be considered in the light of variation across studies. Our review differs in that we have drawn different types of interventions together into a single review that focuses on people with asthma rather than on a broader category of chronic disease, and, when appropriate, we have been able to pool study results.

\section{AUTHORS' CONCLUSIONS}

\section{Implications for practice}

Our findings suggest that interventions to improve ICS adherence in adults and children with asthma can increase adherence, whether objectively or subjectively measured. This finding was consistent across the three comparisons performed to measure this. The clinical relevance of this improvement, highlighted by uncertain and inconsistent impact on clinical outcomes such as quality of life and asthma control, is less clear. Overall, we have low to moderate confidence in these findings owing to concerns about risk of bias and inconsistency.

\section{Implications for research}

Guidelines for asthma management consistently call for routine discussion of adherence with patients, and evidence suggests that poor adherence may contribute to unfavourable outcomes. This fact emphasises the importance of research conducted to investigate interventions that may be recommended to practitioners and their patients. Future studies would benefit from ensuring that investigators use validated tools for outcome measurement, such as the Asthma Control Test (ACT), the Asthma Control Questionnaire (ACQ) and the Asthma Quality of Life Questionnaire (AQLQ), and provide adequate details regarding baseline asthma severity among participants. Given that our confidence in our findings was reduced by concerns about performance and detection biases, we suggest that some form of blinding or active control is important to include, when possible. This would help to elucidate the contribution of the intervention itself to improved adherence, beyond the potential benefit of 
inclusion in an adherence trial. It may be helpful for trialists to prespecify a threshold for 'acceptable' adherence and to perform a dichotomous analysis of those achieving this level and those not achieving it. The inconsistent impact observed in terms of clinical outcomes may have occurred because most participants did not achieve this threshold (Comparisons 1 and 2), or because baseline/ control group adherence was already at a high level (Comparison 3). Targeting those at high risk or known to have poor adherence may provide evidence that is more 'useful' in the real world, which may be affected by budget constraints.

\section{ACKNOWLEDGEMENTS}

Julia Walters was the Editor for this review and commented critically on the review.

The Background and Methods sections of this review are based on a standard template used by the Cochrane Airways Group.

We would like to thank Juliet Foster and Wei Xuan for providing the intracluster correlation coefficient for Foster 2014. 


\section{R E F E R E N C E S}

\section{References to studies included in this review \\ ACTRN12606000508572 \{published data only\}}

ACTRN12606000508572. Does combination therapy increase adherence with inhaled corticosteroids and improve clinical outcomes in asthma?. apps.who.int/trialsearch/Trial2.aspx? TrialID=ACTRN12606000508572 (first received 5 February 2007).

Perrin K, Williams M, Wijesinghe M, James K, Weatherall M, Beasley R. Erratum: Randomized controlled trial of adherence with single or combination inhaled corticosteroid/long-acting beta-agonist inhaler therapy in asthma (Journal of Allergy and Clinical Immunology (2010) 126 (505-10)). Journal of Allergy and Clinical Immunology 2012;129(6):1691.

* Perrin K, Williams M, Wijesinghe M, James K, Weatherall M, Beasley R. Randomized controlled trial of adherence with single or combination inhaled corticosteroid/long-acting betaagonist inhaler therapy in asthma. Journal of Allergy and Clinical Immunology 2010;126(3):505-10.

\section{ACTRN12607000489493 \{published data only\}}

ACTRN12607000489493. The impact of providing feedback on adherence in childhood asthma. www.anzctr.org.au/Trial/ Registration/TrialReview.aspx?id=82288 (first received 14 September 2007).

* Burgess SW, Sly PD, Devadason SG. Providing feedback on adherence increases use of preventive medication by asthmatic children. Journal of Asthma 2010;47(2):198-201.

\section{ADERE PEDIATRIC 1 \{published data only\}}

* ADERE PEDIATRIC 1. Prospective, parallel-group, randomized, open label study to evaluate the impact of additional guidance from the health professionals team on treatment compliance of children aged between 6 and 14 years old with persistent moderate or severe asthma, receiving the combination salmeterol/fluticasone $50 / 250 \mathrm{mcg}$ (Seretide) twice a day. ADERE PROJECT (Pediatric). //www.gskclinicalstudyregister.com/study/ADERE\%20PEDIATRIC\%201? search=compound\&compound=fluticasone-propionatesalmeterol\#rs (first received 28 September 2008).

\section{Bender 2010 \{published data only\}}

* Bender BG, Apter A, Bogen DK, Dickinson P, Fisher L, Wamboldt FS, et al. Test of an interactive voice response intervention to improve adherence to controller medications in adults with asthma. Journal of the American Board of Family Medicine 2010;23(2):159-65.

\section{Black 2008 \{published data only}

* Black PN, Garratt E, Arandjus C, Salmon BT, Sutherland G. An inhaler with ring tones improves compliance with inhaled steroids in childhood asthma [Abstract]. American Thoracic Society International Conference; May 16-21, 2008; Toronto. 2008:Poster \#A46.

\section{Bosley 1994 \{published data only\}}

* Bosley CM, Parry DT, Cochrane GM. Patient compliance with inhaled medication: does combining beta-agonists with corticosteroids improve compliance?. European Respiratory Journal 1994;7(3):504-9.

\section{Burgess 2007 \{published data only\}}

* Burgess SW, Sly PD, Cooper DM, Devadason SG. Novel spacer device does not improve adherence in childhood asthma. Pediatric Pulmonology 2007;42(8):736-9.

\section{Chan 2015 \{published data only\}}

* Chan AH, Stewart AW, Harrison J, Camargo CA Jr, Black PN, Mitchell EA. The effect of an electronic monitoring device with audiovisual reminder function on adherence to inhaled corticosteroids and school attendance in children with asthma: a randomised controlled trial. Lancet Respiratory Medicine 2015;3(3):210-9.

Charles 2007 \{published data only\}

* Charles T, Quinn D, Weatherall M, Aldington S, Beasley R, Holt $S$. An audiovisual reminder function improves adherence with inhaled corticosteroid therapy in asthma. Journal of Allergy and Clinical Immunology 2007;119(4):811-6.

\section{Chatkin 2006 \{published data only\}}

* Chatkin JM, Blanco DC, Scaglia N, Wagner MB, Fritscher CC, Chatkin J, et al. Impact of a low-cost and simple intervention in enhancing treatment adherence in a Brazilian asthma sample. Journal of Asthma 2006;43(4):263-6.

Foster 2014 \{published data only\}

* Foster J, Smith L, Usherwood T, Sawyer S, Reddel H. Electronic reminders improve adherence with preventer inhalers in Australian primary care patients. Respirology 2014;0:24 [TO 034].

Foster JM, Usherwood T, Smith L, Sawyer SM, Xuan W, Rand CS et al. Inhaler reminders improve adherence with controller treatment in primary care patients with asthma. Journal of Allergy and Clinical Immunology 2014;134(6):1260-8.

\section{Gallefoss 1999 \{published data only\}}

* Gallefoss F, Bakke PS. How does patient education and self-management among asthmatics and patients with chronic obstructive pulmonary disease affect medication? American Journal of Respiratory and Critical Care Medicine 1999;160(6):2000-5.

Gallefoss F, Bakke PS. Impact of patient education and selfmanagement on morbidity in asthmatics and patients with chronic obstructive pulmonary disease. Respiratory Medicine 2000;94(3):279-87. [CRS: 4900100000008905]

Gallefoss F, Bakke PS, Rsgaard PK, Kjaersgaard P. Quality of life assessment after patient education in a randomized controlled study on asthma and chronic obstructive pulmonary disease. American Journal of Respiratory and Critical Care Medicine 1999;159(3):812-7. [CENTRAL: 160267; CRS: 4900100000006265 ; PUBMED: 10051255] 


\section{Gerald 2009 \{published data only\}}

Gerald LB, McClure LA, Harrington KF, Mangan JM, Gibson L, Atchison J, et al. Design of the supervised asthma therapy study: implementing an adherence intervention in urban elementary schools. Contemporary Clinical Trials 2008;29(2):304-10.

* Gerald LB, McClure LA, Mangan JM, Harrington KF, Gibson L, Erwin $S$, et al. Increasing adherence to inhaled steroid therapy among schoolchildren: randomized, controlled trial of school-based supervised asthma therapy. Pediatrics 2009;123(2):466-74.

Gerald LB, Patel K, Zhang S, McClure L. Secondhand smoke exposure and asthma morbidity among elementary school children enrolled in a clinical trial. Chest 2007;132(4):461. [DOI: 10.1378/chest.132.4_MeetingAbstracts.461]

McClure LA, Harrington KF, Graham H, Gerald LB. Internet-based monitoring of asthma symptoms, peak flow meter readings, and absence data in a school-based clinical trial. Clinical Trials 2008;5(1):31-7.

\section{Halterman 2004 \{published data only\}}

* Halterman JS, Szilagyi PG, Yoos HL, Conn KM, Kaczorowski JM, Holzhauer RJ, et al. Benefits of a school-based asthma treatment program in the absence of secondhand smoke exposure: results of a randomized clinical trial. Archives of Pediatric and Adolescent Medicine 2004;158(5):460-7.

\section{Hart 2002 \{published data only\}}

* Hart CAH, Love AM, Gibson NA, Morgan N, Paton JY. Effects of an educational intervention directed at parental beliefs and anxieties about inhaled steroid medication of adherence. American Journal of Respiratory and Critical Care Medicine 2002;165:A420.

\section{Kamps 2008 \{published data only\}}

Kamps JL. Improving adherence to inhaled corticosteroids in children with asthma [Dissertation]. University of Kansas, 2002.

* Kamps JL, Rapoff MA, Roberts MC, Varela RE, Barnard M, Olson N. Improving adherence to inhaled corticosteroids in children with asthma: a pilot of a randomized clinical trial. Children's Health Care 2008;37(4):261-77.

\section{Koufopoulos 2016 \{published data only\}}

Koufopoulos JT, Conner MT, Gardner PH, Kellar I. A web-based and mobile health social support intervention to promote adherence to inhaled asthma medications: randomized controlled trial. Journal of Medical Internet Research 2016;18(6):e122. [CRS: 4900132000024092; PUBMED: 27298211]

Mann 1992 \{published data only\}

* Mann M, Eliasson O, Patel K, ZuWallack RL. A comparison of the effects of bid and qid dosing on compliance with inhaled flunisolide. Chest 1992;101(2):496-9.

\section{Mehuys 2008 \{published data only\}}

Mehuys E, Van Bortel L, De Bolle L, Van Tongelen I, Annemans L, Remon JP, et al. Effectiveness of pharmacist intervention for asthma control improvement. European Respiratory Journal 2008;31(4):790-9.

* Mehuys E, van Bortel L, de Bolle L, van Tongelen I, Remon J$P$, Annemans L, et al. Does pharmacist intervention lead to appropriate use of asthma medication and improved asthma control? [Leidt apothekersadvies over het optimaal gebruik van astmamedicatie tot een verbetering van de astmacontrole? Een gerandomiseerde gecontroleerde studie]. Farmaceutisch Tijdschrift voor Belgie 2008;85(1):1-9.

\section{NCT00115323 \{published data only\}}

Apter AJ, Bogen DK, Wang X, Rand CS, McElligott S, Polsky D, et al. Intervening to improve adherence and asthma outcomes in urban adults with moderate or severe asthma [Abstract]. American Journal of Respiratory and Critical Care Medicine 2011;183:A3791.

* Apter AJ, Wang X, Bogen DK, Rand CS, McElligott S, Polsky D, et al. Problem solving to improve adherence and asthma outcomes in urban adults with moderate or severe asthma: a randomized controlled trial. Journal of Aallergy and Clinical Immunology 2011;128(3):516-23.

NCT00115323. Comparison of two medication adherence strategies to improve asthma treatment adherence [Individualized interventions to improve asthma adherence]. https://clinicaltrials.gov/show/NCT00115323 (first received 21 June 2005). [NCT00115323]

\section{NCT00149487 \{published data only\}}

* NCT00149487. Enhancing treatment adherence in pediatric asthma with a problem solving intervention [Randomized controlled trial of problem solving intervention to enhance treatment adherence in pediatric asthma]. https:// clinicaltrials.gov/ct2/show/NCT00149487 (first received 6 September 2005).

NCT00149487. Randomized controlled trial of problem solving intervention to enhance treatment adherence in pediatric asthma. clinicaltrials.gov/show/NCT00149487 (first received 6 September 2005).

Rohan J, Drotar D, McNally K, Schluchter M, Riekert K, Vavrek P, et al. Adherence to pediatric asthma treatment in economically disadvantaged African-American children and adolescents: an application of growth curve analysis. Journal of Pediatric Psychology 2010;35(4):394-404.

NCT00166582 \{published data only\}

Adams CD, Joseph KE, MacLaren JE, DeMore M, Koven L, Detweiler MF, et al. Parent-youth teamwork in pediatric asthma management [Abstract]. Journal of Allergy and Clinical Immunology 2004;113(2):S159.

* Duncan CL, Hogan MB, Tien KJ, Graves MM, Chorney JM, Zettler MD, et al. Efficacy of a parent-youth teamwork intervention to promote adherence in pediatric asthma. Journal of Pediatric Psychology 2013;38(6):617-28.

NCT00166582. Parent-youth teamwork in pediatric asthma management. https://clinicaltrials.gov/show/NCT00166582 (first received 9 September 2009). 


\section{NCT00233181 \{published data only\}}

NCT00233181. Adherence intervention for minority children with asthma. clinicaltrials.gov/show/NCT00233181 (first received 3 October 2005).

* Otsuki M, Eakin MN, Rand CS, Butz AM, Hsu VD, Zuckerman IH, et al. Adherence feedback to improve asthma outcomes among inner-city children: a randomized trial. Pediatrics 2009;124(6):1513-21.

\section{NCT00414817 \{published data only\}}

NCT00414817. Telephone-based program to promote inhaled corticosteroid adherence among individuals with asthma [Phone calls to promote adherence with inhaled corticosteroids]. clinicaltrials.gov/show/NCT00414817 (first received 20 December 2006).

Vollmer WM, Feldstein A, Smith DH, Dubanoski JP, Waterbury A, Schneider JL, et al. Use of automated phone calls to support inhaled corticosteroids (ICS) adherence. American Thoracic Society International Conference; May 15-20, 2009; San Diego. 2009:A1089 [Poster \#518].

Vollmer WM, Feldstein A, Smith DH, Dubanoski JP, Waterbury A, Schneider JL, et al. Use of health information technology to improve medication adherence. American Journal of Managed Care 2011;17(12):SP79-87.

Vollmer WM, Xu M, Feldstein A, Smith D, Waterbury A, Rand C. Comparison of pharmacy-based measures of medication adherence. BMC Health Services Research 2012;12:155.

\section{NCT00459368 \{published data only\}}

Ahmedani BK, Peterson EL, Wells KE, Rand CS, Williams LK. Asthma medication adherence: the role of God and other health locus of control factors. Annals of Allergy, Asthma \& Immunology 2013;110(2):75-9.

NCT00459368. Using information technology to improve asthma adherence (AFFIRM) [Adherence feedback for improving respiratory medication use]. clinicaltrials.gov/show/ NCT00459368 (first received 9 April 2007).

* Williams LK, Peterson EL, Wells K, Campbell J, Wang M, Chowdhry VK, et al. A cluster-randomized trial to provide clinicians inhaled corticosteroid adherence information for their patients with asthma. Journal of Allergy and Clinical Immunology 2010;126(2):225-31.

\section{NCT00516633 \{published data only\}}

* Hederos CA, Janson S, Hedlin G. Group discussions with parents have long-term positive effects on the management of asthma with good cost-benefit. Acta Paediatrica 2005;94(5):602-8.

NCT00516633. Intervention study to improve adherence in asthma [Does improved information in the form of group discussions with parents of newly diagnosed asthmatic children lead to a better quality of life for the families, an improved adherence and better development of the lung function of the children?]. clinicaltrials.gov/show/NCT00516633 (first received 13 August 2007).

\section{NCT00958932 \{published data only\}}

Bender BG, Cvietusa P, Goodrich G, Lowe CR, Nuanes H, Shetterly S, et al. A 24-month randomized, controlled trial of an automated speech recognition program to improve adherence in pediatric asthma. Journal of Allergy and Clinical Immunology 2014;133(2 Suppl):AB166.

* Bender BG, Cvietusa PJ, Goodrich GK, Lowe R, Nuanes HA, Rand $C$, et al. Pragmatic trial of health care technologies to improve adherence to pediatric asthma treatment: a randomized clinical trial. JAMA Pediatrics 2015;169(4):317-23.

NCT00958932. Telecommunication enhanced asthma management. clinicaltrials.gov/show/NCT00958932 (first received 13 August 2009). [NCT00958932]

\section{NCT01064869 \{published data only\}}

Gamble J, Heaney LG. An individualised nurse-led programme to improve adherence in patients with difficult asthma - 12 month outcomes. American Journal of Respiratory and Critical Care Medicine 2010;181(1):A3258.

* Gamble J, Stevenson M, Heaney LG. A study of a multi-level intervention to improve non-adherence in difficult to control asthma. Respiratory Medicine 2011;105(9):1308-15.

NCT01064869. A nurse led programme to improve adherence in difficult asthma [Evaluation of the benefits of an individualised menu driven nurse led programme to improve adherence in difficult asthma]. clinicaltrials.gov/show/NCT01064869 (first received 8 February 2010).

\section{NCT01132430 \{published data only\}}

Lavoie K, Moullec G, Blais L, Beauchesne M-F, Lemiere C, Labrecque $M$, et al. The efficacy of brief motivational interviewing to improve medication adherence in poorly controlled, nonadherent asthmatics: results from a randomized controlled pilot study [Abstract]. Chest 2011;140(4):915A.

Lavoie KL, Lemiere C, Labrecque M, Blais L, Beauchesne M, Moullec $G$, et al. The efficacy of motivational interviewing on asthma medication adherence in non-adherent, poorly controlled asthmatics: preliminary results of the asthma control trial (ACT). Psychosomatic Medicine 2011;7(3):A-9.

* Lavoie KL, Moullec G, Lemiere C, Blais L, Labrecque M, Beauchesne M-F, et al. Efficacy of brief motivational interviewing to improve adherence to inhaled corticosteroids among adult asthmatics: results from a randomized controlled pilot feasibility trial. Patient Preference and Adherence 2014;8:1555-69.

NCT01132430. Motivational interviewing for medication adherence in asthma [Impact of a motivational interviewing intervention on medication adherence in patients with asthma]. https://clinicaltrials.gov/show/NCT01132430 (first received 27 May 2010).

\section{NCT01169883 \{published data only\}}

Mosnaim G, Li H, Martin M, Belice PJ, Avery E, Ryan N, et al. The use of coping peer support and $\mathrm{mp} 3$ technology to improve adherence to inhaled corticosteroids among low- 
income minority adolescents. Journal of Allergy and Clinical Immunology 2013;131(2):AB133 [478].

\begin{abstract}
* Mosnaim G, Li H, Martin M, Richardson D, Belice PJ, Avery E, et al. The impact of peer support and mp3 messaging on adherence to inhaled corticosteroids in minority adolescents with asthma: a randomized, controlled trial. Journal of Allergy and Clinical Immunology: In Practice 2013;1(5):485-93.
\end{abstract}

NCT01169883. Coping peer intervention for adherence. https:// clinicaltrials.gov/show/NCT01169883 (first received 23 July 2010).

Powell L. The impact of peer support and mp3 messaging on adherence to inhaled corticosteroids in minority adolescents with asthma: a randomized, controlled trial. Journal of Allergy and Clinical Immunology 2013;0(5):485-93.

\section{NCT01175434 \{published data only\}}

* Halterman JS, Fagnano M, Montes G, Fisher S, Tremblay P, Tajon R, et al. The school-based preventive asthma care trial: results of a pilot study. Journal of Pediatrics 2012;161(6):1109-15.

Halterman JS, Sauer J, Fagnano M, Montes G, Fisher S, Tremblay P, et al. Working toward a sustainable system of asthma care: development of the School-Based Preventive Asthma Care Technology (SB-PACT) trial. Journal of Asthma 2012;49(4):395-400.

* NCT01175434. School-based preventive asthma care technology: a trial using a novel technology to improve adherence (SB-PACT). https://clinicaltrials.gov/ct2/show/ NCT01175434 (first received 16 April 2010).

\section{NCT01714141 \{published data only\}}

* Kolmodin MacDonell K, Naar S, Gibson-Scipio W, Lam P, Secord E. The Detroit young adult asthma project: pilot of a technology-based medication adherence intervention for African-American emerging adults. Journal of Adolescent Health 2016;59(4):465-71. [DOI: 10.1016/j.jadohealth.2016.05.016]

NCT01714141. Multi-component technology intervention for minority emerging adults with asthma. https://clinicaltrials.gov/ ct2/show/NCT01714141 (accessed 21 July 2016).

\section{NCT02413528 \{published data only\}}

* NCT02413528. Pilot study of a mobile asthma adherence intervention [Pilot study of a mobile intervention to increase adherence to asthma medication among adolescents]. https:// clinicaltrials.gov/show/NCT02413528 (first received 7 April 2015).

\section{NCT02451709 \{published data only\}}

Morton R, Everard M, Elphick H. Randomised control trial to investigate whether electronic adherence monitoring with reminder alarms and feedback can improve clinical outcomes in childhood asthma. European Respiratory Journal 2015;46:OA4772.

* Morton RW, Elphick HE, Rigby AS Daw WJ, King DA, Smith LJ, et al. STAAR: a randomised controlled trial of electronic adherence monitoring with reminder alarms and feedback to improve clinical outcomes for children with asthma. Thorax 2016;0:1-8.

NCT02451709. STudy of Asthma Adherence Reminders (STAAR) [Can electronic adherence monitors with feedback and daily reminders improve adherence and health outcomes in children with asthma?]. clinicaltrials.gov/show/NCT02451709 (first received 5 May 2015).

\section{Onyirimba 2003 \{published data only\}}

* Onyirimba F, Apter A, Reisine S, Litt M, McCusker C, Connors M, et al. Direct clinician-to-patient feedback discussion of inhaled steroid use: its effect on adherence. Annals of Allergy, Asthma and Immunology 2003;90(4):411-5.

\section{Price 2010 \{published data only\}}

* Price D, Robertson A, Bullen K, Rand C, Horne R, Staudinger H. Improved adherence with once-daily versus twice-daily dosing of mometasone furoate administered via a dry powder inhaler: a randomized open-label study. BMC Pulmonary Medicine 2010;10:1.

\section{Strandbygaard 2010 \{published data only\}}

* Strandbygaard U, Thomsen SF, Backer V. A daily SMS reminder increases adherence to asthma treatment: a three-month follow-up study. Respiratory Medicine 2010;104(2):166-71.

Ulrik 2009 \{published data only\}

* Ulrik CS, Claudius BK, Tamm M, Harving H, Siersted HC, Backer V, et al. Effect of asthma compliance enhancement training on asthma control in patients on combination therapy with salmeterol/fluticasone propionate: a randomised controlled trial.[Erratum appears in Clin Respir J. 2009 Jul;3(3):185]. Clinical Respiratory Journal 2009;3(3):161-8.

\section{Vasbinder 2015 E-MATIC \{published data only\}}

Goossens LMA, Vasbinder EC, van Den Bemt PMLA, RuttenVan Molken MPMH. Cost-effectiveness of real-time medication monitoring in children with asthma. Value in Health 2014;17(7):A329.

Vasbinder E, Goossens L, Janssens H, de Winter B, van Dijk L, Vulto $A$, et al. E-monitoring of asthma therapy to improve compliance in children (E-MATIC). European Respiratory Journal 2016;46:758-67. [DOI: 10.1183/13993003.01698-2015]

Vasbinder EC, Goossens LMA, Janssens $\mathrm{H}$, de Winter BCM, van Dijk L, Vulto AG, et al. E-Monitoring of asthma therapy to improve compliance in children (E-MATIC). Pharmacoepidemiology and Drug Safety 2015;24(S1):489. [DOI: $10.1002 / p d s]$

Vasbinder EC, Janssens HM, Rutten-van Molken MP, van Dijk L, de Winter BC, de Groot RC, et al. e-Monitoring of asthma therapy to improve compliance in children using a real-time medication monitoring system (RTMM): the e-MATIC study protocol. BMC Medical Informatics and Decision Making 2013;13(1):38. 


\section{References to studies excluded from this review}

\section{Armour 2007 \{published data only\}}

Armour C, Bosnic-Anticevich S, Brillant M, Burton D, Emmerton L, Krass I, et al. Pharmacy Asthma Care Program (PACP) improves outcomes for patients in the community. Thorax 2007;62(6):496-502. [CRS: 4900100000019940]

\section{Canino 2016 \{published data only\}}

Canino G, Shrout PE, Vila D, Ramirez R, Rand C. Effectiveness of a multi-level asthma intervention in increasing controller medication use: a randomized control trial. Journal of Asthma 2016;53(3):301-10.

\section{Coté 1997 \{published data only\}}

Coté J, Cartier A, Robichaud P, Boutin H, Malo JL, Rouleau M, et al. Influence on asthma morbidity of asthma education programs based on self-management plans following treatment optimization. American Journal of Respiratory and Critical Care Medicine 1997;155(5):1509-14. [CENTRAL: 139695; CRS: 4900100000005679; 4900100000005679; PUBMED: Â 9154850]

\section{Dal Negro 2002 \{published data only\}}

Dal Negro RW, Micheletto C, Bisato R, Trevisan F, Pomari C, Tognella S. Telephonic blind assessment on the adhesion to the therapy with a long-acting beta2-adrenergic and a steroid separately administered or associated in a single device in mild-to-moderate asthmatics. GIMT - Giornale Italiano Delle Malattie del Torace 2002;56(6):442-7. [CENTRAL: 642637; CRS: 4900100000022202; EMBASE: 2008145327]

\section{Delaronde 2005 \{published data only\}}

Delaronde S, Peruccio DL, Bauer BJ. Improving asthma treatment in a managed care population. American Journal of Managed Care 2005;11(6):361-8. [CENTRAL: 522723; CRS: 4900100000018571; EMBASE: 2005284883; PUBMED: 15974555]

\section{Demiralay 2002 \{published data only\}}

Demiralay R. Comparison of the effects of three forms of individualized education on asthma knowledge in asthmatic patients. Turkish Journal of Medical Sciences 2002;32(1):57-64. [CENTRAL: 385086; CRS: 4900100000012071 ; EMBASE: 2002075912]

\section{Demiralay 2004 \{published data only\}}

Demiralay R. The effects of asthma education on knowledge, behavior and morbidity in asthmatic patients. Turkish Journal of Medical Sciences 2004;34(5):319-26. [CENTRAL: 507694; CRS: 4900100000017963; EMBASE: 2004511376]

\section{Fiks 2015 \{published data only\}}

Fiks AG, Mayne SL, Karavite DJ, Suh A, O'Hara R, Localio AR, et al. Parent-reported outcomes of a shared decision-making portal in asthma: a practice-based RCT. Pediatrics 2015;135(4):e965-73. [CENTRAL: 1066974; CRS: 4900126000027102; EMBASE: 2015934354; PUBMED: 25755233]

\section{Fujita 2002 \{published data only\}}

Fujita K, Nagasaka Y, Fujita M, Nakano N, Miyatake A. Adherence with two types of inhaled corticosteroids as a primary controller regimen in adult asthma patients. European Respiratory
Journal 2002;20(Suppl 38):304s. [CENTRAL: 460779; CRS: 4900100000015978; 4900100000015978]

Gallefoss 2002 \{published data only\}

Gallefoss F, Bakke PS. The effect of patient education in asthma, a randomized controlled trial [Effekter av astmaopplaering i en randomisert, kontrollert undersøkelse]. Tidsskrift for Den Norske Laegeforening 2002;122(28):2702-6. [CENTRAL: 412693; CRS: 4900100000013789; 4900100000013789; PUBMED: 12523089]

Garcia-Cardenas 2013 \{published data only\}

Garcia-Cardenas V, Sabater-Hernandez D, Kenny P, MartinezMartinez F, Faus MJ, Benrimoj SI. Effect of a pharmacist intervention on asthma control. A cluster randomised trial. Respiratory Medicine 2013;107(9):1346-55. [CENTRAL: 872110; CRS: 4900100000088347; EMBASE: 2013535321; PUBMED: 23810267]

\section{Gerald 2012 \{published data only\}}

Gerald JK, Gerald LB, Chinchilli VM, Bioty N, Martinez FD. Adherence to rescue inhaled corticosteroid use during the TREXA Trial [Abstract]. American Journal of Respiratory and Critical Care Medicine 2012;185(Meeting Abstracts):A2200. [CENTRAL: 834379; CRS: 4900100000060647; EMBASE: 71986726]

\section{Goeman 2013 \{published data only\}}

* Goeman D, Jenkins C, Crane M, Paul E, Douglass J. Educational intervention for older people with asthma: a randomised controlled trial. Patient Education and Counseling 2013;93(3):586-95. [CENTRAL: 871532; CRS: 4900100000089383 ; EMBASE: 2013751567; PUBMED: 24007766]

Goeman DP, Jenkins CR, Paul E, Crane MA, Douglass JA. Older peoples adherence to inhaled corticosteroid medication: objective and subjective measurement [Abstract]. Respirology 2013;0:37 [0108].

\section{Guenette 2015 \{published data only\}}

Guenette L, Breton MC, Gregoire JP, Jobin MS, Bolduc Y, Boulet LP, et al. Effectiveness of an asthma integrated care program on asthma control and adherence to inhaled corticosteroids. Journal of Asthma 2015;52(6):638-45. [CENTRAL: 1092030; CRS: 4900132000006519; EMBASE: 2015332048; PUBMED: 25539138]

\section{Holt 2004 \{published data only\}}

Holt S, Masoli M, Beasley R. Increasing compliance with inhaled corticosteroids through the use of combination therapy. Journal of Allergy and Clinical Immunology 2004;113(2):219-20. [CRS: 4900132000022697; PUBMED: 14767433]

\section{Iqbal 2004 \{published data only\}}

Iqbal S, Ritson S, Prince I, Denyer J, Everard ML. Drug delivery and adherence in young children. Pediatric Pulmonology 2004;37(4):311-7. [CENTRAL: 468153; CRS: 4900100000016282; EMBASE: 2004182501; PUBMED: 15022127]

\section{Janson 2003 \{published data only\}}

Janson SL, Fahy JV, Covington JK, Paul SM, Gold WM, Boushey HA. Effects of individual self-management education 
on clinical, biological, and adherence outcomes in asthma. American Journal of Medicine 2003;115(8):620-6. [CENTRAL: 459320; CRS: 4900100000015906; PUBMED: 14656614]

\section{Janson 2009 \{published data only\}}

Janson SL, McGrath KW, Covington JK, Cheng SC, Boushey HA. Individualized asthma self-management improves medication adherence and markers of asthma control. Journal of Allergy and Clinical Immunology 2009;123(4):840-6. [CENTRAL: 683492; CRS: 4900100000023383; 4900100000023383; PUBMED: 19348923]

\section{Jonasson 1999 \{published data only\}}

Jonasson G, Carlsen K-H, Sodal A, Jonasson C, Mowinckel P, Carlsen $\mathrm{KH}$. Patient compliance in a clinical trial with inhaled budesonide in children with mild asthma. European Respiratory Journal 1999;14(1):150-4. [CENTRAL: 167596; CRS: 4900100000006536; PUBMED: 10489843]

\section{Jonasson 2000 \{published data only\}}

Jonasson G, Carlsen K-H, Mowinckel P. Asthma drug adherence in a long term clinical trial. Archives of Disease in Childhood 2000;83(4):330-3. [CENTRAL: 299665; CRS: 4900100000008841; EMBASE: 2000351185; PUBMED: 10999870]

\section{Krishnan 2012 \{published data only\}}

Krishnan JA, Bender BG, Wamboldt FS, Szefler SJ, Adkinson NFJ, Zeiger RS, et al. Adherence to inhaled corticosteroids: an ancillary study of the Childhood Asthma Management Program clinical trial. Journal of Allergy and Clinical Immunology 2012;129(1):112-8. [CENTRAL: 833012; CRS: 4900100000056408 ; EMBASE: 2011709418; PUBMED: 22104610]

\section{Kuna 2006 \{published data only\}}

* Kuna P, Creemers JPHM, Vondra V, Black PN, Lindqvist A, Nihlen $U$, et al. Once-daily dosing with budesonide/formoterol compared with twice-daily budesonide/formoterol and oncedaily budesonide in adults with mild to moderate asthma. Respiratory Medicine 2006;100(12):2151-9.

\section{Martin 2015 \{published data only\}}

Martin MA, Mosnaim GS, Olson D, Swider S, Karavolos K, Rothschild S. Results from a community-based trial testing a community health worker asthma intervention in Puerto Rican youth in Chicago. Journal of Asthma 2015;52(1):59-70.

* Martin MA, Mosnaim GS, Olson D, Swider S, Karavolos K, Rothschild S. Results from a community-based trial testing a community health worker asthma intervention in Puerto Rican youth in Chicago. Journal of Asthma 2015;52(1):59-70.

Martin MA, Olson D, Mosnaim G, Ortega D, Rothschild SK. Recruitment, asthma characteristics, and medication behaviors in Midwestern Puerto Rican youth: data from Project CURA. Annals of Allergy, Asthma \& Immunology 2012;109(2):121-7.

\section{Mishra 2005 \{published data only\}}

Mishra N, Rao KVR, Padhi SK. Asthma education for better compliance in disease management. Indian Journal of Allergy Asthma and Immunology 2005;19(1):25-8. [CENTRAL: 591604; CRS: 4900100000020258; 4900100000020258]

\section{Munks-Lederer 2001 \{published data only\}}

Munks-Lederer C, Dhein Y, Richter B, Worth H. [Evaluation of a structured education program for adult outpatient asthmatics]. [German] [Evaluation eines ambulanten strukturierten AsthmaSchulungsprogramms fur Erwachsene. Eine Pilotstudie]. Pneumologie (Stuttgart, Germany) 2001;55(2):84-90. [CRS: 4900132000022768; PUBMED: 11268889]

\section{NCT00181194 \{published data only\}}

NCT00181194. Reducing asthma disparities by improving provider-patient communication about asthma severity and adherence with therapy. clinicaltrials.gov/show/NCT00181194 (first received 13 September 2005). [CRS: 4900132000022880]

\section{NCT00201188 \{published data only\}}

NCT00201188. Encouraging communication between doctors and patients to improve adherence to asthma medication. clinicaltrials.gov/ct2/show/NCT00201188 (first received 13 September 2005). [CENTRAL: 591422; CRS: 4900100000020088]

\section{NCT00381355 \{published data only\}}

* Ducharme FM, Zemek RL, Chalut D, McGillivray D, Noya FJD, Resendes $\mathrm{S}$, et al. Written action plan in pediatric emergency room improves asthma prescribing, adherence, and control. American Journal of Respiratory and Critical Care Medicine 2011;183(2):195-203.

NCT00381355. RCT of a written action plan vs. usual care in children with acute asthma [Does the use of a new written action plan increase short-term adherence to prescribed medication and asthma control in children treated for an asthma attack in the emergency department: a randomized controlled trial]. clinicaltrials.gov/show/NCT00381355 (first received 25 September 2006).

\section{NCT01106326 \{published data only\}}

NCT01106326. A pilot study to improve preventive asthma care for urban adolescents. clinicaltrials.gov/show/NCT01106326 (first received 16 April 2010). [CRS: 4900132000022892]

\section{NCT01128348 \{published data only\}}

Apter AJ, Wan F, Reisine S, Bogen DK, Rand C, Bender B, et al. Feasibility, acceptability and preliminary effectiveness of patient advocates for improving asthma outcomes in adults. Journal of Asthma 2013;50(8):850-60. [CRS: 4900100000090929]

NCT01128348. A patient advocate and literacy-based treatment of asthma (HAP). clinicaltrials.gov/ct2/show/NCT01128348 (first received 20 May 2010). [CRS: 4900132000022908]

\section{NCT01644357 \{published data only\}}

NCT01644357. Project implementation of pharmaceutical care in severe asthma in outpatient pharmacy department. clinicaltrials.gov/show/NCT01644357 (first received 17 July 2012). [CRS: 4900132000006193]

\section{NCT02093013 \{published data only\}}

NCT02093013. Impact of an integrated care intervention program on asthmatic patients. clinicaltrials.gov/show/ NCT02093013 (first received 18 March 2014). [CRS: 4900132000022877] 


\section{NCT02363192 \{published data only\}}

NCT02363192. The effectiveness of pharmacist interventions in improving asthma control and quality of life in patients with difficult asthma. clinicaltrials.gov/show/NCT02363192 (first received 9 February 2015). [CENTRAL: 1068129; CRS: 4900132000001641]

\section{NCT02426801 \{published data only\}}

NCT02426801. Feasibility of a mobile intervention to increase adherence to asthma medication among children age 11 to 19 in an urban setting. clinicaltrials.gov/show/NCT02426801 (first received 7 April 2015). [CRS: 4900132000022874]

\section{Nikander 1998 \{published data only\}}

Nikander K, Denyer J, Cobos C. Compliance with nebulized budesonide in Spanish children with asthma using adaptive aerosol delivery (AAD) [abstract]. European Respiratory Journal. Supplement 1998;12 Suppl 28:88S. [CRS: 4900132000021904]

\section{Nikander 2003 \{published data only\}}

Nikander K, Arheden L, Denyer J, Cobos N. Parents' adherence with nebulizer treatment of their children when using an adaptive aerosol delivery (AAD) system. Journal of Aerosol Medicine 2003;16(3):273-81. [CENTRAL: 451668; CRS: 4900100000015759; EMBASE: 2003388853; PUBMED: 14572325

\section{Patel 2013 \{published data only\}}

Patel M, Pilcher J, Travers J, Perrin K, Shaw D, Black P, et al. Use of metered-dose inhaler electronic monitoring in a real-world asthma randomized controlled trial. Journal of Allergy and Clinical Immunology 2013;1(1):83-91. [CENTRAL: 862186; CRS: 4900100000079022; EMBASE: 2013324091; PUBMED: 24229826]

\section{Petitto 2012 \{published data only\}}

Petitto J, Jones SM. Adherence to inhaled corticosteroids: an ancillary study of the childhood asthma management program clinical trial. Pediatrics 2012;130(Suppl 1):S37-8. [CRS: 4900132000021801]

\section{Pongchaidecha 2005 \{published data only\}}

Pongchaidecha N, Trakarnkitwichit U, Pituknitinunth K. Effects of inpatient drug counseling on compliance of asthmatic and COPD patients. Thai Journal of Hospital Pharmacy 2005;15(1):28-37. [CENTRAL: 764858; CRS: 4900100000025581; 4900100000025581]

\section{Sajadi 2016 \{published data only\}}

Sajadi M, Bagheri M, Hekmatpou D, Borsi H. The effect of using the care model of "sensitization" on medication adherence in asthmatic patients. Global Journal of Health Science 2016;8(11):54960. [CENTRAL: 1161118; CRS: 4900132000023315; PUBMED: 27241410]

\section{Schacher 2006 \{published data only\}}

Schacher C, Dhein Y, Münks-Lederer C, Vollmer T, Worth H. Evaluation of a structured outpatient education program for adult asthmatics. [German] [Evaluation eines strukturierten ambulanten Schulungsprogramms für erwachsene Asthmatiker]. Deutsche Medizinische Wochenschrift (1946) 2006;131(12):606-10. [CENTRAL: 555769; CRS: 4900100000019318; EMBASE: 2006164520; PUBMED: 16544235]
Schultz 2012 \{published data only\}

Schultz A, Sly PD, Zhang G, Venter A, Devadason SG, Le Souef PN. Usefulness of parental response to questions about adherence to prescribed inhaled corticosteroids in young children. Archives of Disease in Childhood 2012;97(12):1092-6. [CENTRAL: 839479; CRS: 4900100000068530; EMBASE: 2012686510; 4900100000068530; PUBMED: 23100609]

Sovani 2008 \{published data only\}

* Sovani MP, Whale Cl, Oborne J, Cooper S, Mortimer K, Ekström T, et al. Poor adherence with inhaled corticosteroids for asthma: can using a single inhaler containing budesonide and formoterol help?. British Journal of General Practice 2008;58(546):37-43.

Wilson 2010 \{published data only\} NCT00217945. Does shared decision-making improve adherence in asthma. https://clinicaltrials.gov/show/ NCT00217945 (first received 19 September 2005).

* Wilson SR, Strub P, Buist AS, Knowles SB, Lavori PW, Lapidus J, et al. Shared treatment decision making improves adherence and outcomes in poorly controlled asthma. American Journal of Respiratory and Critical Care Medicine 2010;181(6):566-77.

Wolthers 2002 \{published data only\}

Wolthers OD, Allen DB. Inhaled corticosteroids, growth, and compliance. New England Journal of Medicine 2002;347(15):1210-1. [CRS: 4900132000022728; PUBMED: 12374890]

\section{References to studies awaiting assessment}

ISRCTN83334596 \{published data only\}

ISRCTN83334596. Is compliance with inhaled therapy in asthma increased by the use of small volume spacers?. http:// isrctn.com/ISRCTN83334596 (first received 30 September 2004).

NCT00269282 \{published data only\}

* NCT00269282. Motivating asthma adherence in urban teens. clinicaltrials.gov/ct2/show/NCT00269282 (first received 21 December 2005)

\section{NCT01253330 \{published data only\}}

* NCT01253330. Usage, usability \& effect on adherence and clinical outcomes of text message reminders for adolescents with asthma [Study of the usage, usability, acceptability, and effect on adherence and clinical outcomes of a web based text messaging system for adolescents with asthma- phase 2]. clinicaltrials.gov/ct2/show/NCT01253330 (first received 29 November 2010).

\section{NCT02045875 \{published data only\}}

* NCT02045875. Improving asthma control in the real world: a systematic approach to improving Dulera adherence. clinicaltrials.gov/ct2/show/NCT02045875 (first received 23 January 2014). 


\section{NCT02176694 \{published data only\}}

* NCT02176694. Adolescent controlled text messaging to improve asthma medication adherence in primary care (ACT Me). clinicaltrials.gov/ct2/show/NCT02176694 (first received 9 June 2014)

\section{References to ongoing studies}

NCT01381159 \{published data only\}

* NCT01381159. Motivational Intervention for Asthma (MI-ACT). clinicaltrials.gov/show/NCT01381159 (first received 21 June 2011).

\section{NCT02170883 \{published data only\}}

NCT02170883. EmPhAsIS: empowering pharmacists in asthma management through interactive SMS. clinicaltrials.gov/ct2/ show/NCT02170883 (first received 19 June 2014).

* de Vera MA, Sadatsafavi M, Tsao NW, Lynd LD, Lester R, Gastonguay L, et al. Empowering pharmacists in asthma management through interactive SMS (EmPhAsIS): study protocol for a randomized controlled trial. Trials 2014;15(1):488.

NCT02203266 \{published data only\}

* NCT02203266. Teaching inhaler use with the INCA device in a community pharmacy setting [A randomised, parallel-group, multi-centre trial using a novel INCA tracker device to measure and monitor compliance and technique of seretide diskus inhaler in a community pharmacy setting]. clinicaltrials.gov/ show/NCT02203266 (first received 27 July 2014).

\section{NCT02307669 \{published data only\}}

* NCT02307669. Inhaler adherence in severe unstable asthma (INCA-SUN) [A study on inhaler adherence to improve poor asthma control]. clinicaltrials.gov/show/NCT02307669 (first received 21 April 2014).

\section{NCT02386722 \{published data only\}}

* NCT02386722. Interventions to improve inhalative adherence [Impact of a pharmaceutical care intervention to improve adherence of inhaled medication in asthma and COPD patients]. clinicaltrials.gov/show/NCT02386722 (first received 14 February 2014).

\section{NCT02426814 \{published data only\}}

* NCT02426814. Assessment of a mobile intervention to increase adherence to asthma medication among adolescents. clinicaltrials.gov/show/NCT02426814 (first received 7 April 2015).

\section{NCT02556073 \{published data only\}}

* NCT02556073. ICS/LABA combination with integrated dose counter and smartphone app to improve asthma control [The use of fluticasone propionate/salmeterol inhaler with integrated dose counter and smartphone self management to improve airway inflammation and asthma control]. clinicaltrials.gov/show/NCT02556073 (first received 25 November 2015).
NCT02615743 \{published data only\}

* NCT02615743. Automated adherence feedback for high risk children with asthma. clinicaltrials.gov/show/NCT02615743 (first received 23 November 2015).

\section{NCT02715219 \{published data only\}}

* NCT02715219. Effectiveness of an AEP on patient's knowledge, medication adherence and inhaler technique [Effectiveness of an asthma education programme on patient's knowledge, medication adherence and inhaler technique: randomized control trial]. clinicaltrials.gov/show/NCT02715219 (first received 25 February 2016).

NCT02768623 \{published data only\}

NCT02768623. Evaluation of a community pharmacist managed asthma consultation service. clinicaltrials.gov/show/ NCT02768623 (first received 8 March 2016).

\section{NCT02787174 \{published data only\}}

NCT02787174. A computer-based ED intervention to improve pediatric asthma medicine adherence (ED-AMAP). clinicaltrials.gov/ct2/show/NCT02787174 (first received 19 May 2016).

NTR5061 \{published data only\}

NTR5061. Development and testing of an adolescent adherence patient tool for asthma. http://www.trialregister.nl/trialreg/ admin/rctview.asp?TC=5061 (first received 17 February 2015)

Sulaiman 2016 \{published data only\}

NCT01529697. Prospective study of the feedback from an adherence monitor on asthma control. clinicaltrials.gov/show/ NCT01529697 (accessed 7 February 2012).

* Sulaiman I, Hale EM, Holmes M, Hughes C, D'Arcy S, Taylor T, et al. A protocol for a randomised clinical trial of the effect of providing feedback on inhaler technique and adherence from an electronic device in patients with poorly controlled severe asthma. BMJ Open 2016;6(1):e009350.

\section{Additional references}

\section{Anglada-Martinez 2014}

Anglada-Martinez H, Riu-Viladoms G, Martin-Conde M, RoviraIllamola M, Sotoca-Momblona JM, Codina-Jane C. Does $m$ Health increase adherence to medication? Results of a systematic review. International Journal of Clinical Practice 2014;69(1):9-32. [CRS: 4900132000036192]

\section{Barnes 1993}

Barnes PJ, Pedersen S. Efficacy and safety of inhaled corticosteroids in asthma. American Review of Respiratory Diseases 1993;148:1-26.

\section{Barnes 1996}

Barnes PJ, Jonsson B, Klim JB. The costs of asthma. European Respiratory Journal 1996;9:636-42. 


\section{Barnes 2003}

Barnes PJ, Adcock IM. How do corticosteroids work in asthma?. Annals of Internal Medicine 2003;139:359-70.

\section{Bender 2002}

Bender BG. Overcoming barriers to non adherence in asthma treatment. Journal of Allergy and Clinical Immunology 2002;109(6 Suppl):554-9.

\section{Bender 2004}

Bender BG, Rand C. Medication non-adherence and asthma treatment cost. Current Opinion in Allergy and Clinical Immunology 2004;4(3):191-5.

\section{Bender 2005}

Bender BG, Bender SE. Patient-identified barriers to asthma treatment adherence: responses to interviews, focus groups, and questionnaires. Immunology and Allergy Clinics of North America 2005;25(1):107-30.

\section{BNF}

Joint Formulary Committee. British National Formulary (online). https://www.bnf.org/products/bnf-online/ accessed 13 December 2016). [http://www.medicinescomplete.com (accessed 2 February 2016)]

\section{Bårnes 2015}

Bårnes CB, Ulrik SC. Asthma and adherence to inhaled corticosteroids: current status and future perspectives. Respiratory Care 2015;60(3):455-68.

\section{Campbell 2000}

Campbell M, Fitzpatrick R, Haines A, Kinmonth AL, Sandercock P, Spiegelhalter D. Framework for design and evaluation of complex interventions to improve health. $B M J$ 2000;321:694-6.

\section{CDC 2016}

Centers for Disease Control and Prevention (CDC). Common asthma triggers. https://www.cdc.gov/asthma/triggers.html (accessed 13 December 2016). [http://www.cdc.gov/asthma/ triggers.html (accessed 2 February 2016)]

\section{Clark 1999}

Clark N, Jones P, Keller S, Vermiere I. Patient factors and compliance with asthma therapy. Respiratory Medicine 1999;93:856-62.

\section{Cochrane 1999}

Cochrane GM, Horne R, Chanez I. Compliance in asthma. Respiratory Medicine 1999;93:763-9.

\section{Covidence 2015 [Computer program]}

Veritas Health Innovation. Covidence systematic review software. Veritas Health Innovation, 2015. [https:// www.covidence.org/]

\section{Dibello 2014}

Dibello K, Boyar K, Abrenica S, Sandford Worral P. The effectiveness of text messaging programs on adherence to treatment regimens among adults aged 18 to 45 years diagnosed with asthma: a systematic review. JBI Database of Systematic Reviews and Implementation Report 2014;12(4):485-32. [CRS: 4900132000036180]

\section{Dinwiddie 2002}

Dinwiddie R, Müller WG. Adolescent treatment compliance in asthma. Journal of the Royal Society of Medicine 2002;95(2):68-71.

\section{Elmagarmid 2014}

Elmagarmid A, Fedorowicz Z, Hammady H, Ilyas I, Khabsa M, Ouzzani M. Rayyan: a systematic reviews web app for exploring and filtering searches for eligible studies for Cochrane Reviews. Evidence-Informed Public Health: Opportunities and Challenges. Abstracts of the 22nd Cochrane Colloquium; 2014 21-26 Sep; Hyderabad, India. 2014.

\section{Ershad 2016}

Ershad Sarabi R, Sadoughi F, Jamshidi Orak R, Bahaadinbeigy K. The effectiveness of mobile phone text messaging in improving medication adherence for patients with chronic diseases: a systematic review. Iranian Red Crescent Medical Journal 2016;18(5):e25183. [CRS: 4900132000036191]

\section{GINA 2016}

Global Initiative for Asthma. Global Strategy for Asthma Management and Prevention, 2016. www.ginasthma.org (accessed 13 December 2016). [http://www.ginasthma.org/ (accessed 2 February 2016)]

\section{Global Asthma Report 2014}

Global Asthma Network. The Global Asthma Report 2014. http:// www.globalasthmareport.org/ (accessed 13 December 2016). [http://www.globalasthmareport.org/index.php (accessed 2 February 2016)]

\section{GRADEpro GDT [Computer program]}

GRADE Working Group, McMaster University. GRADEpro GDT. Version accessed 6 February 2016. Hamilton (ON): GRADE Working Group, McMaster University, 2014.

\section{Hall 2014}

Hall RL, Willgoss T, Humphrey LJ, Kongsø JH. The effect of medical device dose-memory functions on patients' adherence to treatment, confidence, and disease self-management. Patient Preference and Adherence 2014;8:775-88. [CRS: 4900132000036185]

\section{Higgins 2011}

Higgins JPT, Green S (editors). Cochrane Handbook for Systematic Reviews of Interventions Version 5.1 [updated March 2011]. The Cochrane Collaboration. Available from www.cochrane-handbook.org

\section{Horne 2002}

Horne R, Weinman J. Self-regulation and self-management in asthma: exploring the role of illness perceptions and treatment beliefs in explaining non-adherence to preventer medication. Psychology and Health 2002;17:17-32. 


\section{Johnson 2015}

Johnson KB, Patterson BL, Ho Y-X, Chen Q, Nian H, Davison CL. The feasibility of text reminders to improve medication adherence in adolescents with asthma. Journal of the American Medical Informatics Association 2015;0:1-8. [DOI: 10.1093/jamia/ ocv158]

\section{Krishnan 2001}

Krishnan JA, Diette GB, Skinner EA, Clark BD, Steinwachs D, Wu AW. Race and sex differences in consistency of care with national asthma guidelines in managed care organizations. Archives of Internal Medicine 2001;161(13):1660-8.

\section{Lasmar 2009}

Lasmar L, Camargos P, Champs NS, Fonseca MT, Fontes MJ, Ibiapina C. Adherence rate to inhaled corticosteroids and their impact on asthma control. Allergy 2009;64:784-9.

\section{Mahkinova 2015}

Makhinova T, Barner JC, Richards KM, Rascati KL. Asthma controller medication adherence, risk of exacerbation, and use of rescue agents among Texas Medicaid patients with persistent asthma. Journal of Managed Care and Specialty Pharmacy 2015;21(12):1124-32.

\section{McCambridge 2014}

McCambridge J, Witton J, Elbourne DR. Systematic review of the Hawthorne effect: new concepts are needed to study research participation effects. Journal of Clinical Epidemiology 2014;67(3):267-77.

\section{Moher 2009}

Moher D, Liberati A, Tetzlaff J, Altman D. Preferred reporting items for systematic reviews and meta-analyses: the PRISMA statement. PLoS Medicine 2009;6(7):e1000097. [DOI: 10.1371/ journal.pmed.1000097]

\section{Mulvaney 2013}

Mulvaney SA, Ho YX, Cala CM, Chen Q, Nian H, Patterson BL. Assessing adolescent asthma symptoms and adherence using mobile phones. Journal of Medical Internet Research 2013;15(7):e141. [DOI: 10.2196/jmir.2413]

\section{Murphy 2012}

Murphy AC, Proeschal A, Brightling CE, Wardlaw AJ, Pavord I, Bradding P. The relationship between clinical outcomes and medication adherence in difficult-to-control asthma. Thorax 2012;67(8):751-3.

\section{Nieuwlaat 2014}

Nieuwlaat R, Wilczynski N, Navarro T, Hobson N, Jeffery R, Keepanasseril A. Interventions for enhancing medication adherence. Cochrane Database of Systematic Reviews 2014, Issue 11. [DOI: 10.1002/14651858.CD000011.pub4]

\section{NRAD 2014}

National Review of Asthma Deaths. Why asthma still kills: the national review of asthma deaths. https:// www.rcplondon.ac.uk/sites/default/files/why-asthma-still-killsfull-report.pdf (accessed 7 April 2016).

\section{Rand 1994}

Rand CS, Wise RA. Measuring adherence to asthma medication regimens. American Journal of Respiratory and Critical Care Medicine 1994;149(2):S69-78.

\section{RevMan 2014 [Computer program]}

The Nordic Cochrane Centre, The Cochrane Collaboration. Review Manager (RevMan). Version 5.3. Copenhagen: The Nordic Cochrane Centre, The Cochrane Collaboration, 2014.

\section{Rodrigo 2004}

Rodrigo GJ, Rodrigo C, Hall JB. Acute asthma in adults. A review. Chest 2004;125(3):1081-102.

\section{Tran 2014}

Tran N, Coffman JM, Sumino K, Cabana MD. Patient reminder systems and asthma medication adherence: a systematic review. Journal of Asthma 2014;51(5):536-43. [CRS: 4900132000036172]

\section{WHO 2013}

World Health Organization. Asthma fact sheets. http:// www.who.int/mediacentre/factsheets/fs307/en/ (accessed 13 December 2016). [http://www.who.int/mediacentre/factsheets/ fs307/en/ (accessed 2 February 2016)]

\section{WHO Report 2003}

World Health Organization. Adherence to long-term therapies. Evidence for action. http://www.who.int/chp/knowledge/ publications/adherence_report/en/ (accessed 13 December 2016). [ISBN 924154599 2]

\section{Williams 2003}

Williams LK, Pladevall M, Xi H, Peterson EL, Joseph C, Lafata JE. Relationship between adherence to inhaled corticosteroids and poor outcomes among adults with asthma. Journal of Allergy and Clinical Immunology 2004;114(6):1288-93.

\section{Wu 2014}

Wu YP, Pai AL. Health care provider-delivered adherence promotion interventions: a meta-analysis. Pediatrics 2014;133(6):e1698-707. [CRS: 4900132000036181]

\section{Yasmin 2016}

Yasmin F, Banu B, Zakir SM, Sauerborn R, Ali L, Souares A. Positive influence of short message service and voice call interventions on adherence and health outcomes in case of chronic disease care: a systematic review. BMC Medical Informatics and Decision Making 2016;16:46. [CRS: 4900132000036196]

\section{References to other published versions of this review Kew 2016}

Kew KM, Normansell R, Stovold E. Interventions to improve adherence to inhaled steroids for asthma. Cochrane Database of Systematic Reviews 2016, Issue 6. [DOI: 10.1002/14651858.CD012226] 
* Indicates the major publication for the study

CHARACTERISTICS OF STUDIES

Characteristics of included studies [ordered by study ID]

ACTRN12606000508572

Methods Design: open-label, parallel-group randomised controlled trial

Duration: 24 weeks

Setting: Medical Research Institute of New Zealand and the P3 Research Clinical Trials Unit at Bowen Hospital, Wellington, New Zealand

Trial registration: ACTRN12606000508572

Participants

Population: 111 adolescents and adults with asthma randomised to intervention (combination inhaler) $(n=57)$ or control (separate inhaler) $(n=54)$

Age: 16 to 65 years; mean (SD) age in the adherence group 45.5 (13.8) years and in the control group $49.2(11.2)$ years

Baseline asthma severity: Those with a significant exacerbation in the last month were excluded

Inclusion criteria: adults in the Wellington region 16 to 65 years of age; diagnosis of asthma; and currently taking ICS at a stable dose with or without a separate LABA inhaler

Exclusion criteria: diagnosis of chronic obstructive pulmonary disease, current use of a combination ICS/LABA inhaler, pregnant or lactating women, history of other clinically significant disease, significant exacerbation of asthma in the previous month requiring clinic or hospital attendance

Percentage withdrawn: 5.3\% from the adherence group and 9.3\% from the control group

Other allowed medication: not reported

Interventions

Intervention summary: $125 \mathrm{mg}$ FP and $25 \mathrm{mg}$ salmeterol in a combination Smartinhaler, 2 actuations twice daily. The Smartinhaler casing recorded the date and time of each actuation. Participants were not told that adherence would be monitored

Control summary: $125 \mathrm{mg}$ FP and $25 \mathrm{mg}$ salmeterol in separate Smartinhalers, 2 actuations twice daily. The Smartinhaler casing recorded the date and time of each actuation. Participants were not told that adherence would be monitored

Complex intervention: no

Outcomes

Outcomes measured: $\mathrm{FEV}_{1}$, ACQ, Asthma Exacerbation Questionnaire, need for oral steroids or doctor visits over previous 6 weeks. Primary adherence measure was percentage of doses taken over last 6 weeks of the study; secondary adherence measures were adherence during the other 6 -week periods of the study, percentage of fully adherent days, proportion who were $>50 \%,>80 \%$ or $>90 \%$ adherent over each 6-week period, overuse defined as $>2$ doses taken within a 6-hour period or $>4$ doses within a 24 -hour period (\% of days when this occurred)

Adherence calculation: electronic Smartinhaler data - number of doses taken as a percentage of those prescribed. All calculations were made after exclusion of dose dumping, defined as 6 or more actuations within a 5-minute period

Notes

Type of publication: single peer-reviewed journal article

Funding: GlaxoSmithKline (GSK)

GSK ID number: SAM106689 
ACTRN12606000508572 (Continued)

Risk of bias

\begin{tabular}{|c|c|c|}
\hline Bias & Authors' judgement & Support for judgement \\
\hline $\begin{array}{l}\text { Random sequence genera- } \\
\text { tion (selection bias) }\end{array}$ & Low risk & $\begin{array}{l}\text { "Randomization was by computer-generated random code supplied by a sta- } \\
\text { tistician. The sequence was imbedded in a Microsoft Access Database (Mi- } \\
\text { crosoft Corp, Redmond, Wash) by a third party and concealed from the re- } \\
\text { searchers until the time the subject was enrolled and entered into the data- } \\
\text { base" }\end{array}$ \\
\hline $\begin{array}{l}\text { Allocation concealment } \\
\text { (selection bias) }\end{array}$ & Low risk & $\begin{array}{l}\text { "The sequence was imbedded in a Microsoft Access Database (Microsoft Corp, } \\
\text { Redmond, Wash) by a third party and concealed from the researchers until the } \\
\text { time the subject was enrolled and entered into the database" }\end{array}$ \\
\hline $\begin{array}{l}\text { Blinding of participants } \\
\text { and personnel (perfor- } \\
\text { mance bias) } \\
\text { All outcomes }\end{array}$ & Unclear risk & $\begin{array}{l}\text { Although participants were aware that they were taking combined or separate } \\
\text { inhalers, adherence was measured covertly with a SmartInhaler; this was the } \\
\text { main outcome measured. However, ACQ may be at risk of performance bias }\end{array}$ \\
\hline $\begin{array}{l}\text { Blinding of outcome as- } \\
\text { sessment (detection bias) } \\
\text { All outcomes }\end{array}$ & Unclear risk & $\begin{array}{l}\text { Although blinding of outcome assessors was not described, adherence was } \\
\text { measured objectively with a SmartInhaler; this was the only outcome mea- } \\
\text { sured. However, ACQ is participant reported and may be at risk of detection } \\
\text { bias }\end{array}$ \\
\hline $\begin{array}{l}\text { Incomplete outcome data } \\
\text { (attrition bias) } \\
\text { All outcomes }\end{array}$ & Low risk & $\begin{array}{l}\text { Only } 8 \text { participants withdrew ( } 3 \text { from the combined inhaler group and } 5 \text { from } \\
\text { the separate inhaler group). All are accounted for in the flow diagram, and } \\
\text { drop-out occurred for similar reasons }\end{array}$ \\
\hline $\begin{array}{l}\text { Selective reporting (re- } \\
\text { porting bias) }\end{array}$ & High risk & $\begin{array}{l}\text { Prospectively registered trial (ACTRN12606000508572). All outcomes listed in } \\
\text { trial registration have been clearly reported, but the study mentions the Asth- } \\
\text { ma Exacerbation Questionnaire and the need for oral steroids and doctor visits } \\
\text { over the previous } 6 \text { weeks, which are not reported in the paper }\end{array}$ \\
\hline Other bias & Low risk & None noted \\
\hline
\end{tabular}

Methods Design: open-label, parallel-group randomised controlled trial

Duration: 4 months

Setting: 1 paediatric asthma clinic within an outer metropolitan general hospital in Australia

Trial registration: not reported

Participants

Population: 26 children with asthma randomised to receive adherence feedback $(n=14)$ or usual care $(n=12)$

Age: 6 to 14 years; mean age in the adherence feedback group 9.1 years and in the control group 9.3 years

Baseline asthma severity: intervention group: $\mathrm{FEV}_{1} \%$ predicted $=72.9$, mean fluticasone dose (mcg/ d) 300; number with symptoms or reliever use 3 or more times per week $=10$. Control group: $\mathrm{FEV}_{1} \%$ predicted $=77.5$, mean fluticasone dose $(\mathrm{mcg} / \mathrm{d}) 250$, number with symptoms or reliever use 3 or more times per week $=8$ 
ACTRN12607000489493 (Continued)

Inclusion criteria: Children given a diagnosis of asthma at between 6 and 14 years of age (inclusive) were eligible for enrolment if their asthma was not well controlled despite prescribed preventive medication. Suboptimal control was based on reported history of asthma symptoms (wheeze or limitation of activity) occurring more than twice a week and requiring reliever medication and/or reduced lung function (reproducible $\mathrm{FEV}_{1}<80 \%$ predicted)

Exclusion criteria: not reported

Percentage withdrawn: no withdrawal from trial

Other allowed medication: not reported

Interventions

Intervention summary: Adherence data collected via Smartinhaler were shared with the child, parent and physician during consultation for those allocated to the intervention group. These data were incorporated in the management plan for the coming month. Reviews were performed monthly with the child's usual physician

Control summary: Children in the control group had their Smartinhaler collected and were given a new device. Their adherence remained unknown to parent, child and respiratory physician. Reviews were performed monthly with the child's usual physician

Complex intervention: yes

Outcomes Outcomes measured: adherence, symptoms (via questionnaire), lung function

Adherence calculation: Adherence was calculated as a percentage of prescribed doses registered by the Smartinhaler, between midnight and midday or between midday and midnight for morning and evening doses, respectively, or at any time during the day for once-daily dosing

Notes Type of publication: single peer-reviewed full-text journal article

Funding: not reported

\section{Risk of bias}

\begin{tabular}{lll}
\hline Bias & Authors' judgement & Support for judgement \\
\hline $\begin{array}{l}\text { Random sequence genera- } \\
\text { tion (selection bias) }\end{array}$ & Unclear risk & $\begin{array}{l}\text { "After providing informed written consent, children were randomly allocated } \\
\text { to either the intervention or control group through the use of sealed opaque } \\
\text { envelopes" }\end{array}$ \\
& Not clear how the order of sealed envelopes was generated
\end{tabular}

\begin{tabular}{ll}
\hline $\begin{array}{l}\text { Allocation concealment } \\
\text { (selection bias) }\end{array}$ & "After providing informed written consent, children were randomly allocated \\
to either the intervention or control group through the use of sealed opaque \\
envelopes"
\end{tabular}

\begin{tabular}{|c|c|c|}
\hline $\begin{array}{l}\text { Blinding of participants } \\
\text { and personnel (perfor- } \\
\text { mance bias) }\end{array}$ & High risk & $\begin{array}{l}\text { No blinding of participants or personnel described. Although primary outcome } \\
\text { - adherence - was measured by an electronic counter, other outcomes (such as } \\
\text { SABA use) may be subject to performance bias }\end{array}$ \\
\hline
\end{tabular}

\begin{tabular}{lll}
\hline $\begin{array}{l}\text { Blinding of outcome as- } \\
\text { sessment (detection bias) }\end{array}$ & High risk & $\begin{array}{l}\text { No blinding of outcome assessors described. Main outcome - adherence - ob- } \\
\text { jectively measured, but other outcomes (such as reported SABA use) subject to } \\
\text { detection bias as the unblinded parent is the outcome assessor }\end{array}$ \\
\hline $\begin{array}{l}\text { Incomplete outcome data } \\
\begin{array}{l}\text { (attrition bias) } \\
\text { All outcomes }\end{array}\end{array}$ & Low risk & All participants completed the study \\
\hline
\end{tabular}


ACTRN12607000489493 (Continued)

Selective reporting (re- Unclear risk No prospective trial registration identified; symptoms measured but not reporting bias) ported so could not be included in meta-analysis. No measure of variance is given for the adherence outcome, nor for the secondary outcomes of FEV 1 and controller medication use. $P$ values are not exact ( 1 decimal place). Other outcomes reported appropriately

Other bias Low risk None noted

\section{ADERE PEDIATRIC 1}

Methods

Design: open-label, parallel-group randomised controlled trial

Duration: 90 weeks

Setting: 1 site. Brazil

Trial registration: ADERE PEDIATRIC 1 (GSK trial register)

Participants

Population: 298 children with asthma randomised to a telephone follow-up intervention $(n=149)$ or to usual care $(n=149)$

Age: 6 to 14 years; mean age (SD) in the intervention group 8.9 (2.4) years and in the control group 9.0 (2.5) years

Baseline asthma severity: Of those who completed the trial in the intervention group, 67 had moderate and 41 severe asthma, and in the control group, 74 had moderate and 37 severe asthma

Inclusion criteria: moderate or severe asthma defined by SPT II Brazillian Consensus on Asthma Management

Exclusion criteria: comorbidities that may interfere with study evaluation, systemic steroids required for more than 7 days; patients treated with allergen immunotherapy

Percentage withdrawn: $28 \%$ from the intervention group and $27 \%$ from the usual care group

Other allowed medication: not reported

Interventions

Intervention summary: medical guidance and follow-up telephone call from a healthcare professional every 15 days

Control summary: medical guidance; no telephone follow-up

Complex intervention: no

Outcomes

Outcomes measured: level of compliance, disease control evaluated by 5-point questionnaire, quality of life (SF-36)

Adherence calculation: percentage of actual number of doses of salmeterol/fluticasone propionate divided by number of expected doses

Funding: GlaxoSmithKline

NB: participants from non-intervention group not followed up, no conclusions drawn from protocol. No peer-reviewed publication

\section{Risk of bias}


ADERE PEDIATRIC 1 (Continued)

\begin{tabular}{|c|c|c|}
\hline Bias & Authors' judgement & Support for judgement \\
\hline $\begin{array}{l}\text { Random sequence genera- } \\
\text { tion (selection bias) }\end{array}$ & Unclear risk & $\begin{array}{l}\text { "Subjects were randomized to intervention or non-intervention" - no further } \\
\text { details }\end{array}$ \\
\hline $\begin{array}{l}\text { Allocation concealment } \\
\text { (selection bias) }\end{array}$ & Unclear risk & No details \\
\hline $\begin{array}{l}\text { Blinding of participants } \\
\text { and personnel (perfor- } \\
\text { mance bias) } \\
\text { All outcomes }\end{array}$ & High risk & No blinding of participants or personnel; described as open-label \\
\hline $\begin{array}{l}\text { Blinding of outcome as- } \\
\text { sessment (detection bias) } \\
\text { All outcomes }\end{array}$ & High risk & No blinding of outcome assessors; described as open-label \\
\hline $\begin{array}{l}\text { Incomplete outcome data } \\
\text { (attrition bias) } \\
\text { All outcomes }\end{array}$ & High risk & $\begin{array}{l}>25 \% \text { drop-out in both groups. Control group not followed up as planned, so } \\
\text { missing data for entire outcomes for this group. Study protocol was violated }\end{array}$ \\
\hline $\begin{array}{l}\text { Selective reporting (re- } \\
\text { porting bias) }\end{array}$ & High risk & $\begin{array}{l}\text { Multiple planned outcomes, including primary outcome (adherence 'not avail- } \\
\text { able'), or available only for the intervention group }\end{array}$ \\
\hline Other bias & Low risk & None noted \\
\hline
\end{tabular}

Bender 2010

Methods Design: single-blind, parallel-group randomised controlled trial

Duration: 10 weeks

Setting: single site; participants recruited through newspaper adverts; in association with community allergy practices. USA

Trial registration: not reported

Population: 50 adults with asthma randomised to an interactive voice response (IVR) intervention ( $\mathrm{n}=$ 25) or usual care (UC) $(n=25)$

Age: 18 to 65 years; mean age (SD) in IVR group 39.6 (12.8) years and in UC group 43.5 (14.3) years

Baseline asthma severity: physician-diagnosed asthma for which they were prescribed daily inhaled corticosteroid treatment; no other severity information given

Inclusion criteria: adults 18 to 65 years old who had physician-diagnosed asthma for which they were prescribed daily inhaled corticosteroid treatment. Participants were recruited through newspaper advertising and in co-operation with community allergy practices and received $\$ 25$ for each completed study visit

Exclusion criteria: significant disease or disorder that, in the opinion of the investigator, might influence results of the study or the patient's ability to participate in the study (this included other chronic health disorders, current substance abuse or dependence, mental retardation or psychiatric disorder); current participation in another asthma-related research or clinical trial

Percentage withdrawn: no withdrawal

Other allowed medication: not specifically reported 
Bender 2010 (Continued)

Interventions

Intervention summary: 2 automated IVR telephone calls separated by 1 month, with 1 additional call if recently reported symptoms of poorly controlled disease or failure to fill a prescription. Calls were completed in less than 5 minutes and included content designed to inquire about asthma symptoms, deliver core educational messages, encourage refilling of inhaled corticosteroid prescriptions and increase communication with providers

Control summary: usual care

Complex intervention: no

Outcomes Outcomes measured: AQLQ, ACT, BMQ, adherence with use of an electronic monitor

Adherence calculation: electronic adherence device or canister weight to give a mean \% adherence (exact details of calculation not provided)

Notes

Type of publication: single peer-reviewed full-text journal article

Funding: supported by the Investigator-Sponsored Study Program of AstraZeneca

\section{Risk of bias}

\begin{tabular}{|c|c|c|}
\hline Bias & Authors' judgement & Support for judgement \\
\hline $\begin{array}{l}\text { Random sequence genera- } \\
\text { tion (selection bias) }\end{array}$ & Low risk & $\begin{array}{l}\text { A randomization table generated before study initiation determined group as- } \\
\text { signment by order of entry into the study }\end{array}$ \\
\hline $\begin{array}{l}\text { Allocation concealment } \\
\text { (selection bias) }\end{array}$ & Unclear risk & No details \\
\hline $\begin{array}{l}\text { Blinding of participants } \\
\text { and personnel (perfor- } \\
\text { mance bias) } \\
\text { All outcomes }\end{array}$ & High risk & $\begin{array}{l}\text { No blinding of participants described. Main outcome - adherence - objectively } \\
\text { measured, but other outcomes such as ACQ and AQLQ subject to performance } \\
\text { bias }\end{array}$ \\
\hline $\begin{array}{l}\text { Blinding of outcome as- } \\
\text { sessment (detection bias) } \\
\text { All outcomes }\end{array}$ & High risk & $\begin{array}{l}\text { Investigators remained blind to treatment until final data set was completed. } \\
\text { However, for participant-reported outcomes such a AQLQ and ACQ, the partic- } \\
\text { ipant is the outcome assessor; therefore these outcomes are at high risk of de- } \\
\text { tection bias }\end{array}$ \\
\hline $\begin{array}{l}\text { Incomplete outcome data } \\
\text { (attrition bias) } \\
\text { All outcomes }\end{array}$ & Low risk & $\begin{array}{l}\text { Although attrition not specifically reported, end of study data given for all } 50 \\
\text { randomised participants }\end{array}$ \\
\hline $\begin{array}{l}\text { Selective reporting (re- } \\
\text { porting bias) }\end{array}$ & Unclear risk & $\begin{array}{l}\text { No prospective trial registration identified, but all outcomes stated in methods } \\
\text { clearly reported }\end{array}$ \\
\hline Other bias & Low risk & None noted \\
\hline
\end{tabular}

\section{Black 2008}

Methods

Design: parallel-group randomised controlled trial; blinding not stated

Duration: 2 months

Setting: set in New Zealand; no other details reported

Trial registration: not reported 
Black 2008 (Continued)

Participants

Population: 40 children with asthma randomised to an inhaler alarm intervention $(n=20)$ or usual care $(n=20)$

Age: 7 to 17 years; no further details reported

Baseline asthma severity: 'symptomatic asthma despite being on inhaled corticosteroids'

Inclusion criteria: children aged 7 to 17 years with symptomatic asthma despite taking inhaled corticosteroids

Exclusion criteria: not reported

Percentage withdrawn: withdrawal not reported

Other allowed medication: not reported

Interventions

Intervention summary: inhaler alarm with 14 different tones, 1 for each morning and evening of the week

Control summary: usual care (inhaler alarm turned off)

Complex intervention: no

\section{Outcomes}

Outcomes measured: AQLQ, prebronchodilator $\mathrm{FEV}_{1}$, use of salbutamol, adherence to inhaled steroid

Adherence calculation: Adherence was expressed as a percentage; exact calculation not reported

Notes Type of publication: conference abstract

Funding: not reported

\section{Risk of bias}

\begin{tabular}{lll}
\hline Bias & Authors' judgement & Support for judgement \\
\hline $\begin{array}{l}\text { Random sequence genera- } \\
\text { tion (selection bias) }\end{array}$ & Unclear risk & No details \\
\hline $\begin{array}{l}\text { Allocation concealment } \\
\text { (selection bias) }\end{array}$ & Unclear risk & No details \\
\hline
\end{tabular}

\begin{tabular}{|c|c|c|}
\hline $\begin{array}{l}\text { Blinding of participants } \\
\text { and personnel (perfor- }\end{array}$ & High risk & $\begin{array}{l}\text { No blinding of participants or personnel described. Some outcomes (e.g. } \\
\text { AQLQ) may be influenced by knowledge of group allocation }\end{array}$ \\
\hline
\end{tabular}
mance bias)

All outcomes

Blinding of outcome assessment (detection bias)

All outcomes

\section{High risk}

No blinding of outcome assessor described, and not clear how adherence data were collected and calculated. Self-report outcomes (e.g. AQLQ) may be subject to detection bias

Incomplete outcome data Unclear risk $\quad$ Attrition not reported
(attrition bias)

All outcomes

Selective reporting (re- High risk
porting bias)

Conference abstract; no trial registration identified. Study reported only as a conference abstract from 2008 and does not appear to have been published in full. Therefore, limited details about methods and outcomes, in particular, no measure of variance for the AQLQ

Other bias Low risk None noted


Bosley 1994

Methods

Design: open-label, multi-centre, parallel-group randomised controlled trial

Duration: 12 weeks

Setting: 4 general practices and a hospital outpatient clinic. UK

Trial registration: not reported

Participants Population: 102 adults with asthma randomised to receive a combined inhaler $(n=51)$ or separate inhalers $(n=51)$

Age: 18 to 70 years; mean age of all trial completers (36 in each group) 44 years (range 20 to 69 years)

Baseline asthma severity: mean duration of illness 13.9 years (range 0.25 to 54 years). No details of baseline asthma severity given

Inclusion criteria: patients with asthma, 18 to 70 years of age, who required treatment with regular inhaled steroids and beta-agonists (as assessed by their own doctor)

Exclusion criteria: not reported

Percentage withdrawn: $30 \%$ from each trial arm

Other allowed medication: not reported

Interventions Intervention summary: Treatment group was given 1 Turbuhaler inhaler containing a fixed combination of terbutaline $(250 \mu \mathrm{g}$ per dose) and budesonide ( $100 \mu \mathrm{g}$ per dose)

Control summary: Control group was given 2 Turbuhaler inhalers - 1 containing terbutaline $(250 \mu \mathrm{g}$ per dose) and 1 containing budesonide (100 $\mu$ g per dose)

Complex intervention: no

Outcomes $\quad$ Outcomes measured: adherence, lung function measures (FVC and FEV 1 )

Adherence calculation: percent adherence $=$ number of doses taken $\times 100 /$ number of doses prescribed - measured using Turbuhaler Inhalation Computer

Notes Type of publication: single peer-reviewed full-text journal article

Funding: study funded by the Astra Clinical Research Unit, which also provided the Turbuhaler Inhalation Computer

\section{Risk of bias}

\begin{tabular}{lll}
\hline Bias & Authors' judgement & Support for judgement \\
\hline $\begin{array}{l}\text { Random sequence genera- } \\
\text { tion (selection bias) }\end{array}$ & Unclear risk & $\begin{array}{l}\text { "They were randomly divided into treatment and control groups" - no further } \\
\text { details }\end{array}$ \\
\hline $\begin{array}{l}\text { Allocation concealment } \\
\text { (selection bias) }\end{array}$ & Unclear risk & No details \\
\hline $\begin{array}{l}\text { Blinding of participants } \\
\text { and personnel (perfor- } \\
\text { mance bias) } \\
\text { All outcomes }\end{array}$ & Low risk & $\begin{array}{l}\text { Open-label design; although outcomes (adherence with an electronic monitor } \\
\text { and lung function) are unlikely to be highly susceptible to influence according } \\
\text { to participants' and personnel's knowledge of group allocation. "In order to } \\
\text { obtain as accurate a picture of "normal" behaviour as possible, patients were } \\
\text { not told that the Turbuhalers contained TICs [Turbuhaler Inhalation Comput- } \\
\text { er] or that their compliance was being monitored" }\end{array}$ \\
\hline
\end{tabular}


Bosley 1994 (Continued)

Blinding of outcome as- Low risk Open-label design, although outcomes (adherence with a covert electronic sessment (detection bias) monitor and lung function) are unlikely to be highly susceptible to influence All outcomes according to outcome assessors' knowledge of group allocation

Incomplete outcome data High risk (attrition bias)

Approximately $30 \%$ drop-out in both arms of the trial. Participants who

All outcomes dropped out were younger but otherwise did not differ from those who completed according to trial report. However, no flow diagram presented, so unclear if reasons for drop-out were balanced

Selective reporting (re- Unclear risk porting bias)

No prospective trial registration identified, but all outcomes stated in methods clearly reported

Other bias Low risk None noted

\section{Burgess 2007}

Methods

Design: parallel-group randomised controlled trial; blinding not stated

Duration: 13 weeks

Setting: private and public paediatric respiratory clinics. Australia

Trial registration: not reported

Participants

Population: 47 children with asthma randomised to receive a 'Funhaler' $(n=26)$ or a control spacer ( $n$ $=21$ )

Age: 18 months to 7 years; mean age in the Funhaler group 3.4 years and in the control group 3.8 years

Baseline asthma severity: intervention group: mean frequency of wheeze (5-point scale) = 1.9; number with exacerbation in previous month $=8$; mean fluticasone dose $(\mathrm{mg} / \mathrm{d})=166$. Control group: mean frequency of wheeze $(5$-point scale) $=1.9$; number with exacerbation in previous month $=3$; mean fluticasone dose $(\mathrm{mg} / \mathrm{d})=193$

Inclusion criteria: children with diagnosis of asthma, 18 months to 7 years of age, taking preventive asthma medication on a daily basis

Exclusion criteria: not reported

Percentage withdrawn: $8 \%$ from the intervention arm and 5\% from the control arm

Other allowed medication: not reported

Interventions

Intervention summary: small-volume spacer that incorporates an incentive toy (spinning disk and whistle) that is driven by the child's expired breath (the 'Funhaler')

Control summary: a control spacer (Aerochamber Plus)

Complex intervention: no

Outcomes

Outcomes measured: adherence, symptoms (from a 'symptoms questionnaire'), exacerbations (defined as the child having received a course of prednisolone initiated by the parent in response to an escalation of symptoms requiring regular reliever medication more than 4th-hourly for 24 hours as per asthma management plan or prescription of prednisolone by the child's primary care physician)

Adherence calculation: Adherence was evaluated as a percentage of prescribed doses registered by the Smartinhaler between midnight and midday and between midday and midnight for morning and evening doses, respectively, or at any time during the day for once-daily dosing 
Burgess 2007 (Continued)

Notes

Type of publication: single peer-reviewed full-text journal article

Funding: not reported

\section{Risk of bias}

\begin{tabular}{|c|c|c|}
\hline Bias & Authors' judgement & Support for judgement \\
\hline $\begin{array}{l}\text { Random sequence genera- } \\
\text { tion (selection bias) }\end{array}$ & Low risk & $\begin{array}{l}\text { "All subjects were then randomized to either the FunHaler or a control spacer } \\
\text { using a minimization computer program (Minim) with equal weighting for age, } \\
\text { sex and level of maternal education" }\end{array}$ \\
\hline $\begin{array}{l}\text { Allocation concealment } \\
\text { (selection bias) }\end{array}$ & Unclear risk & No details \\
\hline $\begin{array}{l}\text { Blinding of participants } \\
\text { and personnel (perfor- } \\
\text { mance bias) } \\
\text { All outcomes }\end{array}$ & High risk & $\begin{array}{l}\text { No blinding of participants or personnel described. Although primary outcome } \\
\text { - adherence - was measured by an electronic counter, other outcomes (such as } \\
\text { symptoms) may be subject to performance bias }\end{array}$ \\
\hline $\begin{array}{l}\text { Blinding of outcome as- } \\
\text { sessment (detection bias) } \\
\text { All outcomes }\end{array}$ & High risk & $\begin{array}{l}\text { No blinding of outcome assessors described. Main outcome - adherence - ob- } \\
\text { jectively measured, but other outcomes (such as symptoms) subject to detec- } \\
\text { tion bias, as the unblinded parent is the outcome assessor }\end{array}$ \\
\hline $\begin{array}{l}\text { Incomplete outcome data } \\
\text { (attrition bias) } \\
\text { All outcomes }\end{array}$ & Low risk & $\begin{array}{l}\text { Attrition low and balanced ( }<10 \% \text { in both arms) and all drop-outs accounted } \\
\text { for }\end{array}$ \\
\hline $\begin{array}{l}\text { Selective reporting (re- } \\
\text { porting bias) }\end{array}$ & Unclear risk & $\begin{array}{l}\text { No prospective trial registration identified; symptoms measured but not re- } \\
\text { ported numerically so could not be included in meta-analysis. Other outcomes } \\
\text { reported appropriately }\end{array}$ \\
\hline Other bias & Low risk & None noted \\
\hline
\end{tabular}

Chan 2015

Methods Design: open-label, parallel-group randomised controlled trial

Duration: 6 months

Setting: participants recruited from emergency departments, followed up in community. New Zealand

Trial registration: ACTRN12613001353785

Participants

Population: 220 children with asthma randomised to receive an audiovisual inhaler reminder $(n=110)$ or usual care $(n=110)$

Age: 5 to 15 years; mean age (SD) in audiovisual reminder group was 8.9 (2.5) years and in control group was 8.9 (2.6) years

Baseline asthma severity: intervention group: mean (SD) asthma morbidity score 9.3 (2.2); mean (SD) Childhood Asthma Control Test score 18.8 (4.4); mean (SD) FEV 1 (\% predicted) 92 (17). Control group: mean (SD) asthma morbidity score 9.2 (2.5); mean (SD) Childhood Asthma Control Test score 18.8 (4.2); mean (SD) $\mathrm{FEV}_{1}$ (\% predicted) 90 (17)

Inclusion criteria: children and adolescents 6 to 15 years of age who attended the regional emergency department in Auckland, New Zealand, with a suspected diagnosis of asthma exacerbation and were 
Chan 2015 (Continued)

screened for eligibility; patients with a diagnosis of acute asthma who were on treatment or needed treatment with twice-daily inhaled corticosteroids

Exclusion criteria: diagnosis of a chronic lung disease other than asthma, congenital heart disease; living outside the Auckland catchment area; diagnosis of a severe chronic medical disorder that causes impaired immunity or increased morbidity

Percentage withdrawn: $2 \%$ from the intervention arm and 5\% from the control arm

Other allowed medication: other asthma drugs, including LABAs and theophylline

Intervention summary: covert electronic monitoring device for use with preventive inhalers (SmartTrack) with the audiovisual function enabled

Control summary: covert electronic monitoring device for use with preventive inhalers (SmartTrack) with the audiovisual function disabled

\section{Complex intervention: no}

Outcomes

Outcomes measured: adherence to preventive inhaled corticosteroids; number of days absent from school and whether or not parents or carers were absent from work for 1 day or longer; asthma control (CACT); asthma symptoms (Asthma Morbidity Score); exacerbations since previous visit; unscheduled doctor, emergency clinic or hospital visits; rescue medication use; lung function

Adherence calculation: Adherence was defined as the proportion of preventer doses taken relative to the number of doses prescribed. This proportion was calculated by measuring the degree of deviation from the prescribed dose up to the prescribed dose (i.e. non-adherence, up to a maximum of $0 \%$ nonadherence) and subtracting from 1 (i.e. 100\% adherence)

Notes

Type of publication: single peer-reviewed full-text journal article

Funding: Health Research Council of New Zealand and Cure Kids

\section{Risk of bias}

\begin{tabular}{|c|c|c|}
\hline Bias & Authors' judgement & Support for judgement \\
\hline $\begin{array}{l}\text { Random sequence genera- } \\
\text { tion (selection bias) }\end{array}$ & Low risk & $\begin{array}{l}\text { "Using a simple, unrestricted block randomisation with block sizes of 200, we } \\
\text { randomly assigned patients" }\end{array}$ \\
\hline $\begin{array}{l}\text { Allocation concealment } \\
\text { (selection bias) }\end{array}$ & Low risk & $\begin{array}{l}\text { "The study statistician provided the randomisation group to investigators in } \\
\text { opaque, sealed envelopes, which were opened by investigators and research } \\
\text { assistants in consecutive order to allocate participants to their randomisation } \\
\text { group. Envelopes were sealed to investigators, and research assistants did not } \\
\text { know the next allocation group" }\end{array}$ \\
\hline \multirow[t]{2}{*}{$\begin{array}{l}\text { Blinding of participants } \\
\text { and personnel (perfor- } \\
\text { mance bias) } \\
\text { All outcomes }\end{array}$} & High risk & $\begin{array}{l}\text { "Participants were unaware of the adherence monitoring function of either } \\
\text { device, but were informed that the reliever monitoring device was to be used } \\
\text { with their reliever inhaler to enable investigators to know when the drug was } \\
\text { running out" }\end{array}$ \\
\hline & & $\begin{array}{l}\text { Primary outcome - adherence - was monitored covertly and objectively with } \\
\text { an electronic device. However, other outcomes such as CACT are subject to risk } \\
\text { of performance bias }\end{array}$ \\
\hline $\begin{array}{l}\text { Blinding of outcome as- } \\
\text { sessment (detection bias) } \\
\text { All outcomes }\end{array}$ & High risk & $\begin{array}{l}\text { No blinding of outcome assessors described. Primary outcome - adherence - } \\
\text { was monitored covertly and objectively with an electronic device. However, } \\
\text { other outcomes such as CACT and parent-reported exacerbations are subject } \\
\text { to risk of detection bias, as participant or parent is the outcome assessor }\end{array}$ \\
\hline
\end{tabular}


Chan 2015 (Continued)

Incomplete outcome data Low risk Low drop-out $(<5 \%)$ in both arms; all participants accounted for and ITT (attrition bias) analysis performed

All outcomes

\begin{tabular}{|c|c|c|}
\hline $\begin{array}{l}\text { Selective reporting (re- } \\
\text { porting bias) }\end{array}$ & Low risk & $\begin{array}{l}\text { Retrospectively registered trial. All planned outcome measures in trial regis- } \\
\text { tration and methods reported }\end{array}$ \\
\hline
\end{tabular}

Other bias Low risk None noted

Charles 2007

Methods Design: open-label, parallel-group randomised controlled trial

Duration: 24 weeks

Setting: participants recruited from research volunteer databases, newspaper advertisements and informal contacts. New Zealand

Trial registration: not reported

Participants Population: 110 people with asthma randomised to receive an audiovisual inhaler reminder $(n=55)$ or usual care $(n=55)$

Age: 12 to 65 years; median age (range) in audiovisual reminder group was 39 (13 to 65) years and in control group was 35 (15 to 64 ) years

Baseline asthma severity: intervention group: baseline ICS dose: median (range) 500 (100 to 2000); PEF: mean (SD) 434 (99). Control group: baseline ICS dose: median (range) 500 (100 to 4000); PEF: mean (SD) 444 (128)

Inclusion criteria: requirement to take regular ICS at a fixed dose, no exacerbation in previous month or run-in period, not pregnant or lactating;if of child-bearing potential, using contraception

Exclusion criteria: diagnosis of chronic obstructive pulmonary disease, use of a long-acting beta-agonist, history of other clinically significant disease. Individuals were required to not be taking a long-acting beta-agonist to avoid the potential influence of such treatment on adherence to ICS therapy

Percentage withdrawn: $20 \%$ from the intervention arm and $16 \%$ from the control arm

Other allowed medication: not reported, apart from the criterion that participants could NOT be taking a long-acting beta-agonist

Interventions Intervention summary: covert electronic monitoring device for use with preventive inhalers (SmartInhaler) with the audiovisual function enabled

Control summary: covert electronic monitoring device for use with preventive inhalers (SmartInhaler) with the audiovisual function disabled

Complex intervention: no

Outcomes

Outcomes measured: adherence to ICS, Asthma Control Questionnaire (ACQ), peak expiratory flow (PEF)

Adherence calculation: adherence defined as the proportion of medication taken as prescribed over the latter half of the trial (expressed as a percentage) 
Funding: supported by a research grant from GlaxoSmithKline, UK. The sponsor had no involvement in study design; collection, analysis or interpretation of data; writing of the report; or the decision to submit for publication

\section{Risk of bias}

\begin{tabular}{lll}
\hline Bias & Authors' judgement & Support for judgement \\
\hline $\begin{array}{l}\text { Random sequence genera- } \\
\text { tion (selection bias) }\end{array}$ & Low risk & "The randomization was by reference to a computer-generated random code" \\
\hline $\begin{array}{l}\text { Allocation concealment } \\
\text { (selection bias) }\end{array}$ & Low risk & $\begin{array}{l}\text { "The randomization was by reference to a computer-generated random code } \\
\text { concealed from the researcher who opened an envelope at the time of ran- } \\
\text { domization" }\end{array}$ \\
\hline
\end{tabular}

$\begin{array}{ll}\begin{array}{l}\text { Blinding of participants } \\ \text { and personnel (perfor- }\end{array} & \text { High risk } \\ \begin{array}{l}\text { mance bias) } \\ \text { All outcomes }\end{array} & \begin{array}{l}\text { "Subjects were informed that the purpose of the study was to determine the } \\ \text { outcome when patients with asthma on a wide range of ICS doses and in- } \\ \text { haler devices were changed to standard treatment via the novel Smartinhaler } \\ \text { MDI device. Subjects were not informed of the electronic adherence monitor } \\ \text { placed within their FP MDI" } \\ \text { Primary outcome - adherence - was monitored covertly and objectively with } \\ \text { an electronic device. However, other outcomes such as ACQ are subject to risk } \\ \text { of performance bias }\end{array}\end{array}$

Blinding of outcome as- High risk sessment (detection bias) All outcomes
No blinding of outcome assessors described. Primary outcome - adherence was monitored covertly and objectively with an electronic device. However, other outcomes such as ACQ are subject to the risk of detection bias, as the participant is the outcome assessor

Incomplete outcome data Unclear risk
(attrition bias)

(attrition bias)

Drop-out moderately high ( $16 \%$ to $20 \%$ ), although quite balanced. All partici-

All outcomes pants accounted for in flow diagram. 11 participants in the intervention group and 9 participants in the control group "did not provide data" in the final 12week period of the study. It is not clear whether these participants were included in the analysis

\begin{tabular}{lll}
\hline $\begin{array}{l}\text { Selective reporting (re- } \\
\text { porting bias) }\end{array}$ & Unclear risk & $\begin{array}{l}\text { No prospective trial registration identified, but all outcomes stated in methods } \\
\text { clearly reported }\end{array}$
\end{tabular}

Other bias Low risk None noted

\section{Chatkin 2006}

Methods Design: open-label, parallel-group, multi-centre randomised controlled trial

Duration: 13 weeks

Setting: ' 15 states of the country'. Brazil

Trial registration: not reported

Participants

Population: 271 people with asthma randomised to receive telephone calls to promote adherence $(\mathrm{n}=$ $140)$ or usual care $(n=131)$

Age: 12 years of age and older; mean age (SD) in the telephone call group was 43.3 (15) years and in the control group was 44.4 (16.6) years 
Baseline asthma severity: intervention group: proportion with severe persistent asthma 47.1\%; proportion with history of asthma emergencies $30.7 \%$; proportion with history of asthma hospitalisations $48.6 \%$. Control group: proportion with severe persistent asthma $47.3 \%$; proportion with history of asthma emergencies $38.9 \%$; proportion with history of asthma hospitalisations $53.4 \%$

Inclusion criteria: 12 years of age or older with moderate to severe persistent asthma according to GINA criteria and the Third Brazilian Consensus on Asthma Management; residential phone number; ability to comprehend study procedures and to sign the relevant consent form

Exclusion criteria: mild persistent asthma, pregnancy or breast feeding, intention to move during the study, regular use or recent past abuse of alcohol or illicit drugs, clinically significant active general medical conditions

Percentage withdrawn: Report states that 293 participants were 'screened'; 4 were excluded for not fulfilling inclusion criteria, 8 for not responding to telephone calls and 10 for not returning the monitoring disk to the office. It is not clear whether these participants were excluded before or after randomisation, and if after randomisation, from which arm they were excluded. Baseline characteristics and results are given for only 271 participants

Other allowed medication: not reported

Intervention summary: telephone calls every 2 weeks to reinforce asthma management and to promote adherence, delivered by a specially trained nursing student

Control summary: usual care

Complex intervention: no

\begin{tabular}{ll}
\hline Outcomes & Outcomes measured: adherence \\
Adherence calculation: percentage of patients taking $85 \%$ or more of prescribed doses as measured \\
by electronic monitor
\end{tabular}

Notes Type of publication: single peer-reviewed full-text journal article

Funding: funded by GSK-Brazil

\section{Risk of bias}

\begin{tabular}{lll}
\hline Bias & Authors' judgement & Support for judgement \\
\hline $\begin{array}{l}\text { Random sequence genera- } \\
\text { tion (selection bias) }\end{array}$ & Unclear risk & "Subjects were randomized" - no further details \\
\hline $\begin{array}{l}\text { Allocation concealment } \\
\text { (selection bias) }\end{array}$ & Unclear risk & No details \\
\hline $\begin{array}{l}\text { Blinding of participants } \\
\text { and personnel (perfor- } \\
\text { mance bias) }\end{array}$ & Low risk & $\begin{array}{l}\text { No blinding of participants or personnel described. However, the only out- } \\
\text { come measured - adherence - was monitored objectively with an electronic } \\
\text { device }\end{array}$ \\
\hline $\begin{array}{l}\text { Blinding of outcome as- } \\
\text { sessment (detection bias) }\end{array}$ & Low risk & $\begin{array}{l}\text { No blinding of participants or personnel described. However, the only out- } \\
\text { come measured - adherence - was monitored objectively with an electronic } \\
\text { device }\end{array}$ \\
\hline $\begin{array}{l}\text { Incomplete outcome data } \\
\text { (attrition bias) } \\
\text { All outcomes }\end{array}$ & Unclear risk & $\begin{array}{l}\text { Drop-out not reported for each arm (22 dropped out in total); total numbers } \\
\text { randomised at start of intervention not clear }\end{array}$ \\
\hline
\end{tabular}


Chatkin 2006 (Continued)

Selective reporting ( $\mathrm{re}$ High risk No prospective trial registration identified. Adherence not reported in a way porting bias) that can be included in a meta-analysis (percentages per group with no measure of variance, only an inexact $P$ value

Other bias Unclear risk None noted

Foster 2014

Methods Design: open-label, 4-arm cluster randomised trial

Duration: 6 months

Setting: 60 GPs. To minimise cross-contamination between intervention groups, only $1 \mathrm{GP}$ from a practice could participate. Australia

Trial registration: ACTRN12610000854033

Participants

Population: $60 \mathrm{GPs}$ (of which 55 attended training, and 43 were available to enrol patients) were randomised to be trained in 1 of the following 4 interventions: personalised adherence discussion (PAD); inhaler reminders and feedback (IRF); PAD + IRF; or usual care. GP participants then enrolled 143 patient participants between them; PAD $n=24 ; \operatorname{IRF} n=35 ;$ PAD + IRF $n=41$; usual care $n=43$

Age: enrolled patients 14 to 65 years of age; mean age (SD) in PAD group 42.3 (15.6) years; in IRF group 40 (30.7) years; in PAD + IRF group 39.7 (17.1) years; in usual care group 40 (14.1) years

Baseline asthma severity: $\mathrm{FEV}_{1} \%$ predicted mean (SD) in the PAD group 67.3 (21.3); in the IRF group 84.4 (19.4); in the PAD + IRF group 78.0 (15.2); in the usual care group 75.7 (22.0); percentage prescribed high-dose (> $500 \mathrm{mcg} / \mathrm{d}$ ) inhaled steroids: PAD group 54\%, IRF group 40\%, PAD + IRF group $66 \%$, usual care group $44 \%$

Inclusion criteria: 14 to 65 years of age; suboptimal asthma control; twice-daily ICS/LABA for at least 1 month

Exclusion criteria: asthma exacerbation in the last month; use of combined inhaler as maintenance/reliever; major respiratory disease (e.g. COPD); serious uncontrolled medical conditions; clinically important visual or auditory impairment; shift workers with a variable roster; pregnant or lactating women

Percentage withdrawn: $13 \%$ from the PAD arm, 0\% from the IRF arm, 22\% from the PAD + IRF arm, 5\% from the usual care arm

Other allowed medication: not reported

Intervention summary (1): PAD: GPs asked participants to complete a short questionnaire about barriers to controller inhaler use. GPs were trained to carry out a personalised discussion about the participant's key barrier(s) to adherence and to help the participant set goals and goal-achievement strategies around an asthma issue that the participant wished to resolve, using patient-centered materials

Intervention summary (2): IRF: Participants received twice-daily SmartTrack reminders for missed ICS/LABA doses. They could customise ringtones/ring times, cancel individual reminders or switch reminders off completely. Each month, GPs received an automated e-mail to view a website graph of their patients' daily ICS/LABA use; the participant could log in to view his or her own graph at any time. GPs were asked to discuss the ICS/LABA use graph with the participant at the study follow-up visit or at any subsequent appointments, at the GP's discretion. Only GPs in PAD groups were trained in specific communication strategies for discussing adherence

Intervention summary (3): PAD + IRF: both PAD and IRF components as outlined above 
Control summary: All GPs in all groups received usual care training. This included advice on writing an asthma action plan (10 minutes), demonstration and review of inhaler technique (10 minutes) and recent changes to asthma guidelines (15 minutes)

Complex intervention: yes

Outcomes measured: ACT score; Mini-AQLQ; HADS; MARS-A; FEV ; $_{\text {; exacerbations }}$
$\begin{aligned} & \text { Adherence calculation: monitored with SmartTrack device on inhaler. Calculation of adherence not } \\ & \text { described }\end{aligned}$

Notes Type of publication: single peer-reviewed full-text journal article

Funding: National Health and Medical Research Council of Australia (ID571053)

\section{Risk of bias}

\begin{tabular}{lll}
\hline Bias & Authors' judgement & Support for judgement \\
\hline $\begin{array}{ll}\text { Random sequence genera- } \\
\text { tion (selection bias) }\end{array}$ & Low risk & "Each GP's patients represented 1 cluster. GPs were randomized separately 1:1 \\
& & to active and control groups for the 2 interventions, using a $2 \times 2$ factorial de- \\
& sign, allowing the effect of the 2 interventions (given in addition to UC) to be \\
& tested separately and together, in comparison with UC alone. Randomization \\
& of GPs was by a computer-generated program prepared by an independent \\
& statistician before study start, with an automated minimization algorithm to \\
& ensure a balance of randomization across 3 stratification factors"
\end{tabular}

$\begin{array}{ll}\begin{array}{l}\text { Allocation concealment } \\ \text { (selection bias) }\end{array} & \text { Unclear risk } \\ & \begin{array}{l}\text { "Allocation concealment for GPs was maintained before study start, and re- } \\ \text { vealed to each GP only during the training workshop" }\end{array} \\ & \begin{array}{l}\text { However, it is unclear whether allocation was concealed from investigators } \\ \text { until randomisation had occurred }\end{array}\end{array}$

\begin{tabular}{|c|c|c|}
\hline $\begin{array}{l}\text { Blinding of participants } \\
\text { and personnel (perfor- } \\
\text { mance bias) }\end{array}$ & High risk & $\begin{array}{l}\text { No blinding of participants (GPs or their patients) described. Most of the out- } \\
\text { comes measured are subjective and are susceptible to influence from knowl- } \\
\text { edge of group allocation }\end{array}$ \\
\hline
\end{tabular}

Blinding of outcome as- High risk sessment (detection bias) Primary outcome - ACT - was collected via telephone by a researcher blinded All outcomes to group allocation. However, for many outcomes, measures are subject to risk of detection bias, as the participant is the outcome assessor

\begin{tabular}{|c|c|c|}
\hline $\begin{array}{l}\text { Incomplete outcome data } \\
\text { (attrition bias) } \\
\text { All outcomes }\end{array}$ & High risk & $\begin{array}{l}\text { Primary analysis was by intention to treat. However, drop-out was somewhat } \\
\text { unbalanced, with } 5 \% \text { dropping out from the usual care group, } 13 \% \text { from the } \\
\text { PAD group, } 0 \% \text { from IRF group and } 21 \% \text { from the IRF + PAD group }\end{array}$ \\
\hline
\end{tabular}

\begin{tabular}{|c|c|c|}
\hline $\begin{array}{l}\text { Selective reporting (re- } \\
\text { porting bias) }\end{array}$ & Unclear risk & $\begin{array}{l}\text { No prospective trial registration identified, but all outcomes stated in methods } \\
\text { clearly reported }\end{array}$ \\
\hline
\end{tabular}

\begin{tabular}{ll}
\hline Other bias $\quad$ Low risk & None noted \\
\hline
\end{tabular}

Mesign: single-blind, parallel-group randomised controlled trial
Duration: 1 year

Setting: recruited at outpatient chest clinic and followed up by GPs. Norway 
Gallefoss 1999 (Continued)

Trial registration: not reported

Participants Population: 78 adults with asthma randomised to an asthma education intervention $(\mathrm{n}=39)$ or usual care $(\mathrm{n}=39)$

Age: 18 to 70 years; mean age (SD) in the intervention group 41 (12) years and in the control group 44 (12) years

Baseline asthma severity: $\mathrm{FEV}_{1} \%$ predicted (SD) in the intervention group 93 (13) and in the control group 95 (17). 95\% were using an ICS at baseline in the intervention group and $97 \%$ in the control group

Inclusion criteria: asthma, defined as prebronchodilator $\mathrm{FEV}_{1} \geq 80 \%$ of predicted value; positive reversibility test; documented $20 \%$ spontaneous variability $\left(\mathrm{PEF}\right.$ or $\left.\mathrm{FEV}_{1}\right)$; positive methacholine test

Exclusion criteria: unstable coronary heart disease, heart failure, serious hypertension, diabetes mellitus, kidney or liver failure

Percentage withdrawn: $18 \%$ from the intervention group and $0 \%$ from the usual care group

Other allowed medication: not reported

Interventions

Intervention summary: patient brochure; $2 \times 2$ hour group sessions (separate groups for asthma and COPD patients). First session delivered by doctor, second by pharmacist; 1 or 2 individual sessions with nurse or physiotherapist; individual treatment plan

Control summary: standard treatment plan; GP follow-up for 1 year

Complex intervention: yes

Outcomes Outcomes measured: patient compliance, GP visits, absenteeism, days in hospital

Adherence calculation: Medication compliance was coded to Daily Defined Doses (DDD). Dispensed medication reported from local pharmacies on monthly basis. Compliance calculated as prescribed DDD/dispensed DDD $\times 100$. Defined a priori patients as compliant at $75 \%$

Notes

Type of publication: 2 peer-reviewed full-text journal articles reporting different outcomes

Funding: Norwegian Medical Association Fund for Quality Improvement

\section{Risk of bias}

\begin{tabular}{lll}
\hline Bias & Authors' judgement & Support for judgement \\
\hline $\begin{array}{l}\text { Random sequence genera- } \\
\text { tion (selection bias) }\end{array}$ & Low risk & $\begin{array}{l}\text { "At inclusion they signed a written consent and were then randomized to an } \\
\text { intervention group or a control group using random number tables" }\end{array}$ \\
\hline $\begin{array}{l}\text { Allocation concealment } \\
\text { (selection bias) }\end{array}$ & Unclear risk & No details \\
\hline $\begin{array}{l}\text { Blinding of participants } \\
\begin{array}{l}\text { and personnel (perfor- } \\
\text { mance bias) }\end{array}\end{array}$ & High risk & $\begin{array}{l}\text { No blinding of participants or personnel described. Outcomes measured were } \\
\text { relatively objective (e.g. exacerbations, hospitalisations, GP visits, absen- } \\
\text { teeism), but participant knowledge of group allocation may have affected } \\
\text { health care-seeking behaviour }\end{array}$ \\
\hline
\end{tabular}

Blinding of outcome as- High risk sessment (detection bias) All outcomes
No blinding of outcome assessors described; although some outcomes measured were relatively objective and unlikely to be affected by assessors' knowledge of group allocation, patient-reported outcomes such as QOL may be at risk

Unbalanced drop-out: $0 \%$ in control group but $18 \%$ in intervention group 
Gallefoss 1999 (Continued)

All outcomes

\section{Selective reporting (re- High risk} porting bias)
No prospective trial registration found; multiple publications, each including a different set of outcomes. Not clear if all measured outcomes have been reported

\begin{tabular}{lll}
\hline Other bias $\quad$ Low risk noned & Noned
\end{tabular}

\section{Gerald 2009}

\begin{tabular}{ll}
\hline Methods & Design: open-label, parallel-group randomised controlled trial \\
Duration: intervention delivered over 65 weeks \\
Setting: school setting. USA \\
Trial registration: NCT00110383 \\
Population: 290 children with asthma randomised to supervised ICS therapy at school ( $\mathrm{n}=145)$ or usu- \\
al care $(\mathrm{n}=145)$ \\
Age: 5 to 18 years; mean age $(\mathrm{SD})$ in the intervention group 11.1 (2) years and in the control group 10.8 \\
(2.1) years
\end{tabular}

Baseline asthma severity: intervention group: 22 had mild asthma, 113 moderate asthma and 9 severe asthma; control group: 24 had mild asthma, 115 moderate asthma and 14 severe asthma

Inclusion criteria: physician-diagnosed asthma, requiring daily controller medication

Exclusion criteria: children not able to switch medications to budesonide

Percentage withdrawn: $14 \%$ from the intervention group and $21 \%$ from the usual care group

Other allowed medication: Children could take additional medications if their physician considered this necessary

Interventions

Intervention summary: Child took inhaler medication at a set time each schoolday under the supervision of staff members. Child was provided education in using the inhaler if he or she was observed to use the inhaler incorrectly. Daily monitoring

Control summary: continued usual parent or self-supervised daily ICS treatment. Daily monitoring

Complex intervention: no

Outcomes Outcomes measured: episode of poor asthma control (EPAC); rescue medications; school absences; peak flow; rescue medication use at school

Adherence calculation: not applicable

Type of publication: single peer-reviewed full-text journal article
Funding: National Institutes of Health Grant R01HL075043; AstraZeneca provided the medications
(Pulmicort Turbuhaler)

\section{Risk of bias}

Bias Authors' judgement Support for judgement


Gerald 2009 (Continued)
Random sequence genera- Low risk
"A random sequence of treatment codes, stratified according to school sys- tion (selection bias) tem, was generated"

\begin{tabular}{|c|c|c|}
\hline $\begin{array}{l}\text { Allocation concealment } \\
\text { (selection bias) }\end{array}$ & Low risk & $\begin{array}{l}\text { "Allocation was concealed", although no details given regarding how this was } \\
\text { achieved }\end{array}$ \\
\hline
\end{tabular}

\begin{tabular}{|c|c|c|}
\hline $\begin{array}{l}\text { Blinding of participants } \\
\text { and personnel (perfor- } \\
\text { mance bias) }\end{array}$ & High risk & $\begin{array}{l}\text { "Patients, their parents, and study staff were not blinded to intervention con- } \\
\text { dition; however, physicians were blinded to their patient's } \\
\text { intervention condition" }\end{array}$ \\
\hline All outcomes & & $\begin{array}{l}\text { Main outcome (EPAC) measured might be subject to performance bias, as par- } \\
\text { ticipant knowledge of group allocation may have affected behaviour }\end{array}$ \\
\hline
\end{tabular}

\begin{tabular}{lll}
\hline $\begin{array}{l}\text { Blinding of outcome as- } \\
\text { sessment (detection bias) }\end{array}$ & High risk & No blinding of outcome assessors described. Main outcome (EPAC) measured \\
All outcomes & might be subject to detection bias, as participant knowledge of group alloca- \\
& tion may have affected behaviour, such as decision to use rescue medication \\
& or absenteeism from school
\end{tabular}

$\begin{array}{ll}\begin{array}{l}\text { Incomplete outcome data } \\ \text { (attrition bias) }\end{array} & \text { High risk } \\ \text { All outcomes } & \begin{array}{l}\text { Drop-out was somewhat higher in the control group (20.7\%) than in the inter- } \\ \text { vention group (13.8\%), and data do not appear to have been imputed for those } \\ \text { who did not complete the study. The length of the study explains the extent } \\ \text { of drop-out, although the quantity of missing data and imbalance between } \\ \text { groups may still have affected endpoint scores }\end{array}\end{array}$

\begin{tabular}{lll}
\hline $\begin{array}{l}\text { Selective reporting (re- } \\
\text { porting bias) }\end{array}$ & High risk & $\begin{array}{l}\text { Prospectively published protocol and main outcome measure - EPAC - clear- } \\
\text { ly reported. However, some data not reported in a way that would allow inclu- } \\
\text { sion in a meta-analysis (e.g. QOL) }\end{array}$ \\
\hline Other bias & Low risk & None noted \\
\hline
\end{tabular}

Halterman 2004

Design: open-label, parallel-group randomised controlled trial
Duration: 9 weeks
Setting: schools in the Rochester City School District. USA
Trial registration: not reported

Participants

Population: 184 children with asthma randomised to school-based care $(n=93)$ or usual care $(n=91)$

Age: 3 to 7 years; mean age in each group not reported

Baseline asthma severity: not reported

Inclusion criteria: symptoms consistent with mild persistent or more severe asthma; 3 to 7 years of age; enrolled in the Rochester City School District; family had access to a working telephone for monthly follow-up telephone calls

Exclusion criteria: children scheduled to move from the school district within 6 months; Spanish-speaking families enrolled in study year 2 only

Percentage withdrawn: $4 \%$ from the intervention group and $0 \%$ from the usual care group

Other allowed medication: Children using more than 1 preventive medication were instructed to continue with their other medications (in addition to the fluticasone given through school) at the discretion of their primary care provider 
Halterman 2004 (Continued)

Interventions

Intervention summary: School nurse administered fluticasone once each day the child was in school

Control summary: carers and parents notified of their child's asthma severity. No medications received in school through the programme

Complex intervention: no

Outcomes

Outcomes measured: number of symptom-free days during the 2 weeks before the follow-up interview; asthma symptoms; night-time asthma symptoms; need for rescue inhaler use; absenteeism

Adherence calculation: not applicable

Notes

Type of publication: peer-reviewed journal article

Funding: Halcyon Hill Foundation, Webster, NY; Robert Wood Johnson Foundation's Generalist Physician Faculty Scholars Program. GlaxoSmithKline, Research Triangle Park, NC, donated fluticasone propionate and spacers used in this study

\section{Risk of bias}

\begin{tabular}{lll}
\hline Bias & Authors' judgement & Support for judgement \\
\hline $\begin{array}{l}\text { Random sequence genera- } \\
\text { tion (selection bias) }\end{array}$ & Low risk & $\begin{array}{l}\text { "Randomization was stratified by current use of preventive medications and } \\
\text { was blocked in groups of } 6 . \text { Pairs of siblings were assigned randomly to the } \\
\text { same group. Randomization cards were made from a table of random num- } \\
\text { bers" }\end{array}$ \\
\hline $\begin{array}{l}\text { Allocation concealment } \\
\text { (selection bias) }\end{array}$ & Low risk & $\begin{array}{l}\text { "Randomization cards were made from a table of random numbers and were } \\
\text { kept in sealed, opaque, sequentially numbered envelopes until after the base- } \\
\text { line assessment was completed. Following randomization, families and prima- } \\
\text { ry care providers were notified of the child's group allocation" }\end{array}$ \\
\hline
\end{tabular}

\section{Blinding of participants High risk} and personnel (perfor-

mance bias)

All outcomes
No blinding of participants or personnel described. Some outcomes (e.g. PAQLQ, health care-seeking behaviour) may be subject to risk of performance bias from knowledge of group allocation
Blinding of outcome as- High risk sessment (detection bias)

All outcomes

\begin{abstract}
"To ensure an unbiased assessment, an independent research group, blinded to each child's group allocation, conducted the follow-up interviews"
\end{abstract}

However, for participant-reported outcomes, such as symptoms and PAQLQ, the unblinded participant is the outcome assessor; therefore, these outcomes are at risk of detection bias

All but 4 participants (for whom no data were available - all from the intervention group) were included in the primary analysis

$\begin{array}{ll}\begin{array}{l}\text { Incomplete outcome data } \\ \text { (attrition bias) }\end{array} & \text { Low risk } \\ \text { All but } 4 \text { participants (for whom no data were available - all from the interven- } \\ \text { tion group) were included in the primary analysis }\end{array}$

All outcomes

\begin{tabular}{|c|c|c|}
\hline $\begin{array}{l}\text { Selective reporting (re- } \\
\text { porting bias) }\end{array}$ & Unclear risk & $\begin{array}{l}\text { No prospective trial registration identified, although all outcomes listed in } \\
\text { methods reported }\end{array}$ \\
\hline
\end{tabular}

\begin{tabular}{lll}
\hline Other bias $\quad$ Low risk & None noted \\
\hline
\end{tabular}

\section{Hart 2002}

Methods

Design: parallel-group randomised controlled trial; blinding not stated

Duration: 13 weeks 
Hart 2002 (Continued)

Setting: not reported. UK

Trial registration: not reported

Participants Population: 83 'pre-school' children with asthma randomised to an asthma education intervention or
usual care ( $\mathrm{n}$ for each group not given)

Age: 'pre-school children'; no further details reported

Baseline asthma severity: not reported

Inclusion criteria: 'asthmatic pre-school children'; no further details reported

Exclusion criteria: not reported

Percentage withdrawn: not reported

Other allowed medication: not reported based on contents of booklet

Control summary: usual care

Complex intervention: yes

\begin{tabular}{ll}
\hline Outcomes & $\begin{array}{l}\text { Outcomes measured: adherence; beliefs } \\
\text { Adherence calculation: } \text { medication electron } \\
\text { en }\end{array}$ \\
\hline Notes & $\begin{array}{l}\text { Type of publication: conference abstract } \\
\text { Funding: National Asthma Campaign, UK }\end{array}$
\end{tabular}

\section{Risk of bias}

\begin{tabular}{|c|c|c|}
\hline Bias & Authors' judgement & Support for judgement \\
\hline $\begin{array}{l}\text { Random sequence genera- } \\
\text { tion (selection bias) }\end{array}$ & Unclear risk & Children were "randomly allocated" - no further details \\
\hline $\begin{array}{l}\text { Allocation concealment } \\
\text { (selection bias) }\end{array}$ & Unclear risk & No details \\
\hline $\begin{array}{l}\text { Blinding of participants } \\
\text { and personnel (perfor- } \\
\text { mance bias) } \\
\text { All outcomes }\end{array}$ & High risk & No description of procedures to blind participants or personnel \\
\hline $\begin{array}{l}\text { Blinding of outcome as- } \\
\text { sessment (detection bias) } \\
\text { All outcomes }\end{array}$ & High risk & No description of procedures to blind outcome assessors \\
\hline $\begin{array}{l}\text { Incomplete outcome data } \\
\text { (attrition bias) } \\
\text { All outcomes }\end{array}$ & Unclear risk & Drop-out not reported, so unclear how many participants completed the study \\
\hline $\begin{array}{l}\text { Selective reporting (re- } \\
\text { porting bias) }\end{array}$ & High risk & $\begin{array}{l}\text { Conference abstract, so minimal details given. No prospective trial registration } \\
\text { identified }\end{array}$ \\
\hline
\end{tabular}


Hart 2002 (Continued)
Other bias
Low risk
None noted

Kamps 2008

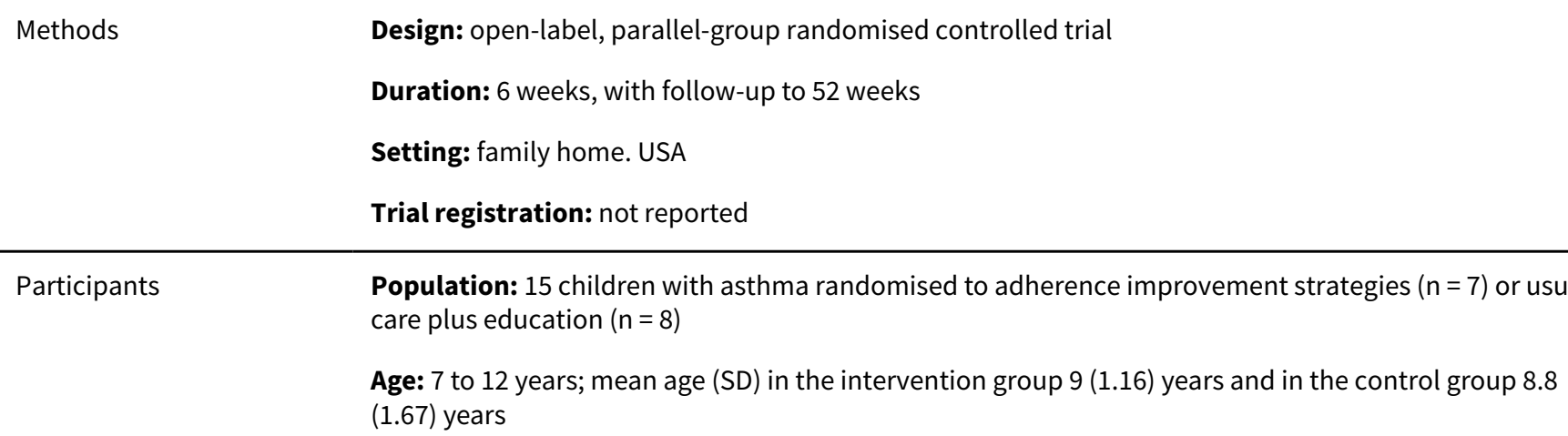

Baseline asthma severity: not reported

Inclusion criteria: children 7 to 12 years of age with diagnosis of asthma

Exclusion criteria: not reported

Percentage withdrawn: $0 \%$ from the intervention group and $0 \%$ from the usual care group

Other allowed medication: not reported

Interventions

Intervention summary: focused education, monitoring, contingency management, discipline techniques

Control summary: comprehensive asthma education covering topics from the "Air Wise" programme

Complex intervention: yes

\section{Outcomes}

Outcomes measured: adherence (MDILog); pulmonary function; PedsQL Asthma module; healthcare costs

Adherence calculation: (number of actuations per day/number of actuations prescribed) $\times 100$ (mean $\%$ dose per day per child)

Notes

Type of publication: single peer-reviewed journal article

Funding: National Institute of Child Health \& Human Development Grant number HD34784

\section{Risk of bias}

\begin{tabular}{lll}
\hline Bias & Authors' judgement & Support for judgement \\
\hline $\begin{array}{l}\text { Random sequence genera- } \\
\text { tion (selection bias) }\end{array}$ & Low risk & $\begin{array}{l}\text { A randomisation table was developed by a statistics consultant before partici- } \\
\text { pant recruitment to assign children to a group; we assigned children to groups } \\
\text { on the basis of this table }\end{array}$ \\
\hline $\begin{array}{l}\text { Allocation concealment } \\
\text { (selection bias) }\end{array}$ & Unclear risk & No details \\
\hline $\begin{array}{l}\text { Blinding of participants } \\
\begin{array}{l}\text { and personnel (perfor- } \\
\text { mance bias) }\end{array}\end{array}$ & High risk & No description of procedures to blind participants or personnel \\
\hline
\end{tabular}


Kamps 2008 (Continued)

All outcomes

$\begin{array}{lll}\begin{array}{l}\text { Blinding of outcome as- } \\ \text { sessment (detection bias) }\end{array} & \text { High risk } & \begin{array}{l}\text { No description of procedures to blind outcome assessors; in the case of VAS re- } \\ \text { sults and QOL results, the participant/career, who was aware of group alloca- } \\ \text { All outcomes }\end{array} \\ \text { tion, is the outcome assessor }\end{array}$

All outcomes tion, is the outcome assessor

Incomplete outcome data High risk Very small study; less than $50 \%$ in each arm completed the study

(attrition bias)

All outcomes

Selective reporting (re- High risk

porting bias)

No prospective trial registration identified. Such small numbers make results difficult to interpret and combine in a meta-analysis; SDs small despite small sample sizes so will be falsely highly weighted in meta-analysis. Unable to extract adherence data owing to statistical method (pooled series time analysis) used to analyse and no raw data presented

\begin{tabular}{ll}
\hline Other bias $\quad$ Low risk $\quad$ None noted \\
\hline
\end{tabular}

\section{Koufopoulos 2016}

Methods Design: open-label, parallel-group, proof-of-concept randomised controlled trial

Duration: 9 weeks

Setting: recruited through emails sent to 40 largest universities in the UK requesting that those with individuals managing their asthma with an ICS preventer should consider enrolling

Trial registration: ISRCTN29399269

Participants

Population: 216 adults with asthma randomised to an online community intervention ("AsthmaVillage") ( $n=99)$ or no online community intervention ("AsthmaDiary") ( $=117)$

Age: mean (SD) in the intervention group 27.2 (9.2) years and in the control group 28.8 (10.1) years

Baseline asthma severity: not reported

Inclusion criteria: individuals managing their asthma with an ICS preventer

Exclusion criteria: failed to complete the eligibility questionnaire $(n=256)$ or baseline measures $(n=$ 228), did not have asthma ( $n=105)$, were not prescribed an ICS preventer inhaler for a weekly regimen of at least 1 dose per week $(n=87)$, failed to complete informed consent $(n=35)$, had previously participated in the pilot study $(n=9)$

Percentage withdrawn: $60.6 \%$ from the intervention group and $45.3 \%$ from the usual care group ('withdrawn' defined as insufficiently engaging in the intended intervention)

Other allowed medication: not reported and write posts, comments or questions. Questions and comments needed to be answered by community members themselves because no experimenter intervention was provided once the trial had begun. The only feedback participants could receive during the trial was that received from other participants because this intervention was optimised for implementation at scale and at low cost. This trial attempted to determine the value of an online community, implemented without the added support of a community manager to engage members

Control summary: Control condition comprised an online diary, AsthmaDiary. This online diary was created with the use of Google Forms. A single-item survey was created: "How many times did you take your preventer?" Participants randomised to the control condition could report the number of puffs and, after entering their unique PIN, hit "submit". Because participants did not need to log in with a 
Koufopoulos 2016 (Continued)

username to fill out the form, participants used a PIN that allowed their posts to be identified by the researcher. Participants in the control condition could not see the posts of other participants and could not otherwise know whether other participants were posting on their condition

Complex intervention: no

Outcomes Outcomes measured: medication adherence (SMAQ), website activity/'adherence'

Adherence calculation: SMAQ was recalculated with dichotomous scoring of all variables (more than 2 missed uses was treated as non-adherent) and reverse scoring of item 4 of the SMAQ ("Thinking about the last week, how often have you not taken your asthma preventer medicine as prescribed?")

Notes Type of publication: single peer-reviewed journal article

Funding: funded by a pilot grant from the University of Leeds School of Psychology. A Fulbright Scholarship from the US-UK Fulbright Commission supported the first study author

\section{Risk of bias}

\begin{tabular}{lll}
\hline Bias & Authors' judgement & Support for judgement \\
\hline $\begin{array}{l}\text { Random sequence genera- } \\
\text { tion (selection bias) }\end{array}$ & Low risk & $\begin{array}{l}\text { "Randomization occurred through a random number generator, yielding two } \\
\text { unequal groups" }\end{array}$ \\
\hline
\end{tabular}

Allocation concealment Unclear risk "The experimenters then manually separated the two lists and emailed both (selection bias) groups log-in instructions"

It seems unlikely that allocation was not concealed given the nature of the study design (i.e. the participant is 'remote'), but this is not a standard description of an allocation procedure, so we cannot be sure exactly what the process entailed

\begin{tabular}{|c|c|c|}
\hline $\begin{array}{l}\text { Blinding of participants } \\
\text { and personnel (perfor- } \\
\text { mance bias) } \\
\text { All outcomes }\end{array}$ & High risk & $\begin{array}{l}\text { Participants were not blinded to group allocation and knowledge of group al- } \\
\text { location, and adherence monitoring may have affected their self-reported ad- } \\
\text { herence (e.g. those in the intervention arm systematically over-estimating ad- } \\
\text { herence) }\end{array}$ \\
\hline
\end{tabular}

\begin{tabular}{lll}
\hline $\begin{array}{l}\text { Blinding of outcome as- } \\
\text { sessment (detection bias) } \\
\text { All outcomes }\end{array}$ & High risk & $\begin{array}{l}\text { The participant is the outcome assessor for the main outcome - self-reported } \\
\text { adherence - and as participants were aware of group allocation, we consider } \\
\text { this outcome to be at high risk of bias }\end{array}$ \\
\hline $\begin{array}{l}\text { Incomplete outcome data } \\
\begin{array}{l}\text { (attrition bias) } \\
\text { All outcomes }\end{array}\end{array}$ & High risk & $\begin{array}{l}\text { Very high and unbalanced drop-out (60\% in intervention arm and 45\% in con- } \\
\text { trol arm). Although an ITT analysis was performed for the primary outcome - } \\
\text { self-reported adherence - it is unclear how this high level of drop-out may have } \\
\text { impacted the results }\end{array}$ \\
\hline $\begin{array}{l}\text { Selective reporting (re- } \\
\text { porting bias) }\end{array}$ & High risk & $\begin{array}{l}\text { Trial retrospectively registered (ISRCTN 29399269), but not all outcomes re- } \\
\text { ported in trial report, including AQLQ }\end{array}$ \\
\hline Other bias & Low risk & None noted \\
\hline
\end{tabular}

\section{Mann 1992}

Design: open-label, parallel-group randomised controlled trial
Duration: 6 weeks, with follow-up to 6 weeks
Setting: clinic and private practice. USA


Mann 1992 (Continued)

Trial registration: not reported.

Participants Population: 16 adults with asthma randomised to twice-daily (bid) dosing $(n=8)$ or 4 -times-daily (qid) dosing $(n=8)$

Age: over 18 years of age; mean age (SD) in the intervention group 46.9 (10) years and in the control group $42.3(12.1)$ years

Baseline asthma severity: intervention group: 2 on maintenance oral steroids; control group: 4 on maintenance oral steroids

Inclusion criteria: clinical stable asthma, requiring regular ICS

Exclusion criteria: not reported

Percentage withdrawn: $0 \%$ from the intervention group and $0 \%$ from the usual care group

Other allowed medication: "other asthma therapy continued throughout the study"

Intervention summary: 4 inhalations flunisolide twice daily
Control summary: 2 inhalations flunisolide, 4 times daily
Complex intervention: no
Notes: Participants changed to flunisolide at beginning of study if necessary. Both groups used bid dos-
ing for a run-in period to establish a baseline

Outcomes Outcomes measured: compliance; PEFR; symptom score

Adherence calculation: \% days with more or less than prescribed 8 inhalations; mean inhalations per day; frequency distribution of total daily inhalation; number inhaler responses per day

$\begin{array}{ll}\text { Notes } & \text { Type of publication: single peer-reviewed journal article } \\ & \text { Funding: not reported }\end{array}$

Risk of bias

\begin{tabular}{lll}
\hline Bias & Authors' judgement & Support for judgement \\
\hline $\begin{array}{ll}\text { Random sequence genera- } \\
\text { tion (selection bias) }\end{array}$ & Unclear risk & "After informed consent was obtained, patients were randomized into two \\
& & $\begin{array}{l}\text { groups of eight each. Randomization was stratified so each group contained } \\
\text { four clinic and four private practice patients" - no further details given about } \\
\text { how stratified random sequence was generated }\end{array}$ \\
\hline
\end{tabular}

\begin{tabular}{lll}
\hline $\begin{array}{l}\text { Allocation concealment } \\
\text { (selection bias) }\end{array}$ & Unclear risk & No details \\
\hline $\begin{array}{l}\text { Blinding of participants } \\
\text { and personnel (perfor- } \\
\text { mance bias) }\end{array}$ & Unclear risk & $\begin{array}{l}\text { No description of procedures to blind participants or personnel. However, pri- } \\
\text { mary outcome measure - adherence - objectively measured and unlikely to be } \\
\text { prone to performance or detection bias. Participants were unaware that the } \\
\text { primary aim of the study was to assess compliance. Subjective nature of sec- } \\
\text { ondary outcomes, such as asthma symptoms, may result in higher risk of bias }\end{array}$ \\
\hline $\begin{array}{l}\text { Blinding of outcome as- } \\
\text { sessment (detection bias) } \\
\text { All outcomes }\end{array}$ & Unclear risk & $\begin{array}{l}\text { No description of procedures to blind outcome assessors. However, primary } \\
\text { outcome measure - adherence - objectively measured and unlikely to be prone } \\
\text { to performance or detection bias. Subjective nature of secondary outcomes, } \\
\text { such as asthma symptoms, may result in higher risk of bias }\end{array}$
\end{tabular}


Mann 1992 (Continued)

Incomplete outcome data Low risk "One patient did not use the NC at all for 39 of the 42 study days, but actuat(attrition bias) ed the device 109 times on the day of the three-week visit, and 56 times on the All outcomes day of the six-week visit. This patient was dropped and replaced in the study."

No other withdrawals reported

\begin{tabular}{|c|c|c|}
\hline $\begin{array}{l}\text { Selective reporting (re- } \\
\text { porting bias) }\end{array}$ & Unclear risk & $\begin{array}{l}\text { No prospective trial registration identified, although all outcomes listed in } \\
\text { methods reported in text }\end{array}$ \\
\hline
\end{tabular}

Other bias Low risk None noted

Mehuys 2008

Methods Design: open-label, parallel-group randomised controlled trial

Duration: 6 months

Setting: 66 community pharmacies in Belgium

Trial registration: not reported

Participants

Population: 201 adults with asthma randomised to adherence education $(n=107)$ or control $(n=94)$

Age: 18 to 50 years of age; mean age (range) in the intervention group 32.5 (19 to 51) years and in the control group 36.3 (17 to 51 ) years

Baseline asthma severity: intervention group: mean (range) ACT score: 19.3 (10 to 25); 89.5\% on ICS at baseline; control group: 19.7 (11 to 25 ); $93.9 \%$ on ICS at baseline

Inclusion criteria: required to carry a prescription for asthma medication; under treatment for asthma for at least 12 months; "using" controller medication; making regular visits to the pharmacy

Exclusion criteria: smoking history of more than 10 pack-years, another severe disease (e.g. cancer) and an ACT score at screening < 15 (indicating seriously uncontrolled asthma; for ethical reasons, these patients were immediately referred to their GP or respiratory specialist) or $=25$ (indicating complete asthma control; no room for improvement)

Percentage withdrawn: $25 \%$ from the intervention group and $26 \%$ from the usual care group

Other allowed medication: not reported

Interventions

Intervention summary: At the first visit, pharmacist delivered personal education about using an inhaler correctly; understanding asthma symptoms, triggers and early warnings; understanding asthma controller and reliever therapy; facilitating adherence to use of controller; and stopping smoking. At visits 2 and 3 ( 1 and 3 months), pharmacist gave advice based on participant's ACT score

Control summary: usual pharmacy care. All participants filled in an asthma diary in the 2-week run-in period but had no further contact outside of usual pharmacy visits

Complex intervention: yes

Outcomes

Outcomes measured: Asthma Control Test (Dutch), diary card data (nocturnal awakenings, rescue medication use, PEF), asthma-related ED visits and hospitalisations, AQLQ, Knowledge of Asthma and Asthma Medicine questionnaire (KAAM), inhalation technique checklist

Adherence calculation: Adherence was measured using refill rates and self-reporting via an adherence scale 
Funding: not reported

\section{Risk of bias}

Bias Authors' judgement Support for judgement

Random sequence genera- Low risk tion (selection bias)

"The sequence of allocation to either control or intervention group was predetermined by the investigators based on a randomisation table"

\begin{tabular}{ll}
\hline $\begin{array}{l}\text { Allocation concealment } \\
\text { (selection bias) }\end{array}$ & "Serially numbered, closed envelopes were made for each participating phar- \\
& macy. The envelope with the lowest number was opened by the pharmacist \\
upon inclusion of a new patient"
\end{tabular}

Blinding of participants High risk and personnel (performance bias)

All outcomes

\section{Blinding of outcome as- High risk} sessment (detection bias) All outcomes
It was not possible to blind participants, so although adherence is measured objectively using pharmacy data, many other outcomes such as ACT and AQLQ are subject to potential performance bias, as participants know to which group they were assigned

Incomplete outcome data High risk (attrition bias)

Blinding of outcome assessors is not described, and although the primary outcome (adherence measured using pharmacy data) is not prone to detection bias, other patient-reported outcomes (such as ACT and AQLQ) are at risk because the participant is the outcome assessor

All outcomes

Approximately $25 \%$ of participants dropped out of each arm of the trial. Although reasons were similar and baseline characteristics of those completing and not completing did not differ significantly, rate of drop-out is high, and we cannot be sure that this did not affect the results. Secondary outcomes were analysed per protocol rather than by ITT

\begin{tabular}{|c|c|c|}
\hline $\begin{array}{l}\text { Selective reporting (re- } \\
\text { porting bias) }\end{array}$ & Unclear risk & $\begin{array}{l}\text { No prospective trial registration identified, although all outcomes listed in } \\
\text { methods reported in text/tables }\end{array}$ \\
\hline
\end{tabular}

Other bias Low risk None noted

\section{NCT00115323}

$\begin{array}{ll}\text { Methods } & \text { Design: open-label, parallel-group randomised controlled trial } \\ & \text { Duration: intervention delivered over } 13 \text { weeks; follow-up continued to } 26 \text { weeks }\end{array}$

Setting: primary care and asthma specialty practices serving low-income inner-city neighbourhoods with high prevalence of asthma morbidity. USA

Trial registration: NCT00115323

Participants

Population: 333 adults with asthma randomised to a problem-solving (PS) intervention $(n=165)$ or an asthma education (AE) intervention $(n=168)$

Age: minimum age 18; mean age (SD) in PS group 49 years (13) and in AE group 49 (14) years

Baseline asthma severity: sufficiently severe to require treatment with ICS. FEV $\mathrm{F}_{1} \%$ predicted (SD) in PS group 66 (19) and in AE group 64 (19)

Inclusion criteria: English- or Spanish-speaking adults with moderate or severe persistent asthma according to National Heart, Lung, and Blood Institute Expert Panel Report 3 guidelines. Inclusion criteria were designed to identify patients with sufficiently severe and reversible asthma who were likely to benefit from ICS therapy. Specific criteria included the following: age $\geq 18$ years; physician's diagnosis 
NCT00115323 (Continued)

of asthma; prescription for an ICS-containing medication for asthma; and evidence of reversible airflow obstruction, that is, an increase $\geq 15 \%$ and $200 \mathrm{~mL}$ in $\mathrm{FEV}_{1}$ with asthma treatment over the previous 3 years, or an increase in $\mathrm{FEV}_{1}$ or $\mathrm{FVC} \geq 12 \%$ and $200 \mathrm{~mL}$ in $\mathrm{FEV}_{1}$ within 30 minutes of inhaled albuterol. Smokers were included

Exclusion criteria: severe psychiatric problems such as obvious mania or schizophrenia that would make it impossible for individuals to understand or carry out problem solving

Percentage withdrawn: not specifically reported

Other allowed medication: not specifically reported

Interventions

Intervention summary: four 30 -minute sessions. Individualised intervention involved 4 interactive steps, usually 1 per research session, aimed at improving or maintaining adherence. Step 1: breaking problems into small achievable pieces; Step 2: brainstorming for alternative solutions; Step 3: choosing the best solution by weighing the consequences, both desirable and undesirable, of each candidate solution (between third and fourth meetings, the solution was tried); Step 4: evaluating and revising chosen solution. Intervention delivered to participants by a research co-ordinator (college graduates interested in health-related or education carers or further schooling, committed to working with patients and having a research experience. Co-ordinators were diverse in race/ethnicity, as were participants)

Control summary: four 30-minute sessions, each focused on an asthma patient education topic unrelated to self-management, adherence or ICS therapy. Topics covered included proper technique for using an albuterol-rescue metered dose inhaler and a dry powder inhaler or spacer, depending on the patient's medications; use of peak flow meters; common asthma triggers; and pathophysiology of asthma. These sessions did not involve discussion of problem solving or adherence, only a didactic presentation of health information. Delivered to participants by a research co-ordinator (college graduates interested in health-related or education carers or further schooling, committed to working with patients and having a research experience. Co-ordinators were diverse in race/ethnicity, as were participants)

Complex intervention: yes

Outcomes

Outcomes measured: adherence to ICS regimen prescribed by participant's physician assessed by an electronic monitor; Mini-AQLQ; ACQ; spirometry ( $\mathrm{FEV}_{1}$ and FVC); hospitalisations and ED visits for asthma or any cause; patient satisfaction

Adherence calculation: Daily ICS adherence was calculated as (\# actuations downloaded/\# prescribed) $\times 100$ (using an electronic adherence monitor attached to the inhaler)

Notes

Type of publication: single peer-reviewed full-text journal article

Funding: supported by grants from the National Institutes of Health (HL070392, HL088469)

\section{Risk of bias}

\begin{tabular}{lll}
\hline Bias & Authors' judgement & Support for judgement \\
\hline $\begin{array}{l}\text { Random sequence genera- } \\
\text { tion (selection bias) }\end{array}$ & Low risk & $\begin{array}{l}\text { "Subjects were randomized according to a computer-generated algorithm in } \\
1: 1 \text { ratio" }\end{array}$ \\
\hline $\begin{array}{l}\text { Allocation concealment } \\
\text { (selection bias) }\end{array}$ & Unclear risk & No details \\
\hline $\begin{array}{l}\text { Blinding of participants } \\
\begin{array}{l}\text { and personnel (perfor- } \\
\text { mance bias) }\end{array}\end{array}$ & High risk & $\begin{array}{l}\text { No blinding of participants or personnel described. Main outcome - adherence } \\
\text { - objectively measured, but other outcomes such as ACQ and AQLQ are subject } \\
\text { to performance bias }\end{array}$ \\
\hline
\end{tabular}




\section{NCT00115323 (Continued)}

Blinding of outcome assessment (detection bias)

All outcomes
High risk

No blinding of outcome assessors described. Main outcome - adherence - objectively measured, but other outcomes such as ACQ and AQLQ are subject to detection bias as the unblinded participant is the outcome assessor

\begin{tabular}{lll}
$\begin{array}{l}\text { Incomplete outcome data } \\
\text { (attrition bias) }\end{array}$ & Unclear risk & Attrition not reported \\
All outcomes & \\
\hline $\begin{array}{l}\text { Selective reporting (re- } \\
\text { porting bias) }\end{array}$ & Low risk & Prospectively registered trial (NCT00115323). All outcomes reported
\end{tabular}

Other bias Low risk None noted

Methods Design: open-label, parallel-group, multi-centre randomised controlled trial

Duration: 17 weeks, with follow-up continuing to 1 year

Setting: recruitment from primary and subspecialty care, inpatient and emergency department settings at 1 large paediatric tertiary care centre. USA

Trial registration: NCT00149487

Participants

Population: 141 children with asthma randomised to a problem-solving intervention or family-based education ( $\mathrm{n}$ for each group not reported)

Age: 5 to 17 years; mean age not reported

Baseline asthma severity: not reported

Inclusion criteria: African American, family income below the poverty line, physician-based diagnosis of asthma of at least 12 months, moderate to severe asthma (moderate asthma includes daily symptoms, daily use of inhaled short-acting beta-agonist, exacerbations more than 2 times per week that affect activity and night-time symptoms more often than once a week, $\mathrm{FEV}_{1}$ or PEF between $60 \%$ and $80 \%$ predicted and $\mathrm{PEF}$ variability $>30 \%$; severe asthma includes continual symptoms, limited physical activity, frequent exacerbations together with frequent night-time symptoms, $\mathrm{FEV}_{1}$ or $\mathrm{PEF}<60 \%$ predicted and PEF variability $>30 \%$ ). Likely to be on a stable and daily medication (inhaled steroid) that can be modified electronically for the time period required to participate in the study

Exclusion criteria: serious comorbid chronic condition, serious developmental disability, income exceeding poverty level

Percentage withdrawn: not reported

Other allowed medication: not reported

Interventions

Intervention summary: intervention tailored to observed adherence behaviours and identified barriers to increasing adherence in African American children and adolescents with asthma and their families

Control summary: family education

Complex intervention: yes

Outcomes

Outcomes measured: adherence, frequency of asthma symptoms, utilisation of healthcare services, use of reliever medication 
Adherence calculation: adherence defined as correspondence between medication doses taken each day and prescribed dose, tracked by electronic monitoring device during months 9 to 12 of the study

Notes

Type of publication: single peer-reviewed full-text journal article and NCT record with no study results provided. Full-text publication of RCT findings not found; above data extracted from a paper describing observational data related to trial participants

Funding: National Heart, Lung, and Blood Institute (NHLBI)

\section{Risk of bias}

\begin{tabular}{lll}
\hline Bias & Authors' judgement & Support for judgement \\
\hline $\begin{array}{l}\text { Random sequence genera- } \\
\text { tion (selection bias) }\end{array}$ & Unclear risk & "Randomized" but no further details \\
\hline $\begin{array}{l}\text { Allocation concealment } \\
\text { (selection bias) }\end{array}$ & Unclear risk & No details \\
\hline $\begin{array}{l}\text { Blinding of participants } \\
\text { and personnel (perfor- } \\
\text { mance bias) }\end{array}$ & High risk & No blinding of participants or personnel described \\
All outcomes & \\
\hline
\end{tabular}

Blinding of outcome as- High risk No blinding of outcome assessors described

sessment (detection bias)

All outcomes

$\begin{aligned} & \text { Incomplete outcome data } \\ & \text { (attrition bias) }\end{aligned}$
Algh risk $\quad$ Drop-out not reported for each arm; 49/141 dropped out overall (35\%)

All outcomes

\begin{tabular}{lll}
\hline $\begin{array}{l}\text { Selective reporting (re- } \\
\text { porting bias) }\end{array}$ & High risk & $\begin{array}{l}\text { Unable to identify full-text report of the RCT. Observational study on same co- } \\
\text { hort reported. No study results posted on clinicalrials.gov. Not able to include } \\
\text { any outcomes in meta-analysis }\end{array}$ \\
\hline Other bias & Low risk & None noted \\
\hline
\end{tabular}

Methods Design: open-label, 3-arm, parallel-group randomised controlled trial

Duration: 2 months

Setting: recruited from asthma clinics at a rural, university-based hospital in northeastern United States and an urban-based children's hospital in the Midwest

Trial registration: NCT00166582

Participants

Population: 55 children with asthma randomised to receive a team work intervention $(n=19)$, an asthma education intervention $(n=19)$ or usual care $(n=17)$

Age: 9 to 15 years; mean age (SD) 11.1 (1.9) years across the 3 groups (mean age not given for each group)

Baseline asthma severity: team work intervention group: mild persistent asthma $=37.5 \%$, moderate persistent asthma $=50.0 \%$, severe persistent asthma $=12.5 \%$; asthma education group: mild persistent asthma $=25.0 \%$, moderate persistent asthma $=56.2 \%$, severe persistent asthma $=18.8 \%$; usual care 
NCT00166582 (Continued)

group: mild persistent asthma $=18.8 \%$, moderate persistent asthma $=62.5 \%$, severe persistent asthma $=18.8 \%$

Inclusion criteria: child with diagnosis of persistent asthma for at least 6 months; fluticasone MDI taken daily; and no evidence of neurological or significant cognitive impairment (per parent report). Suspected history of medication non-adherence not required

Exclusion criteria: not reported

Percentage withdrawn: $16 \%$ from both teamwork intervention and asthma education intervention groups and $6 \%$ from usual care group

Other allowed medication: not reported
Intervention summary (1): teamwork: emphasised the importance of parents and youth sharing responsibility for the patient's asthma management and learning methods for addressing conflicts associated with increased responsibility of youth. Involved handouts on adolescent development, promoting youth independence, appropriate parental medication supervision and problem solving around asthma management conflicts. MDI Log-II served as the primary source of adherence information for families. ICS adherence goals were set in consultation with physician (lowest 70\%). Four sessions 2 to 3 weeks apart delivered by a 'therapist'

Intervention summary (2): asthma education: similar to the teamwork group, families in this group received and reviewed written materials with the researcher during sessions. These materials covered topics often found in asthma education programmes. Time spent with families generally was equivalent to that of its parallel teamwork session, thereby creating an attention control condition. Four sessions 2 to 3 weeks apart delivered by a 'therapist'

Control summary: Youth in the usual care group completed all assessments at the same time interval as other participants but did not receive guidance beyond usual care. On completion of follow-up, these families were provided feedback on their child's medication adherence and were offered an opportunity to receive either of the 2 interventions

Complex intervention: yes

Outcomes measured: adherence to ICS using MDI Log-II; parent-adolescent conflict (CBQ-20); health outcomes (FSI); lung function; consumer satisfaction (CSQ)

Adherence calculation: Mean daily adherence was defined as follows: total number of puffs inhaled divided by total number of puffs prescribed, multiplied by 100

\begin{tabular}{|c|c|c|}
\hline \multirow[t]{2}{*}{ Notes } & \multicolumn{2}{|c|}{ Type of publication: single peer-reviewed full-text journal article } \\
\hline & \multicolumn{2}{|c|}{$\begin{array}{l}\text { Funding: supported by the National Institute of Child Health and Human Development (R03- } \\
\text { HD039767-02) }\end{array}$} \\
\hline \multicolumn{3}{|l|}{ Risk of bias } \\
\hline Bias & Authors' judgement & Support for judgement \\
\hline $\begin{array}{l}\text { Random sequence genera- } \\
\text { tion (selection bias) }\end{array}$ & Low risk & $\begin{array}{l}\text { "Initially, youth were randomly assigned (via computer-generated number se- } \\
\text { quence) to one of three parallel groups... subsequent participants were as- } \\
\text { signed using a randomized block design to maintain group balance across } \\
\text { variables" }\end{array}$ \\
\hline $\begin{array}{l}\text { Allocation concealment } \\
\text { (selection bias) }\end{array}$ & High risk & $\begin{array}{l}\text { The sequence was available to the research assistant who recruited partici- } \\
\text { pants into the study, as participants were immediately randomised; thus, the } \\
\text { research assistant might have been aware of group allocation before partici- } \\
\text { pants were randomised }\end{array}$ \\
\hline
\end{tabular}




\section{NCT00166582 (Continued)}

Blinding of participants and personnel (performance bias)

All outcomes
High risk

No blinding of participants or personnel described. The main outcome measured - adherence - was monitored objectively with an electronic device, but other outcomes such as functional severity index and satisfaction may have been affected by knowledge of group allocation

\section{Blinding of outcome as- High risk sessment (detection bias)}

All outcomes

No blinding of outcome assessors described. The main outcome - adherence - was monitored objectively with an electronic device. However, other outcomes such as functional severity index are subject to risk of detection bias, as the participant is the outcome assessor

Incomplete outcome data Low risk (attrition bias)

Drop-out lower in the standard care group (6\%) than in the 2 active groups (both 16\%); all participants accounted for in the flow diagram, but uneven

All outcomes drop-out may have skewed results because these people were not included in the analyses

Selective reporting (re- Unclear risk
porting bias)

Prospectively registered trial (NCT00166582), although details minimal in trial registration and outcomes not specified. However, all outcome measures listed in methods of the paper are reported clearly

Other bias Low risk None noted

Methods Design: single-blind, parallel-group randomised controlled trial

Duration: 78 weeks

Setting: Paediatric ED in Baltimore. USA

Trial registration: NCT00233181

Participants

Population: 250 children with asthma randomised to adherence monitoring and education $(n=83)$, education $(n=84)$ or usual care $(n=83)$

Age: 2 to 12 years of age; mean (SD) age in the adherence group 6.5 (3.43) years, in the education group 7.1 (3.37) years and in the control group $7.4(3.3)$ years

Baseline asthma severity: not reported

Inclusion criteria: eligible for randomisation when between 2 and 12 years of age, physician-diagnosed asthma, 2 ED visits or 1 hospitalisation for asthma in the preceding year, resided in Baltimore City, prescribed an asthma controller medication

Exclusion criteria: not reported

Percentage withdrawn: $8.4 \%$ from the adherence group, 3.5\% from the education group and $8.4 \%$ from the control group

Other allowed medication: not reported monitoring with feedback, asthma control and adherence goal setting, reinforcement (praise and lowcost rewards), and strategies for self-monitoring medication use

Intervention summary (2): five 30- to 45-minute home visits by trained asthma educators (AEs) 1, 2, 3, 4 and 8 weeks after randomization. $A B C$ intervention is a home-based asthma education programme with 5 core components: review of prescribed asthma regimen and training in medication, spacer and peak flow technique; development of an asthma action plan; identification of barriers to accessing 
NCT00233181 (Continued)

healthcare services and problem solving to reduce barriers; discussion of beliefs and concerns about asthma and medications; and provision of written asthma education materials

Control summary: asthma education booklet and resource guide that provided information about low-cost asthma care providers, social services, legal services and other resources. Regardless of group assignment, participants were regularly encouraged to receive care from their primary care provider

Complex intervention: yes

Outcomes

Outcomes measured: self-reported adherence; pharmacy-based adherence; career reports of symptoms, night-time awakenings, ED visits, hospitalisations and courses of OCS in the previous 6 months

Adherence calculation: Pharmacy-based adherence was calculated as number of ICS refills per quarter, converted into equivalent values; rates were defined as number of ICS canisters dispensed quarterly (where $3=100 \%$ adherence). Self-reported adherence was $\%$ use/prescribed dose $\times 100$

Nype of publication: single peer-reviewed journal article
Funding: National Heart, Lung, and Blood Institute grant HL063333

\title{
Risk of bias
}

\begin{tabular}{lll}
\hline Bias & Authors' judgement & Support for judgement \\
\hline $\begin{array}{ll}\text { Random sequence genera- } \\
\text { tion (selection bias) }\end{array}$ & Low risk & "To mask staff to group assignment during recruitment, the statistician creat- \\
& & $\begin{array}{l}\text { ed block randomization schema and placed the randomization assignments } \\
\text { into sealed envelopes, which were opened after families completed baseline } \\
\text { surveys" }\end{array}$ \\
\hline
\end{tabular}

\begin{tabular}{ll}
\hline $\begin{array}{l}\text { Allocation concealment } \\
\text { (selection bias) }\end{array}$ & Low risk \\
& $\begin{array}{l}\text { "To mask staff to group assignment during recruitment, the statistician creat- } \\
\text { ed block randomization schema and placed the randomization assignments } \\
\text { into sealed envelopes, which were opened after families completed baseline } \\
\text { surveys" }\end{array}$
\end{tabular}

Blinding of participants High risk Participants were not blinded to group allocation, and knowledge of group aland personnel (perfor- location and adherence monitoring may have affected healthcare utilisation mance bias)

All outcomes behaviour, as well as adherence behaviour, beyond the effect intended by trialists

Blinding of outcome as- $\quad$ High risk
sessment (detection bias)

All outcomes

\begin{abstract}
"Trained research assistants who were blinded to study assignments conducted surveys by telephone"

However, all asthma morbidity measures were career reported, and therefore were at risk of detection bias, as the career is the outcome assessor for these self-reported outcomes
\end{abstract}

\begin{tabular}{|c|c|c|}
\hline $\begin{array}{l}\text { Incomplete outcome data } \\
\text { (attrition bias) } \\
\text { All outcomes }\end{array}$ & Low risk & $\begin{array}{l}\text { More than } 80 \% \text { of participants in all } 3 \text { arms completed all questionnaires and } \\
\text { follow-up. Results analysed as ITT, and all randomised participants included in } \\
\text { the ITT analysis }\end{array}$ \\
\hline
\end{tabular}

\begin{tabular}{|c|c|c|}
\hline $\begin{array}{l}\text { Selective reporting (re- } \\
\text { porting bias) }\end{array}$ & High risk & $\begin{array}{l}\text { Prospectively registered trial (NCT00233181), but not all outcomes (e.g. QOL) } \\
\text { reported in the published paper }\end{array}$ \\
\hline
\end{tabular}

Other bias Low risk None noted

Methods Design: open-label, pragmatic, parallel-group randomised controlled trial


NCT00414817 (Continued)

Duration: 78 weeks

Setting: conducted through 2 Kaiser Permanente research centres in Hawaii and Baltimore. USA

Trial registration: NCT00414817

Participants

Population: 14,064 adults with asthma randomised to receive interactive voice response calls or usual care. Not all participants were previous ICS users. 3171 of the intervention group and 3260 of the usual care group described as the primary analysis sample - previous ICS users

Age: 18 years of age and older; ages reported in categories rather than as mean (SD)

Baseline asthma severity: $33.3 \%$ had comorbid COPD; other characteristics included recent ED visit, hospitalisation or OCS burst for asthma; current SABA usage; and number of medications used

Inclusion criteria: Target population consisted of KPNW and KPH members 18 years of age and older who were members for the 12 months before randomisation, had been seen for asthma and received at least 1 dispensing of a respiratory medication during that time frame. For study of both primary and secondary ICS adherence, target population included individuals without evidence of prior ICS use. Present analysis focuses on the subset of 6903 individuals with ICS dispensing during baseline year

Exclusion criteria: Individuals meeting the above criteria were included in the final analysis sample only if they had ever received (or for usual care participants would have qualified for) an intervention call

Percentage withdrawn: of 6903 previous users qualifying for analysis, 3171 were included in the intervention analysis sample and 3260 in the usual care analysis sample

Other allowed medication: not reported

Interventions

Intervention summary: interactive voice recognition (IVR) intervention including 3 basic IVR call types, each typically lasting 2 to 3 minutes: refill reminder call, for people whose last ICS dispensing was at least a month ago and who should have $<30$ days supply left, reminded participants that they were due for a refill and offered a transfer to the automated pharmacy refill line and/or information about KP's online refill service; tardy refill call, for people > 1 month past refill date, reminded participants they were due for an ICS refill, assessed asthma control, explored ICS adherence barriers and provided tailored educational messages; and initiator/restart call, for participants who were starting ICS for the first time or were lapsed users, included probes for asthma control and adherence barriers and offered tailored educational messages

Control summary: usual care

Complex intervention: no

Outcomes

Outcomes measured: 8 alternative measures of pharmacy-based adherence, described as continuous multiple-interval measures of medication availability and gaps. Clinicaltrials.gov lists the primary outcome as days' supply of ICS available as documented in participants' pharmacy records at 19 months, and secondary outcomes as health status from survey responses (subset), utilisation of acute healthcare services from medical record data and an economic analysis. Multiple post hoc analyses provided in published reports

Adherence calculation: 8 alternative measures of pharmacy-based adherence (one of the resulting publications is a comparison of pharmacy-based measures of medication adherence)

Notes Type of publication: multiple peer-reviewed journal articles

Funding: NHLBI

\section{Risk of bias}




\section{NCT00414817 (Continued)}

Random sequence genera- Unclear risk tion (selection bias)

"Randomization stratified by region and the clinic facility to which each patient was paneled" - but no further details about how the random sequence was generated

\begin{tabular}{lll}
\hline $\begin{array}{l}\text { Allocation concealment } \\
\text { (selection bias) }\end{array}$ & Unclear risk & No details \\
\hline $\begin{array}{l}\text { Blinding of participants } \\
\text { and personnel (perfor- } \\
\text { mance bias) }\end{array}$ & High risk & $\begin{array}{l}\text { Although it was not possible to blind participants to group allocation, the pri- } \\
\text { mary outcome (adherence) was measured objectively using pharmacy data. } \\
\text { All outcomes }\end{array}$ \\
$\begin{array}{l}\text { However, as participants would have been aware that they were taking part } \\
\text { in a trial of adherence and were being monitored, this may have affected their } \\
\text { adherence behaviour beyond the effect intended by the intervention }\end{array}$
\end{tabular}

Blinding of outcome as- Low risk sessment (detection bias)

All outcomes
Blinding of outcome assessors is not described; however, the nature of the primary outcomes (adherence measured using pharmacy data) makes them not prone to detection bias
Owing to the trial design, it was not possible to measure attrition in the usual way

(attrition bias)

Unclear risk

All outcomes

Selective reporting (re- High risk

porting bias)

Prospectively registered trial (NCT00414817), but many outcomes of interest not presented numerically, so unable to include it in the meta-analysis ("We also observed no significant intervention effects on reliever medication (SABA) use, quality of life, asthma control, or the rate of acute asthma health care utilization")

Other bias Low risk None noted

\section{NCT00459368}

Mesign: single-blind, parallel-group, stratified cluster randomised trial
Duration: 52 weeks

Setting: primary care: 34 clusters ('practices' comprising 193 providers). USA

Trial registration: NCT00459368

Participants

Population: 2698 adults and children with asthma from 34 clusters ('practices' comprising 193 providers) randomised to adherence education and individualised patient adherence information (17 practices, 88 providers, 1335 participants) or adherence education alone (17 practices, 105 providers, 1363 participants)

Age: 5 to 56 years of age; mean age (SD) in the adherence education and individualised patient adherence information group 26.8 (17.4) years and in the adherence education alone group 28.8 (17.4) years

Baseline asthma severity: physician diagnosis of asthma and prescription for ICS in the preceding 2 years; no other severity information given

Inclusion criteria: Eligible primary care practices had to have access to electronic prescription writing. Eligible patients had to fulfil the following criteria: recent previous electronic prescription for an ICS; 5 to 56 years of age as of 30 April 2007; continuous enrolment in the affiliated health maintenance organisation (HMO) for at least 1 year before 30 April 2007; prescription drug coverage as of 30 April 2007; at least 1 physician diagnosis of asthma and no diagnosis of chronic obstructive pulmonary disease or congestive heart failure after 19 January 2005; and at least 1 visit to a primary care provider in the year before 30 April 2007 
Exclusion criteria: ICS medication stopped and not restarted, left the HMO before start of the intervention

Percentage withdrawn: $22 \%$ from the adherence education and individualised patient adherence information arm and $24 \%$ from the adherence education alone arm

Other allowed medication: Participants continued their normal medication

Intervention summary: Physicians assigned to both groups received an audio compact disc, a digi-
tal video disc and a booklet that contained information on the most recent national asthma guidelines
and methods for discussing medication non-adherence with patients. Physicians in the intervention
arm could also view their patients' individual adherence data generated by ePrescribing

Control summary: as above, but physicians were not able to view their patients' individual adherence data

Complex intervention: yes

Outcomes

Outcomes measured: patient adherence to ICS in last 3 months of intervention (i.e. an individual-level outcome accounting for practice clusters), time to and number of the following events during the intervention period: asthma-related emergency department visit, asthma-related hospitalisation and oral steroid use. Post hoc analysis revealed that the change in adherence between baseline and study end differed between participants in intervention and control arms

Adherence calculation: Based on data from electronic prescribing, calculated days of supply was calculated to estimate adherence as a continuous measure of medication availability equal to the cumulative days of supply divided by the number of days of observation. This estimates the proportion of time that participants took their medication

Notes Type of publication: multiple peer-reviewed full-text journal articles

Funding: supported by grants from the National Heart, Lung, and Blood Institute (HL79055), the National Institute of Allergy and Infectious Diseases (Al61774, Al79139), the National Institute of Diabetes and Digestive and Kidney Diseases (DK64695), National Institutes of Health; the Fund for Henry Ford Hospital; and the Strategic Program for Asthma Research of the American Asthma Foundation

\section{Risk of bias}

\begin{tabular}{lll}
\hline Bias & Authors' judgement & Support for judgement \\
\hline $\begin{array}{l}\text { Random sequence genera- } \\
\text { tion (selection bias) }\end{array}$ & Low risk & $\begin{array}{l}\text { Practices were randomised with stratification for whether the practice was a } \\
\text { paediatric practice (i.e. paediatrics vs family medicine and internal medicine) } \\
\text { to achieve approximately equal partitioning of children and adults in both } \\
\text { study arms. One researcher (E.L.P.) generated the random allocation sequence } \\
\text { within strata, and the identities of the practices were concealed at the time of } \\
\text { randomisation }\end{array}$
\end{tabular}

\begin{tabular}{|c|c|c|}
\hline $\begin{array}{l}\text { Allocation concealment } \\
\text { (selection bias) }\end{array}$ & Low risk & The identities of practices were concealed at the time of randomisation \\
\hline $\begin{array}{l}\text { Blinding of participants } \\
\text { and personnel (perfor- } \\
\text { mance bias) } \\
\text { All outcomes }\end{array}$ & Unclear risk & $\begin{array}{l}\text { Healthcare providers (rather than individual participants) were randomised } \\
\text { and were aware of group allocation. It is unclear how their knowledge of group } \\
\text { allocation may have impacted the adherence of their patients in ways unin- } \\
\text { tended by the intervention itself }\end{array}$ \\
\hline $\begin{array}{l}\text { Blinding of outcome as- } \\
\text { sessment (detection bias) } \\
\text { All outcomes }\end{array}$ & Low risk & $\begin{array}{l}\text { Study staff was masked to the individual practice treatment assignment, and } \\
\text { the primary outcome - adherence as calculated from pharmacy data - is objec- } \\
\text { tive }\end{array}$ \\
\hline
\end{tabular}




\section{NCT00459368 (Continued)}

Incomplete outcome data Low risk Although $>20 \%$ of participants did not complete the trial ( $22 \%$ in the interven(attrition bias) tion arm and $24 \%$ in the control arm), we carried forward their last 3 months of

All outcomes adherence and analysed data in the primary analysis

\begin{tabular}{|c|c|c|}
\hline $\begin{array}{l}\text { Selective reporting (re- } \\
\text { porting bias) }\end{array}$ & Low risk & $\begin{array}{l}\text { Prospectively registered trial (NCT00459368). All outcomes reported in at least } \\
1 \text { of several associated publications }\end{array}$ \\
\hline
\end{tabular}

Other bias Low risk None noted

Methods Design: open-label, parallel-group randomised controlled trial

Duration: 26 weeks, with follow-up to 78 weeks

Setting: children 'in our region' given diagnosis of asthma in previous 1 to 2 months. Sweden

Trial registration: not reported

Participants

Population: 60 children with asthma and their parents randomised to group discussions plus basic education $(n=32)$ or basic education $(n=28)$

Age: 3 months to 6 years of age; mean age (SD) in the intervention group 28.1 months and in the control group 26.1 months

Baseline asthma severity: not reported

Inclusion criteria: moderate or severe asthma defined by SPT II Brazillian Consensus on Asthma Management

Exclusion criteria: not reported

Percentage withdrawn: $9 \%$ from the intervention group and $14 \%$ from the usual care group

Other allowed medication: not reported

Interventions

Intervention summary: meetings in a group setting with both parents. Afternoon sessions of 1.5 hours' duration; 3 weekly meetings soon after asthma diagnosis and a follow-up meeting at 6 months. Session involved 3 paediatricians, 3 nurses and 2 psychologists. One nurse was present on all occasions. The method applied was based on the concept of concordance, meaning that we tried to "speak the same language" as the parents and to reach an alliance with them on how to look upon asthma and its management. Our goal was to reach their "main worry" and, apart from teaching about asthma, we asked the key question: "What is asthma to you?" Our intention was to use dialogue and peer education, whereby the group was encouraged to share personal experiences. In each group session, leaders had a list of subjects that were to be covered during the discussion. Attendees also received basic education

Control summary: basic education about asthma and its treatment, including how to use the Nebunette, and information on environmental control at first visit to the clinic. Participants received a written treatment plan for which the principle was high dose initially, then, in association with URTI, stepping down therapy to the lowest possible dose according to the status of the child. Treatment was stopped if the child had no asthma symptoms for 6 months

Complex intervention: yes

Outcomes

Outcomes measured: presence of parents at group meetings; personal view on adherence at inclusion and after 6 and 18 months; how many days the child was hospitalised; how many times participants had to seek emergency help for asthma; exacerbations, as defined by the need for parents to stay at 
NCT00516633 (Continued)

home to take care of their child because of asthma symptoms; objective measures of adherence; adherence according to parents

Adherence calculation: diaries and weighing of MDIs used between 12 and 18 months after inclusion

Notes

Type of publication: single peer-reviewed journal article

Funding: Primary Care Unit in the county of Varmland. AstraZeneca provided the medicines

\section{Risk of bias}

\begin{tabular}{|c|c|c|}
\hline Bias & Authors' judgement & Support for judgement \\
\hline $\begin{array}{l}\text { Random sequence genera- } \\
\text { tion (selection bias) }\end{array}$ & Unclear risk & $\begin{array}{l}\text { "The parents of the } 60 \text { children were randomized consecutively in groups of } \\
\text { four to either the intervention or the control group" - but no further details } \\
\text { about how this was achieved }\end{array}$ \\
\hline $\begin{array}{l}\text { Allocation concealment } \\
\text { (selection bias) }\end{array}$ & Unclear risk & No details \\
\hline $\begin{array}{l}\text { Blinding of participants } \\
\text { and personnel (perfor- } \\
\text { mance bias) } \\
\text { All outcomes }\end{array}$ & High risk & $\begin{array}{l}\text { "The nurses carried out the randomization and the three doctors that were in- } \\
\text { volved in the group sessions also performed the follow-up visits. Therefore, a } \\
\text { complete blinding procedure could not be established" }\end{array}$ \\
\hline $\begin{array}{l}\text { Blinding of outcome as- } \\
\text { sessment (detection bias) } \\
\text { All outcomes }\end{array}$ & High risk & $\begin{array}{l}\text { "The nurses carried out the randomization and the three doctors that were in- } \\
\text { volved in the group sessions also performed the follow-up visits. Therefore, a } \\
\text { complete blinding procedure could not be established" }\end{array}$ \\
\hline $\begin{array}{l}\text { Incomplete outcome data } \\
\text { (attrition bias) } \\
\text { All outcomes }\end{array}$ & Low risk & $\begin{array}{l}\text { High levels of follow-up in both arms ( } 86 \% \text { in control group, } 91 \% \text { in interven- } \\
\text { tion group); all withdrawals accounted for in the publication }\end{array}$ \\
\hline $\begin{array}{l}\text { Selective reporting (re- } \\
\text { porting bias) }\end{array}$ & High risk & $\begin{array}{l}\text { No prospective trial registration identified. Many outcomes reported narra- } \\
\text { tively in text but with insufficient numerical detail for inclusion in the meta- } \\
\text { analyses. Within-group or whole study population results sometimes present- } \\
\text { ed rather than between-group differences. 'N.S.' frequently reported rather } \\
\text { than exact CIs, SDs or P values }\end{array}$ \\
\hline Other bias & Low risk & None noted \\
\hline
\end{tabular}

\section{NCT00958932}

Methods Design: open-label, pragmatic, parallel-group randomised controlled trial

Duration: 2 years

Setting: 18 primary care and 2 specialty care medical offices, 2 contract hospitals and more than 800 physicians. USA

Trial registration: NCT00958932

\section{Participants}

Population: 1187 children with asthma randomised to speech recognition (SR) intervention $(n=590)$ or usual care (UC) $(n=597)$

Age: 3 to 12 years of age; mean age (SE) in SR group $8.2(0.13)$ years and in the UC group $8.1(0.13)$ years 
Baseline asthma severity: diagnosed persistent asthma for which daily inhaled corticosteroid treatment was prescribed. Children in the SR group had inpatient visits/person-year, mean (SE), number 0.04 (0.01); ED visits/person-year, mean (SE), number 0.09 (0.02); oral steroid bursts/person-year mean (SE), number 0.469 (0.04); primary care visits/person-year, mean (SE), number $2.3(0.08)$; and children in the UC group had inpatient visits/person-year, mean (SE), number 0.04 (0.01); ED visits/person-year, mean (SE), number 0.09 (0.02); oral steroid bursts/person-year, mean (SE), number 0.383 (0.04); primary care visits/person-year, mean (SE), number $2.4(0.10)$

Inclusion criteria: 3 to 12 years of age, diagnosis of persistent asthma, 1 or more ICS prescriptions filled in the prior 6 months. Participants were limited to those enrolled in KPCO (Kaiser Permanente Colorado; a group-model health maintenance organisation) for at least 1 year to ensure that patients were consistently given a diagnosis of persistent asthma and to establish a baseline ICS adherence rate

Exclusion criteria: identified by physician as having a life-threatening comorbid condition; sibling already included in the study; parent who declined to participate; instructed to take an ICS only intermittently or as needed; obtained medication from a non-KPCO pharmacy

Percentage withdrawn: $23 \%$ from the SR arm and 25\% from the UC arm

Other allowed medication: Participants continued their normal medication

Intervention summary: Speech recognition telephone calls to parents in the intervention condition were triggered when an inhaled corticosteroid refill was due or overdue. Calls were automatically tailored with medical and demographic information from the electronic health record and from parent answers to questions during the call regarding recent refills or a desire to receive help refilling, to learn more about asthma control or to speak with an asthma nurse or a pharmacy staff member. All standard asthma resources remained available to both intervention groups throughout the duration of the study

Control summary: All standard asthma resources remained available to the usual care group throughout the duration of the study

Complex intervention: no

Outcomes

Outcomes measured: adherence to ICS, beta 2 -agonist use, oral steroid use; asthma-related visits for primary healthcare services, ED visits, hospitalisations and after-hours visits on weekends or weekdays after 6 PM; participant satisfaction

Adherence calculation: Adherence was expressed as proportion of days covered (PDC) over 24 months. PDC was calculated as total number of ICS days supplied divided by period for which medication was prescribed

Notes

Type of publication: single peer-reviewed full-text journal article

Funding: supported by grant 1R01HL084067-01A2 from the National Institutes of Health. The National Institutes of Health had no role in design and conduct of the study; collection, management, analysis and interpretation of data; preparation, review or approval of the manuscript; and decision to submit the manuscript for publication

\section{Risk of bias}

Bias Authors' judgement Support for judgement

$\begin{array}{ll}\begin{array}{l}\text { Random sequence genera- } \\ \text { tion (selection bias) }\end{array} & \text { Unclear risk } \\ \end{array}$
tion (selection bias) tail given in the study report or protocol

\begin{tabular}{lll}
\hline $\begin{array}{l}\text { Allocation concealment } \\
\text { (selection bias) }\end{array}$ & Unclear risk & No details \\
\hline $\begin{array}{l}\text { Blinding of participants } \\
\begin{array}{l}\text { and personnel (perfor- } \\
\text { mance bias) }\end{array}\end{array}$ & High risk & $\begin{array}{l}\text { No blinding of participants or personnel described. Main outcomes are related } \\
\text { to usage of healthcare services and may be influenced by participants' knowl- } \\
\text { edge of group allocation }\end{array}$
\end{tabular}


NCT00958932 (Continued)

All outcomes

\begin{tabular}{|c|c|c|}
\hline $\begin{array}{l}\text { Blinding of outcome as- } \\
\text { sessment (detection bias) } \\
\text { All outcomes }\end{array}$ & Low risk & $\begin{array}{l}\text { No blinding of outcome assessor described. However, main outcomes are } \\
\text { related to usage of healthcare services, which was obtained from medical } \\
\text { records and is unlikely to be influenced by knowledge of group allocation }\end{array}$ \\
\hline
\end{tabular}

All outcomes

Although drop-out was relatively high (> 20\%) owing to loss of insurance, it

Incomplete outcome data Low risk

(attrition bias)

was balanced and trialists performed an intention-to-treat analysis; partici-

All outcomes pants who lost insurance coverage during the 2-year study period were included in a secondary analysis for evaluation of potential sample attrition bias

Selective reporting (re- Low risk porting bias)

Prospectively registered trial (NCT00958932) and protocol available online. All main outcomes of interest reported; trialists state they will report rescue medication use in the protocol, but this information does not appear in the main report

\begin{tabular}{lll}
\hline Other bias $\quad$ Low risk noned \\
\hline
\end{tabular}

\section{NCT01064869}

Methods $\quad \begin{aligned} & \text { Design: single-blind, parallel-group randomised controlled trial } \\ & \text { Duration: intervention delivered over } 12 \text { weeks. Follow-up continued to } 1 \text { year }\end{aligned}$

Setting: Regional Difficult Asthma Service. Northern Ireland

Trial registration: not reported

\section{Participants}

Population: 20 people with asthma attending a difficult asthma service facility randomised to individualised psychoeducational nurse-led intervention $(n=9)$ or usual care $(n=11)$

Age: age range not reported, but mean age (SD) in the intervention group was 50 (9.1) years and in the control group 45.2 (10) years

Baseline asthma severity: All participants had 'difficult asthma' - defined as persistent symptoms, despite treatment at BTS/SIGN step 4/5. Baseline mean (SD) \% predicted FEV 174.4 (20.5)

Inclusion criteria: difficult asthma, defined as persistent symptoms, despite treatment at BTS/SIGN step 4/5; attendance at the Northern Ireland Regional Difficult Asthma Service; non-adherence after phase 1 of the study (received a patient concordance discussion); age over 18 years

Exclusion criteria: current tobacco smoking or significant other comorbidity that contributed to persistent respiratory symptoms

Percentage withdrawn: $22 \%$ from the intervention group and $0 \%$ from the usual care group

Other allowed medication: ICS/LABA; prednisolone

Control summary: usual care

Complex intervention: yes

Outcomes

Outcomes measured: change in adherence to inhaled combination therapy; daily prescribed dose of ICS; courses of rescue oral corticosteroids; total inhaled and nebulised beta-agonist doses; hospital admissions and lung function; ACQ; AQLQ; HADS; State Trait Anxiety Scale 
Adherence calculation: $\%$ of inhaled combination therapy prescriptions refilled and change in number of participants in each group filling $\leq 50 \%$ of prescription refills

Notes

Type of publication: single peer-reviewed full-text journal article

Funding: Research and Development Office, Northern Ireland

\section{Risk of bias}

\begin{tabular}{|c|c|c|}
\hline Bias & Authors' judgement & Support for judgement \\
\hline $\begin{array}{l}\text { Random sequence genera- } \\
\text { tion (selection bias) }\end{array}$ & Unclear risk & $\begin{array}{l}\text { "Patients were randomly allocated to either the intervention or control group" } \\
\text { - no further details }\end{array}$ \\
\hline $\begin{array}{l}\text { Allocation concealment } \\
\text { (selection bias) }\end{array}$ & Unclear risk & None noted \\
\hline $\begin{array}{l}\text { Blinding of participants } \\
\text { and personnel (perfor- } \\
\text { mance bias) } \\
\text { All outcomes }\end{array}$ & High risk & $\begin{array}{l}\text { Trial described as 'single blind' but blinding not further described. Seems un- } \\
\text { likely that participants or personnel would have been masked, and many out- } \\
\text { comes (e.g. ACQ, AQLQ) were subject to risk of performance bias }\end{array}$ \\
\hline $\begin{array}{l}\text { Blinding of outcome as- } \\
\text { sessment (detection bias) } \\
\text { All outcomes }\end{array}$ & High risk & $\begin{array}{l}\text { Trial described as 'single blind' but blinding not further described. Seems un- } \\
\text { likely that participants or personnel would have been masked, so likely out- } \\
\text { come assessors were masked. However, many outcomes (e.g. ACQ, AQLQ) sub- } \\
\text { ject to risk of detection bias, as the unblinded participant is the outcome as- } \\
\text { sessor }\end{array}$ \\
\hline $\begin{array}{l}\text { Incomplete outcome data } \\
\text { (attrition bias) } \\
\text { All outcomes }\end{array}$ & High risk & $\begin{array}{l}\text { Drop-out unbalanced, although small numbers in both arms ( } 0 \% \text { drop-out in } \\
\text { control group, } 22 \% \text { in intervention group) }\end{array}$ \\
\hline $\begin{array}{l}\text { Selective reporting (re- } \\
\text { porting bias) }\end{array}$ & Unclear risk & $\begin{array}{l}\text { No prospective trial registration identified, although all outcomes listed in } \\
\text { methods reported }\end{array}$ \\
\hline Other bias & Low risk & None noted \\
\hline
\end{tabular}

\section{NCT01132430}

Methods

Design: single-blind, parallel-group randomised controlled trial

Duration: 6 weeks, with follow-up to 52 weeks

Setting: Outpatient clinic. Single site. Canada

Trial registration: not reported.

Participants

Population: 54 adults with asthma randomised to motivational interviewing (MI) ( $n=26)$ or usual care $(n=28)$

Age: over 18 years of age; mean age (SD) in the intervention group was 52 (15) years and in the control group 49 (16) years

Baseline asthma severity: intervention group: ACT score 17 (4); ACQ 1.7 (0.9); control group: ACT score 17 (4); ACQ score 2.1 (1.1) 
Inclusion criteria: age 18 years; primary diagnosis of moderate to severe persistent asthma; prescribed stable dose of ICS for at least 12 months before enrolment; uncontrolled asthma according to ACQ; non-adherence (filling $<50 \%$ prescribed ICS in the past 12 months)

Exclusion criteria: comorbid condition with greater risk than asthma (COPD, CVD, etc.), severe psychopathology; current substance abuse; cognitive or language difficulties; plan to become pregnant; plan to leave Quebec over course of the study

Percentage withdrawn: $30.77 \%$ from the intervention group and $21.43 \%$ from the usual care group

Other allowed medication: not reported

Interventions
Intervention summary: individual session based on an MI manual, with the overall goal of enhancing participant motivation to take ICS

Control summary: Participants received whichever treatments were prescribed by their physician, which may include an action plan or referral to asthma education. Participants were given the opportunity to receive $\mathrm{MI}$ after study completion

Complex intervention: yes

Outcomes

Outcomes measured: ICS adherence; self-reported adherence; asthma control; asthma-related quality of life; asthma-related self-efficacy

Adherence calculation: number of treatment days/total number of days ( 6 months and 12 months)

Notes Type of publication: single peer-reviewed journal article

Funding: unrestricted investigator-initiated grant from GSK, salary awards from Fonds del la Recherche Quebec (FRQS) and Canadian Institute of Health Research. Scholarship support from FRQS

\section{Risk of bias}

\begin{tabular}{lll}
\hline Bias & Authors' judgement & Support for judgement \\
\hline $\begin{array}{l}\text { Random sequence genera- } \\
\text { tion (selection bias) }\end{array}$ & Low risk & $\begin{array}{l}\text { "Following the completion of all baseline assessments, patients were random- } \\
\text { ized to Ml or UC using a computer algorithm that generated a random code" }\end{array}$ \\
\hline $\begin{array}{l}\text { Allocation concealment } \\
\text { (selection bias) }\end{array}$ & Low risk & $\begin{array}{l}\text { "Patients were randomized to Ml or UC using a computer algorithm that gen- } \\
\text { erated a random code that was kept in a concealed envelope until opened by } \\
\text { the study coordinator at the time of randomization as per the CONSORT guide- } \\
\text { lines" }\end{array}$ \\
\hline
\end{tabular}

\begin{tabular}{|c|c|c|}
\hline $\begin{array}{l}\text { Blinding of participants } \\
\text { and personnel (perfor- }\end{array}$ & High risk & $\begin{array}{l}\text { No description of procedures to blind participants or personnel. Subjective na- } \\
\text { ture of many secondary outcomes results in high risk of bias }\end{array}$ \\
\hline
\end{tabular}
mance bias)

All outcomes

Blinding of outcome as- Unclear risk
sessment (detection bias) All outcomes

\begin{abstract}
"With the exception of the visual analog scales assessing patients' impressions on the MI intervention (which were completed at baseline and immediately postintervention only), all postintervention assessments were completed inhospital at 6 and 12 months postintervention by a research assistant who was blinded to patient group. To increase the success of blinding, patients were instructed not to disclose their group assignment to the research assistant"
\end{abstract}

However, for some outcomes (such as AQLQ and ACT), participants the outcome assessor were unblinded; therefore, these outcomes are at risk of bias

\begin{tabular}{|c|c|c|}
\hline $\begin{array}{l}\text { Incomplete outcome data } \\
\text { (attrition bias) }\end{array}$ & Low risk & $\begin{array}{l}\text { Over } 20 \% \text { drop-out in both arms; however, ITT and per-protocol analyses were } \\
\text { performed, and results were very similar overall }\end{array}$ \\
\hline
\end{tabular}


NCT01132430 (Continued)

Selective reporting (reporting bias)

Unclear risk

No prospective trial registration identified, although all outcomes listed in methods clearly reported

Other bias Low risk None noted

Mesign: open-label, parallel-group randomised controlled trial
Duration: 10 weeks
Setting: 3 primary care practices at Rush University Medical Center in Chicago, Illinois. USA
Trial registration: not reported

Participants

Population: 68 adolescents with asthma randomised to adherence messaging and group sessions ( $\mathrm{n}=$ 34) or an "attention control" $(n=34)$

Age: 11 to 16 years of age; mean age (range) in the intervention group was 13.3 (11 to 16) years and in the control group 13.6 (11 to 16 ) years

Baseline asthma severity: intervention group: $85.3 \%$ of participants had uncontrolled asthma at baseline; control group: $76.5 \%$ had uncontrolled asthma at baseline

Inclusion criteria: self-identified as African American or Hispanic, given diagnosis of persistent asthma, possessing an active prescription for a daily ICS for asthma. Persistent asthma was defined as asthma symptoms (e.g. cough, wheeze, shortness of breath, chest tightness) more than 2 days per week or night-time awakenings more often than twice a month; or taking a prescribed daily ICS for asthma

Exclusion criteria: career or child unable to speak English, comorbidities that could interfere with study participation, $\geq 48 \%$ adherence over 2 weeks during the run-in period. Participants with $\geq 48 \%$ adherence were excluded, as the aim of the study was to target children with poor adherence

Percentage withdrawn: $15 \%$ from both intervention and control groups

Other allowed medication: not reported

Interventions

Intervention summary: All participants received medical supervision, peak flow meters and an iPod during the run-in. Those in the intervention group received music tracks and attended coping peer group sessions led by social workers during weeks 1 to 4 and 6 to 9 . Session leaders were trained to use a motivational interviewing approach and to follow the study guide. During the session, participants developed and recorded 2 to 4 messages from the discussion to encourage daily use of ICS, to be played at random between music tracks

Control summary: All participants received medical supervision, peak flow meters and an iPod during the run-in. Those in the attention control group attended weekly individual sessions with a research assistant who did not promote adherence. They received the same number of iPod messages as those in the active intervention group, with content promoting adherence to ICS; also played at random between music tracks but recorded by an asthma doctor rather than by peers

Complex intervention: yes

Outcomes

Outcomes measured: ICS adherence (measured at baseline and at 5 and 10 weeks), asthma knowledge (ZAP Caregiver Asthma Knowledge Instrument), ICS knowledge, ICS self-efficacy, social support, asthma exacerbations

Adherence calculation: average daily adherence over previous 14 days, measured with the electronic medication monitor for ICS 
Funding: National Heart, Lung, and Blood Institute grants K23 HL092292 and R21 HL098812. Support in the form of study drug was provided by a grant from GlaxoSmithKline (FLV114794)

\section{Risk of bias}

\begin{tabular}{|c|c|c|}
\hline Bias & Authors' judgement & Support for judgement \\
\hline $\begin{array}{l}\text { Random sequence genera- } \\
\text { tion (selection bias) }\end{array}$ & Low risk & $\begin{array}{l}\text { "Blocked group randomization, using a computer-generated allocation sched- } \\
\text { ule" }\end{array}$ \\
\hline $\begin{array}{l}\text { Allocation concealment } \\
\text { (selection bias) }\end{array}$ & Unclear risk & No details \\
\hline $\begin{array}{l}\text { Blinding of participants } \\
\text { and personnel (perfor- } \\
\text { mance bias) } \\
\text { All outcomes }\end{array}$ & High risk & $\begin{array}{l}\text { It was not possible to blind participants, although adherence, the only report- } \\
\text { ed outcome of interest for this review, was measured objectively. However, } \\
\text { awareness of intervention group and monitoring may have affected adherence } \\
\text { behaviour beyond the effect intended by the intervention }\end{array}$ \\
\hline $\begin{array}{l}\text { Blinding of outcome as- } \\
\text { sessment (detection bias) } \\
\text { All outcomes }\end{array}$ & Low risk & $\begin{array}{l}\text { "Outcomes data were collected at baseline and at } 5 \text { and } 10 \text { weeks post-ran- } \\
\text { domization (during the active treatment phase) by research assistants blinded } \\
\text { to the participants' group assignment" }\end{array}$ \\
\hline $\begin{array}{l}\text { Incomplete outcome data } \\
\text { (attrition bias) } \\
\text { All outcomes }\end{array}$ & Low risk & $\begin{array}{l}\text { More than } 80 \% \text { in both arms attended at least } 1 \text { follow-up visit (at } 5 \text { or } 10 \\
\text { weeks) and were included in the analysis; reasons for dropping out were simi- } \\
\text { lar between the } 2 \text { groups }\end{array}$ \\
\hline $\begin{array}{l}\text { Selective reporting (re- } \\
\text { porting bias) }\end{array}$ & Unclear risk & $\begin{array}{l}\text { Prospectively registered trial (NCT01169883); outcomes listed on trial register } \\
\text { clearly reported (although medians and IQR used, so unable to include it in the } \\
\text { meta-analysis). Several outcomes of interest in this review were listed as mea- } \\
\text { sured in the methods section of the published report but were not reported in } \\
\text { the results (e.g. unscheduled visits, exacerbations) }\end{array}$ \\
\hline Other bias & Low risk & None noted \\
\hline
\end{tabular}

\section{NCT01175434}

Methods Design: open-label, parallel-group randomised controlled trial
Duration: 6 to 8 months

Setting: schools in the Rochester City School District. USA

Trial registration: NCT01175434

Age: 3 to 10 years of age; mean age (SD) in each intervention group $7.5(1.7)$ years and in usual care group $7.0(1.8)$ years

Baseline asthma severity: baseline PAQLQ in the intervention group $6.25(0.8)$ and baseline QOL 5.82 (1.2)

Inclusion criteria: children with physician-diagnosed asthma with persistent symptoms based on NHLBI guidelines

Exclusion criteria: career unable to speak and understand English, no access to a working phone for follow-up surveys, plan to leave the school district within 6 months;any other significant medical con- 
NCT01175434 (Continued)

ditions, including congenital heart disease, cystic fibrosis or other chronic lung disease, that could interfere with assessment of asthma-related measures

Percentage withdrawn: $2 \%$ from the intervention group and $0 \%$ from the usual care group

Other allowed medication: not specifically reported; assumed children continued with usual medication

\begin{abstract}
Interventions Intervention summary: systematic Web-based screening to assess children's asthma using guideline-based symptom questions along with an algorithm to compute NHLBI severity or control classification; report of generation and electronic communication with primary care provider for authorisation of directly observed therapy with preventive asthma medications through school; prescription of guideline-based preventive medications purchased through the child's health insurance and delivered to schools and children's homes by a local pharmacy; directly observed administration of medications at school by a school nurse or health aide; and systematic reassessment of symptoms using the same system, with guideline-based adjustments to therapy as needed
\end{abstract}

Control summary: Similar to children receiving the intervention, children in the usual care group were screened for eligibility with the online screening tool at the beginning of the school year, but reports were not sent to their primary care provider and directly observed therapy was not implemented at school

Complex intervention: yes

Outcomes

Outcomes measured: feasibility; mean symptom-free days over 2 weeks, averaged over the study period; numbers of days and nights with symptoms; activity limitations; rescue medication use; school absenteeism; parent sleep interruption; change in family plans due to the child's asthma over the prior 2 weeks; Pediatric Asthma Caregiver's Quality of Life Questionnaire (PACQLQ); utilisation of healthcare services (office, ED visits, hospitalisations and non-urgent visits for asthma care); fractional exhaled nitric oxide

Adherence calculation: recorded as part of feasibility assessment only in children randomised to the intervention arm

Notes

Type of publication: peer-reviewed journal article

Funding: funded by the National Heart, Lung, and Blood Institute of the National Institutes of Health (RC1HL099432)

\title{
Risk of bias
}

\begin{tabular}{lll}
\hline Bias & Authors' judgement & Support for judgement \\
\hline $\begin{array}{l}\text { Random sequence genera- } \\
\text { tion (selection bias) }\end{array}$ & Low risk & $\begin{array}{l}\text { Randomisation was stratified by use of a preventive asthma medication at } \\
\text { baseline. A permutated block design was used to ensure an equal balance of } \\
\text { children in each group over time. The randomisation scheme was indepen- } \\
\text { dently developed by the Biostatistics Center }\end{array}$ \\
\end{tabular}

\begin{tabular}{|c|c|c|}
\hline $\begin{array}{l}\text { Allocation concealment } \\
\text { (selection bias) }\end{array}$ & Low risk & $\begin{array}{l}\text { The randomisation scheme was independently developed by the Biostatistics } \\
\text { Center; the interviewer called the Study Co-ordinator, who provided the par- } \\
\text { ticipant's ID number and treatment assignment }\end{array}$ \\
\hline $\begin{array}{l}\text { Blinding of participants } \\
\text { and personnel (perfor- } \\
\text { mance bias) } \\
\text { All outcomes }\end{array}$ & High risk & $\begin{array}{l}\text { It was not possible to blind participants and personnel to group allocation. Al- } \\
\text { though some outcomes may be more objective (such as hospitalisations), oth- } \\
\text { er outcomes such as unscheduled visits and patient-reported outcomes (e.g. } \\
\text { quality of life) may have been affected by participant (or career) knowledge of } \\
\text { group allocation }\end{array}$ \\
\hline
\end{tabular}

Blinding of outcome as- High risk sessment (detection bias) All outcomes
Although the trial reports that "all follow up data were collected by a research group blinded to the child's group allocation" for outcomes such as quality of 


$\begin{array}{ll}\begin{array}{l}\text { Incomplete outcome data } \\ \text { (attrition bias) }\end{array} & \text { Low risk } \\ \text { All outcomes } & \begin{array}{l}\text { Only } 1 \text { participant from the intervention group was lost to follow-up before } \\ \text { starting the intervention. The remainder were analysed in the groups to which } \\ \text { they were randomised }\end{array}\end{array}$

\begin{tabular}{lll}
\hline $\begin{array}{l}\text { Selective reporting (re- } \\
\text { porting bias) }\end{array}$ & High risk & $\begin{array}{l}\text { Prospectively registered trial (NCT01175434); however, peer-reviewed publi- } \\
\text { cation reports outcomes not prespecified (e.g. quality of life). Unclear if other } \\
\text { outcomes of interest (such as asthma control) may have been measured but } \\
\text { not reported }\end{array}$ \\
\hline Other bias & Low risk & None noted \\
\hline
\end{tabular}

\section{NCT01714141}

\begin{tabular}{ll}
\hline Methods & Design: open-label, parallel-group randomised controlled trial \\
& Duration: 13 weeks \\
& Setting: an urban university and an affiliated medical centre, Detroit. USA \\
& Trial registration: not reported \\
\hline Participants & $\begin{array}{l}\text { Population: } 49 \text { young adults with asthma randomised to multi-component, technology-based inter- } \\
\text { vention }(n=25) \text { or asthma education }(n=24)\end{array}$
\end{tabular}

Age: 18 to 29 years; mean age (SD) in the intervention group 21.8 (4) years and in the control group 23.1 (3.4) years

Baseline asthma severity: intervention group: asthma exacerbations in last month mean (SD) 1.8 (2.0), ACT mean (SD) 14.0 (3.1), $\mathrm{FEV}_{1}$ mean (SD) 80.0\% (21.6). Control group: asthma exacerbations in last month mean (SD) 2.4 (4.6), ACT mean (SD) 14.4 (3.1), $\mathrm{FEV}_{1}$ mean (SD) 80.4\% (15.7)

Inclusion criteria: 18 to 29 years old, African American with diagnosis of persistent asthma, prescribed a controller medication. Individuals also had to have access to a cell phone with texting capability and to report $<80 \%$ adherence in the past 30 days and score $\leq 19$ on the ACT

Exclusion criteria: pregnancy, inability to understand written or spoken English, another serious medical condition requiring regular medication, active psychiatric disorder that would interfere with study participation

Percentage withdrawn: $8 \%$ from the intervention group and $4 \%$ from the usual care group

Other allowed medication: not reported

Interventions

Intervention summary: Intervention consisted of 2 "Computerized Intervention Authoring Software" (CIAS)-delivered sessions with personalised, daily text messaged reminders to take medication delivered between these sessions. "Ecological Momentary Assessment" (EMA) via text messaging was conducted before the first intervention session to gather real-time data on participants' medication adherence and asthma symptoms. These data were used to tailor the intervention session for each participant

Control summary: Control participants completed CIAS-delivered asthma education matched for length, location and method of delivery of the intervention session. Control session was delivered by the avatar "Peedy the parrot" and included interactive features such as quizzes and responses to poll questions. Content focused on facts and myths about asthma, control of environmental factors and pharmacological management. Control participants received text messages between sessions via CareSpeak, but message content was the same for all participants and contained general facts about 
NCT01714141 (Continued)

asthma. Control participants also received 7 days of EMA before the first session, but data were not used to tailor the session

\section{Complex intervention: no}

Outcomes

Outcomes measured: adherence, asthma control (ACT), lung function ( $\left.F E V_{1}\right)$, participant satisfaction

Adherence calculation: calculated from self-reported number of doses missed compared with prescribed doses

$\begin{array}{ll}\text { Notes } & \text { Type of publication: single peer-reviewed journal article } \\ \text { Funding: supported by a grant from the National Institutes of Health (NHLBI, 1R34HL107664-01A1 } \\ \text { (K.K.M.)) }\end{array}$

\section{Risk of bias}

\begin{tabular}{lll}
\hline Bias & Authors' judgement & Support for judgement \\
\hline $\begin{array}{l}\text { Random sequence genera- } \\
\text { tion (selection bias) }\end{array}$ & $\begin{array}{l}\text { Low risk } \\
\text { ized them to receive either the intervention ( } \mathrm{n}=25) \text { or control }(\mathrm{n}=24) "\end{array}$ & $\begin{array}{l}\text { Of note is a baseline imbalance in males and females with fewer males in the } \\
\text { control arm, but this is more likely to be the result of small numbers in the trial } \\
\text { than failure of randomisation }\end{array}$
\end{tabular}

\begin{tabular}{|c|c|c|}
\hline $\begin{array}{l}\text { Allocation concealment } \\
\text { (selection bias) }\end{array}$ & Low risk & $\begin{array}{l}\text { "After completing the questionnaires, the computer automatically random- } \\
\text { ized them to receive either the intervention }(n=25) \text { or control }(n=24) "\end{array}$ \\
\hline
\end{tabular}

\begin{tabular}{|c|c|c|}
\hline $\begin{array}{l}\text { Blinding of participants } \\
\text { and personnel (perfor- } \\
\text { mance bias) } \\
\text { All outcomes }\end{array}$ & High risk & Participants and personnel were not blinded to group allocation \\
\hline $\begin{array}{l}\text { Blinding of outcome as- } \\
\text { sessment (detection bias) } \\
\text { All outcomes }\end{array}$ & High risk & $\begin{array}{l}\text { Blinding of outcome assessors is not described. In addition, for many out- } \\
\text { comes in this trial (self-reported adherence, ACT, etc.), the participant is the } \\
\text { outcome assessor; therefore, we judge this study to be at high risk of bias }\end{array}$ \\
\hline $\begin{array}{l}\text { Incomplete outcome data } \\
\text { (attrition bias) } \\
\text { All outcomes }\end{array}$ & Low risk & Low and balanced drop-out $(<10 \%)$ in both arms \\
\hline $\begin{array}{l}\text { Selective reporting (re- } \\
\text { porting bias) }\end{array}$ & Unclear risk & $\begin{array}{l}\text { No prospective trial registration identified, but all planned outcomes clearly } \\
\text { reported }\end{array}$ \\
\hline Other bias & Low risk & None noted \\
\hline
\end{tabular}

\section{NCT02413528}

Methods Design: open-label, parallel-group randomised controlled trial

Duration: 12 weeks

Setting: 1 university centre in New York. USA

Trial registration: NCT02413528 
NCT02413528 (Continued)

Participants

Population: 12 adolescents with asthma planned to be randomised to adherence monitoring app and sensor or standard care with monitoring via sensor

Age: 11 to 19 years

Baseline asthma severity: not reported

Inclusion criteria: asthma diagnosis, currently on a daily controller HFA medication for asthma, English-speaking, access to a smartphone or tablet

Exclusion criteria: pregnancy, foster care, emancipated minor

Percentage withdrawn: not applicable

Other allowed medication: not reported

Interventions

Intervention summary: Participants would have been given an inhaler sensor to monitor medication use and a mobile phone application that would send them reminders and provide an opportunity to see their own medication use and win incentives for adherence

Control summary: Participants would have been given an inhaler sensor to monitor medication use and a sham version of the mobile app that would not include reminders or incentives

Complex intervention: no

Outcomes Outcomes measured: real-time medication adherence; asthma control (ACT)

Adherence calculation: not reported

Notes Type of publication: trial registration only

Funding: CoheroHealth

NB: Study terminated owing to "wireless connectivity challenges with device and mobile app"

\section{Risk of bias}

\begin{tabular}{lll}
\hline Bias & Authors' judgement & Support for judgement \\
\hline $\begin{array}{l}\text { Random sequence genera- } \\
\text { tion (selection bias) }\end{array}$ & Unclear risk & Described as "randomised" on NCT record - but no further details \\
\hline $\begin{array}{l}\text { Allocation concealment } \\
\text { (selection bias) }\end{array}$ & Unclear risk & No details \\
\hline
\end{tabular}

Blinding of participants High risk Described as open-label but minimal details given
and personnel (perfor-
mance bias)
All outcomes

\begin{tabular}{|c|c|c|}
\hline $\begin{array}{l}\text { Blinding of outcome as- } \\
\text { sessment (detection bias) } \\
\text { All outcomes }\end{array}$ & Unclear risk & Described as open-label but minimal details given \\
\hline
\end{tabular}

\begin{tabular}{lll}
\hline $\begin{array}{l}\text { Incomplete outcome data } \\
\text { (attrition bias) } \\
\text { All outcomes }\end{array}$ & Unclear risk & $\begin{array}{l}\text { Unable to assess as no study results posted; terminated owing to "wireless } \\
\text { connectivity challenges with device and mobile app" }\end{array}$ \\
\hline $\begin{array}{l}\text { Selective reporting (re- } \\
\text { porting bias) }\end{array}$ & Unclear risk & Unable to assess as no study results posted \\
\hline
\end{tabular}


NCT02413528 (Continued)

Other bias Low risk None noted

Methods Design: open-label, parallel-group randomised controlled trial

Duration: 1 year

Setting: hospital clinics in Sheffield or Rotherham

Trial registration: NCT02451709

Participants

Population: 90 children with asthma randomised to electronic adherence monitoring with reminders and feedback $(n=47)$ or monitoring with no reminders or feedback $(n=43)$

Age: 6 to16 years of age; mean age (SD) in the intervention group $10.4(2.9)$ years and in the control group $10.2(2.9)$ years

Baseline asthma severity: poorly controlled asthma; BTS level 3 or above

Inclusion criteria: Participants had to be taking regular inhaled steroids, with no change in their medication in the last month and an ACQ score $\geq 1.5$, indicating poorly controlled asthma. Electronic monitoring devices available for this trial were compatible only with Seretide or Symbicort inhalers. Therefore, all participants were at BTS level 3 at the start of the trial

Exclusion criteria: could not speak English, had another significant chronic condition

Percentage withdrawn: 15\% from the intervention group and 9\% from the control group, but all randomised participants were included in the primary ITT analysis, with the exception of 1 control group participant who was withdrawn after randomisation for not meeting eligibility criteria

Other allowed medication: not reported

Intervention summary: Adherence was electronically monitored with regular feedback provided at clinic visits, during which the importance of adherence was emphasised and personalised strategies for improvement were devised. Devices also played medication reminder alarms. Alarms sounded for 5 seconds, every minute for 15 minutes (or until actuation), if the inhaler had not been actuated within the previous 6 hours of the specified time. Devices were locked to prevent tampering

Control summary: Control participants had the same EMDs attached to their regular inhaler and were told that the devices monitored how often inhalers were taken, but that these data would not be reviewed. Participants were seen in their standard asthma clinic, and data were downloaded but were not reviewed. Alarms were disabled, and the devices locked

Complex intervention: yes

Outcomes

Outcomes measured: adherence, change in $\mathrm{ACQ}, \mathrm{FEV} / \mathrm{\%}$, number of unplanned attendances at general practitioner (GP)/emergency department (ED) for asthma since last visit (as reported by parents), number of courses of oral steroids

required, number of days off school due to asthma, use of beta-agonists in the past week, BTS level of asthma therapy, mini PAQLQ

Adherence calculation: calculated for each 3-month period, both morning and afternoon doses, and recorded as a percentage. This was calculated as number of doses actually taken/number of doses prescribed $\times 100$

Notes

Type of publication: peer-reviewed journal article

Funding: Sheffield Children's Hospital Charity 
NCT02451709 (Continued)

Risk of bias

\begin{tabular}{|c|c|c|}
\hline Bias & Authors' judgement & Support for judgement \\
\hline $\begin{array}{l}\text { Random sequence genera- } \\
\text { tion (selection bias) }\end{array}$ & Low risk & $\begin{array}{l}\text { Participants were randomised via permuted block randomisation, with alloca- } \\
\text { tion of } 1: 1 \text { created from a computer-generated random number sequence }\end{array}$ \\
\hline $\begin{array}{l}\text { Allocation concealment } \\
\text { (selection bias) }\end{array}$ & Low risk & $\begin{array}{l}\text { Allocation of participants involved phoning the independent holder of the ran- } \\
\text { domisation code }\end{array}$ \\
\hline $\begin{array}{l}\text { Blinding of participants } \\
\text { and personnel (perfor- } \\
\text { mance bias) } \\
\text { All outcomes }\end{array}$ & High risk & $\begin{array}{l}\text { Owing to the nature of the intervention, neither participants nor study team } \\
\text { members were blinded. Although adherence, lung function and oral steroid } \\
\text { use might be considered objective outcomes, potential for performance bias } \\
\text { remains for outcomes such as AQLQ and ACQ }\end{array}$ \\
\hline $\begin{array}{l}\text { Blinding of outcome as- } \\
\text { sessment (detection bias) } \\
\text { All outcomes }\end{array}$ & High risk & $\begin{array}{l}\text { Blinding of outcome assessors is not described; although some outcomes are } \\
\text { relatively objective and are not prone to detection bias (adherence, lung func- } \\
\text { tion and oral corticosteroid use), others such as ACQ and AQLQ involve the un- } \\
\text { blinded participant as the outcome assessor }\end{array}$ \\
\hline $\begin{array}{l}\text { Incomplete outcome data } \\
\text { (attrition bias) } \\
\text { All outcomes }\end{array}$ & Low risk & $\begin{array}{l}\text { Less than } 15 \% \text { drop-out in both arms; all but } 1 \text { participant included in the in- } \\
\text { tention-to-treat primary analysis }\end{array}$ \\
\hline $\begin{array}{l}\text { Selective reporting (re- } \\
\text { porting bias) }\end{array}$ & High risk & $\begin{array}{l}\text { Prospectively registered trial (NCT02451709); all outcomes specified in the } \\
\text { methods are mentioned in the paper, although some non-numerically (e.g. mi- } \\
\text { ni-PAQLQ, BMQ, SABA use, IPQ), so could not be included in the meta-analysis }\end{array}$ \\
\hline Other bias & Low risk & None noted \\
\hline
\end{tabular}

Onyirimba 2003

Mesign: single-blind, parallel-group randomised controlled trial
Duration: 10 weeks

Setting: 1 asthma centre at Saint Francis Hospital, Connecticut. USA

Trial registration: not reported

Participants

Population: 30 adults with asthma randomised to adherence monitoring and education or monitoring without feedback ( $\mathrm{n}$ randomised to each arm not reported)

Age: over 18 years of age; mean (SD) age in the intervention group 45 (11) years and in the control group 53 (14) years

Baseline asthma severity: intervention group: mean $\mathrm{FEV}_{1} 78 \%$ predicted; mean (SD) ED visits in the past year 2.3 (2.4); 80\% on LABA; mean (SD) AQLQ score 4.34 (1.62). Control group: mean FEV $163 \%$ predicted; mean (SD) ED visits in the past year 1.0 (0.8); 100\% on LABA; mean (SD) AQLQ score 3.75 (1.39)

Inclusion criteria: Adults with moderate to severe asthma were considered for the study if they met all of the following inclusion criteria: referral to the Asthma Center at Saint Francis Hospital and Medical Center; 1 or more markers of low socioeconomic status (Medicaid or no insurance, family income $<\$ 20,000$, less than a high school education); prebronchodilator $\mathrm{FEV}_{1}<80 \%$ of predicted and $15 \%$ predicted greater reversibility after bronchodilator administration; and regular use of inhaled steroids and willingness to change the schedule, if necessary, to twice-daily dosing

Exclusion criteria: not reported 
Percentage withdrawn: 10 participants in the intervention group and 9 in the control groups completed the trial. Numbers randomised to each arm not reported

Other allowed medication: Use of long-acting oral or inhaled bronchodilators, theophylline and oral corticosteroid was permissible

Interventions

Intervention summary: Intensive asthma education and management was provided by a nurse and/or respiratory therapist over approximately a 3-week period, with follow-up for 7 additional weeks. Content was based on NAEPP guidelines covering goals of therapy, signs of worsening asthma, types of medications, importance of prophylactic medication, proper MDI technique, use of PEF meter, patient satisfaction and QOL and environmental evaluation and education. Data from MDI Chronologs were downloaded at each visit and were reviewed with the clinician, who emphasised techniques or strategies to improve adherence when necessary, according to type and timing of non-adherence

Control summary: Control group visited to complete outcome measures, and data were downloaded from Chronologs, but no education or adherence advice was given

Complex intervention: yes

Outcomes Outcomes measured: adherence to ICS, albuterol use (mean actuations per 24 hours for each week), AQLQ, FEV 1

Adherence calculation: overall mean weekly adherence and percentage of days with overuse

Notes

Type of publication: single peer-reviewed journal article

Funding: in part by an award from the University of Connecticut Health Center Research Advisory Committee

\section{Risk of bias}

\begin{tabular}{|c|c|c|}
\hline Bias & Authors' judgement & Support for judgement \\
\hline $\begin{array}{l}\text { Random sequence genera- } \\
\text { tion (selection bias) }\end{array}$ & Unclear risk & "patients were randomized into 1 of 2 groups" - no further details \\
\hline $\begin{array}{l}\text { Allocation concealment } \\
\text { (selection bias) }\end{array}$ & Unclear risk & No details \\
\hline $\begin{array}{l}\text { Blinding of participants } \\
\text { and personnel (perfor- } \\
\text { mance bias) }\end{array}$ & High risk & $\begin{array}{l}\text { "Patients were told that these instruments recorded the time and date of each } \\
\text { MDI actuation but were blinded to the study hypothesis" }\end{array}$ \\
\hline All outcomes & & $\begin{array}{l}\text { Although participants were blinded to the study hypothesis, knowledge of } \\
\text { group allocation and the fact that adherence was being monitored may have } \\
\text { altered adherence behaviour beyond the effect intended by trialists }\end{array}$ \\
\hline $\begin{array}{l}\text { Blinding of outcome as- } \\
\text { sessment (detection bias) } \\
\text { All outcomes }\end{array}$ & High risk & $\begin{array}{l}\text { Although trialists went to some lengths to blind outcome assessors ("For the } \\
\text { initial period, patients met at the first visit and three subsequent visits with a } \\
\text { nurse and/or respiratory therapist blinded to the patients' group"), for AQLQ } \\
\text { the participant is the outcome assessor; therefore, such outcomes are present- } \\
\text { ed at risk of detection bias }\end{array}$ \\
\hline $\begin{array}{l}\text { Incomplete outcome data } \\
\text { (attrition bias) } \\
\text { All outcomes }\end{array}$ & High risk & $\begin{array}{l}10 / 30 \text { participants did not complete the study; it is not clear how many were } \\
\text { randomised to each group or whether reasons for dropping out were similar } \\
\text { between groups }\end{array}$ \\
\hline $\begin{array}{l}\text { Selective reporting (re- } \\
\text { porting bias) }\end{array}$ & Unclear risk & $\begin{array}{l}\text { No prospective trial registration identified, although all outcomes listed in } \\
\text { methods were reported in text/tables }\end{array}$ \\
\hline Other bias & Low risk & None noted \\
\hline
\end{tabular}


Duration: 12 weeks

Setting: 143 sites in the UK

Trial registration: not reported

Participants

Population: 1233 participants with asthma randomised to intervention (once-daily ICS) $(n=611)$ or control (twice-daily ICS) ( $\mathrm{n}=622)$

Age: 12 years of age and older; mean (SD not reported) age in the adherence group 50.9 years and in the control group 50.9 years

Baseline asthma severity: intervention group: mean duration of asthma 16.4 years; control group: mean duration of asthma 16.2 years

Inclusion criteria: treated with beclomethasone dipropionate (BDP) hydrofluoroalkane $(\leq 500 \mu \mathrm{g} / \mathrm{d})$ or BDP chlorofluorocarbon $(\leq 1000 \mu \mathrm{g} / \mathrm{d}$ ) for $\geq 12$ weeks, with stable BDP dosing regimen for $\geq 4$ weeks immediately before study entry. Inclusion of patients who used BDP as their prior ICS therapy was justified because BDP was the ICS prescribed most commonly in the UK at the time the study was conducted, thereby providing a patient population as large and as homogeneously treated as possible. Eligible patients had no clinically significant disease that would interfere with study evaluation, and female patients of childbearing potential were required to use medically accepted birth control

Exclusion criteria: ventilator support required for respiratory failure due to asthma within the previous 5 years, hospitalisation within the previous 3 months due to asthma

Percentage withdrawn: $16.5 \%$ from the adherence group and $15.3 \%$ from the control group

Other allowed medication: not reported

Interventions

Intervention summary: mometasone furoate (MF) DPI $400 \mu \mathrm{g}$ once daily in the evening. Participants were instructed in inhaler use and peak flow measurement to demonstrate proficiency and received salbutamol for rescue medication. They were also given diary cards and were instructed to follow an asthma action plan formulated at their first visit

Control summary: mometasone furoate DPI $200 \mu \mathrm{g}$ twice daily. Participants were instructed in inhaler use and peak flow measurement to demonstrate proficiency and received salbutamol for rescue medication. They were given diary cards and were instructed to follow an asthma action plan formulated at their first visit

\section{Complex intervention: no}

Outcomes measured: Primary outcome was adherence measured by the counter. Secondary outcomes included self-report adherence, physician's assessment of response, quality of life on the Integrated Therapeutics Group Asthma Short Form (ITG-ASF) (week 12), utilisation of healthcare resources and number of days missed from work or school. Adverse events were recorded at all visits, and an abbreviated physical exam was performed at visits 1 and 4. Evaluation of asthma worsening was performed at all visits, defined as increased use of rescue medication ( $>12$ inhalations on 2 consecutive days), a decrease in peak flow $>25 \%$ on 2 consecutive days or clinical asthma exacerbations (unscheduled doctor's visit, hospitalisation, ER visit and/or use of additional asthma medications other than short-acting beta-agonists)

Adherence calculation: Adherence was calculated as the number of administered doses (as determined by device counter number) times 100 divided by the number of scheduled doses. Data were not included for analysis if invalid (e.g. gross misuse of device, missing treatment end dates, device malfunction) 
Price 2010 (Continued)

Funding: Schering Corp., a division of Merck \& Co.

\section{Risk of bias}

Bias Authors' judgement Support for judgement

Random sequence genera- Unclear risk tion (selection bias)

"Patients were randomized to receive either MF-DPI $400 \mu \mathrm{g}$ once-daily in the evening or MF DPI $200 \mu \mathrm{g}$ twice-daily from inhalers measuring $220 \mu \mathrm{g} /$ actuation and delivering $200 \mu \mathrm{g} /$ inhalation"

\begin{tabular}{lll}
\hline $\begin{array}{l}\text { Allocation concealment } \\
\text { (selection bias) }\end{array}$ & Unclear risk & No details \\
\hline $\begin{array}{l}\text { Blinding of participants } \\
\text { and personnel (perfor- } \\
\text { mance bias) }\end{array}$ & High risk & $\begin{array}{l}\text { Trial is described as open-label; although adherence was measured objective- } \\
\text { ly with a device counter, knowledge of group allocation and monitoring may } \\
\text { have affected adherence behaviour. In addition, patient-reported outcomes, } \\
\text { such as HRQOL, are susceptible to risk of performance bias }\end{array}$ \\
\hline
\end{tabular}

$\begin{array}{lll}\begin{array}{l}\text { Blinding of outcome as- } \\ \text { sessment (detection bias) }\end{array} & \text { High risk } & \begin{array}{l}\text { Trial is described as open-label; although adherence was measured objective- } \\ \text { ly with a device counter, knowledge of group allocation may have affected pa- } \\ \text { All outcomes }\end{array} \\ \begin{array}{l}\text { tient-reported outcomes, such as HRQOL, for which the participant is the out- } \\ \text { come assessor }\end{array}\end{array}$

\begin{tabular}{ll}
\hline $\begin{array}{l}\text { Incomplete outcome data } \\
\text { (attrition bias) }\end{array}$ & Low risk \\
All outcomes & Drop-out $<20 \%$ in both groups, and reasons for discontinuation appear similar \\
\end{tabular}

All outcomes

\begin{tabular}{lll}
\hline $\begin{array}{l}\text { Selective reporting (re- } \\
\text { porting bias) }\end{array}$ & Unclear risk & $\begin{array}{l}\text { No prospective trial registration identified, although all outcomes listed in } \\
\text { methods were reported in text/tables. Asthma worsening was not reported as } \\
\text { planned }\end{array}$ \\
\hline Other bias & Low risk & None noted \\
\hline
\end{tabular}

Strandbygaard 2010

Design: open-label, parallel-group randomised controlled trial
Duration: 12 weeks
Setting: 1 university hospital. Denmark
Trial registration: not reported

Participants

Population: 26 adults with asthma randomised to SMS adherence reminders $(n=12)$ or usual care (no reminders) $(n=14)$

Age: 18 to 45 years of age; mean (SD not reported) age in the intervention group 34.4 years and in the control group 30.7 years

Baseline asthma severity: among the randomised participants: 8 (30.8\%) were categorised as mild persistent (GINA 2), $16(61.5 \%)$ as moderate persistent (GINA 3) and $2(7.7 \%)$ as severe persistent (GINA 4). Before enrolment into the study, 9 participants (34.6\%) had used SABA as monotherapy, 9 (34.6\%) had used ICS (alone or in combination with LABA and/or SABA) and the remaining $8(30.8 \%)$ had not used any treatment at all over the last 3 months

Inclusion criteria: diagnosis of asthma based on clinical history and daily symptoms, age between 18 and 45 years, positive methacholine challenge test with PD20 $\leq 4 \mathrm{mmol}$ 
Strandbygaard 2010 (Continued)

Exclusion criteria: other medical comorbidities, smoking history of more than 10 pack-years

Percentage withdrawn: $17 \%$ from the intervention group and $14 \%$ from the control group

Other allowed medication: not reported

Interventions

Intervention summary: 4-week run-in on LABA/ICS, then 12 weeks of daily SMS reminders. SMS reminder was sent daily at $10 \mathrm{AM}$ on cell phone over the following 8 weeks. All enrolled participants received a thorough education concerning the necessity of ICS treatment in asthma, and all were provided with knowledge of disease mechanisms and correct inhaler technique

Control summary: 4-week run-in on LABA/ICS and no reminders. All enrolled participants received a thorough education concerning the necessity of ICS treatment in asthma, and all were provided with knowledge of disease mechanisms and correct inhaler technique

\section{Complex intervention: no}

Outcomes

Outcomes measured: mean rate of adherence to asthma treatment, reimbursement for asthma medication, change in exhaled nitric oxide levels, lung function, airway responsiveness

Adherence calculation: Adherence rate was registered as the percentage of medicine actually taken by participants, calculated from medicine dose count on the Discos Seretide and number of days between clinical examinations: ( 60 dose-count) $/ 2 \times$ days $\times 100 \%$

Notes Type of publication: single peer-reviewed journal article

Funding: GlaxoSmithKline provided a financial contribution to the service on the Internet including the short message service provided by CIM mobility

NB: Only $34.6 \%$ of people had taken ICS in the last 3 months, and $30.8 \%$ no treatment at all, but everyone was put on Seretide at the start of the study

\section{Risk of bias}

\begin{tabular}{|c|c|c|}
\hline Bias & Authors' judgement & Support for judgement \\
\hline $\begin{array}{l}\text { Random sequence genera- } \\
\text { tion (selection bias) }\end{array}$ & Low risk & $\begin{array}{l}\text { "Randomisation was done by means of automatic computer generation of ran- } \\
\text { domisation numbers in blocks of six" }\end{array}$ \\
\hline $\begin{array}{l}\text { Allocation concealment } \\
\text { (selection bias) }\end{array}$ & Unclear risk & No details \\
\hline $\begin{array}{l}\text { Blinding of participants } \\
\text { and personnel (perfor- } \\
\text { mance bias) } \\
\text { All outcomes }\end{array}$ & High risk & $\begin{array}{l}\text { Trial is not described as blinded; although adherence was measured objective- } \\
\text { ly with a device counter, knowledge of group allocation and monitoring may } \\
\text { have affected adherence behaviour. In addition, patient-reported outcomes, } \\
\text { such as ACQ and AQLQ, are susceptible to risk of performance bias }\end{array}$ \\
\hline $\begin{array}{l}\text { Blinding of outcome as- } \\
\text { sessment (detection bias) } \\
\text { All outcomes }\end{array}$ & High risk & $\begin{array}{l}\text { Trial is not described as blinded; although adherence was measured objective- } \\
\text { ly with a device counter, knowledge of group allocation affected patient-re- } \\
\text { ported outcomes, such as ACQ and AQLQ, for which the participant is the out- } \\
\text { come assessor }\end{array}$ \\
\hline $\begin{array}{l}\text { Incomplete outcome data } \\
\text { (attrition bias) } \\
\text { All outcomes }\end{array}$ & Unclear risk & $\begin{array}{l}\text { Drop-out }<20 \% \text { in both groups, but reasons for discontinuation not given and } \\
\text { no participant flow diagram presented. Also unclear how many participants } \\
\text { are included in the primary analysis, as this is presented in the text and not in a } \\
\text { table }\end{array}$ \\
\hline $\begin{array}{l}\text { Selective reporting (re- } \\
\text { porting bias) }\end{array}$ & Unclear risk & $\begin{array}{l}\text { No prospective trial registration identified, although all outcomes listed in } \\
\text { methods reported in text/tables }\end{array}$ \\
\hline
\end{tabular}


Strandbygaard 2010 (Continued)

Other bias Low risk None noted

Ulrik 2009

Methods Design: open-label, parallel-group randomised controlled trial

Duration: 12 weeks

Setting: 29 GSK investigational sites in Denmark and Switzerland

Trial registration: NCT00351143; EudraCT no. 2005-0003374-48; ACE104325

Participants

Population: 274 adults with asthma randomised to adherence education and study medication ( $\mathrm{n}=$ 140) or study medication only $(n=134)$

Age: over 18 years of age; mean (SD) age in the intervention group 40.5 (13.9) years and in the control group 38.7 (14.6) years

Baseline asthma severity: Across the 2 groups, most randomised participants had mild persistent (51\%) or moderate persistent (34\%) asthma

Inclusion criteria: $\geq 18$ years of age; diagnosis of persistent asthma; treatment with at least $250 \mathrm{mg}$ fluticasone propionate bid (or equivalent for other ICS) 4 weeks before the study and/or LABA bid or monotherapy with a short-acting beta ${ }_{2}$-agonist; ability to comply with use of the Asthma Monitor 2 (AM2) and the Asthma Quality of Life Questionnaire (AQLQ). Participants who had an exacerbation during the study period were allowed to remain in the study

Exclusion criteria: known or suspected chronic obstructive pulmonary disease (COPD); pregnancy or lactation; smoking history > 10 pack-years; clinical or laboratory evidence of serious uncontrolled systemic disease; microbiologically verified upper or lower respiratory tract infection within 1 month before screening visit; acute asthma exacerbation requiring hospitalisation/emergency department treatment/treatment with systemic corticosteroids within 3 months before screening visit; furthermore, for entry into treatment period 1 and treatment period 2: changes in asthma medication, including treatment with systemic corticosteroid, during the preceding period; more than 1 week of guideline-defined asthma control before baseline visit/during treatment period 1 ; achieving total control in treatment period 1 (participants randomised at end of treatment period 1 and before entry into treatment period 2 )

Percentage withdrawn: not reported

Other allowed medication: Those who had been treated with oral corticosteroids in the preceding 3 months were excluded from enrolling, and those who needed a change in asthma medication during period 1 were excluded from period 2

Intervention summary: given salmeterol/fluticasone propionate $50 / 250 \mathrm{mg}$ (Diskus ${ }^{\circledR}$ ) bid and salbutamol prn for 12 weeks before randomisation (period 1). Then for 12 weeks (period 2), those who did not achieve total control were randomised and were given 5 patient-centred teaching modules that included education about asthma, risk factors, prognosis, expectations of treatment, correct ways of taking controller and rescue medication and mnemonics as an aid for optimal dosing/timing of medication. Based on both written and oral information. Coaches were trained to use the standardised material at all centres

Control summary: given salmeterol/fluticasone propionate $50 / 250 \mathrm{mg}$ (Diskus ${ }^{\circledR}$ ) bid and salbutamol prn for 12 weeks before randomisation (period 1). Then for 12 weeks (period 2), those who did not achieve total control were randomised and continued with the same study medication

Complex intervention: yes

Outcomes

Outcomes measured: total asthma control; PEF; symptom scores; rescue medication use; number of nights awakenings due to asthma; adverse events; quality of life (AQLQ); medication compliance; 
Ulrik 2009 (Continued)

asthma severity; adverse events (including exacerbations, emergency visits and hospitalisations); vital signs. The asthma monitor AM2 medical device was used to collect the following data on a daily basis: $\mathrm{FEV}_{1}$; pre-dose morning PEF; symptoms; use of rescue medication; night-time awakenings; exacerbations; change of medication due to side effects and emergency doctor visits

Adherence calculation: Treatment compliance was assessed by counting the number of doses in the returned investigational product

Type of publication: single peer-reviewed journal article
Funding: GlaxoSmithKline
NB: Period 2 of interest. During study period 1, all participants were treated with salmeterol/fluticas-
one $50 / 250$. Those who did not achieve total asthma control in treatment period 1 were randomised to
continued treatment with or without adherence education concomitantly for a further 12 weeks (peri-
od 2)

\section{Risk of bias}

\begin{tabular}{|c|c|c|}
\hline Bias & Authors' judgement & Support for judgement \\
\hline $\begin{array}{l}\text { Random sequence genera- } \\
\text { tion (selection bias) }\end{array}$ & Unclear risk & $\begin{array}{l}\text { "subjects who did not achieve total asthma control in treatment period } 1 \text { were } \\
\text { randomised to continued treatment with or without compliance enhancement } \\
\text { training concomitantly for a further } 12 \text { weeks" - no further details }\end{array}$ \\
\hline $\begin{array}{l}\text { Allocation concealment } \\
\text { (selection bias) }\end{array}$ & Unclear risk & No details \\
\hline $\begin{array}{l}\text { Blinding of participants } \\
\text { and personnel (perfor- } \\
\text { mance bias) } \\
\text { All outcomes }\end{array}$ & High risk & $\begin{array}{l}\text { Trial is described as open-label; although adherence was measured objective- } \\
\text { ly with a device counter, knowledge of group allocation and monitoring may } \\
\text { have affected adherence behaviour. In addition, patient-reported outcomes, } \\
\text { such as quality of life, are susceptible to risk of performance bias }\end{array}$ \\
\hline $\begin{array}{l}\text { Blinding of outcome as- } \\
\text { sessment (detection bias) } \\
\text { All outcomes }\end{array}$ & High risk & $\begin{array}{l}\text { Trial is described as open-label; although adherence was measured objective- } \\
\text { ly with a device counter, knowledge of group allocation and monitoring may } \\
\text { have affected patient-reported outcomes, such as quality of life, for which the } \\
\text { participant is the outcome assessor }\end{array}$ \\
\hline
\end{tabular}

Incomplete outcome data Unclear risk
(attrition bias)

All efficacy analyses were performed by intent-to-treat (ITT) analysis on all parAll outcomes ticipants with data entered into the database, who had received at least 1 single dose of trial medication in treatment period 2 (randomised portion of the trial); therefore, this was the population for analysis of the primary endpoint. Sensitivity analyses were performed for the per-protocol population for treatment period 2, which comprised all participants in the ITT-2 population who did not have major protocol violations. The safety population comprised all participants who had received at least 1 single dose of study medication. However, no flow diagram was presented and drop-out was not clearly reported

\begin{tabular}{lll}
$\begin{array}{l}\text { Selective reporting (re- } \\
\text { porting bias) }\end{array}$ & High risk & $\begin{array}{l}\text { Prospectively registered trial (NCT00351143; EudraCT no. 2005-0003374-48). } \\
\text { However, many outcomes of interest were not reported numerically, so could } \\
\text { not used in the meta-analysis }\end{array}$ \\
\hline Other bias & Low risk & None noted \\
\hline
\end{tabular}


Vasbinder 2015 E-MATIC

\begin{tabular}{ll}
\hline Methods & Design: open-label, parallel-group randomised controlled trial \\
Duration: 52 weeks \\
Setting: 5 outpatient clinics. The Netherlands \\
Trial registration: Netherlands Trial Register NTR2583 \\
Population: 219 children with asthma randomised to receive SMS adherence reminders ( $\mathrm{n}=108$ ) or no \\
reminders ( $=111)$ \\
Age: 4 to 11 years of age; mean (SD) age in the intervention group 7.8 (2.2) years and in the control \\
group 7.7 (2.1) years \\
Baseline asthma severity: intervention group: $39.8 \%$ had poorly controlled asthma (ACT); control \\
group: $36.5 \%$ \\
Inclusion criteria: 4 to 11 years of age at the start of the study; doctor-diagnosed asthma for at least 6 \\
months; ICS use for at least 3 months; use of a pMDI; use of fluticasone, fluticasone/salmeterol or be- \\
clomethasone; at least 1 parent/career with a mobile phone \\
Exclusion criteria: refusal to participate in the study \\
Percentage withdrawn: not reported \\
Other allowed medication: not reported
\end{tabular}

Interventions

Intervention summary: All children received an RTMM-device that registers time and date of administered ICS doses. Children in the intervention group received "time-tailored" text messages that were sent only when a dose was at risk of omission

Control summary: All children received an RTMM-device that registers time and date of administered ICS doses. Those in the control group do not receive such text messages

\section{Complex intervention: no}

Outcomes

Outcomes measured: adherence to ICS; asthma control (ACT); frequency of asthma exacerbations and use of healthcare services (pharmacy data checked for OCS use and health records); disease-specific quality of life; school/work absence; paediatric AQLQ; acceptance of e-monitoring; economic evaluation

Adherence calculation: proportion of all prescribed dosages taken by the child within a 6-hour time frame around planned time of inhalation (i.e. from 3 hours before until 3 hours after) calculated from RTMM data on ICS use, attached to the inhaler

Notes Type of publication: multiple peer-reviewed journal articles

Funding: supported by a non-conditional grant from The Netherlands Organisation for Health Research and Development (ZonMw, grand registration number 171101005). The study is also partially sponsored by the pharmaceutical company GlaxoSmithKline. The manufacturer of the RTMM devices, Evalan BV, partially sponsors the study by providing devices at cost price

\section{Risk of bias}

\begin{tabular}{lll}
\hline Bias & Authors' judgement & Support for judgement \\
\hline $\begin{array}{l}\text { Random sequence genera- } \\
\text { tion (selection bias) }\end{array}$ & Low risk & $\begin{array}{l}\text { "Computer-generated block randomisation was used per hospital with block } \\
\text { size of 16 patients" }\end{array}$ \\
\hline
\end{tabular}


Vasbinder 2015 E-MATIC (Continued)
Allocation concealment Low risk
"At registration at the RTMM software interface, children were automatically (selection bias) assigned to the intervention or control group" - suggests that allocation was concealed, as this was performed at an IT interface

\begin{tabular}{|c|c|c|}
\hline $\begin{array}{l}\text { Blinding of participants } \\
\text { and personnel (perfor- } \\
\text { mance bias) } \\
\text { All outcomes }\end{array}$ & High risk & $\begin{array}{l}\text { "Although physicians, researchers and patients were initially blinded for ran- } \\
\text { domisation, patients were generally unblinded shortly after the start of the } \\
\text { study period, when they found out whether they received SMS reminders or } \\
\text { not" }\end{array}$ \\
\hline
\end{tabular}

Knowledge about group allocation may have affected performance, especially in subjective measures such as PAQLQ and CACT

$\begin{array}{lll}\begin{array}{l}\text { Blinding of outcome as- } \\ \text { sessment (detection bias) }\end{array} & \text { High risk } & \begin{array}{l}\text { No blinding of outcome assessors described. Primary outcome - adherence - } \\ \text { measured objectively and not likely to be at risk of detection bias, but for other } \\ \text { All outcomes }\end{array} \\ \text { outcomes (such as PAQLQ and CACT), the unblinded participant/career is the } \\ \text { outcome assessor; therefore, these outcomes are at risk of bias }\end{array}$

Incomplete outcome data High risk
(attrition bias)

(attrition bias)

"Reasons why patients left the study prematurely were not systematically reg-

All outcomes istered", and the total number of people who did not complete the study and hence had to have their data imputed is not reported. The numbers in Figure 2 suggest very low retention of around $50 \%$ in each arm

\begin{tabular}{|c|c|c|}
\hline $\begin{array}{l}\text { Selective reporting (re- } \\
\text { porting bias) }\end{array}$ & Low risk & $\begin{array}{l}\text { Prospectively published protocol and all outcomes clearly reported in main } \\
\text { publication }\end{array}$ \\
\hline
\end{tabular}

Other bias Low risk None noted

ACQ: Asthma Control Questionnaire; ACT: Asthma Control Test; AE: asthma education; AQLQ: Asthma Quality of Life Questionnaire; BDP: beclomethasone dipropionate; BMQ: Beliefs about Medication Questionnaire; BTS/SIGN: British Thoracic Society/Scottish Intercollegiate Guidelines Network; CACT: Childhood Asthma Control Test; CBQ-20: Conflict Behaviour Questionnaire-20; Cl: confidence interval; COPD: chronic obstructive pulmonary disease; CSQ: Consumer Satisfaction Questionnaire; CVD: cardiovascular disease; DDD: Daily Defined Doses; DPI: dry powder inhaler; ED: emergency department; EMA: Ecological Momentary Assessment; EMD: electronic monitoring device; EPAC: episode of poor asthma control; $\mathrm{FEV}_{1}$ : forced expiratory volume in one second; FP: fluticasone propionate; FSI: Functional Severity Index; FVC: forced vital capacity; GINA: Global Initiative for Asthma; GP: general practitioner; GSK: GlaxoSmithKline; HADS: Hospital Anxiety and Depression Scale; HFA inhaler: hydrofluoroalkane inhaler; HMO: health maintenance organisation; HRQOL: health-related quality of life; ICS: inhaled corticosteroids; IPQ: Illness Perceptions Questionnaire; IQR: interquartile ratio; IRF: inhaler reminders and feedback; IT: information technology; ITT: intention-to-treat; IVR: interactive voice response; KAAM: Knowledge of Asthma and Asthma Medicine Questionnaire; KP: Kaiser Permanente; KPCO: Kaiser Permanente Colorado; KPH: Kaiser Permanente Hawaii; KPNW: Kaiser Permanente Northwest; LABA: long-acting beta ${ }_{2}$-agonists; MARS-A: Medication Adherence Report Scale; MD: mean difference; MDI: metered dose inhaler; MI: motivational interviewing; NAEPP: National Asthma Education and Prevention Program; NHLBI: National Heart, Lung, and Blood Institute; NS: not statistically significant; OCS: oral corticosteroid; PAD: personalised adherence discussion; PAQLQ: Paediatric Asthma Quality of Life Questionnaire; PDC: proportion of days covered; PedsQL: Paediatric Quality of Life Inventory; PEF: peak expiratory flow; pMDI: pressurised metered dose inhaler; PS: problem solving; QOL: quality of life; RTMM: real-time medication monitoring; SABA: short-acting beta ${ }_{2}$-agonists; SD: standard deviation; SF-36: Short Form-36; SMAQ: Simplified Medication Adherence Questionnaire; SMS: short message service/text message; SR: speech recognition; UC: usual care; URTI: upper respiratory tract infection; VAS: visual analogue scale

Characteristics of excluded studies [ordered by study ID]

\begin{tabular}{ll}
\hline Study & Reason for exclusion \\
\hline Armour 2007 & Adherence not primary focus \\
\hline Canino 2016 & Adherence not primary focus \\
\hline Coté 1997 & Adherence not primary focus \\
\hline
\end{tabular}




\begin{tabular}{|c|c|}
\hline Study & Reason for exclusion \\
\hline Dal Negro 2002 & Drug trial observing adherence \\
\hline Delaronde 2005 & Adherence not primary focus \\
\hline Demiralay 2002 & Adherence not primary focus \\
\hline Demiralay 2004 & Adherence not primary focus \\
\hline Fiks 2015 & Adherence not primary focus \\
\hline Fujita 2002 & Drug trial observing adherence \\
\hline Gallefoss 2002 & Adherence not primary focus \\
\hline Garcia-Cardenas 2013 & Adherence not primary focus \\
\hline Gerald 2012 & Drug trial observing adherence \\
\hline Goeman 2013 & Trial of tailored asthma education in older adults; adherence not primary focus \\
\hline Guenette 2015 & Wrong study design \\
\hline Holt 2004 & Wrong study design \\
\hline Iqbal 2004 & Wrong study design \\
\hline Janson 2003 & Adherence not primary focus \\
\hline Janson 2009 & Adherence not primary focus \\
\hline Jonasson 1999 & Drug trial observing adherence \\
\hline Jonasson 2000 & Drug trial observing adherence \\
\hline Krishnan 2012 & Drug trial observing adherence \\
\hline Kuna 2006 & $\begin{array}{l}\text { Trial of once-daily vs twice-daily dosing designed to demonstrate equivalent efficacy. Simplifica- } \\
\text { tion of treatment regimen postulated to improve adherence in a real-life setting, but this was a } \\
\text { double-blind, double-dummy trial, and participants in the trial were not aware of which regimen } \\
\text { they had been prescribed. Judged not to be an intervention to improve adherence per se }\end{array}$ \\
\hline Martin 2015 & $<50 \%$ taking ICS at baseline \\
\hline Mishra 2005 & Wrong study design \\
\hline Munks-Lederer 2001 & Adherence not primary focus \\
\hline NCT00181194 & Wrong study design \\
\hline NCT00201188 & Adherence not primary focus \\
\hline NCT00381355 & $\begin{array}{l}\text { Written action plan (WAP) vs unformatted prescription post exacerbation. WAP was multi-faceted } \\
\text { and was intended to modify physician ICS prescribing behaviour as well as participant adherence, } \\
\text { follow-up and asthma management more generally. Adherence to ICS not primary focus of the in- } \\
\text { tervention }\end{array}$ \\
\hline
\end{tabular}




\begin{tabular}{|c|c|}
\hline Study & Reason for exclusion \\
\hline NCT01106326 & Wrong study design \\
\hline NCT01128348 & Adherence not primary focus \\
\hline NCT01644357 & Adherence not primary focus \\
\hline NCT02093013 & Wrong study design \\
\hline NCT02363192 & Adherence not primary focus \\
\hline NCT02426801 & Wrong study design \\
\hline Nikander 1998 & Drug trial observing adherence \\
\hline Nikander 2003 & Drug trial observing adherence \\
\hline Patel 2013 & Drug trial observing adherence \\
\hline Petitto 2012 & Drug trial observing adherence \\
\hline Pongchaidecha 2005 & Not asthma, or mixed population \\
\hline Sajadi 2016 & $\begin{array}{l}\text { Intervention to improve adherence to asthma therapy generally. Number using ICS not report- } \\
\text { ed, and ICS not mentioned anywhere in trial report. Therefore assumed not to be an intervention } \\
\text { aimed at improving adherence to ICS }\end{array}$ \\
\hline Schacher 2006 & Adherence not primary focus \\
\hline Schultz 2012 & Drug trial observing adherence \\
\hline Sovani 2008 & $\begin{array}{l}\text { SMART therapy (single LABA/ICS inhaler for maintenance and reliever) vs separate inhalers for ICS } \\
\text { and SABA, so groups received different medications. This means the effect on measures of asth- } \\
\text { ma control might be a result of LABA therapy, or of improved adherence to ICS, but it is not a clear } \\
\text { enough comparison to judge }\end{array}$ \\
\hline Wilson 2010 & $\begin{array}{l}\text { Shared decision making vs clinician decision making and usual care. Interventions led to different } \\
\text { medication usage, which meant this is not a clear comparison by which to assess ICS adherence, } \\
\text { and that and was not primarily aimed at improving adherence to ICS. Adherence to ICS therefore } \\
\text { not a primary focus of intervention }\end{array}$ \\
\hline Wolthers 2002 & Wrong study design \\
\hline
\end{tabular}

ICS: inhaled corticosteroid; LABA: long-acting beta ${ }_{2}$-agonists; SABA: short-acting beta ${ }_{2}$-agonists; WAP: written action plan

Characteristics of studies awaiting assessment [ordered by study ID]

\section{ISRCTN83334596}

Methods

Participants

Interventions
Randomised controlled trial. Title: Is Compliance With Inhaled Therapy in Asthma Increased by the Use of Small-Volume Spacers? 
ISRCTN83334596 (Continued)

- Large-volume spacer

\begin{tabular}{|c|c|}
\hline Outcomes & Not provided at time of registration \\
\hline Notes & $\begin{array}{l}\text { Trial end date } 01 / 10 / 2003 \text {. Listed as completed and no longer recruiting. No publications identified } \\
\text { and no results posted }\end{array}$ \\
\hline
\end{tabular}

\section{NCT00269282}

$\begin{array}{ll}\text { Methods } & \text { Open-label randomised controlled trial with parallel assignment. Title: Increasing Adherence to } \\ \text { Asthma Medication in Urban Teens }\end{array}$
Asthma Medication in Urban Teens

Participants Inclusion criteria: 10 to 15 years of age; resident of Baltimore City; diagnosis of asthma or reactive airway disease; current emergency department visit or hospitalisation for asthma; prescribed a daily asthma controller medication

Exclusion criteria: plans to move outside of the Baltimore City area within 1 year from study entry; current participation in another asthma education study; families unwilling or unable to participate; families who were enrolled and participated in the pilot study

\begin{tabular}{ll}
\hline Interventions & Self-management (standard care group) vs motivational interviewing plus self-management \\
\hline Outcomes & $\begin{array}{l}\text { Adherence to controller therapy measured by electronic medication monitoring at baseline, } 3 \\
\text { months and } 6 \text { months. Number of symptom-free days, emergency department utilisation and hos- } \\
\text { pitalisation, career/adolescent quality of life - all measured at the same time points }\end{array}$ \\
\hline Notes & $\begin{array}{l}\text { Planned enrolment 207. Primary completion date January 2012. Listed as completed, but no publi- } \\
\text { cations identified and no results posted }\end{array}$ \\
\hline
\end{tabular}

\section{NCT01253330}

\section{Methods}

\section{Participants}

Open-label randomised controlled trial with cross-over assignment. Title: Usage, Usability \& Effect on Adherence and Clinical Outcomes of Text Message Reminders for Adolescents With Asthma

Inclusion criteria: between the ages of 12 and 22; diagnosis of persistent asthma; receiving care at Cincinnati Children's Hospital Medical Center or affiliate; prescription of a controller medication; must have a cell phone that receives text messages; asthma not well controlled based on Asthma Control Test (ACT) score; English speaking

Exclusion criteria: no diagnosis of persistent asthma; receiving asthma care other than at a Cincinnati Children's Hospital Medical Center or affiliate; asthma well controlled based on ACT score; does not have a cell phone that receives text messages or plans to change phones within the next 6 months; not taking a daily asthma controller medication; currently receiving asthma appointment or medication reminder text messages from another source

\begin{tabular}{ll}
\hline Interventions & Text message reminders vs no intervention \\
\hline Outcomes & $\begin{array}{l}\text { Asthma Control Test (ACT), Pediatric Quality of Life Scale (PedsQL), adherence change from base- } \\
\text { line }\end{array}$ \\
\hline Notes & $\begin{array}{l}\text { Planned enrolment 61. Primary completion date December 2012. Listed as completed but no publi- } \\
\text { cations identified and no results posted }\end{array}$ \\
\hline
\end{tabular}


Inclusion criteria: physician diagnosis of asthma of moderate severity; $\geq 18$ years of age; currently receiving an inhaled corticosteroid medication and prescribed Dulera 100/5 as part of standard of care based on asthma severity and dosing guidelines; Asthma Control Questionnaire (ACQ) result > 1.0 at entry; demonstration of correct inhalation technique for use of meter dosed inhalers (MDIs); history of reversible airway obstruction documented by treating physician.

Exclusion criteria: Intermittent asthma (asthma exacerbations or symptoms < 3 days/wk); diagnosis of emphysema in prior year; diagnosis at any time of chronic obstructive pulmonary disease (COPD), chronic bronchitis, cystic fibrosis, bronchiectasis, Churg Strauss, Wegener's, sarcoidosis, pulmonary hypertension or lung cancer; taking any medication documented to have a drug interaction with Dulera

\begin{tabular}{ll}
\hline Interventions & Dulera adherence monitoring with motivational interviewing vs standard asthma care \\
\hline Outcomes & ACQ, adherence to Dulera, validation of an adult asthma adherence questionnaire (AAAQ) \\
\hline Notes & $\begin{array}{l}\text { Planned enrolment 40. Estimated study completion date December 2015. Note from clinicaltrial- } \\
\text { S.gov: "The recruitment status of this study is unknown because the information has not been veri- } \\
\text { fied recently" }\end{array}$ \\
\hline
\end{tabular}

\section{NCT02176694}

\section{Methods}

Participants
Open-label randomised controlled trial with parallel assignment. Title: Adolescent Controlled Text Messaging to Improve Asthma Medication Adherence in Primary Care (ACT Me)

Inclusion criteria: provider-diagnosed persistent asthma; prescription of an inhaled corticosteroid (ICS) in accordance with National Heart, Lung, and Blood Institute (NHLBI) Expert Panel Report 3 guidelines for at least 30 days before enrolment; Asthma Control Test (ACT) score $<20$ (indicating lack of current control);

no provider-diagnosed exacerbation in the 30 days before enrolment; possession of a text-enabled cell phone and plan to keep it throughout the study period; agreement by parents (or participants over 18 years old) to any charges levied by their cell phone carrier for text messages associated with the study if they do not have an unlimited texting plan; ability to speak and read English

Exclusion criteria: another chronic lung disease (which would complicate measurement of asthma control); cognitive or psychiatric disorder that the treating clinician judges would impair study participation; use of Advair Diskus for ICS (for which no reliable electronic monitor exists); current enrolment in another asthma intervention study

Interventions Technology-based system that allows adolescents to compose, schedule and send 1-time or recurring text messages to their own cell phones. Control group receives usual care

Outcomes Adherence each month, feasibility, acceptability and useability of the website, asthma control (ACT), quality of life (Pediatric Quality of Life Scale (PedsQL))

Notes

Planned enrolment 29. Primary completion date December 2015. Listed as completed, but no publications identified and no results posted

\section{Characteristics of ongoing studies [ordered by study ID]}


NCT01381159

\begin{tabular}{ll}
\hline Trial name or title & Motivational Intervention for Asthma (MI-ACT) \\
\hline Methods & Double-blind, parallel-group randomised controlled trial \\
\hline Participants & Patients 18 years of age and older \\
- Primary diagnosis of moderate to severe persistent asthma (as per GINA) & Prescribed inhaled corticosteroid medication (minimum dose of $250 \mu \mathrm{g}$ fluticasone equivalent \\
& per day) for at least 12 consecutive months \\
- Uncontrolled asthma ( $\geq 1.25$ on the Asthma Control Questionnaire) & Coverage by a drug insurance plan \\
- Non-adherence to ICS medication (based on having filled $<50 \%$ of their prescriptions over the \\
past year) \\
- Ability to speak English or French
\end{tabular}

\begin{tabular}{ll}
\hline Interventions & Motivational communication or control \\
\hline Outcomes & Primary outcome measure: inhaled corticosteroid adherence \\
\hline Starting date & January 2011 \\
\hline Contact information & \\
\hline Notes & Link to study registration: https://clinicaltrials.gov/ct2/show/NCT01381159 \\
\hline
\end{tabular}

\section{NCT02170883}

\begin{tabular}{ll}
\hline Trial name or title & EmPhAsIS: Empowering Pharmacists in Asthma Management Through Interactive SMS \\
\hline Methods & Open-label, parallel-group randomised controlled trial \\
\hline Participants & Filling a (incident or prevalent) prescription for inhaled corticosteroids (monotherapy or in com- \\
bination inhaler with long-acting beta-agonists) who have received a diagnosis of asthma from \\
a doctor \\
- Possessing a cell phone with ability to send/receive text messages \\
- Residing in British Columbia (BC), Canada, and planning to reside in BC for the next 12 months \\
- Registered with the medical services plan (MSP, the provincial insure of medically required ser- \\
- Designated pharmacy being main drugstore for patient \\
- Not participating in another interventional study \\
- Providing consent to participate in the study
\end{tabular}

\begin{tabular}{ll}
\hline Interventions & Interactive SMS or usual care \\
\hline Outcomes & Adherence to inhaled corticosteroid medication \\
\hline Starting date & May 2015 \\
\hline Contact information & \\
\hline Notes & https://clinicaltrials.gov/ct2/show/NCT02170883 \\
\hline
\end{tabular}


NCT02203266

\begin{tabular}{ll}
\hline Trial name or title & Teaching Inhaler Use With the INCA Device in a Community Pharmacy Setting \\
\hline Methods & Open-label, parallel-group randomised controlled trial \\
\hline Participants & 18 years old or above \\
- Capable of understanding and willing to provide voluntary informed consent before any proto- & col-specific procedures are performed \\
- Capable of understanding and complying with requirements of the protocol, and demonstrating \\
willingness to attend for all required visits \\
- Capable of taking and willing to take inhaled medication \\
- Valid prescription for use of a Seretide Diskus inhaler or already using a Seretide Diskus inhaler \\
strated by patient having collected 3 prescriptions for any medication in that pharmacy in the 6 \\
months preceding their recruitment into the study
\end{tabular}

\begin{tabular}{ll}
\hline Interventions & Feedback on inhaler use, education or control \\
\hline Outcomes & Rate of adherence \\
\hline Starting date & February 2014 \\
\hline Contact information & \\
\hline Notes & https://clinicaltrials.gov/ct2/show/NCT02203266 \\
\hline
\end{tabular}

\section{NCT02307669}

\begin{tabular}{ll}
\hline Trial name or title & Inhaler Adherence in Severe Unstable Asthma (INCA-SUN) \\
\hline Methods & Double-blind, parallel-group randomised controlled trial \\
\hline Participants & Willing to give voluntary informed consent \\
- Having a clinical diagnosis of asthma- & - Having a bronchodilator FEV $\mathrm{V}_{1}>40 \%$ and $<80 \%$ in the past 1 year \\
- Having current unstable asthma (i.e. ACT score $<19$ ) at enrolment & - Taking 2 or more courses of oral corticosteroids in the prior year, or hospitalisation or ED atten- \\
& dance with an asthma exacerbation in the past year \\
- & 18 years of age or older at time of consent \\
- Capable of understanding and complying with requirements of the protocol, including ability to & attend for all required visits \\
- Ability and willingness to take inhaled medication via a Diskus & In the opinion of the investigator, suitable for use of a salmeterol/fluticasone Diskus inhaler or \\
& already using a salmeterol/fluticasone inhaler
\end{tabular}

\begin{tabular}{ll}
\hline Interventions & Feedback on inhaler use or routine care \\
\hline Outcomes & Adherence to preventer medication; cost and effectiveness of medication \\
\hline Starting date & December 2015 \\
\hline Contact information & \\
\hline
\end{tabular}


NCT02386722

\begin{tabular}{ll}
\hline Trial name or title & Intervention to Improve Inhalative Adherence \\
\hline Methods & Single-blind, parallel-group randomised controlled trial \\
\hline Participants & Inpatients and outpatients older than 18 years with a clinical diagnosis of asthma or COPD \\
& - At least 1 exacerbation in the past year \\
& - Good knowledge of the German language by themselves \\
& Ase of a metered dose Inhaler (e.g. Ventolin $\left.{ }^{\circledR}\right)$, Diskus (e.g.Seretide $\left.{ }^{\circledR}\right)$, Turbohaler (e.g.Symbicort $\left.{ }^{\circledR}\right)$, \\
\hline Interventions & Audio reminders and support calls or control \\
\hline Outcomes & Time to next asthma or COPD exacerbation; number of exacerbations; adherence \\
\hline Starting date & January 2014 \\
\hline Contact information & \\
\hline Notes & https://clinicaltrials.gov/ct2/show/NCT02386722 \\
\hline
\end{tabular}

\section{NCT02426814}

\begin{tabular}{ll}
\hline Trial name or title & $\begin{array}{l}\text { Assessment of a Mobile Intervention to Increase Adherence to Asthma Medication Among Adoles- } \\
\text { cents }\end{array}$ \\
\hline Methods & Open-label, parallel-group randomised \\
\hline Participants & Age 11 to 19 years \\
& - Asthma diagnosis \\
& Current prescription for a hydrofluoroalkane (HFA) asthma controller medication \\
& Having a smartphone or access to a smartphone or tablet \\
\hline Interventions & Medication Monitoring and Mobile App or sham comparator \\
\hline Outcomes & Real-time medication adherence \\
\hline Starting date & August 2015 \\
\hline Contact information & \\
\hline Notes & https://clinicaltrials.gov/ct2/show/NCT02426814
\end{tabular}

\section{NCT02556073}

Trial name or title

ICS/LABA Combination With Integrated Dose Counter and Smartphone App to Improve Asthma Control 
NCT02556073 (Continued)

\begin{tabular}{ll} 
Methods & Open-label, parallel-group randomised \\
\hline Participants & - Symptomatic asthmatic individuals free of controller medication for at least 3 months \\
& • 20 to 70 years of age \\
\hline Interventions & Smartphone self management or routine care \\
\hline Outcomes & Changes in airway inflammation profile; changes in scores of Asthma Control Questionnaire; \\
\hline Starting date & August 2014 \\
\hline Contact information in lung function parameters; numbers of rescue medications used
\end{tabular}

\section{NCT02615743}

\begin{tabular}{ll}
\hline Trial name or title & Asthma Controller Adherence After Hospitalization \\
\hline Methods & Open-label, parallel-group randomised \\
\hline Participants & $\begin{array}{l}\text { Unlimited text messaging plan } \\
\text { (budesonide), Seretide (fluticasone-salmeterol), Advair MDI (fluticasone-salmeterol) or Dulera } \\
\text { (mometasone-formoterol) }\end{array}$ \\
\hline $\begin{array}{l}\text { Primary care received at } 1 \text { of } 3 \text { urban CHOP primary care practices (Karabots, South Philadelphia } \\
\text { or Cobbs Creek) }\end{array}$ \\
\hline Interventions & Daily text message reminders or control \\
\hline Outcomes & Feasibility; acceptability; adherence \\
\hline Starting date & December 2015 \\
\hline Contact information & https://clinicaltrials.gov/ct2/show/NCT02615743 \\
\hline Notes &
\end{tabular}

\section{NCT02715219}

\begin{tabular}{ll}
\hline Trial name or title & Effectiveness of an AEP on Patient's Knowledge, Medication Adherence and Inhaler Technique \\
\hline Methods & Single-blind, parallel-group randomised controlled trial \\
\hline Participants & $\begin{array}{l}\text { Confirmed diagnosis of bronchial asthma in the medical record } \\
\text { U Use of inhaler medication for past } 1 \text { year }\end{array}$ \\
\hline Interventions & Asthma Education Programme (AEP) or routine care \\
\hline
\end{tabular}


NCT02715219 (Continued)

Outcomes

Participant knowledge status regarding asthma; participant medication adherence status; participant inhaler technique

Starting date June 2015

Contact information

Notes

https://clinicaltrials.gov/ct2/show/NCT02715219

\section{NCT02768623}

\begin{tabular}{ll}
\hline Trial name or title & Evaluation of a Community Pharmacist Managed Asthma Consultation Service \\
\hline Methods & Open-label, parallel-group randomised controlled trial \\
\hline Participants & Provided written consent \\
& - Intended to refill all asthma-related prescriptions at the study pharmacy \\
& - Tiven a diagnosis of asthma by a physician or a nurse practitioner \\
& least 2 months \\
& $\begin{array}{l}18 \text { years of age or older } \\
\text { Having uncontrolled asthma (defined as in the past } 4 \text { weeks, patient has used rescue medication } 4 \\
\text { or more times in a given week and/or patient has woken up in the night because of asthma during } \\
\text { a given week) }\end{array}$ \\
\hline Interventions & Comprehensive disease management programme for asthma or control \\
\hline Outcomes & Peak expiratory flow rate; medication adherence; asthma control for at \\
\hline Starting date & May 2016 \\
\hline Contact information & https://clinicaltrials.gov/ct2/show/NCT02768623 \\
\hline Notes &
\end{tabular}

\section{NCT02787174}

\begin{tabular}{ll}
\hline Trial name or title & A Computer-Based ED Intervention to Improve Pediatric Asthma Medicine Adherence (ED-AMAP) \\
\hline Methods & Single-blind, parallel-group randomised controlled trial \\
\hline Participants & - Asthma diagnosis by physician or parent report \\
& - Inhaled corticosteroid asthma controller medicine prescribed \\
\hline Interventions & Interactive tailored asthma medication adherence education on an iPad or routine care \\
\hline Outcomes & Asthma controller medication adherence \\
\hline Starting date & February 2016 \\
\hline
\end{tabular}


NCT02787174 (Continued)

Contact information

Notes https://www.clinicaltrials.gov/ct2/show/NCT02787174

\section{NTR5061}

\begin{tabular}{ll}
\hline Trial name or title & Development and Testing of an Adolescent Adherence Patient Tool for Asthma \\
\hline Methods & Open-label, parallel-group randomised controlled trial \\
\hline Participants & Adolescent patients using ICS registered at 1 of the pharmacies in the UPPER-network \\
& - Age between 12 and 18 years \\
& - Use of ICS: filling of $\geq 2$ prescriptions for ICS or ICS/LABA combination during previous 12 months \\
& Access to a smartphone \\
\hline Interventions & Smartphone application for patients combined with a computer management system for health- \\
& care providers (pharmacists) \\
\hline Outcomes & Adherence \\
\hline Starting date & April 2015 \\
\hline Contact information & \\
\hline Notes & http://www.trialregister.nl/trialreg/admin/rctview.asp?TC=5061 \\
\hline
\end{tabular}

Sulaiman 2016

\begin{tabular}{ll}
\hline Trial name or title & Prospective Study of the Feedback From an Adherence Monitor on Asthma Control (INCA) \\
\hline Methods & Single-blind, parallel-group randomised controlled trial \\
\hline Participants & $\begin{array}{l}\text { Patients prescribed therapy equivalent to step } 3 \text { or higher on the Asthma Management Guidelines } \\
\text { for at least } 3 \text { months } \\
\text { At least } 1 \text { exacerbation in the previous year with systemic glucocorticoids } \\
\text { Uncontrolled/Partially controlled asthma by GINA guidelines }\end{array}$ \\
\hline Interventions & Feedback from a computer log of inhaler use or control \\
\hline Outcomes & Adherence rate \\
\hline Starting date & February 2012 \\
\hline Contact information & https://clinicaltrials.gov/ct2/show/NCT01529697 \\
\hline Notes &
\end{tabular}


ACT: Asthma Control Test; COPD: chronic obstructive pulmonary disease; ED: emergency department; FEV ${ }_{1}$ : forced expiratory volume in one second; GINA: Global Initiative for Asthma; GP: general practitioner; HFA: hydrofluoroalkane; ICS: inhaled corticosteroids; INCA: Inhaler Compliance Assessment device; LABA: long-acting beta ${ }_{2}$-agonist; MDI: metered dose inhaler; SMS: short message service/text message

\section{DATA AND ANALYSES}

\section{Comparison 1. Adherence education versus controls}

\begin{tabular}{|c|c|c|c|c|}
\hline $\begin{array}{l}\text { Outcome or subgroup } \\
\text { title }\end{array}$ & No. of studies & $\begin{array}{l}\text { No. of partici- } \\
\text { pants }\end{array}$ & Statistical method & Effect size \\
\hline $\begin{array}{l}1 \% \text { Adherence (objective } \\
\text { measures) }\end{array}$ & 5 & 280 & Mean Difference (IV, Random, 95\% CI) & $20.13[7.52,32.74]$ \\
\hline 1.1 Complex & 4 & 230 & Mean Difference (IV, Random, 95\% CI) & $21.55[4.71,38.39]$ \\
\hline 1.2 Simple education & 1 & 50 & Mean Difference (IV, Random, 95\% CI) & $15.40[5.98,24.82]$ \\
\hline $\begin{array}{l}2 \% \text { Adherence (all mea- } \\
\text { sures) }\end{array}$ & 10 & 1693 & Mean Difference (IV, Random, 95\% CI) & $11.59[3.72,19.46]$ \\
\hline 2.1 Complex & 8 & 744 & Mean Difference (IV, Random, 95\% Cl) & $12.21[1.26,23.17]$ \\
\hline 2.2 Simple education & 2 & 949 & Mean Difference (IV, Random, 95\% CI) & $10.60[5.17,16.03]$ \\
\hline $3>85 \%$ adherence & 1 & 271 & Odds Ratio (M-H, Random, 95\% Cl) & $2.68[1.61,4.46]$ \\
\hline $\begin{array}{l}4 \text { Exacerbations requir- } \\
\text { ing OCS (people with } 1 \text { or } \\
\text { more) }\end{array}$ & 3 & 349 & Odds Ratio (M-H, Random, 95\% Cl) & $1.82[0.99,3.36]$ \\
\hline 5 Asthma control & 6 & & Mean Difference (IV, Random, 95\% Cl) & Subtotals only \\
\hline $5.1 \mathrm{ACQ}$ & 4 & 455 & Mean Difference (IV, Random, 95\% Cl) & $-0.03[-0.49,0.43]$ \\
\hline $5.2 \mathrm{ACT}$ & 3 & 333 & Mean Difference (IV, Random, 95\% Cl) & $0.30[-0.82,1.43]$ \\
\hline $\begin{array}{l}6 \text { Unsheduled visits to a } \\
\text { healthcare provider (peo- } \\
\text { ple with } 1 \text { or more) }\end{array}$ & 4 & 688 & Odds Ratio (M-H, Random, 95\% Cl) & $0.48[0.19,1.19]$ \\
\hline 6.1 Hospital & 1 & 250 & Odds Ratio (M-H, Random, 95\% Cl) & $1.23[0.56,2.70]$ \\
\hline $6.2 \mathrm{ED}$ & 2 & 367 & Odds Ratio (M-H, Random, 95\% Cl) & $0.23[0.06,0.83]$ \\
\hline $6.3 \mathrm{GP}$ & 1 & 71 & Odds Ratio (M-H, Random, 95\% Cl) & $0.20[0.07,0.54]$ \\
\hline 7 Quality of life (AQLQ) & 6 & 734 & Mean Difference (IV, Random, 95\% CI) & $0.01[-0.20,0.23]$ \\
\hline
\end{tabular}


Analysis 1.1. Comparison 1 Adherence education versus controls, Outcome $1 \%$ Adherence (objective measures).

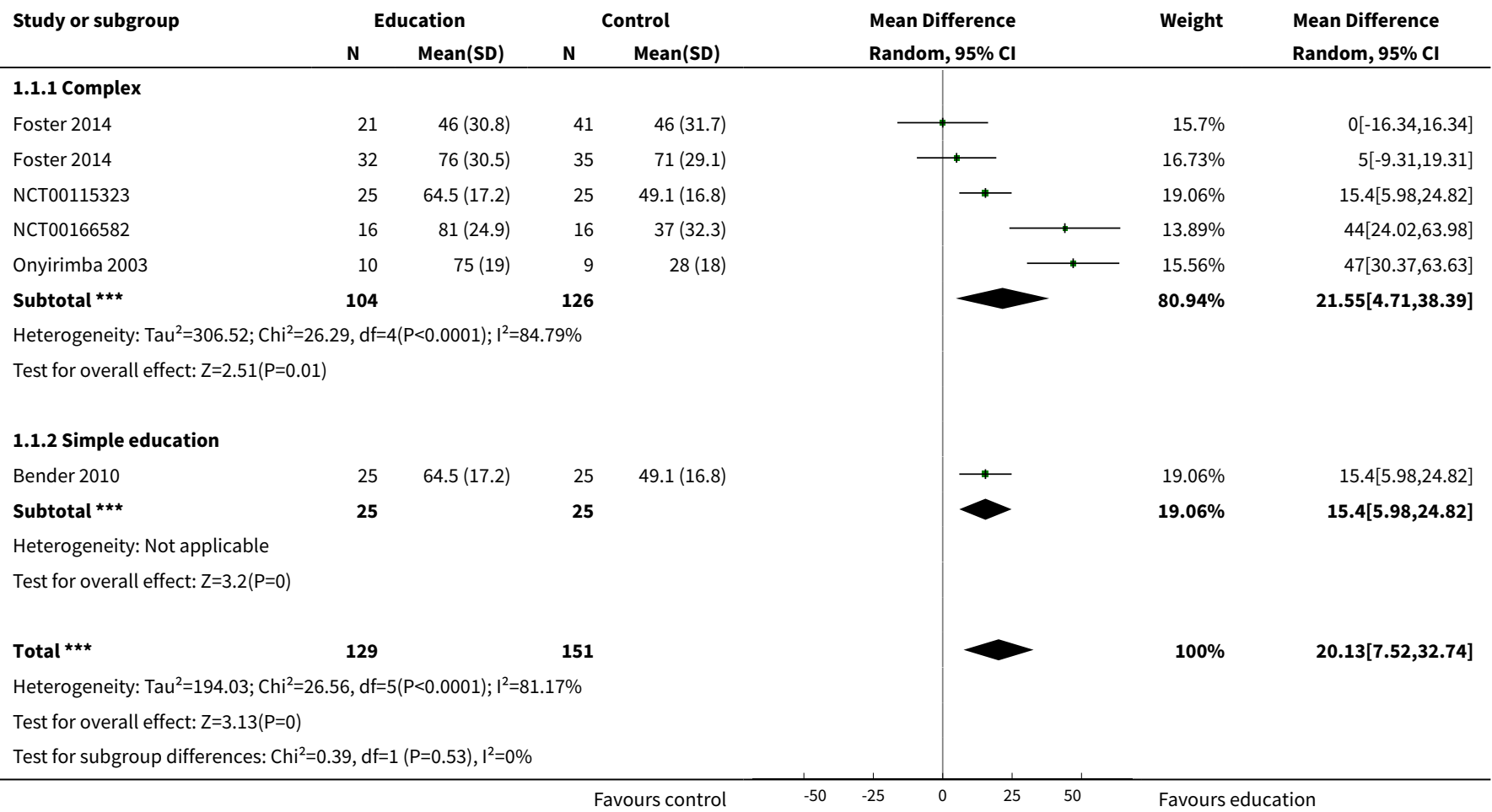

Analysis 1.2. Comparison 1 Adherence education versus controls, Outcome $2 \%$ Adherence (all measures).

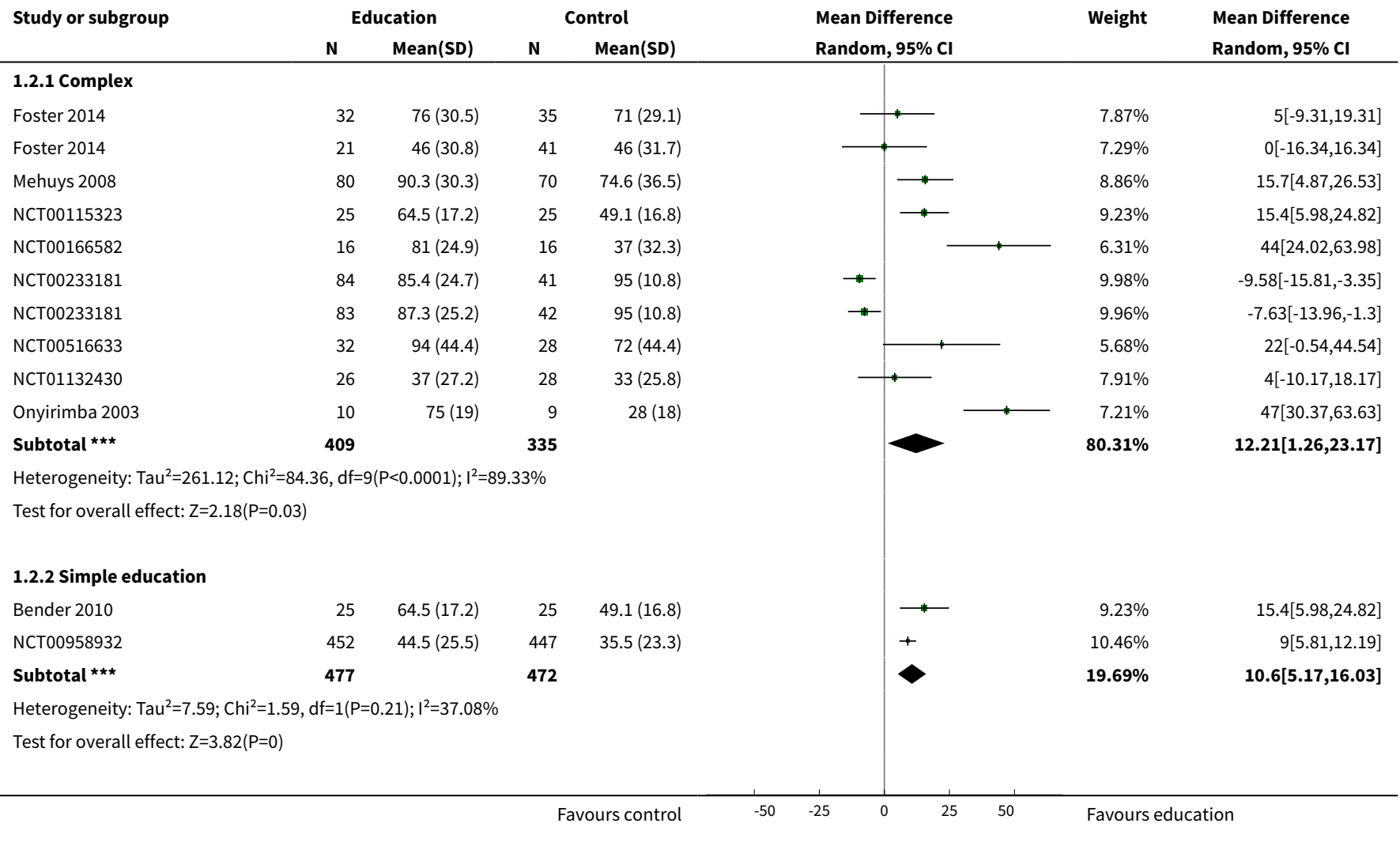




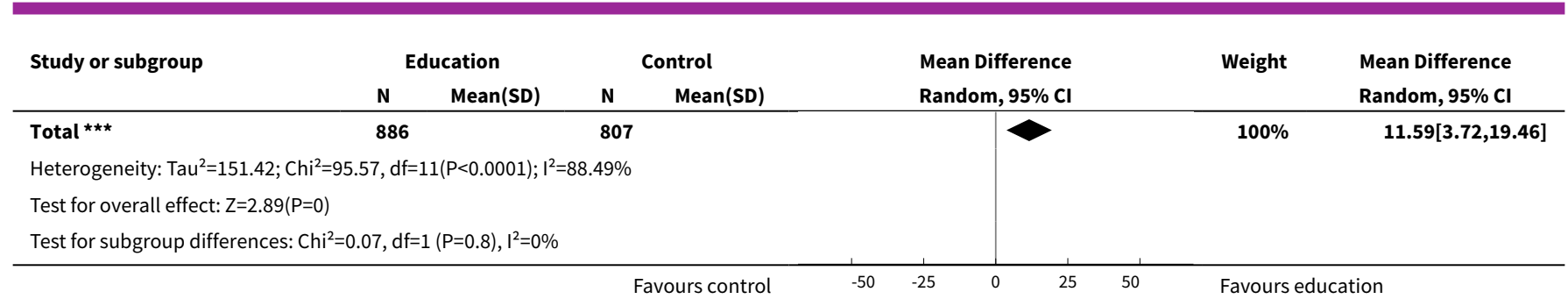

Analysis 1.3. Comparison 1 Adherence education versus controls, Outcome $3>85 \%$ adherence.

\begin{tabular}{|c|c|c|c|c|c|}
\hline Study or subgroup & $\begin{array}{c}\text { Education } \\
\mathrm{n} / \mathrm{N}\end{array}$ & $\begin{array}{c}\text { Control } \\
n / N\end{array}$ & $\begin{array}{c}\text { Odds Ratio } \\
\text { M-H, Random, } 95 \% \mathrm{Cl}\end{array}$ & Weight & $\begin{array}{c}\text { Odds Ratio } \\
\text { M-H, Random, } 95 \% \mathrm{Cl}\end{array}$ \\
\hline Chatkin 2006 & $104 / 140$ & $68 / 131$ & & $100 \%$ & $2.68[1.61,4.46]$ \\
\hline Total $(95 \% \mathrm{Cl})$ & 140 & 131 & & $100 \%$ & $2.68[1.61,4.46]$ \\
\hline \multicolumn{6}{|c|}{ Total events: 104 (Education), 68 (Control) } \\
\hline \multicolumn{6}{|c|}{ Heterogeneity: Not applicable } \\
\hline & & vours control & 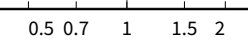 & urs education & \\
\hline
\end{tabular}

Analysis 1.4. Comparison 1 Adherence education versus controls, Outcome 4 Exacerbations requiring OCS (people with 1 or more).

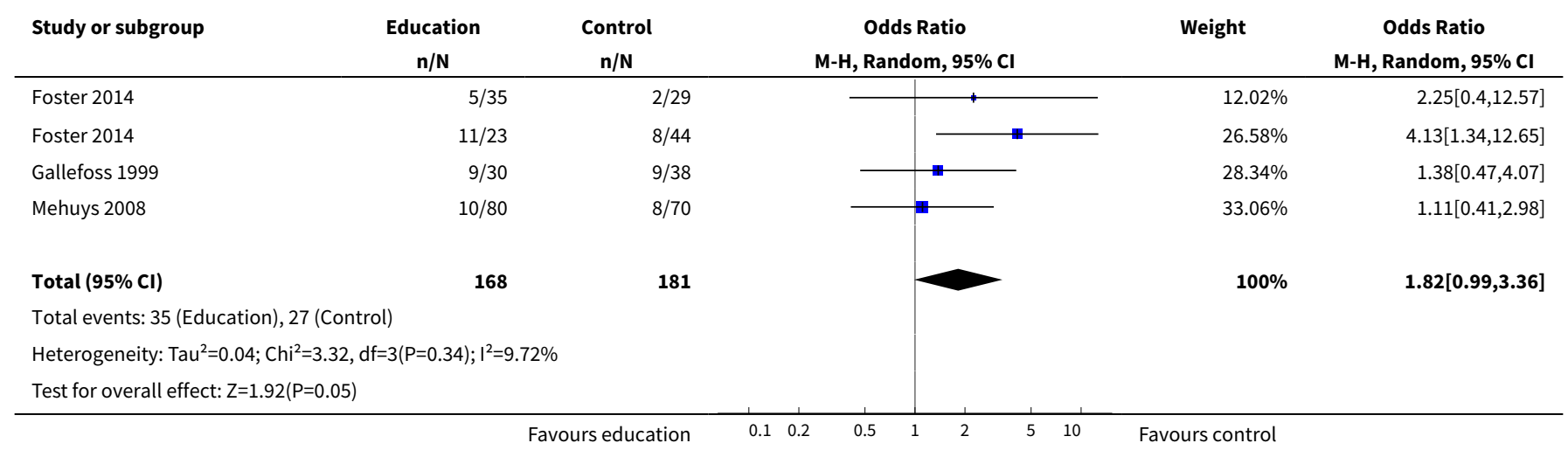

Analysis 1.5. Comparison 1 Adherence education versus controls, Outcome 5 Asthma control.

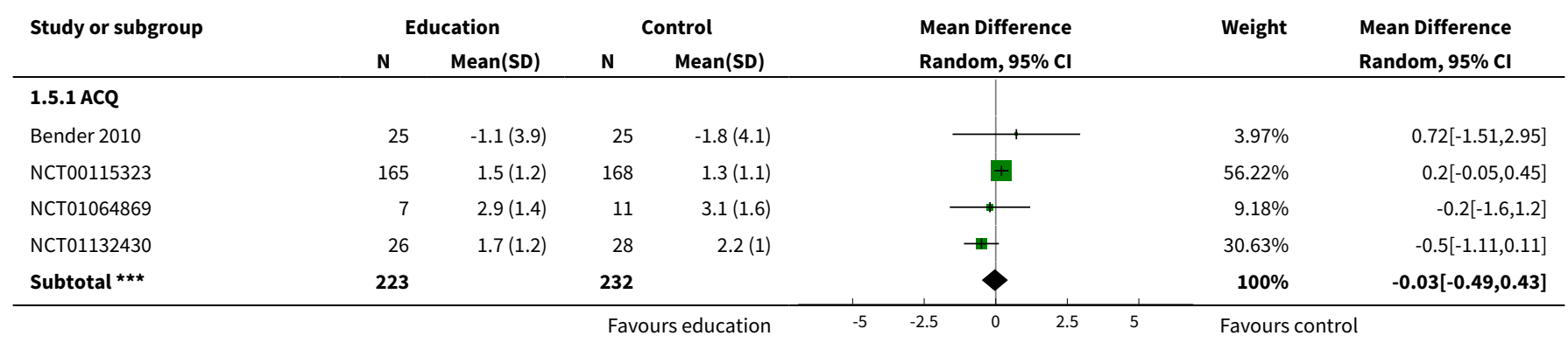




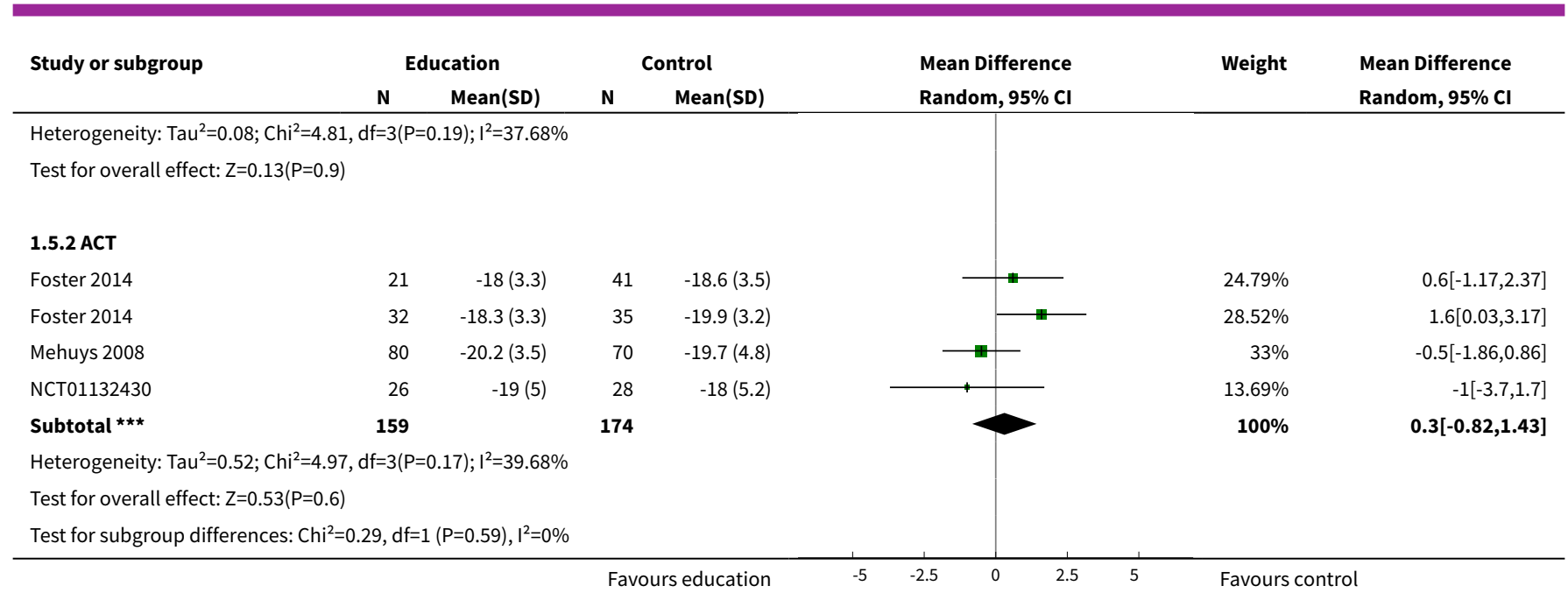

\section{Analysis 1.6. Comparison 1 Adherence education versus controls, Outcome 6 Unsheduled visits to a healthcare provider (people with 1 or more).}

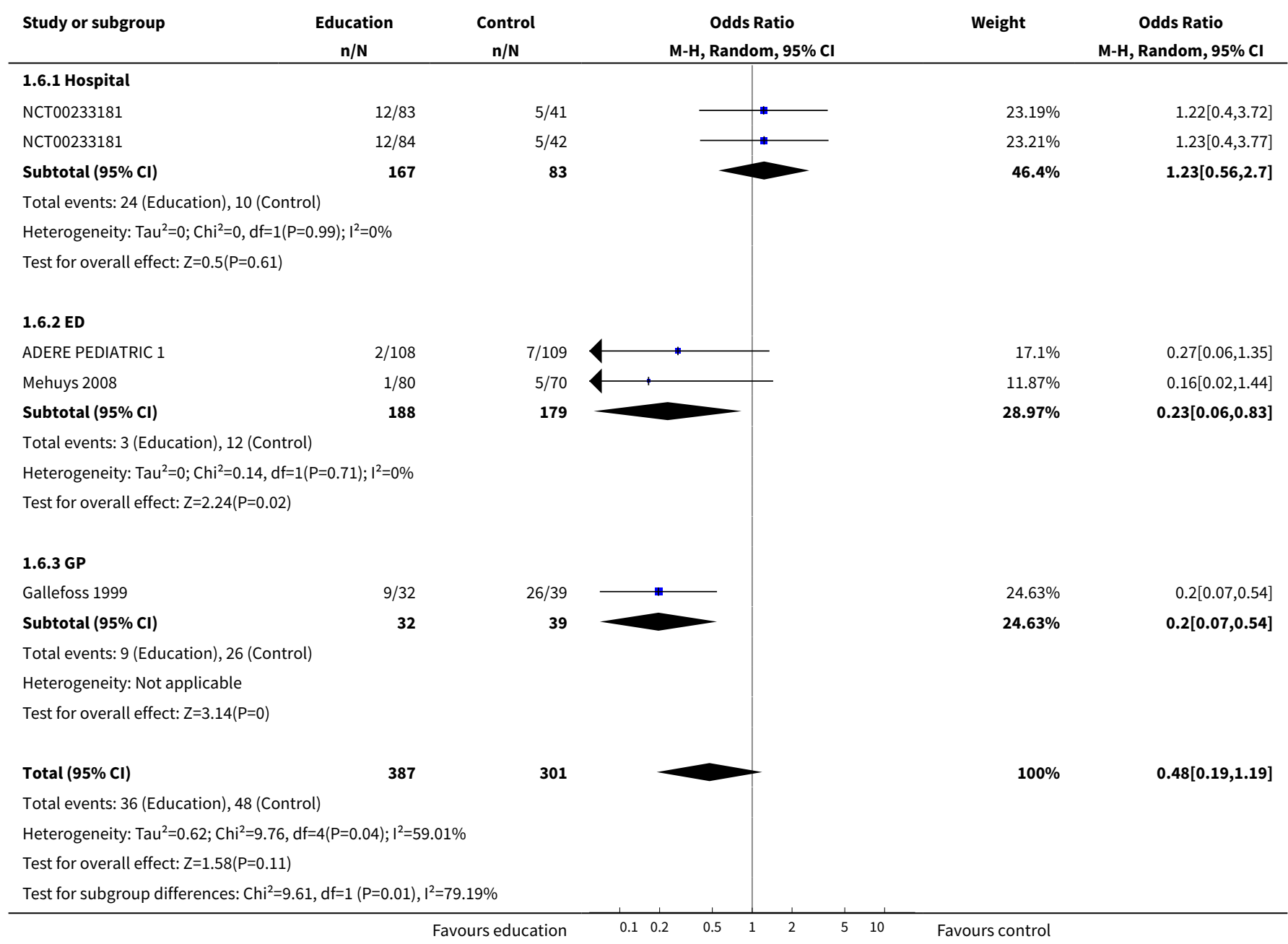


Analysis 1.7. Comparison 1 Adherence education versus controls, Outcome 7 Quality of life (AQLQ).

\begin{tabular}{|c|c|c|c|c|c|c|c|}
\hline \multirow[t]{2}{*}{ Study or subgroup } & \multicolumn{2}{|c|}{ Education } & \multicolumn{2}{|c|}{ Control } & \multirow{2}{*}{$\begin{array}{l}\text { Mean Difference } \\
\text { Random, } 95 \% \mathrm{Cl}\end{array}$} & \multirow[t]{2}{*}{ Weight } & \multirow{2}{*}{$\begin{array}{l}\text { Mean Difference } \\
\text { Random, } 95 \% \mathrm{CI}\end{array}$} \\
\hline & $\mathbf{N}$ & $\operatorname{Mean}(S D)$ & $\mathbf{N}$ & $\operatorname{Mean}(\mathrm{SD})$ & & & \\
\hline Bender 2010 & 25 & $-0.1(0.9)$ & 25 & $-0.4(1.1)$ & $\mathbf{r}$ & $11.25 \%$ & $0.23[-0.32,0.78]$ \\
\hline Foster 2014 & 21 & $4.9(0.9)$ & 41 & $5.4(1)$ & r & $13.91 \%$ & $-0.5[-0.98,-0.02]$ \\
\hline Foster 2014 & 32 & $5.4(1.1)$ & 35 & $5.5(1.2)$ & $\longrightarrow$ & $11.43 \%$ & $-0.1[-0.64,0.44]$ \\
\hline Mehuys 2008 & 80 & $6(0.7)$ & 70 & $5.8(0.9)$ & + & $27 \%$ & $0.2[-0.06,0.46]$ \\
\hline NCT00115323 & 165 & $4.7(1.3)$ & 168 & $4.8(1.4)$ & $\longrightarrow$ & $24.63 \%$ & $-0.1[-0.39,0.19]$ \\
\hline NCT01064869 & 7 & $4.3(1.4)$ & 11 & $3.8(1.6)$ & & $2.19 \%$ & $0.5[-0.9,1.9]$ \\
\hline NCT01132430 & 26 & $5(1.2)$ & 28 & $4.7(1)$ & + & $9.59 \%$ & $0.3[-0.31,0.91]$ \\
\hline 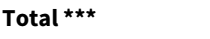 & 356 & & 378 & & & $100 \%$ & $0.01[-0.2,0.23]$ \\
\hline \multicolumn{8}{|c|}{ Heterogeneity: $\mathrm{Tau}^{2}=0.03 ; \mathrm{Chi}^{2}=9.09, \mathrm{df}=6(\mathrm{P}=0.17) ; \mathrm{I}^{2}=33.97 \%$} \\
\hline Test for overall effect & & & & & & & \\
\hline
\end{tabular}

\section{Comparison 2. Electronic trackers or reminders ( \pm feedback) versus controls}

\begin{tabular}{|c|c|c|c|c|}
\hline $\begin{array}{l}\text { Outcome or subgroup ti- } \\
\text { tle }\end{array}$ & No. of studies & $\begin{array}{l}\text { No. of partici- } \\
\text { pants }\end{array}$ & Statistical method & Effect size \\
\hline $\begin{array}{l}1 \% \text { Adherence (objective } \\
\text { measures) }\end{array}$ & 6 & 555 & $\begin{array}{l}\text { Mean Difference (IV, Random, 95\% } \\
\mathrm{Cl} \text { ) }\end{array}$ & $19.86[14.47,25.26]$ \\
\hline 1.1 Reminders/trackers & 3 & 321 & $\begin{array}{l}\text { Mean Difference (IV, Random, 95\% } \\
\text { Cl) }\end{array}$ & $16.29[9.53,23.04]$ \\
\hline 1.2 With feedback & 3 & 234 & $\begin{array}{l}\text { Mean Difference (IV, Random, 95\% } \\
\mathrm{CI})\end{array}$ & $24.98[17.53,32.44]$ \\
\hline $\begin{array}{l}2 \% \text { Adherence (all mea- } \\
\text { sures) }\end{array}$ & 8 & 762 & $\begin{array}{l}\text { Mean Difference (IV, Random, 95\% } \\
\text { CI) }\end{array}$ & $18.41[11.82,25.00]$ \\
\hline 2.1 Reminders/trackers & 4 & 361 & $\begin{array}{l}\text { Mean Difference (IV, Random, 95\% } \\
\mathrm{CI} \text { ) }\end{array}$ & $16.92[10.82,23.02]$ \\
\hline 2.2 With feedback & 4 & 401 & $\begin{array}{l}\text { Mean Difference (IV, Random, 95\% } \\
\text { CI) }\end{array}$ & $20.06[7.27,32.85]$ \\
\hline $\begin{array}{l}3 \text { Exacerbations requiring } \\
\text { OCS (people with at least } \\
\text { 1) }\end{array}$ & 4 & 3063 & Odds Ratio (M-H, Random, 95\% Cl) & $0.72[0.37,1.39]$ \\
\hline 4 Asthma control & 6 & & $\begin{array}{l}\text { Mean Difference (IV, Random, 95\% } \\
\mathrm{CI})\end{array}$ & Subtotals only \\
\hline 4.1 ACQ & 2 & 109 & $\begin{array}{l}\text { Mean Difference (IV, Random, 95\% } \\
\mathrm{CI} \text { ) }\end{array}$ & $0.24[-0.29,0.78]$ \\
\hline $4.2 \mathrm{ACT}$ & 4 & 596 & $\begin{array}{l}\text { Mean Difference (IV, Random, 95\% } \\
\mathrm{Cl} \text { ) }\end{array}$ & $0.74[-0.20,1.69]$ \\
\hline
\end{tabular}




\begin{tabular}{lllll}
\hline $\begin{array}{l}\text { Outcome or subgroup ti- } \\
\text { tle }\end{array}$ & No. of studies & $\begin{array}{l}\text { No. of partici- } \\
\text { pants }\end{array}$ & Statistical method & Effect size \\
\hline $\begin{array}{l}5 \text { Unscheduled visits to a } \\
\text { healthcare provider }\end{array}$ & 3 & & Odds Ratio (M-H, Random, 95\% Cl) & Subtotals only \\
\hline 5.1 ED & 2 & 2918 & Odds Ratio (M-H, Random, 95\% Cl) & $1.14[0.88,1.47]$ \\
\hline 5.2 Hospital & 2 & 2865 & Odds Ratio (M-H, Random, 95\% Cl) & $0.97[0.53,1.78]$ \\
\hline $\begin{array}{l}6 \text { Unscheduled visits to a } \\
\text { healthcare provider }\end{array}$ & 1 & Rate Ratio (Random, 95\% Cl) & Totals not selected \\
\hline 6.1 GP/ED visits & 1 & Rate Ratio (Random, 95\% Cl) & $0.0[0.0,0.0]$ \\
\hline 6.2 Hospitalisations & 1 & Rate Ratio (Random, 95\% Cl) & 0.0 [0.0, 0.0] \\
\hline 7 Absenteeism & 1 & Odds Ratio (M-H, Random, 95\% Cl) & Totals not selected \\
\hline 8 Absenteeism & 1 & Rate Ratio (Fixed, 95\% Cl) & Subtotals only \\
\hline 9 Quality of life (AQLQ) & 4 & Mean Difference (IV, Random, 95\% & -0.03 [-0.20, 0.13] \\
\hline
\end{tabular}

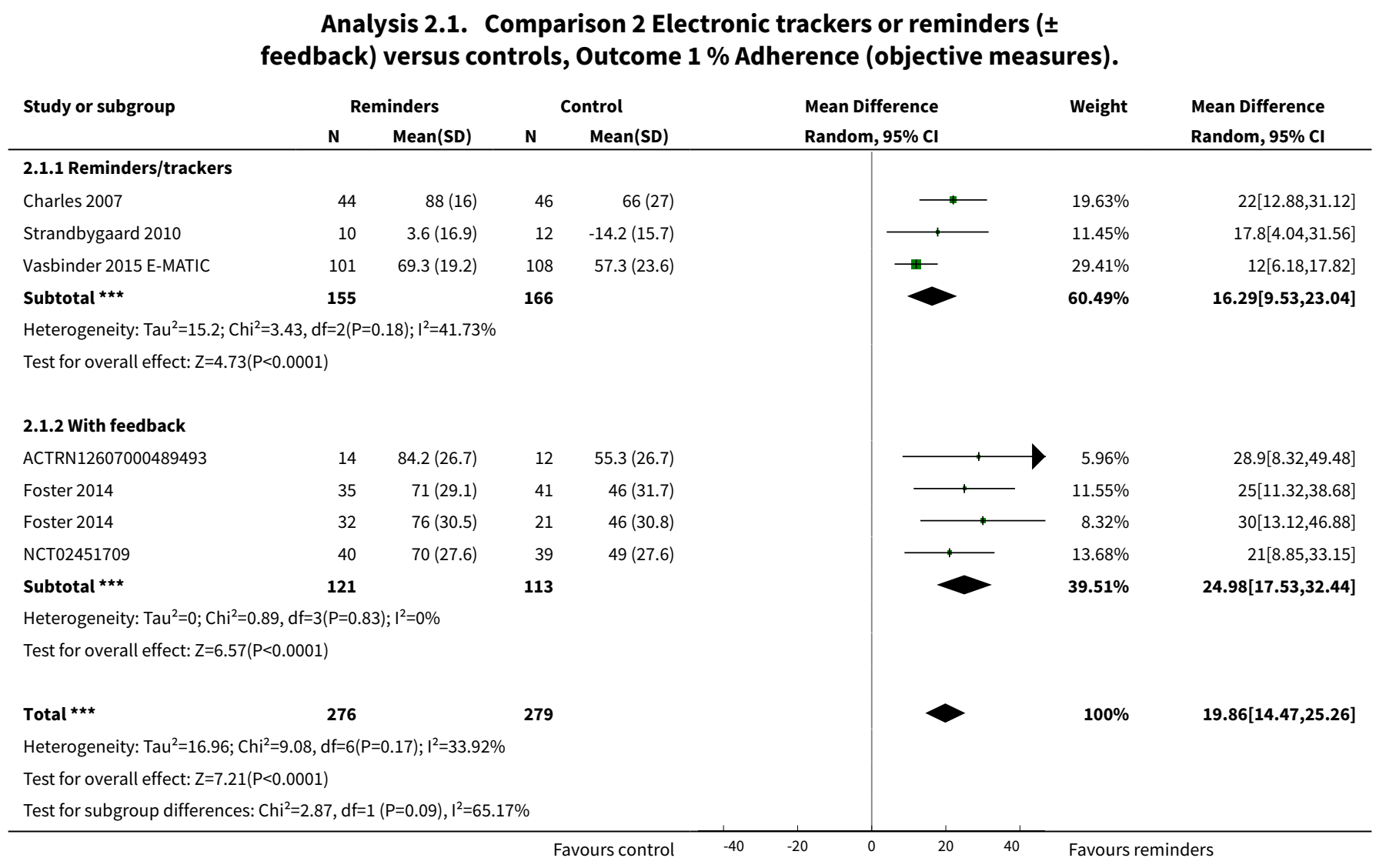


Analysis 2.2. Comparison 2 Electronic trackers or reminders $( \pm$ feedback) versus controls, Outcome $2 \%$ Adherence (all measures).

\begin{tabular}{|c|c|c|c|c|c|c|c|}
\hline \multirow{3}{*}{$\begin{array}{l}\text { Study or subgroup } \\
\text { 2.2.1 Reminders/tracker }\end{array}$} & \multicolumn{2}{|c|}{ Reminders } & \multicolumn{2}{|c|}{ Control } & \multirow{2}{*}{$\begin{array}{l}\text { Mean Difference } \\
\text { Random, } 95 \% \mathrm{CI}\end{array}$} & \multirow[t]{2}{*}{ Weight } & \multirow{2}{*}{$\begin{array}{l}\text { Mean Difference } \\
\text { Random, } 95 \% \mathrm{Cl}\end{array}$} \\
\hline & \multirow[t]{2}{*}{$\mathbf{N}$} & \multirow[t]{2}{*}{ Mean(SD) } & \multirow[t]{2}{*}{$\mathbf{N}$} & \multirow[t]{2}{*}{$\operatorname{Mean}(S D)$} & & & \\
\hline & & & & & & & \\
\hline Black 2008 & 20 & $71.4(31.3)$ & 20 & $46.7(31.3)$ & & $7.16 \%$ & $24.7[5.3,44.1]$ \\
\hline Charles 2007 & 44 & $88(16)$ & 46 & $66(27)$ & & $13.88 \%$ & $22[12.88,31.12]$ \\
\hline Strandbygaard 2010 & 10 & $3.6(16.9)$ & 12 & $-14.2(15.7)$ & $\longrightarrow$ & $10.36 \%$ & $17.8[4.04,31.56]$ \\
\hline Vasbinder 2015 E-MATIC & 101 & $69.3(19.2)$ & 108 & $57.3(23.6)$ & $\longrightarrow$ & $16.48 \%$ & $12[6.18,17.82]$ \\
\hline Subtotal $\star \star \star$ & 175 & & 186 & & & $47.87 \%$ & $16.92[10.82,23.02]$ \\
\hline \multicolumn{8}{|c|}{ Heterogeneity: $\mathrm{Tau}^{2}=11.98 ; \mathrm{Chi}^{2}=4.3, \mathrm{df}=3(\mathrm{P}=0.23) ; \mathrm{I}^{2}=30.23 \%$} \\
\hline \multicolumn{8}{|c|}{ Test for overall effect: $Z=5.43(P<0.0001)$} \\
\hline \multicolumn{8}{|l|}{ 2.2.2 With feedback } \\
\hline ACTRN12607000489493 & 14 & $84.2(26.7)$ & 12 & $55.3(26.7)$ & & $6.64 \%$ & $28.9[8.32,49.48]$ \\
\hline Foster 2014 & 35 & $71(29.1)$ & 41 & $46(31.7)$ & & $10.42 \%$ & $25[11.32,38.68]$ \\
\hline NCT00233181 & 83 & $87.3(25.2)$ & 84 & $85.4(24.7)$ & $\rightarrow$ & $15.12 \%$ & $1.95[-5.63,9.53]$ \\
\hline NCT02451709 & 40 & $70(27.6)$ & 39 & $49(27.6)$ & & $11.5 \%$ & $21[8.85,33.15]$ \\
\hline Subtotal $\star \star \star$ & 204 & & 197 & & & $52.13 \%$ & $20.06[7.27,32.85]$ \\
\hline \multicolumn{8}{|c|}{ Heterogeneity: $\operatorname{Tau}^{2}=160.32 ; \mathrm{Chi}^{2}=18.92, \mathrm{df}=4(\mathrm{P}=0) ; \mathrm{I}^{2}=78.86 \%$} \\
\hline \multicolumn{8}{|c|}{ Test for overall effect: $Z=3.07(P=0)$} \\
\hline Total *** & 379 & & 383 & & & $100 \%$ & $18.41[11.82,25]$ \\
\hline \multicolumn{8}{|c|}{ Heterogeneity: $\mathrm{Tau}^{2}=59.73 ; \mathrm{Chi}^{2}=23.56, \mathrm{df}=8(\mathrm{P}=0) ; \mathrm{I}^{2}=66.05 \%$} \\
\hline \multicolumn{8}{|c|}{ Test for overall effect: $Z=5.48(P<0.0001)$} \\
\hline Test for subgroup differer & $19, \mathrm{df}=$ & $P=0.66), I^{2}=0 \%$ & & & & & \\
\hline
\end{tabular}

Analysis 2.3. Comparison 2 Electronic trackers or reminders ( \pm feedback) versus controls, Outcome 3 Exacerbations requiring OCS (people with at least 1 ).

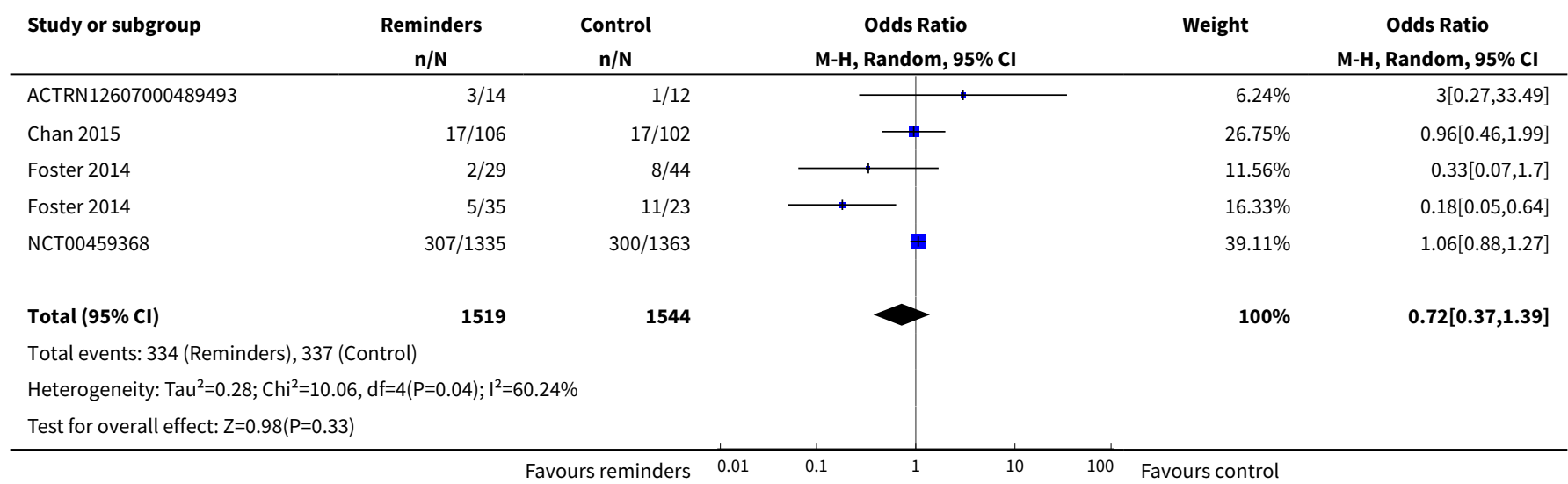


Analysis 2.4. Comparison 2 Electronic trackers or reminders ( \pm feedback) versus controls, Outcome 4 Asthma control.

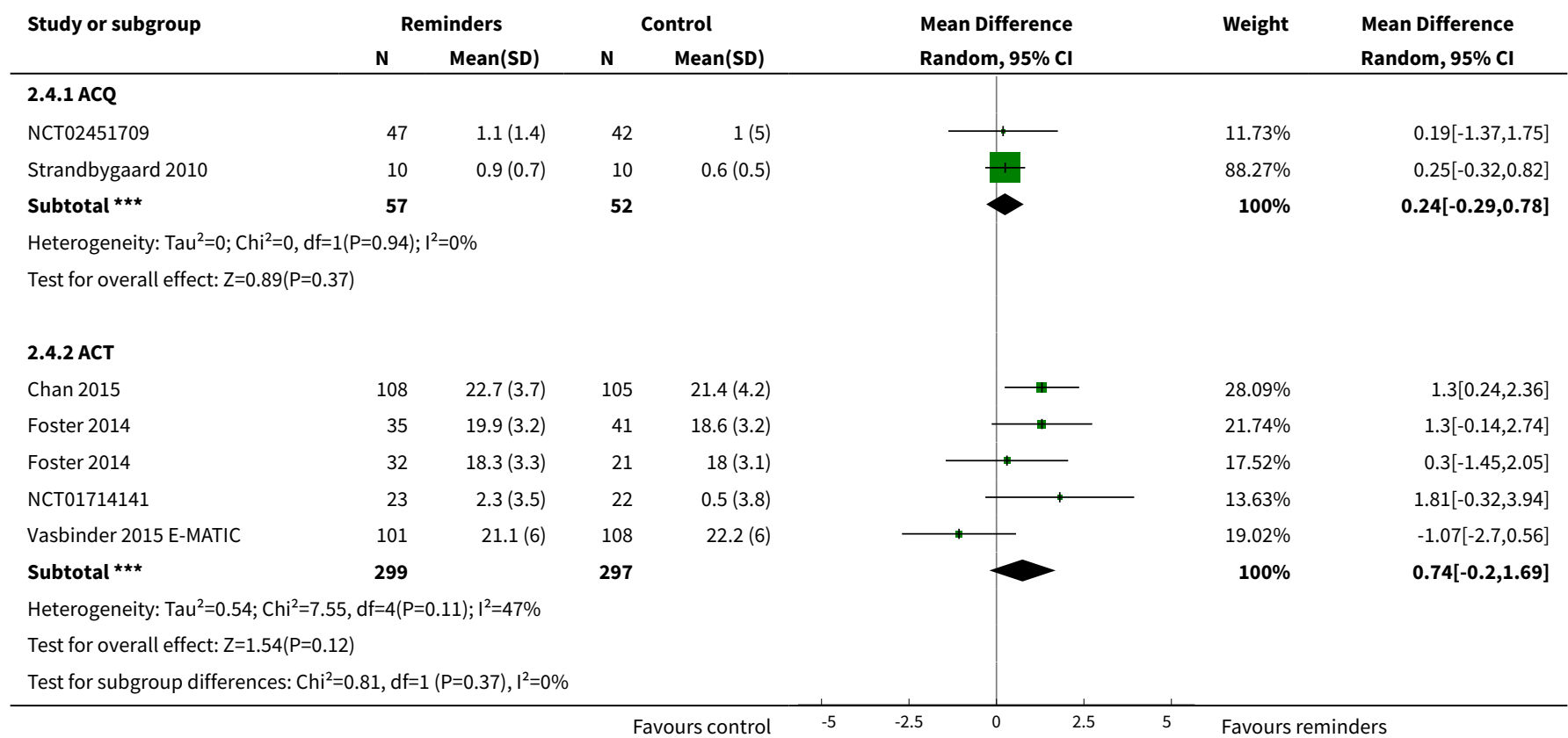

Analysis 2.5. Comparison 2 Electronic trackers or reminders ( \pm feedback) versus controls, Outcome 5 Unscheduled visits to a healthcare provider.

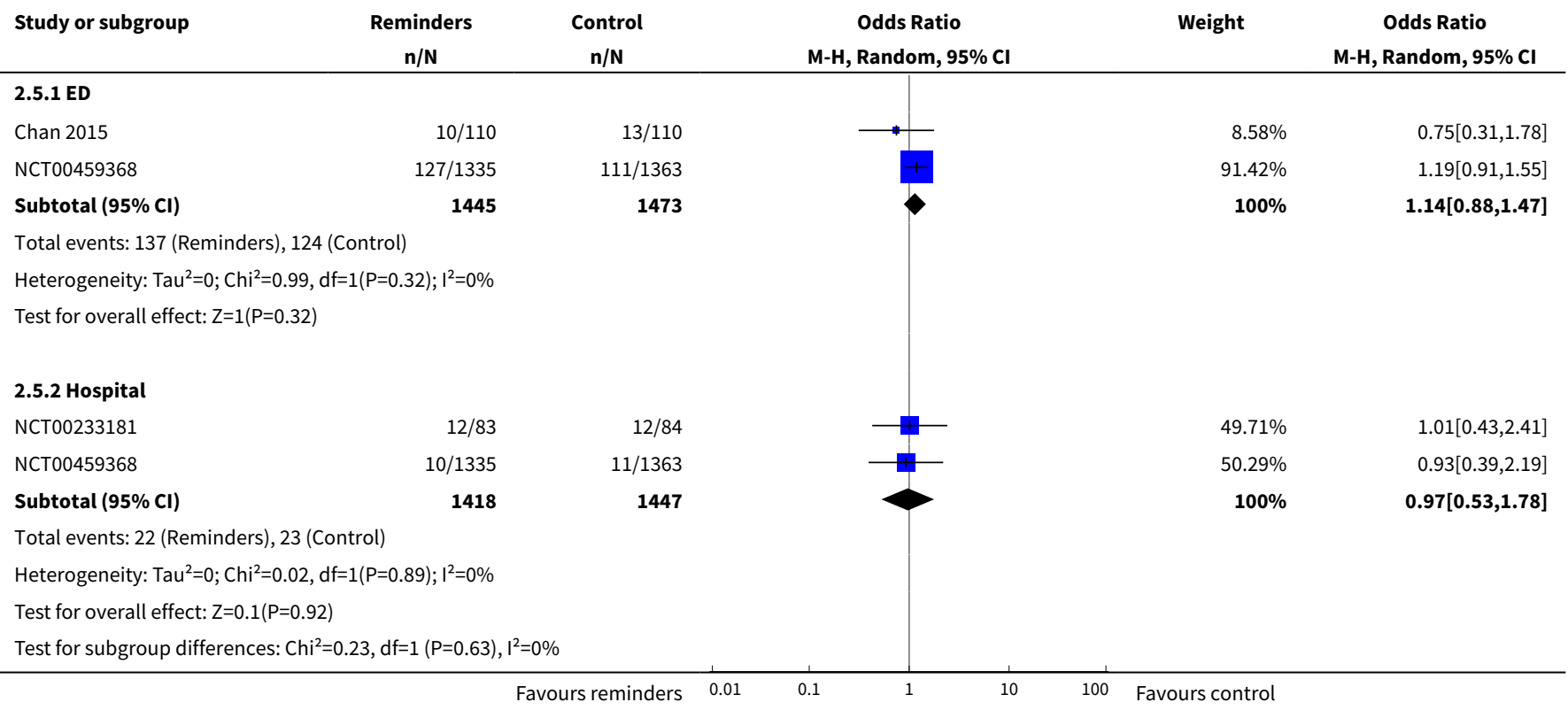


Analysis 2.6. Comparison 2 Electronic trackers or reminders ( \pm feedback) versus controls, Outcome 6 Unscheduled visits to a healthcare provider.

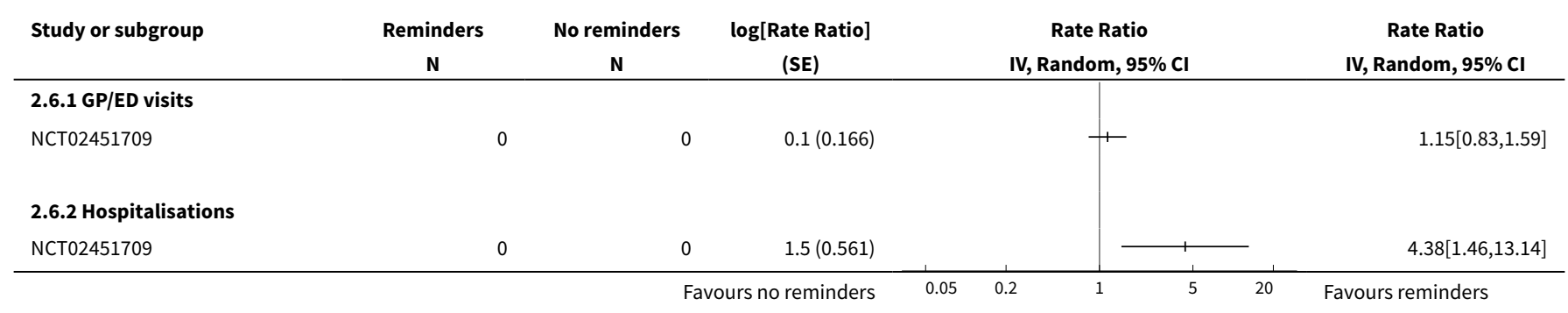

Analysis 2.7. Comparison 2 Electronic trackers or reminders ( \pm feedback) versus controls, Outcome 7 Absenteeism.

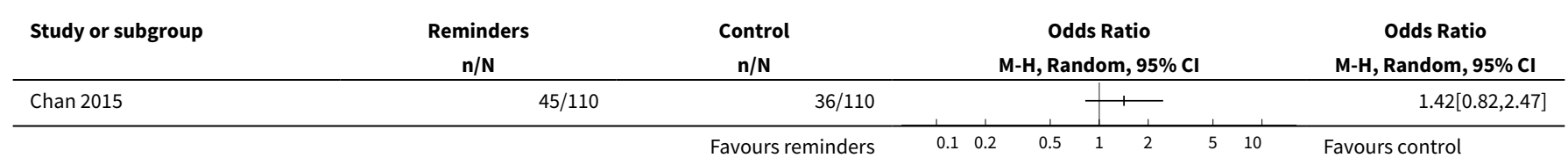

Analysis 2.8. Comparison 2 Electronic trackers or reminders ( \pm feedback) versus controls, Outcome 8 Absenteeism.

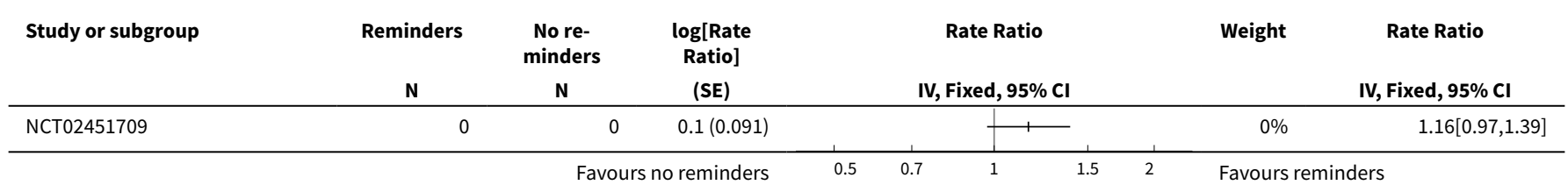

Analysis 2.9. Comparison 2 Electronic trackers or reminders

( \pm feedback) versus controls, Outcome 9 Quality of life (AQLQ).

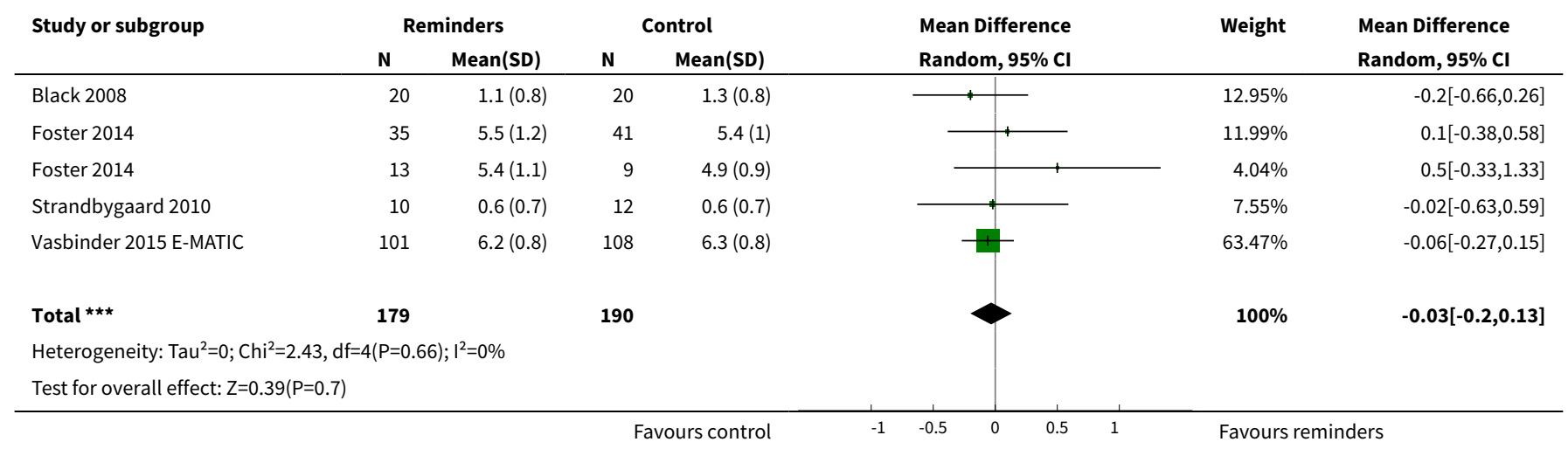


Comparison 3. Simplified versus usual regimens

\begin{tabular}{|c|c|c|c|c|}
\hline Outcome or subgroup title & No. of studies & $\begin{array}{l}\text { No. of partici- } \\
\text { pants }\end{array}$ & Statistical method & Effect size \\
\hline $1 \%$ Adherence & 3 & 1310 & $\begin{array}{l}\text { Mean Difference (IV, Random, 95\% } \\
\mathrm{Cl} \text { ) }\end{array}$ & $4.02[1.88,6.16]$ \\
\hline $\begin{array}{l}2 \text { Exacerbations requiring } \\
\text { OCS }\end{array}$ & 1 & & Odds Ratio (M-H, Random, 95\% Cl) & Totals not selected \\
\hline 3 Asthma control (ACQ) & 1 & & $\begin{array}{l}\text { Mean Difference (IV, Random, 95\% } \\
\mathrm{CI})\end{array}$ & Totals not selected \\
\hline 4 Unscheduled visits & 1 & & Odds Ratio (M-H, Random, 95\% Cl) & Totals not selected \\
\hline $\begin{array}{l}5 \text { Absence from work/ } \\
\text { school }\end{array}$ & 1 & & Odds Ratio (M-H, Random, 95\% Cl) & Totals not selected \\
\hline $\begin{array}{l}6 \text { Quality of life (ITG-ASF \% } \\
\text { change from baseline) }\end{array}$ & 1 & & $\begin{array}{l}\text { Mean Difference (IV, Random, 95\% } \\
\mathrm{CI})\end{array}$ & Totals not selected \\
\hline 7 All adverse events & 1 & & Odds Ratio (M-H, Random, 95\% Cl) & Totals not selected \\
\hline
\end{tabular}

Analysis 3.1. Comparison 3 Simplified versus usual regimens, Outcome $1 \%$ Adherence.

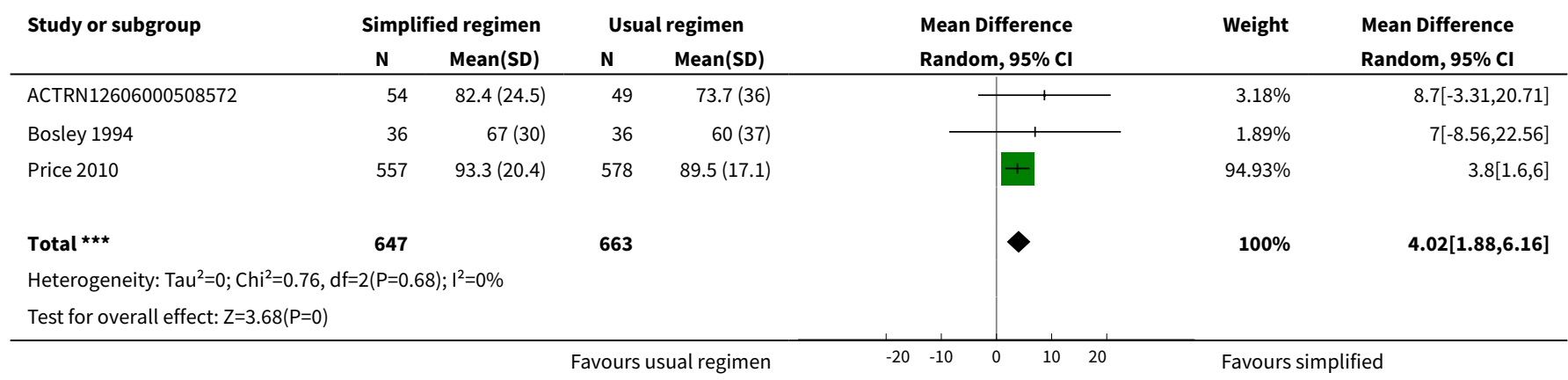

Analysis 3.2. Comparison 3 Simplified versus usual regimens, Outcome 2 Exacerbations requiring ocs.

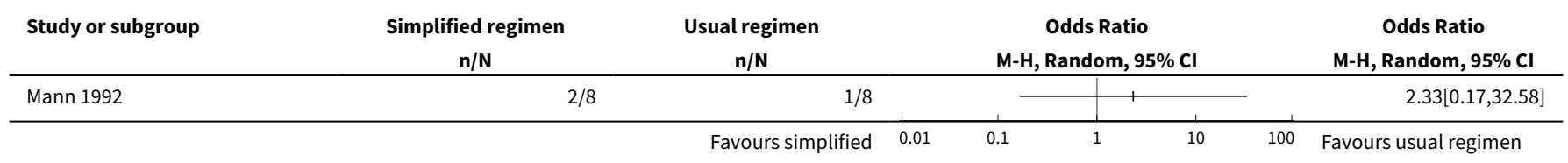


Analysis 3.3. Comparison 3 Simplified versus usual regimens, Outcome 3 Asthma control (ACQ).

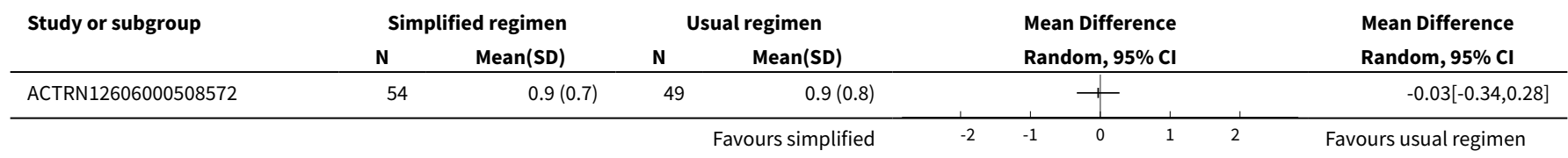

Analysis 3.4. Comparison 3 Simplified versus usual regimens, Outcome 4 Unscheduled visits.

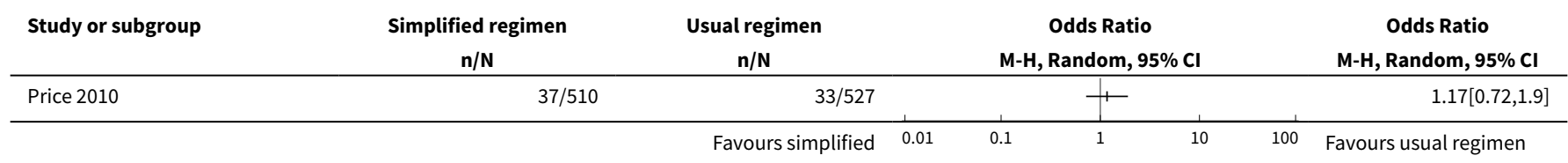

Analysis 3.5. Comparison 3 Simplified versus usual regimens, Outcome 5 Absence from work/school.

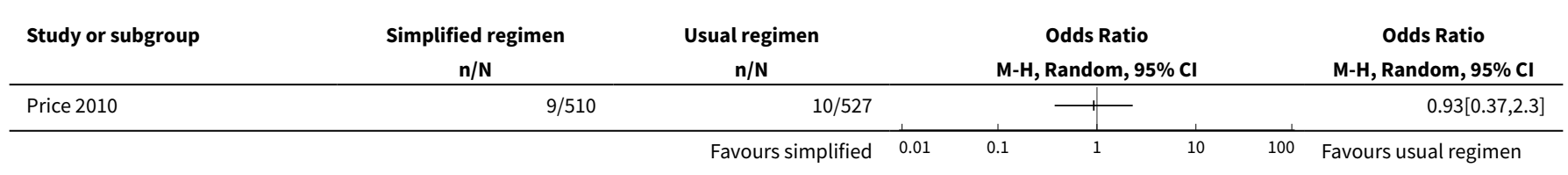

Analysis 3.6. Comparison 3 Simplified versus usual regimens, Outcome 6 Quality of life (ITG-ASF \% change from baseline).

\begin{tabular}{|c|c|c|c|c|c|c|c|}
\hline \multirow[t]{2}{*}{ Study or subgroup } & \multicolumn{2}{|c|}{ Simplified regimen } & \multicolumn{2}{|c|}{ Usual regimen } & \multirow{2}{*}{\multicolumn{2}{|c|}{$\begin{array}{l}\text { Mean Difference } \\
\text { Random, } 95 \% \mathrm{Cl}\end{array}$}} & \multirow{2}{*}{$\begin{array}{l}\text { Mean Difference } \\
\text { Random, } 95 \% \mathrm{CI}\end{array}$} \\
\hline & $\mathbf{N}$ & Mean(SD) & $\mathbf{N}$ & Mean(SD) & & & \\
\hline Price 2010 & 510 & $20(55.5)$ & 527 & $14(55.5)$ & & 1 & $6[-0.76,12.76]$ \\
\hline
\end{tabular}

Analysis 3.7. Comparison 3 Simplified versus usual regimens, Outcome 7 All adverse events.

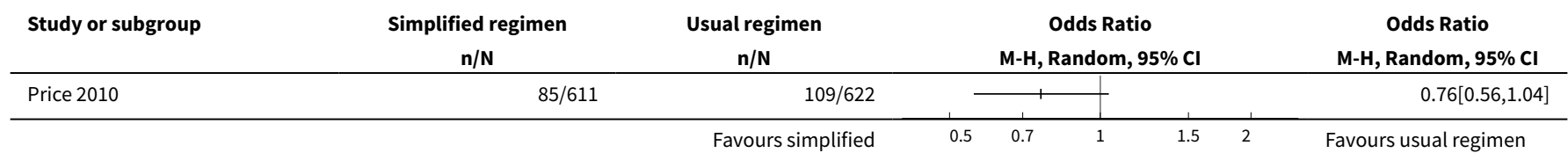

\section{Comparison 4. School-based ICS therapy versus controls}

\begin{tabular}{lllll}
\hline Outcome or subgroup title & No. of studies & $\begin{array}{l}\text { No. of partici- } \\
\text { pants }\end{array}$ & Statistical method & Effect size \\
\hline $\begin{array}{l}1 \text { Unscheduled visits (1 or more hospi- } \\
\text { talisations for any cause) }\end{array}$ & 2 & 279 & $\begin{array}{l}\text { Odds Ratio (M-H, Random, } \\
95 \% \mathrm{Cl})\end{array}$ & $0.58[0.16,2.05]$ \\
\hline
\end{tabular}




\begin{tabular}{lllll}
\hline Outcome or subgroup title & No. of studies & $\begin{array}{l}\text { No. of partici- } \\
\text { pants }\end{array}$ & Statistical method & Effect size \\
\hline 2 Quality of life (PAQLQ) & 2 & 279 & $\begin{array}{l}\text { Mean Difference (IV, Random, } \\
95 \% \text { Cl) }\end{array}$ & $0.25[0.01,0.49]$ \\
\hline
\end{tabular}

Analysis 4.1. Comparison 4 School-based ICS therapy versus controls, Outcome 1 Unscheduled visits (1 or more hospitalisations for any cause).

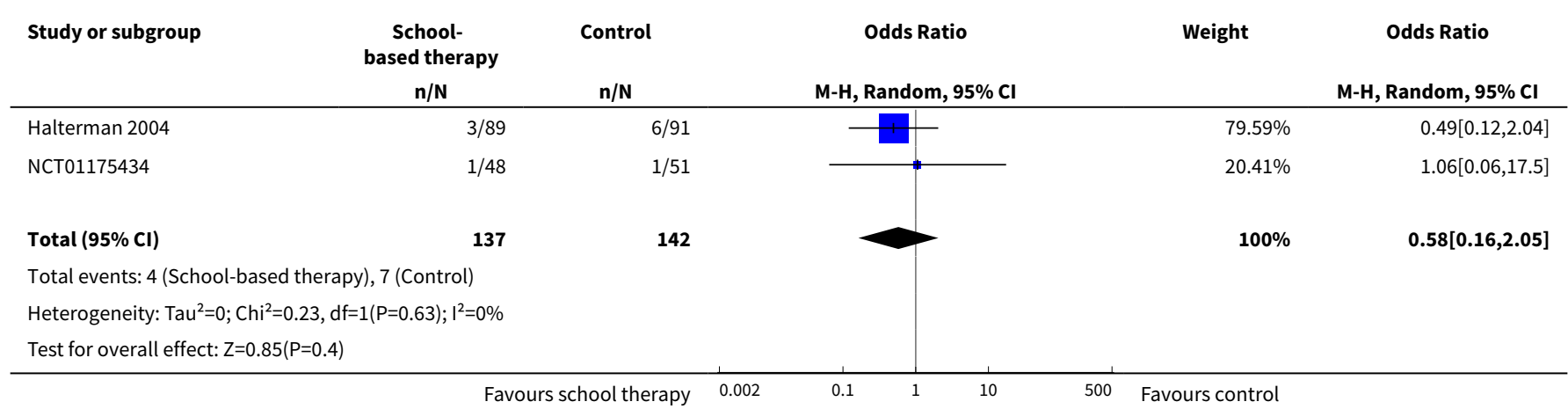

\section{Analysis 4.2. Comparison 4 School-based ICS therapy versus controls, Outcome 2 Quality of life (PAQLQ).}

\begin{tabular}{|c|c|c|c|c|c|c|c|}
\hline \multirow[t]{2}{*}{ Study or subgroup } & \multicolumn{2}{|c|}{$\begin{array}{c}\text { School- } \\
\text { based therapy }\end{array}$} & \multicolumn{2}{|c|}{ Control } & \multirow{2}{*}{$\begin{array}{l}\text { Mean Difference } \\
\text { Random, } 95 \% \mathrm{Cl}\end{array}$} & \multirow[t]{2}{*}{ Weight } & \multirow{2}{*}{$\begin{array}{l}\text { Mean Difference } \\
\text { Random, } 95 \% \mathrm{Cl}\end{array}$} \\
\hline & $\mathbf{N}$ & $\operatorname{Mean}(S D)$ & $\mathbf{N}$ & $\operatorname{Mean}(S D)$ & & & \\
\hline Halterman 2004 & 89 & $0.6(1.2)$ & 91 & $0.2(1.3)$ & $\longrightarrow$ & $42.88 \%$ & $0.39[0.02,0.76]$ \\
\hline NCT01175434 & 48 & $6.5(0.7)$ & 51 & $6.3(0.9)$ & + & $57.12 \%$ & $0.15[-0.17,0.47]$ \\
\hline 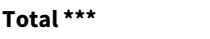 & 137 & & 142 & & & $100 \%$ & $0.25[0.01,0.49]$ \\
\hline \multicolumn{8}{|c|}{ Heterogeneity: $\mathrm{Tau}^{2}=0 ; \mathrm{Chi}^{2}=0.95, \mathrm{df}=1(\mathrm{P}=0.33) ; \mathrm{I}^{2}=0 \%$} \\
\hline \multicolumn{3}{|c|}{ Test for overall effect: $Z=2.07(P=0.04)$} & & & & & \\
\hline
\end{tabular}

\section{Comparison 5. Subgroup analyses for $\%$ adherence}

\begin{tabular}{lllll}
\hline Outcome or subgroup title & No. of studies & $\begin{array}{l}\text { No. of partici- } \\
\text { pants }\end{array}$ & Statistical method & Effect size \\
\hline $\begin{array}{l}1 \text { Comparison 1. Children vs } \\
\text { adults }\end{array}$ & 10 & 1693 & $\begin{array}{l}\text { Mean Difference (IV, Random, 95\% } \\
\text { Cl) }\end{array}$ & $11.59[3.72,19.46]$ \\
\hline $\begin{array}{l}1.1 \text { Children } \\
\text { n }\end{array}$ & 4 & 1241 & $\begin{array}{l}\text { Mean Difference (IV, Random, 95\% } \\
\text { CI) }\end{array}$ & $8.01[-4.77,20.79]$ \\
\hline $\begin{array}{l}1.2 \text { Adults/adolescents and } \\
\text { adults }\end{array}$ & 6 & 452 & $\begin{array}{l}\text { Mean Difference (IV, Random, 95\% } \\
\text { CI) }\end{array}$ & $14.43[5.49,23.36]$ \\
\hline
\end{tabular}




\begin{tabular}{|c|c|c|c|c|}
\hline Outcome or subgroup title & No. of studies & $\begin{array}{l}\text { No. of partici- } \\
\text { pants }\end{array}$ & Statistical method & Effect size \\
\hline $\begin{array}{l}2 \text { Comparison 2. Complex vs } \\
\text { simple interventions }\end{array}$ & 6 & 555 & $\begin{array}{l}\text { Mean Difference (IV, Random, 95\% } \\
\mathrm{CI} \text { ) }\end{array}$ & $19.86[14.47,25.26]$ \\
\hline 2.1 Complex & 3 & 234 & $\begin{array}{l}\text { Mean Difference (IV, Random, 95\% } \\
\mathrm{CI} \text { ) }\end{array}$ & $24.98[17.53,32.44]$ \\
\hline 2.2 Simple & 3 & 321 & $\begin{array}{l}\text { Mean Difference (IV, Random, 95\% } \\
\mathrm{CI} \text { ) }\end{array}$ & $16.29[9.53,23.04]$ \\
\hline $\begin{array}{l}3 \text { Comparison 2. Children vs } \\
\text { adults }\end{array}$ & 6 & 555 & $\begin{array}{l}\text { Mean Difference (IV, Random, 95\% } \\
\mathrm{CI} \text { ) }\end{array}$ & $19.86[14.47,25.26]$ \\
\hline 3.1 Children & 3 & 314 & $\begin{array}{l}\text { Mean Difference (IV, Random, 95\% } \\
\mathrm{CI} \text { ) }\end{array}$ & $17.29[8.32,26.26]$ \\
\hline $\begin{array}{l}3.2 \text { Adults/adolescents and } \\
\text { adults }\end{array}$ & 3 & 241 & $\begin{array}{l}\text { Mean Difference (IV, Random, 95\% } \\
\text { CI) }\end{array}$ & $22.84[16.66,29.02]$ \\
\hline
\end{tabular}

Analysis 5.1. Comparison 5 Subgroup analyses for $\%$ adherence, Outcome 1 Comparison 1 . Children vs adults.

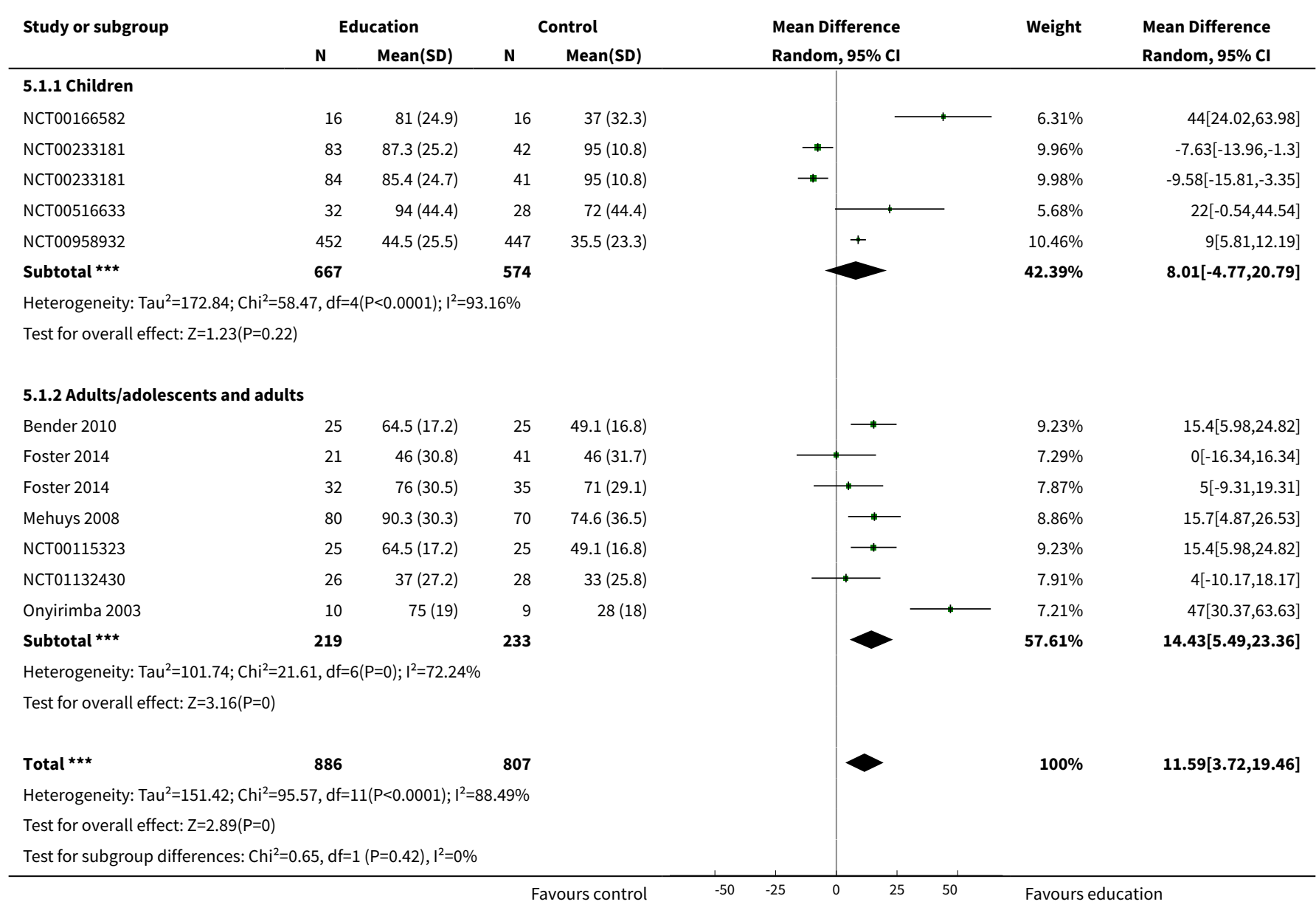




\section{Analysis 5.2. Comparison 5 Subgroup analyses for $\%$ adherence, Outcome 2 Comparison 2. Complex vs simple interventions.}

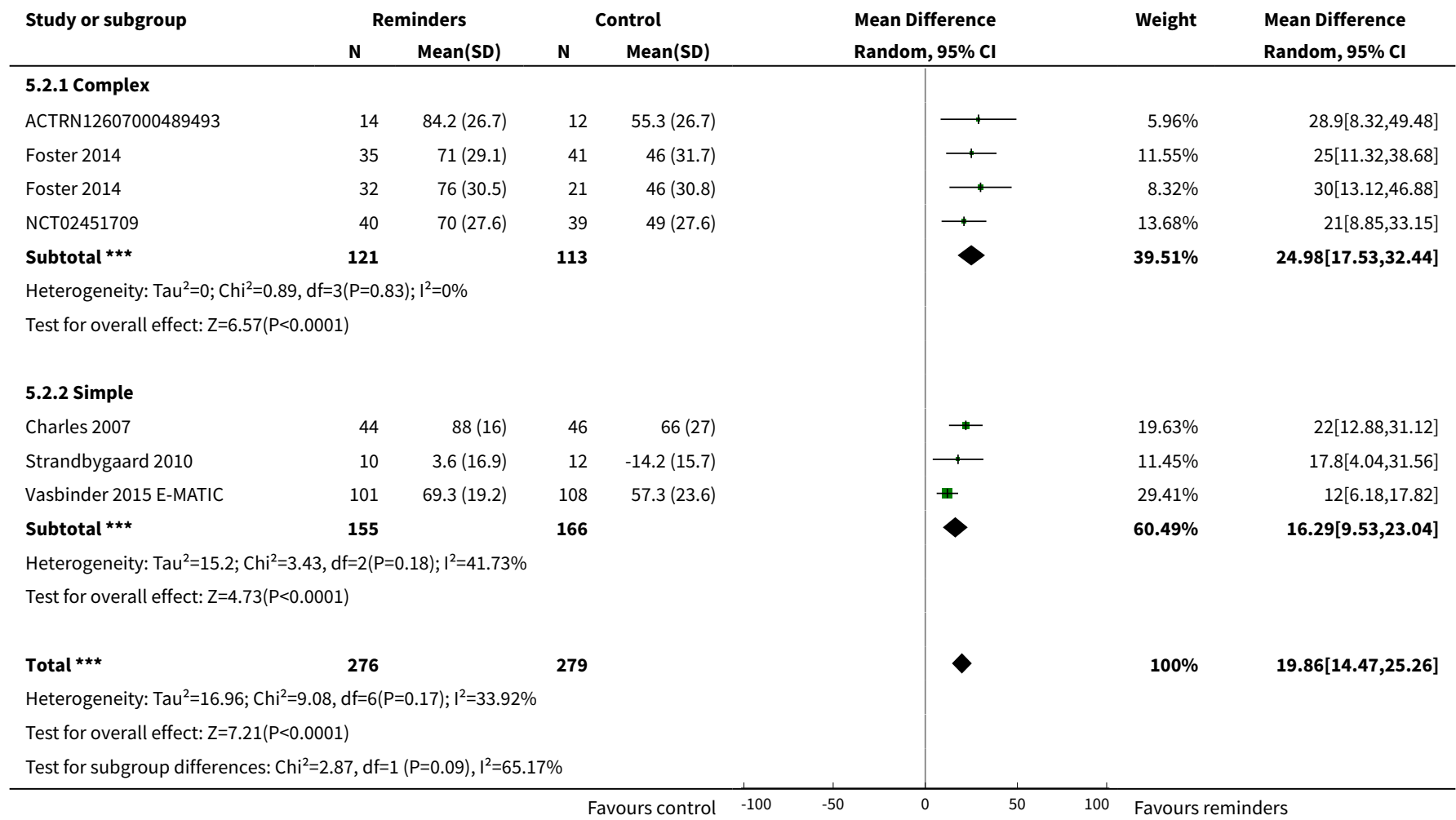

Analysis 5.3. Comparison 5 Subgroup analyses for $\%$ adherence, Outcome 3 Comparison 2 . Children vs adults.

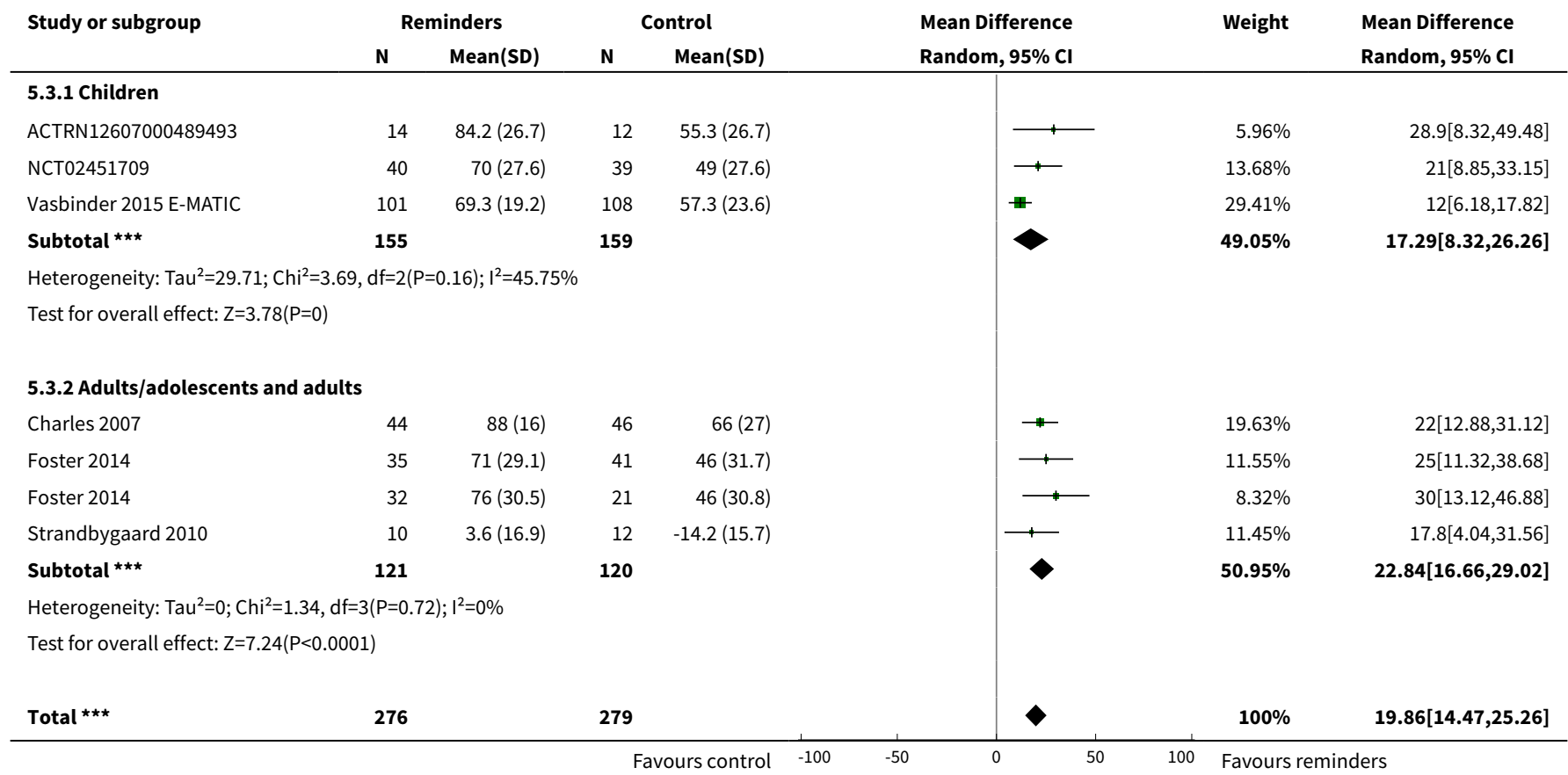




\begin{tabular}{|c|c|c|c|c|c|}
\hline \multirow[t]{2}{*}{ Study or subgroup } & Reminders & Control & \multirow{2}{*}{$\begin{array}{l}\text { Mean Difference } \\
\text { Random, } 95 \% \mathrm{CI}\end{array}$} & \multirow[t]{2}{*}{ Weight } & \multirow{2}{*}{$\begin{array}{l}\text { Mean Difference } \\
\text { Random, } 95 \% \mathrm{Cl}\end{array}$} \\
\hline & Mean(SD) & Mean(SD) & & & \\
\hline \multicolumn{6}{|c|}{ Heterogeneity: $\mathrm{Tau}^{2}=16.96 ; \mathrm{Chi}^{2}=9.08, \mathrm{df}=6(\mathrm{P}=0.17) ; \mathrm{I}^{2}=33.92 \%$} \\
\hline \multicolumn{6}{|c|}{ Test for overall effect: $Z=7.21(P<0.0001)$} \\
\hline \multicolumn{6}{|c|}{ Test for subgroup differences: $\mathrm{Chi}^{2}=1, \mathrm{df}=1(\mathrm{P}=0.32), \mathrm{I}^{2}=0 \%$} \\
\hline
\end{tabular}




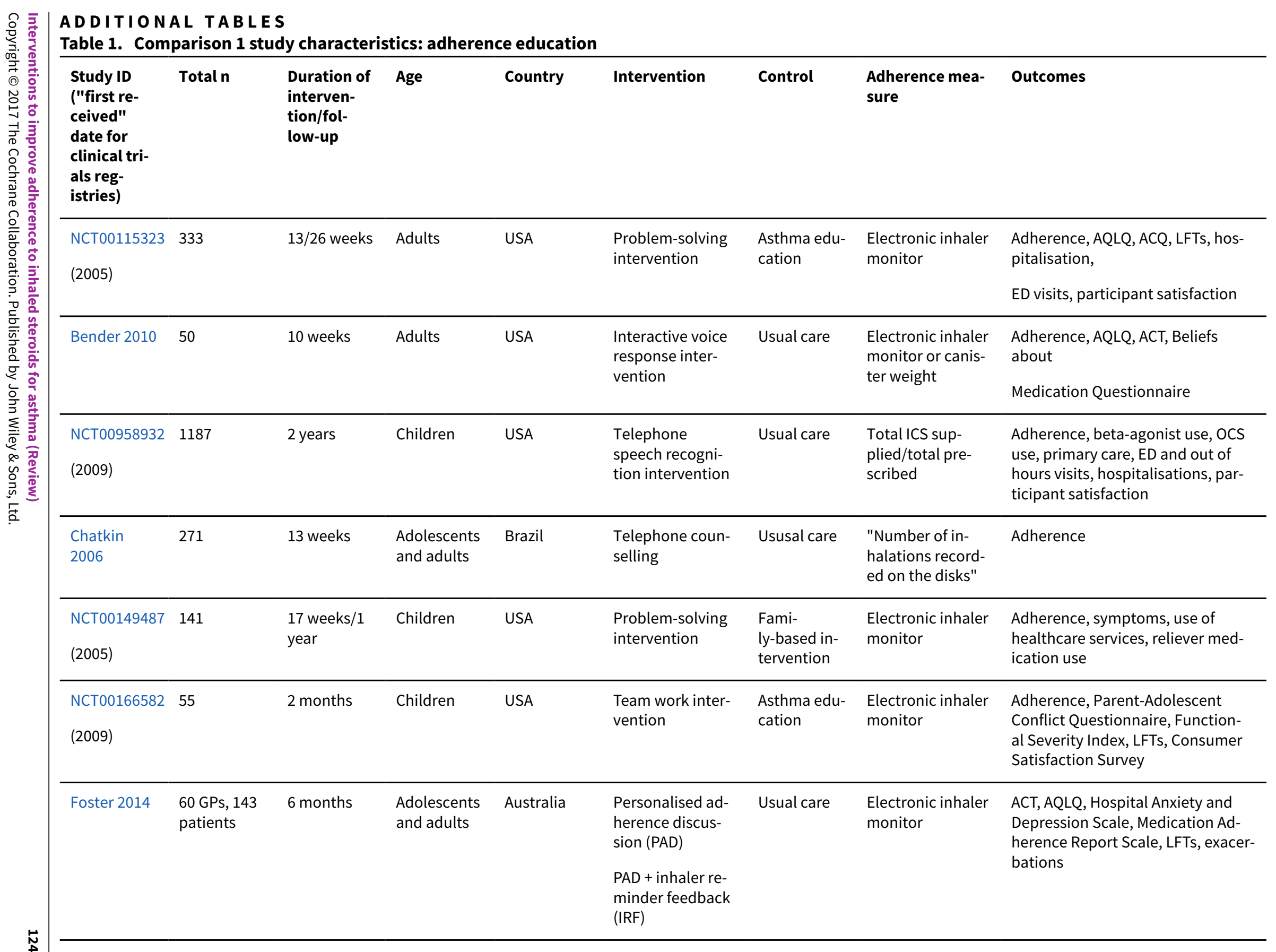




\begin{tabular}{|c|c|c|c|c|c|c|c|c|}
\hline $\begin{array}{l}\text { Gallefoss } \\
1999\end{array}$ & 78 & 1 year & Adults & Norway & $\begin{array}{l}\text { Asthma educa- } \\
\text { tion }\end{array}$ & Usual care & $\begin{array}{l}\text { Prescribed dos- } \\
\text { es/dispensed } \\
\text { doses }\end{array}$ & $\begin{array}{l}\text { Adherence, GP visits, absenteeism, } \\
\text { days in hospital }\end{array}$ \\
\hline $\begin{array}{l}\text { NCT01064869 } \\
(2010)\end{array}$ & 20 & $\begin{array}{l}12 \text { weeks } / 1 \\
\text { year }\end{array}$ & $\begin{array}{l}\text { Not report- } \\
\text { ed, but } \\
\text { mean age } \\
\text { suggests } \\
\text { adults }\end{array}$ & $\begin{array}{l}\text { Northern } \\
\text { Ireland }\end{array}$ & $\begin{array}{l}\text { Nurse-led psy- } \\
\text { choeducation }\end{array}$ & $\begin{array}{l}\text { Ususal care } \\
\text { (difficult } \\
\text { asthma ser- } \\
\text { vice) }\end{array}$ & $\begin{array}{l}\text { Percent of pre- } \\
\text { scriptions refilled }\end{array}$ & $\begin{array}{l}\text { Adherence, OCS, beta-agonist use, } \\
\text { hospital admissions, LFTs, ACQ, } \\
\text { AQLQ, Hospital Anxiety and De- } \\
\text { spression Scale }\end{array}$ \\
\hline $\begin{array}{l}\text { ADERE } \\
\text { PEDIATRIC } 1 \\
(2008)\end{array}$ & 298 & 90 weeks & Children & Brazil & $\begin{array}{l}\text { Telephone fol- } \\
\text { low-up interven- } \\
\text { tion }\end{array}$ & Usual care & $\begin{array}{l}\text { Percentage of ac- } \\
\text { tual doses/num- } \\
\text { ber expected }\end{array}$ & $\begin{array}{l}\text { Adherence, disease control, quality } \\
\text { of life (SF-36) }\end{array}$ \\
\hline Hart 2002 & 83 & 13 weeks & Children & UK & $\begin{array}{l}\text { Asthma educa- } \\
\text { tion }\end{array}$ & Usual care & $\begin{array}{l}\text { Electronic inhaler } \\
\text { monitor }\end{array}$ & $\begin{array}{l}\text { Adherence, beliefs and anxieties } \\
\text { about adherence }\end{array}$ \\
\hline $\begin{array}{l}\text { NCT00516633 } \\
(2007)\end{array}$ & 60 & $\begin{array}{l}26 \text { weeks } / 78 \\
\text { weeks }\end{array}$ & Children & Sweden & $\begin{array}{l}\text { Group discussion } \\
\text { plus basic educa- } \\
\text { tion }\end{array}$ & $\begin{array}{l}\text { Basic educa- } \\
\text { tion }\end{array}$ & $\begin{array}{l}\text { Diaries and canis- } \\
\text { ter weight }\end{array}$ & $\begin{array}{l}\text { Adherence, views on adherence, } \\
\text { days hospitalised, ED visits, exacer- } \\
\text { bations }\end{array}$ \\
\hline Kamps 2008 & 15 & $\begin{array}{l}6 \text { weeks } / 52 \\
\text { weeks }\end{array}$ & Children & USA & $\begin{array}{l}\text { Specific adher- } \\
\text { ence improve- } \\
\text { ment strategies } \\
\text { (education, moni- } \\
\text { toring, etc.) }\end{array}$ & $\begin{array}{l}\text { Usual care } \\
\text { plus educa- } \\
\text { tion }\end{array}$ & $\begin{array}{l}\text { Electronic inhaler } \\
\text { monitor }\end{array}$ & $\begin{array}{l}\text { Adherence, LFTs, PedsQL, health- } \\
\text { care costs }\end{array}$ \\
\hline $\begin{array}{l}\text { NCT01132430 } \\
(2010)\end{array}$ & 54 & $\begin{array}{l}6 \text { weeks/52 } \\
\text { weeks }\end{array}$ & Adults & Canada & $\begin{array}{l}\text { Motivational in- } \\
\text { terviewing }\end{array}$ & Usual care & $\begin{array}{l}\text { Prescribed treat- } \\
\text { ment days/num- } \\
\text { ber of days }\end{array}$ & $\begin{array}{l}\text { Adherence, asthma control, quality } \\
\text { of life, asthma-related self-efficacy }\end{array}$ \\
\hline $\begin{array}{l}\text { Mehuys } \\
2008\end{array}$ & 201 & 6 months & Adults & Belgium & $\begin{array}{l}\text { Adherence edu- } \\
\text { cation }\end{array}$ & Usual care & $\begin{array}{l}\text { Prescription refill } \\
\text { rates, self-report- } \\
\text { ing }\end{array}$ & $\begin{array}{l}\text { ACT, diary card, rescue medica- } \\
\text { tion use, ED visits, hospitalisations, } \\
\text { AQLQ, Knowledge of Asthma and } \\
\text { Asthma Medicine Questionnaire, } \\
\text { inhalation technique }\end{array}$ \\
\hline $\begin{array}{l}\text { NCT01169883 } \\
(2010)\end{array}$ & 68 & 10 weeks & Adolescents & USA & $\begin{array}{l}\text { Adherence mes- } \\
\text { saging and group } \\
\text { sessions }\end{array}$ & $\begin{array}{l}\text { "Attention } \\
\text { control" }\end{array}$ & $\begin{array}{l}\text { Electronic inhaler } \\
\text { monitor }\end{array}$ & $\begin{array}{l}\text { Adherence, asthma knowledge, ICS } \\
\text { knowledge, ICS self-efficacy, social } \\
\text { support, exacerbations }\end{array}$ \\
\hline NCT02413528 & 12 & 12 weeks & Adolescents & USA & $\begin{array}{l}\text { Adherence moni- } \\
\text { toring and incen- }\end{array}$ & Usual care & $\begin{array}{l}\text { Electronic inhaler } \\
\text { monitor }\end{array}$ & Adherence, ACT \\
\hline
\end{tabular}




\begin{tabular}{|c|c|c|c|c|c|c|c|c|}
\hline (2015) & & & & & $\begin{array}{l}\text { tivisation via app } \\
\text { and sensor }\end{array}$ & & & NB: study terminated \\
\hline $\begin{array}{l}\text { Onyirimba } \\
2003\end{array}$ & 30 & 10 weeks & Adults & USA & $\begin{array}{l}\text { Adherence moni- } \\
\text { toring and educa- } \\
\text { tion }\end{array}$ & $\begin{array}{l}\text { Monitor- } \\
\text { ing without } \\
\text { feedback }\end{array}$ & $\begin{array}{l}\text { Electronic inhaler } \\
\text { monitor }\end{array}$ & $\begin{array}{l}\text { Adherence, rescue medication use, } \\
\text { AQLQ, LFTs }\end{array}$ \\
\hline $\begin{array}{l}\text { NCT00233181 } \\
(2005)\end{array}$ & 250 & 78 weeks & Children & USA & $\begin{array}{l}\text { Adherence edu- } \\
\text { cation }\end{array}$ & Usual care & $\begin{array}{l}\text { Prescription refill } \\
\text { rates, self-report- } \\
\text { ing }\end{array}$ & $\begin{array}{l}\text { Adherence, symptoms, night-time } \\
\text { awakenings, ED visits, hospitalisa- } \\
\text { tion, OCS courses }\end{array}$ \\
\hline Ulrik 2009 & 274 & 12 weeks & Adults & $\begin{array}{l}\text { Denmark } \\
\text { and Switzer- } \\
\text { land }\end{array}$ & $\begin{array}{l}\text { Adherence edu- } \\
\text { cation and study } \\
\text { medication }\end{array}$ & $\begin{array}{l}\text { Study med- } \\
\text { ication } \\
\text { alone }\end{array}$ & $\begin{array}{l}\text { Dose counting in } \\
\text { returned investi- } \\
\text { gational product }\end{array}$ & $\begin{array}{l}\text { Adherence, asthma control, LFTs, } \\
\text { symptoms, rescue medication use, } \\
\text { night-time awakenings, adverse } \\
\text { events, AQLQ, asthma severity, ad- } \\
\text { verse events, vital signs }\end{array}$ \\
\hline $\begin{array}{l}\text { NCT00414817 } \\
(2006)\end{array}$ & $\begin{array}{l}14,064 \text { (6903 } \\
\text { previous ICS } \\
\text { users) }\end{array}$ & 78 weeks & Adults & USA & $\begin{array}{l}\text { Telephone in- } \\
\text { teractive voice } \\
\text { recognition inter- } \\
\text { vention }\end{array}$ & Usual care & $\begin{array}{l}\text { Pharmacy-based } \\
\text { adherence mea- } \\
\text { sures }\end{array}$ & $\begin{array}{l}\text { Adherence, use of healthcare ser- } \\
\text { vices, economic evaluation }\end{array}$ \\
\hline
\end{tabular}

ACQ: Asthma Control Questionnaire; ACT: Asthma Control Test; AQLQ: Asthma Quality of Life Questionnaire; ED: emergency department; GP: general practitioner; ICS: inhaled corticosteroid; IRF: inhaler reminder feedback; LFTs: lung function tests; OCS: oral corticosteroid; PAD: personalised adherence discussion; PedsQL: Paediatric Quality of Life Inventory; SF-36: Short-Form Health Survey

\section{Table 2. Comparison 2 study characteristics: electronic trackers or reminders}

\begin{tabular}{|c|c|c|c|c|c|c|c|c|}
\hline Study ID & Total $\mathbf{n}$ & $\begin{array}{l}\text { Duration of } \\
\text { interven- } \\
\text { tion/fol- } \\
\text { low-up }\end{array}$ & Age & Country & Intervention & Control & $\begin{array}{l}\text { Adherence } \\
\text { measure }\end{array}$ & Outcomes \\
\hline Black 2008 & 40 & 2 months & Children & $\begin{array}{l}\text { New } \\
\text { Zealand }\end{array}$ & Inhaler alarm & Usual care & $\begin{array}{l}\text { Electronic in- } \\
\text { haler monitor }\end{array}$ & $\begin{array}{l}\text { Adherence, AQLQ, LFTs, beta-agonist } \\
\text { use }\end{array}$ \\
\hline $\begin{array}{l}\text { AC- } \\
\text { TRN126070004 } \\
(2007)\end{array}$ & $\begin{array}{l}26 \\
89493\end{array}$ & 4 months & Children & Australia & $\begin{array}{l}\text { Adherence feed- } \\
\text { back during con- } \\
\text { sultations }\end{array}$ & Usual care & $\begin{array}{l}\text { Electronic in- } \\
\text { haler monitor }\end{array}$ & Adherence, symptoms, LFTs \\
\hline Chan 2015 & 220 & 6 months & Children & $\begin{array}{l}\text { New } \\
\text { Zealand }\end{array}$ & $\begin{array}{l}\text { Audiovisual in- } \\
\text { haler reminder }\end{array}$ & Usual care & $\begin{array}{l}\text { Electronic in- } \\
\text { haler monitor }\end{array}$ & $\begin{array}{l}\text { Adherence, school/work absences, } \\
\text { ACT, Asthma Morbidity Score, exacer- }\end{array}$ \\
\hline
\end{tabular}




\begin{tabular}{|c|c|c|c|c|c|c|c|c|}
\hline & & & & & & & & bations, unscheduled visits, beta-ag- \\
\hline $\begin{array}{l}\text { Charles } \\
2007\end{array}$ & 110 & 24 weeks & $\begin{array}{l}\text { Adolescents } \\
\text { and adults }\end{array}$ & $\begin{array}{l}\text { New } \\
\text { Zealand }\end{array}$ & $\begin{array}{l}\text { Audiovisual in- } \\
\text { haler reminder }\end{array}$ & Usual care & $\begin{array}{l}\text { Electronic in- } \\
\text { haler monitor }\end{array}$ & Adherence, ACQ, LFTs \\
\hline Foster 2014 & $\begin{array}{l}60 \mathrm{GPs}, 143 \\
\text { patients }\end{array}$ & 6 months & $\begin{array}{l}\text { Adolescents } \\
\text { and adults }\end{array}$ & Australia & $\begin{array}{l}\text { Inhaler reminder } \\
\text { and feedback } \\
\text { (IRF) }\end{array}$ & Usual care & $\begin{array}{l}\text { Electronic in- } \\
\text { haler monitor }\end{array}$ & $\begin{array}{l}\text { ACT, AQLQ, Hospital Anxiety and De- } \\
\text { pression Scale, Medication Adher- } \\
\text { ence Report Scale, LFTs, exacerba- } \\
\text { tions }\end{array}$ \\
\hline $\begin{array}{l}\text { NCT01714141 } \\
(2012)\end{array}$ & 49 & 13 weeks & $\begin{array}{l}\text { Young } \\
\text { adults }\end{array}$ & USA & $\begin{array}{l}\text { Computer ses- } \\
\text { sions and tailored } \\
\text { text reminders }\end{array}$ & $\begin{array}{l}\text { Asthma edu- } \\
\text { cation }\end{array}$ & $\begin{array}{l}\text { Self-reported } \\
\text { missed doses }\end{array}$ & $\begin{array}{l}\text { Adherence, ACT, LFTs, participant } \\
\text { satisfaction }\end{array}$ \\
\hline $\begin{array}{l}\text { NCT02451709 } \\
\text { (2015) }\end{array}$ & 90 & 1 year & Children & UK & $\begin{array}{l}\text { Adherence moni- } \\
\text { toring with feed- } \\
\text { back }\end{array}$ & $\begin{array}{l}\text { Adherence } \\
\text { monitoring } \\
\text { but no feed- } \\
\text { back }\end{array}$ & $\begin{array}{l}\text { Electronic in- } \\
\text { haler monitor }\end{array}$ & $\begin{array}{l}\text { "Clinical outcomes", adherence, } \\
\text { LFTs, exacerbations }\end{array}$ \\
\hline $\begin{array}{l}\text { NCT00233181 } \\
(2005)\end{array}$ & 250 & 78 weeks & Children & USA & $\begin{array}{l}\text { Adherence moni- } \\
\text { toring and educa- } \\
\text { tion }\end{array}$ & $\begin{array}{l}\text { Adherence } \\
\text { education }\end{array}$ & $\begin{array}{l}\text { Prescription re- } \\
\text { fill rates, self-re- } \\
\text { porting }\end{array}$ & $\begin{array}{l}\text { Adherence, symptoms, night-time } \\
\text { awakenings, ED visits, hospitalisa- } \\
\text { tion, OCS courses }\end{array}$ \\
\hline $\begin{array}{l}\text { Strandby- } \\
\text { gaard } 2010\end{array}$ & 26 & 12 weeks & Adults & Denmark & $\begin{array}{l}\text { SMS (text mes- } \\
\text { sage) adherence } \\
\text { reminders }\end{array}$ & Usual care & $\begin{array}{l}\text { "Dose-count" } \\
\text { on the Seretide } \\
\text { was diskus }\end{array}$ & $\begin{array}{l}\text { Adherence, change in FeNO, LFTs, } \\
\text { airway responsiveness }\end{array}$ \\
\hline $\begin{array}{l}\text { Vasbinder } \\
2015 \text { E- } \\
\text { MATIC }\end{array}$ & 219 & 52 weeks & Children & $\begin{array}{l}\text { The Nether- } \\
\text { lands }\end{array}$ & $\begin{array}{l}\text { SMS (text mes- } \\
\text { sage) adherence } \\
\text { reminders }\end{array}$ & Usual care & $\begin{array}{l}\text { Electronic in- } \\
\text { haler monitor }\end{array}$ & $\begin{array}{l}\text { Adherence, ACT, exacerbations, use } \\
\text { of healthcare services, AQLQ, school/ } \\
\text { work absence, acceptance of e-mon- } \\
\text { itoring, economic evaluation }\end{array}$ \\
\hline $\begin{array}{l}\text { NCT00459368 } \\
(2007)\end{array}$ & $\begin{array}{l}2698 \text { ( } 34 \\
\text { clusters) }\end{array}$ & 52 weeks & $\begin{array}{l}\text { Children } \\
\text { and adults }\end{array}$ & USA & $\begin{array}{l}\text { Adherence edu- } \\
\text { cation with ad- } \\
\text { herence feedback }\end{array}$ & $\begin{array}{l}\text { Adherence } \\
\text { education } \\
\text { alone }\end{array}$ & $\begin{array}{l}\text { Electronic pre- } \\
\text { scribing da- } \\
\text { ta/refill rate }\end{array}$ & $\begin{array}{l}\text { Adherence, ED visits, hospitalisation, } \\
\text { OCS use }\end{array}$ \\
\hline
\end{tabular}

ACQ: Asthma Control Questionnaire; ACT: Asthma Control Test; AQLQ: Asthma Quality of Life Questionnaire; ED: emergency department; FeNO: fractional exhaled nitric oxide; ICS: inhaled corticosteroid; LFTs: lung function tests; OCS: oral corticosteroid 
Table 3. Comparison 3 study characteristics: simplified regimens

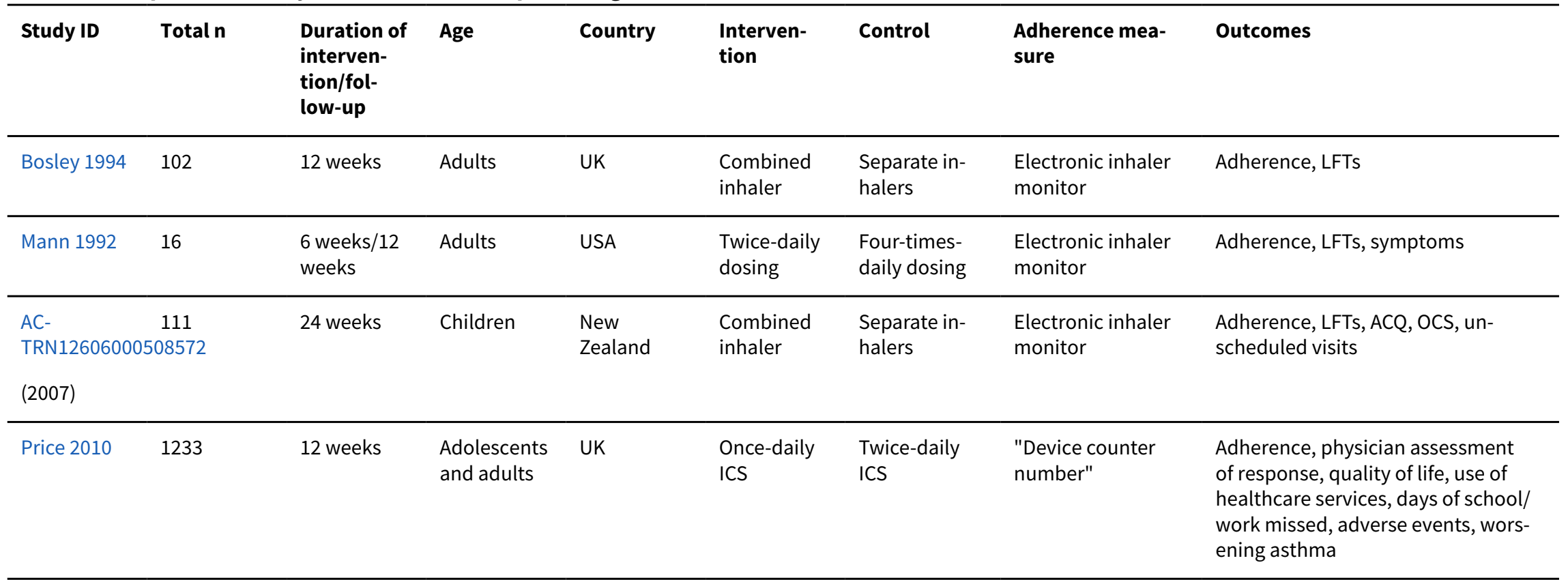

ACQ: Asthma Control Questionnaire; ICS: inhaled corticosteroid; LFTs: lung function tests; OCS: oral corticosteroid

Table 4. Comparison 4 study characteristics: school-based ICS therapy

\begin{tabular}{|c|c|c|c|c|c|c|c|c|}
\hline Study ID & Total $\mathbf{n}$ & $\begin{array}{l}\text { Duration of } \\
\text { interven- } \\
\text { tion/fol- } \\
\text { low-up }\end{array}$ & Age & Country & Intervention & Control & $\begin{array}{l}\text { Adherence } \\
\text { measure }\end{array}$ & Outcomes \\
\hline Gerald 2009 & 290 & 65 weeks & Children & USA & $\begin{array}{l}\text { Supervised } \\
\text { ICS therapy at } \\
\text { school }\end{array}$ & Usual care & $\mathrm{N} / \mathrm{A}$ & $\begin{array}{l}\text { Episodes of poor asthma control, school ab- } \\
\text { sences, rescue medication use at school }\end{array}$ \\
\hline $\begin{array}{l}\text { Halterman } \\
2004\end{array}$ & 184 & 9 weeks & Children & USA & $\begin{array}{l}\text { Supervised } \\
\text { ICS therapy at } \\
\text { school }\end{array}$ & Usual care & $\mathrm{N} / \mathrm{A}$ & $\begin{array}{l}\text { Symptom-free days, daytime and night- } \\
\text { time symptoms, rescue medication use, } \\
\text { school absences }\end{array}$ \\
\hline $\begin{array}{l}\text { NCT01175434 } \\
\text { (2010) }\end{array}$ & 100 & $\begin{array}{l}6 \text { to } 8 \\
\text { months }\end{array}$ & Children & USA & $\begin{array}{l}\text { Supervised } \\
\text { ICS therapy at } \\
\text { school }\end{array}$ & Usual care & $\mathrm{N} / \mathrm{A}$ & $\begin{array}{l}\text { Feasibility, symptom-free days, numbers } \\
\text { of days and nights with symptoms, activity } \\
\text { limitation, rescue medication use, school } \\
\text { absenteeism, parent sleep interruption, }\end{array}$ \\
\hline
\end{tabular}




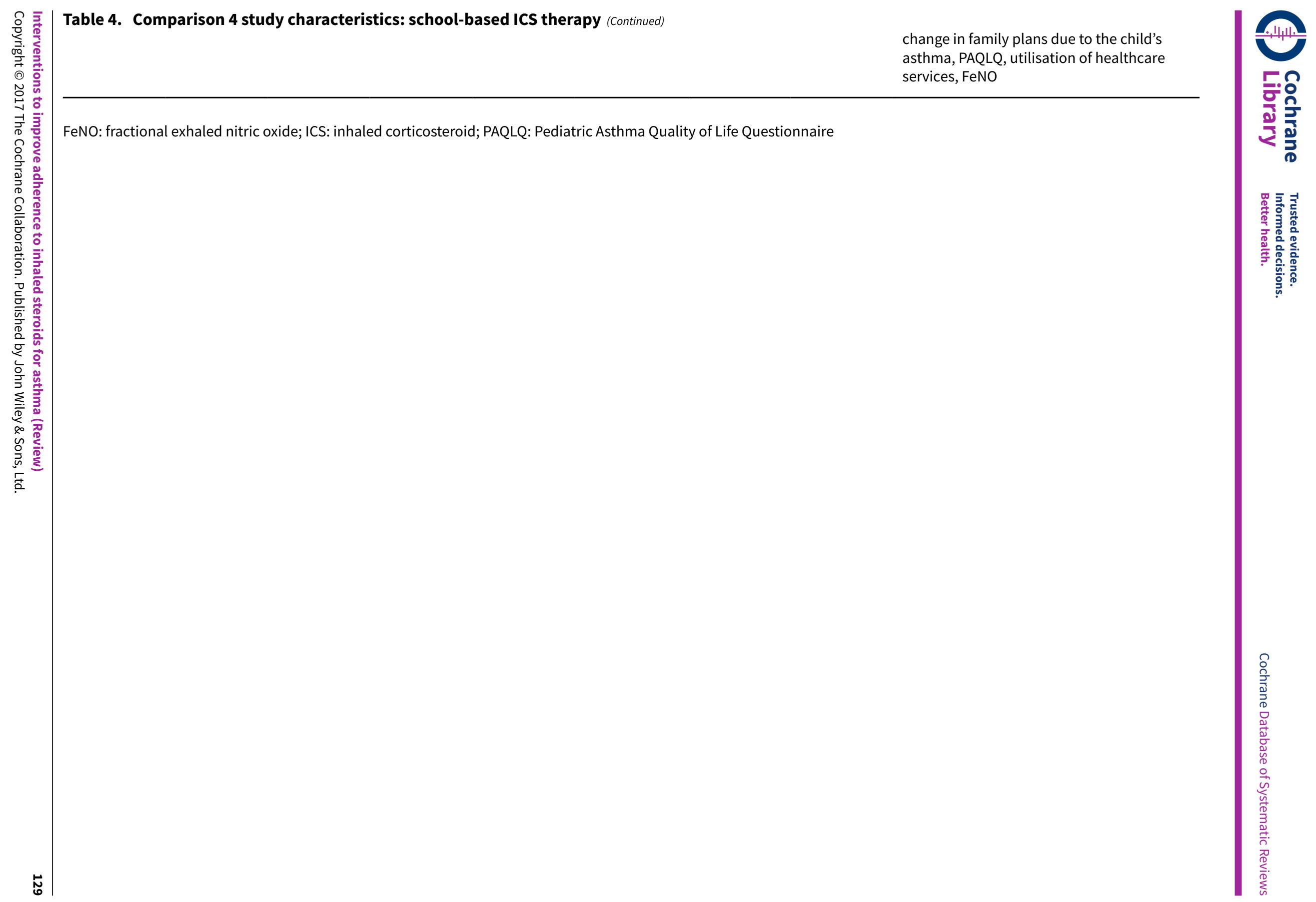




\section{AP PEN DICES}

\section{Appendix 1. Sources and search methods for the Cochrane Airways Group Specialised Register (CAGR)}

Electronic searches: core databases

\begin{tabular}{ll}
\hline Database & Frequency of search \\
\hline CENTRAL & Monthly \\
\hline MEDLINE (Ovid) & Weekly \\
\hline Embase (Ovid) & Weekly \\
\hline PSycINFO (Ovid) & Monthly \\
\hline CINAHL (EBSCO) & Monthly \\
\hline AMED (EBSCO) & Monthly \\
\hline
\end{tabular}

Handsearches: core respiratory conference abstracts

\begin{tabular}{ll}
\hline Conference & Years searched \\
\hline American Academy of Allergy, Asthma and Immunology (AAAAI) & 2001 onwards \\
\hline American Thoracic Society (ATS) & 2001 onwards \\
\hline Asia Pacific Society of Respirology (APSR) & 2004 onwards \\
\hline British Thoracic Society Winter Meeting (BTS) & 2000 onwards \\
\hline Chest Meeting & 2003 onwards \\
\hline European Respiratory Society (ERS) & $1992,1994,2000$ onwards \\
\hline International Primary Care Respiratory Group Congress (IPCRG) & 2002 onwards \\
\hline Thoracic Society of Australia and New Zealand (TSANZ) & 1999 onwards \\
\hline
\end{tabular}

\section{MEDLINE search strategy used to identify trials for the CAGR}

\section{Asthma search}
1. $\exp$ Asthma/
2. asthma\$.mp.
3. (antiasthma\$ or anti-asthma\$).mp.
4. Respiratory Sounds/
5. wheez\$.mp. 
6. Bronchial Spasm/

7. bronchospas\$.mp.

8. (bronch\$ adj3 spasm\$).mp.

9. bronchoconstrict\$.mp.

10. exp Bronchoconstriction/

11. (bronch\$ adj3 constrict\$).mp.

12. Bronchial Hyperreactivity/

13. Respiratory Hypersensitivity/

14. ((bronchial\$ or respiratory or airway\$ or lung\$) adj3 (hypersensitiv\$ or hyperreactiv\$ or allerg\$ or insufficiency)).mp.

15. ((dust or mite\$) adj3 (allerg\$ or hypersensitiv\$)).mp.

16. or/1-15

\section{Filter to identify RCTs}

1. exp "clinical trial [publication type]"/

2. (randomized or randomised).ab,ti.

3. placebo.ab,ti.

4. dt.fs.

5. randomly.ab,ti.

6. trial.ab,ti.

7. groups.ab,ti.

8. or/1-7

9. Animals/

10. Humans/

11. 9 not (9 and 10)

12. 8 not 11

The MEDLINE strategy and RCT filter are adapted to identify trials in other electronic databases.

\section{Appendix 2. Database search strategies}

\section{Cochrane Airways Group Register (CAGR)}

\#1 AST:MISC1

\#2 MeSH DESCRIPTOR Asthma Explode All

\#3 asthma*:ti,ab

\#4 \#1 or \#2 or \#3

\#5 MeSH DESCRIPTOR Adrenal Cortex Hormones Explode All

\#6 inhal ${ }^{\star}$ NEAR (corticosteroid* or steroid* or glucocorticoid ${ }^{\star}$ )

\#7 fluticasone*

\#8 budesonide* 
\#9 beclomethasone*

$\# 10$ ciclesonide*

\#11 flunisolide*

\#12 mometasone*

\#13 triamcinolone*

$\# 14 \# 5$ or \#6 or \#7 or \#8 or \#9 or \#10 or \#11 or \#12 or \#13

\#15 \#4 AND \#14

\#16 MeSH DESCRIPTOR Patient Compliance Explode All

\#17 MeSH DESCRIPTOR Patient Acceptance of Health Care Explode All

\#18 MeSH DESCRIPTOR Patient Dropouts

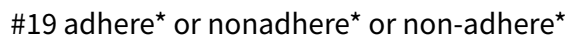

\#20 complian* or noncomplian* or non-complian*

\#21 refusal or refuse ${ }^{\star}: \mathrm{ti}, \mathrm{ab}, \mathrm{kw}$

\#22 concord*:ti,ab,kw

\#23 conform*:ti,ab,kw

\#24 accept*:ti,ab,kw

\#25 comply*:ti,ab,kw

$\# 26 \# 16$ or \#17 or \#18 or \#19 or \#20 or \#21 or \#22 or \#23 or \#24 or \#25

$\# 27 \# 15$ and \#26

[In search line \#1, MISC1 denotes the field in the record where the reference has bene coded for condition, in this case, asthma]

\section{CENTRAL via the Cochrane Register of Studies Online (CRSO)}

\#1MESH DESCRIPTOR Asthma EXPLODE ALL TREES

\#2asthma*:TI,AB,KY

\#3\#1 OR \#2

\#4MESH DESCRIPTOR Adrenal Cortex Hormones EXPLODE ALL TREES

\#5(inhal ${ }^{\star}$ NEAR (corticosteroid ${ }^{*}$ or steroid ${ }^{\star}$ or glucocorticoid ${ }^{\star}$ ) ):TI,AB, KY

$\# 6$ (fluticasone $e^{\star}$ or budesonide* or beclomethasone ${ }^{\star}$ or ciclesonide ${ }^{\star}$ or flunisolide ${ }^{\star}$ or mometasone or triamcinolone $\left.^{\star}\right): \mathrm{TI}, \mathrm{AB}, \mathrm{KY}$ \#7\#4 OR \#5 OR \#6

\#8MESH DESCRIPTOR Patient Compliance EXPLODE ALL TREES

\#9MESH DESCRIPTOR Patient Acceptance of Health Care EXPLODE ALL TREES

\#10MESH DESCRIPTOR Patient Dropouts EXPLODE ALL TREES

$\# 11$ (adhere* or nonadhere ${ }^{\star}$ or non-adhere $\left.{ }^{\star}\right): T I, A B, K Y$

$\# 12$ (complian* or noncomplian* or non-complian*):TI,AB,KY

$\# 13$ (refusal or refuse ${ }^{\star}$ ):TI,AB,KY

\#14concord*:TI,AB,KY

$\# 15$ conform $^{\star}: \mathrm{TI}, \mathrm{AB}, \mathrm{KY}$

$\# 16$ accept ${ }^{\star}: T I, A B, K Y$

$\# 17$ comply*:TI,AB,KY

\#18\#3 OR \#8 OR \#9 OR \#10 OR \#11 OR \#12 OR \#13 OR \#14 OR \#15 OR \#16 OR \#17

\#19\#3 AND \#7 AND \#18

\#20SR-AIRWAYS:CC

\#21\#19 NOT \#20

\section{MEDLINE via Ovid SP}

1. exp Asthma/ 
2. asthma\$.ti,ab.

3. 1 or 2

4. (inhal\$ adj3 (corticosteroid\$ or steroid\$ or glucocorticoid\$)).ti,ab.

5. (fluticasone $\$$ or budesonide $\$$ or beclomethasone $\$$ or ciclesonide $\$$ or flunisolide $\$$ or mometasone $\$$ or triamcinolone $\$$ ).ti,ab.

6.4 or 5

7. exp "Patient Acceptance of Health Care"/

8. (adhere\$ or nonadhere\$ or non-adhere\$).ti,ab.

9. 7 or 8

10. 3 and 6 and 9

11. (controlled clinical trial or randomized controlled trial).pt.

12. (randomized or randomised).ab,ti.

13. placebo.ab,ti.

14. dt.fs.

15. randomly.ab,ti.

16. trial.ab,ti.

17. groups.ab,ti.

18. or/11-17

19. Animals/

20. Humans/

21. 19 not (19 and 20)

22. 18 not 21

23. 10 and 22

\section{ClinicalTrials.gov}

\begin{tabular}{ll}
\hline Search field & Search term \\
\hline Study type & interventional \\
\hline Condition & asthma \\
\hline Intervention & adherence \\
\hline
\end{tabular}

\section{CONTRIBUTIONS OF AUTHORS}

RN drafted the Background and Methods section according to the Cochrane Airways Group template, with input and revisions from KK and ES. ES ran the electronic searches. All three review authors contributed to sifting of search results, data extraction and assessment of risk of bias in duplicate. RN and KK ran the data analyses and graded the evidence. All review authors contributed to the write-up.

\section{DECLARATIONS OF INTEREST}

RN is the Deputy Co-ordinating Editor of the Cochrane Airways Group and is a qualified general practitioner.

ES is the Information Specialist for the Cochrane Airways Group.

KK is a systematic review author who was employed by a Cochrane Airways Programme Grant at the time of writing of this review.

\section{SOURCES OF SUPPORT}

\section{Internal sources}

- Kayleigh Kew, UK.

St George's, University of London

- Rebecca Normansell, UK.

St George's, University of London 
- Elizabeth Stovold, UK.

St George's, University of London

\section{External sources}

- National Institute for Health Research, UK.

Evidence to guide care in adults and children with asthma, 13/89/14

This project was supported by the National Institute for Health Research (NIHR), via Cochrane Infrastructure, Cochrane Programme Grant or Cochrane Incentive funding to the Airways Group. The views and opinions expressed therein are those of the review authors and do not necessarily reflect those of the Systematic Reviews Programme, NIHR, the National Health Service (NHS) or the Department of Health

\section{DIFFERENCES BETWEEN PROTOCOL AND REVIEW}

We did not use Covidence to extract data from the included studies because we found the process too time consuming, and we were unable to capture different types of data using the software. Instead, we used an Excel template commonly used by the Cochrane Airways Group to capture study characteristics, outcome data and risk of bias information.

In the protocol, we listed various factors that may alter the treatment effect; we intended to present these factors in an additional table. We anticipated that the factors listed (type, delivery, dose and schedule of ICS; whether treatment was given in a combination inhaler with a long-acting beta-agonist (LABA), baseline severity of asthma) would document differences between studies, but in practice, studies generally were not designed to assess adherence to a particular type of ICS, dose or regimen, with or without a LABA, so we did not design the table in this way. We have described these factors in the description of studies, and we have presented important clinical and intervention characteristics in Tables 1 to 3.

We had to define post hoc as what constituted an 'objective' measure of adherence. Studies used a variety of measures including selfreport scales, pharmacy refill data, canister weight and electronic monitors. We decided that only electronic monitors could be considered truly objective. In a post hoc change to our analysis plan, we presented studies using objective measures (i.e. electronic inhaler monitors) as the primary analysis for \% adherence, as we deemed this a more useful analysis. An analysis including studies that used all measures then follows.

\section{N DEX TERMS}

\section{Medical Subject Headings (MeSH)}

*Medication Adherence; Administration, Inhalation; Adrenal Cortex Hormones [administration \& dosage]; Anti-Asthmatic Agents [*administration \& dosage]; Asthma [ ${ }^{*}$ drug therapy]; Directly Observed Therapy; Disease Progression; Health Services Needs and Demand [statistics \& numerical data]; Patient Education as Topic; Quality of Life; Randomized Controlled Trials as Topic; Reminder Systems; Steroids [ ${ }^{\star}$ administration \& dosage]; Time Factors

\section{MeSH check words}

Adult; Child; Humans 